\title{
Implementing a Culture of Thinking in Lao EFL \\ Pre-Service Teacher Education: \\ A Case of Reading
}

BY

\section{SAY PHONEKEO}

\author{
A thesis \\ submitted to Victoria University of Wellington \\ in fulfillment of the requirements for the degree of \\ Doctor of Philosophy \\ in Applied Linguistics
}

Victoria University of Wellington

2020 



\section{ABSTRACT}

This study has two phases. Phase 1 aimed at: (1) investigating pre-service teachers' prior experiences of reading and learning to read in English, (2a) exploring the current state of reading instruction, and (2b) finding out the extent to which a culture of thinking (CoT) was practiced when teaching reading in the Lao EFL pre-service teacher education context. A CoT is defined as "a place where a group's collective as well as individual thinking is valued, visible, and actively promoted as the regular, day-to-day experience of all group members" (Ritchhart, Church, \& Morrison, 2011, p. 219). In other words, a CoT is a place where a group of teachers, students, or people come together to conduct learning that benefits all group members and every member of the group is encouraged to interact, share ideas, and think about what is learned. To achieve Phase 1's aims, an exploratory study was employed and a qualitative method was utilized to collect and analyze the data.

Phase 1's findings revealed that the Lao EFL pre-service teachers' prior experiences of reading and learning to read were mostly a matter of learning discrete language features as opposed to meaning construction. The results also found that teachers paid considerable attention to discrete language items in the course of reading instruction rather than language proficiency and critical reading development. The findings also revealed that the CoT practice was not in place for teaching reading in Lao EFL preservice education although it was acknowledged and recognized in the education and curriculum policy. The results of Phase 1 were used as baseline data for Phase 2, a classroom-based intervention.

Phase 2 aimed at determining the extent to which the CoT implementation improved reading comprehension development, fostered learning engagement, and shaped perceptions of learning reading in Lao EFL pre-service teacher education. In order to accomplish the objectives of this phase, a quasi-experimental design was adopted, meaning that two intact classes of intermediate EFL pre-service teachers were recruited 
to participate in this phase. One of the classes was assigned to an experimental group while the other class was a comparison group. In terms of the intervention, thinking routines (e.g., Chalk Talk, Claim-Support-Question, and Connect-Extend-Challenge) were integrated into the three stages of reading instruction (pre-reading, while-reading, and post-reading). The data were collected through a pre-test, immediate post-test, delayedtest, direct classroom observations, a pre-post perception survey, and focus group interviews. They were analyzed using both quantitative and qualitative methods. An effect size analysis was also performed to supplement the $t$ tests used in this phase.

The findings revealed that the CoT implementation had a strong effect $(d=1.01)$ on reading comprehension development and there was a statistical significance between the two groups, $t(59)=3.894, p=.00<.05$. It also fostered interactive and meaningful learning engagement, and changed students' perceptions towards learning reading. Drawing from the findings, it has been suggested that a CoT can be an option for EFL teachers to consider integrating into their classroom practices in order to foster deep and meaningful learning and shape students and teachers' experiences of and attitudes toward learning and teaching English. 


\section{DEDICATION}

Dedicated to my beloved parents who endlessly supported me throughout this journey 


\section{ACKNOWLEDGEMENTS}

First, I would like to acknowledge the New Zealand government for its financial support during my PhD journey. Without this support, my project would not have been able to be completed. In addition, I am thankful to the Faculty of Humanities and Social Sciences for the financial support, which allowed me to present my study overseas.

Second, I would like to express my heartfelt gratitude to my primary supervisor, Professor John Macalister, for his wisdom, guidance, sense of humor, careful reading, tolerance, valuable direction, and trust along this journey. I would also like to express deep appreciation to my secondary supervisor, Associate Professor Jonathan Newton, for his support, enthusiasm, and energy throughout this investigation. His prompt responses and important suggestions contributed a significant part to this project.

I would also like to extend my sincere thanks to my fellow PhD students, staff in the School of Linguistics and Applied Language Studies, and those from whom I received support at Victoria University of Wellington during this project.

A heartfelt thank you for my family: my parents and siblings who provided me with love, support, and sympathy along this project.

Finally, I would like to express my profound gratitude to all my participants at National University of Laos, Vientiane, who welcomed me and provided useful data and insights into the issues under investigation. Without their cooperation and assistance, this thesis would never have been completed. 


\section{Table of Contents}

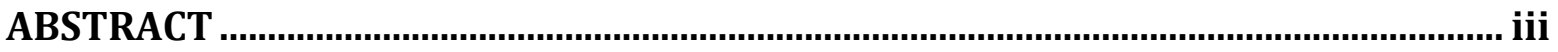

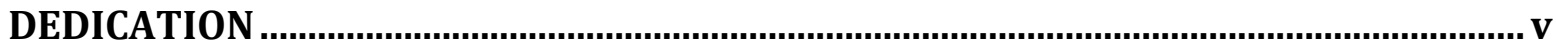

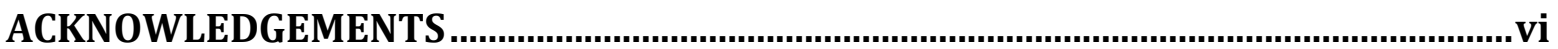

LIST OF TABLES ...................................................................................................... Xvi

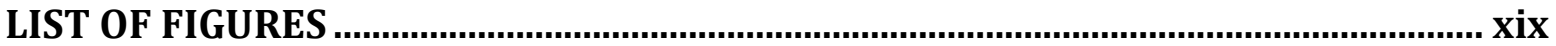

A GLOSSARY OF ABBREVIATIONS ............................................................................ Xxi

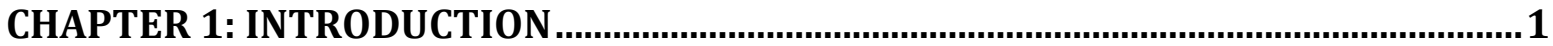

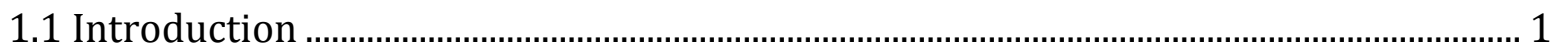

1.2 The research setting

1.3 Rationale for the study ................................................................................................... 3

1.4 Purposes and questions.................................................................................................. 5

1.5 Organization of the thesis ............................................................................................... 6

1.6 Chapter summary........................................................................................................ 7

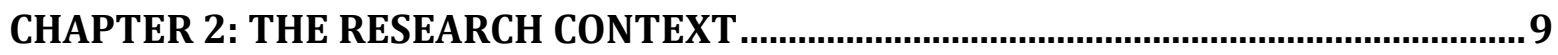

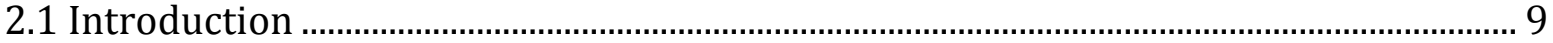

2.2 Geographic and demographic snapshots ...................................................................... 9

2.3 The political, economic, social, and religious context .....................................................10

2.3.1 The political and institutional context ...........................................................................10

2.3.2 The economic context................................................................................................

2.3.3 The socio-cultural context..........................................................................................12

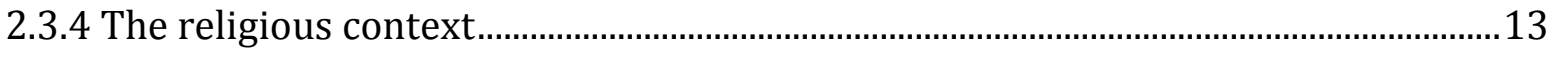

2.4 The educational context …………………………………………………………….....14

2.4.1 Lao education structure ................................................................................................. 14

2.4.2 Education system administration ............................................................................16

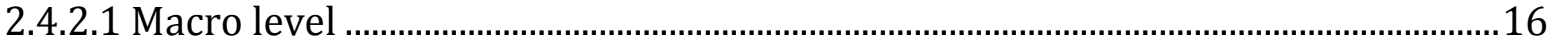

2.4.2.2 Meso-level...............................................................................................................17

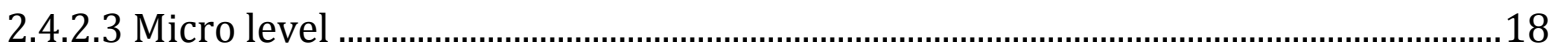

2.4.3 Education sector development and reform plan.........................................................18

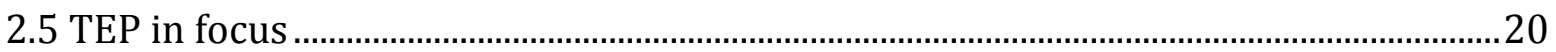




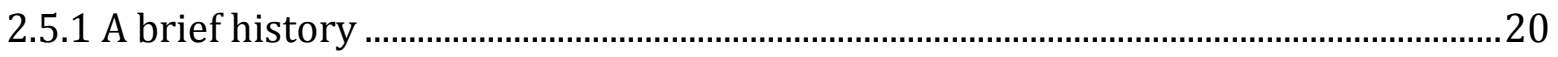

2.5.2 Foreign languages emergence in LPDR......................................................................22

2.5.3 Tensions and constraints in Lao TEP...........................................................................23

2.6 English teacher education programme (ETEP) in focus ...............................................24

2.6.1 ETEP structure, content, and philosophy …………………………………………......25

2.6.2 Current state of English instruction in L PDR...........................................................26

2.6.3 ETEP teaching materials ..............................................................................................2

2.6.4 ETEP physical learning environment …………......................................................28

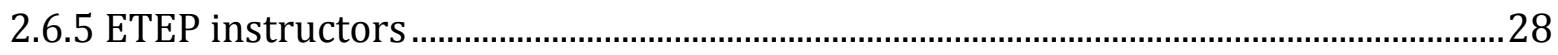

2.7 Chapter summary .....................................................................................................29

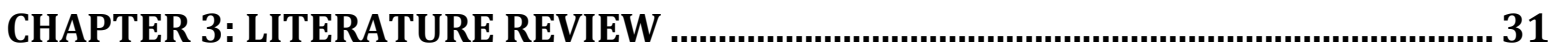

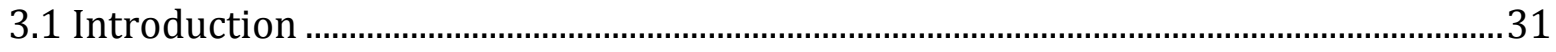

3.2 Introduction to LTC .........................................................................................................

3.2.1 Definition and origin ............................................................................................

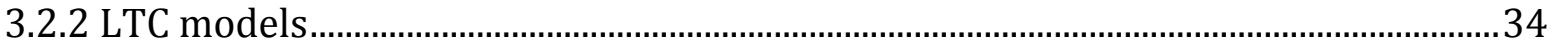

3.2.3 Pre-service teacher cognition construction and change ..............................................39

3.2.4 Empirical studies concerning pre-service English teacher cognition ....................... 41

3.3 Reading literature review ..............................................................................................4

3.3.1 Defining reading.........................................................................................................4

3.3.2 Metacognitive reading strategy .................................................................................46

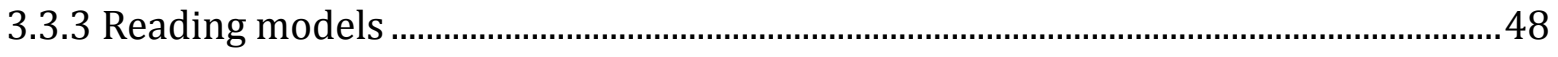

3.3.4 Reading components .................................................................................................4

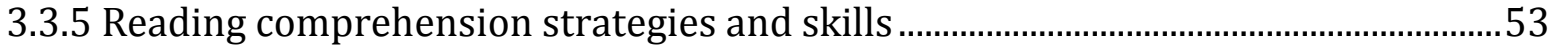

3.3.6 Reading stages and pedagogical implications .............................................................56

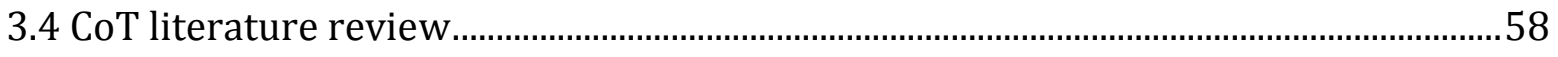

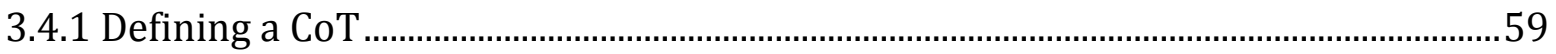

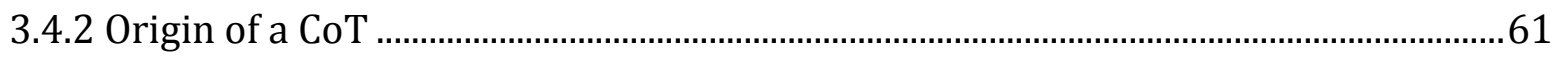

3.4.3 Relationships among critical and creative thinking and a CoT T..................................62

3.4.4 CoT principles and cultural forces .................................................................................63

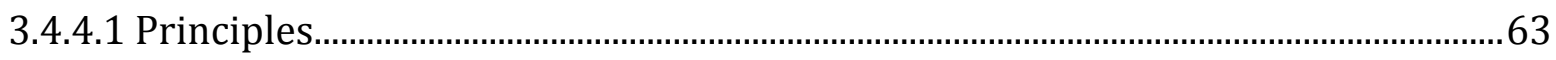




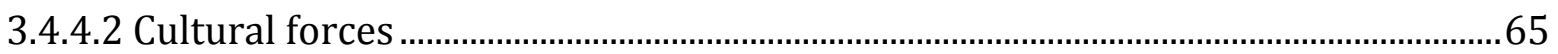

3.4.4.2.1 Definition .................................................................................................................6

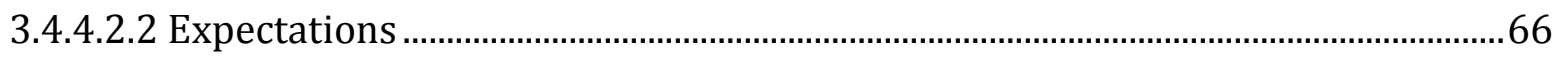

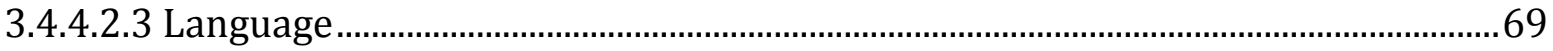

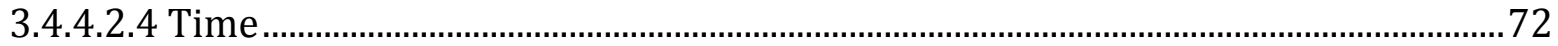

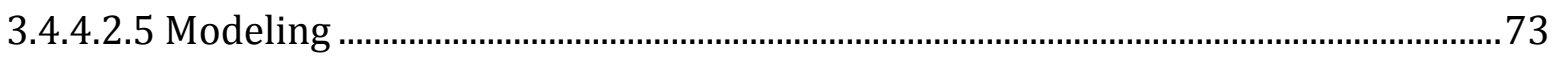

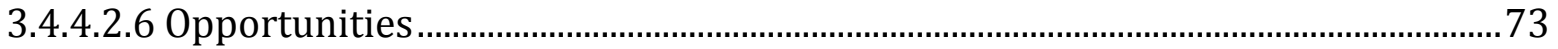

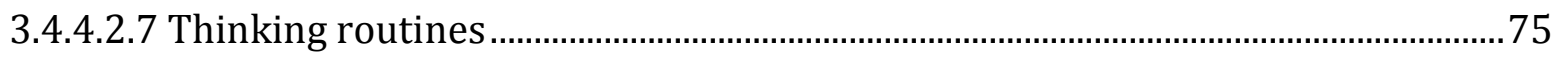

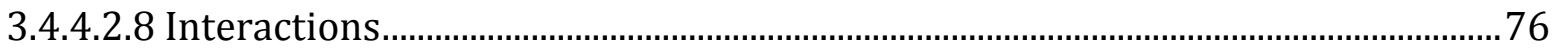

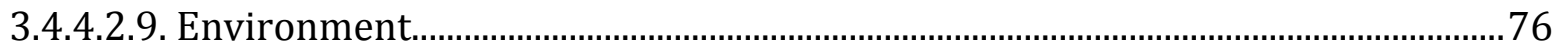

3.4.5 Thinking routines in focus ..........................................................................................

3.4.6 Emergence and related studies of a CoT in L1 Context ...............................................82

3.4.7 Related studies of a CoT in L2 and EFL contexts..........................................................83

3.4.8 CoT pedagogical implications in reading ....................................................................

3.5 Chapter summary ........................................................................................................8

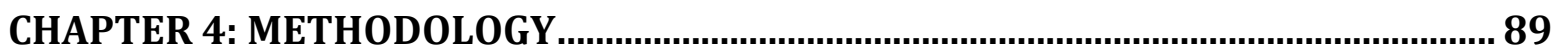

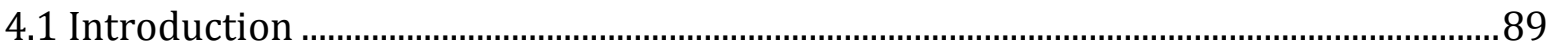

4.2 Methodology for phase 1 …………................................................................................89

4.2.1 Research questions ......................................................................................................

4.2.2 Design for phase 1 ....................................................................................................... 90

4.2.2.1 Exploratory research ..............................................................................................90

4.2.2.2 Ethnographic research........................................................................................ 91

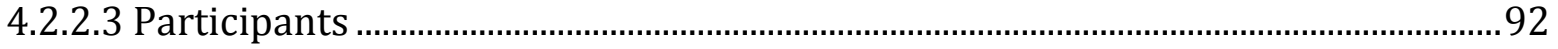

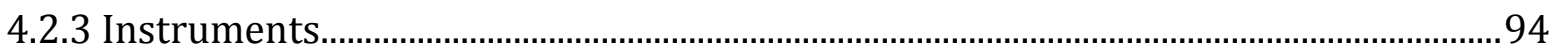

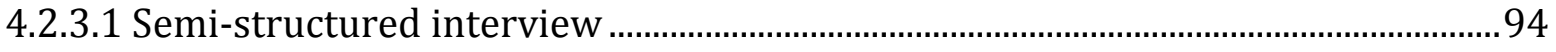

4.2.3.2 Direct classroom observation ..................................................................................96

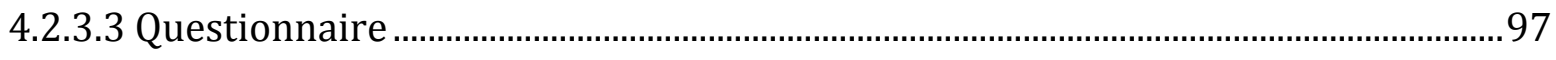

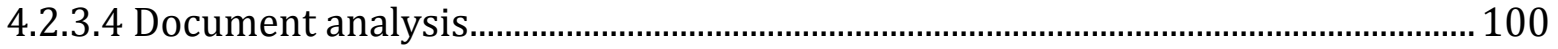

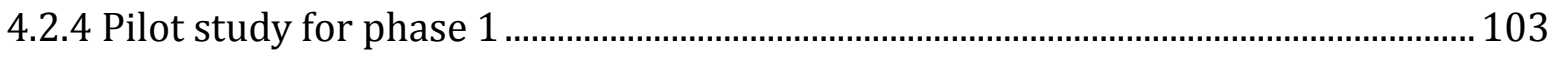

4.3 Methodology for phase 2 ………………………………………………………….... 104 


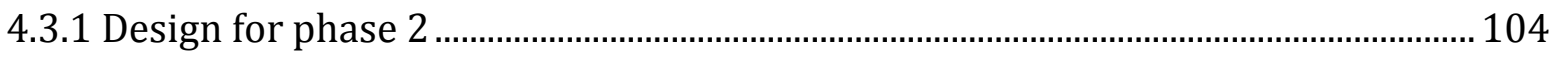

4.3.2 Rationale for explanatory mixed methods design .................................................... 106

4.3.3 Participants (pre-service teachers) ............................................................................ 108

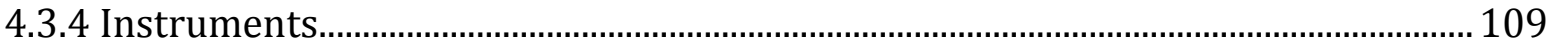

4.3.4.1 Reading test.............................................................................................................. 109

4.3.4.2 Direct classroom observation ............................................................................... 114

4.3.4.3 Focus group interview ......................................................................................... 115

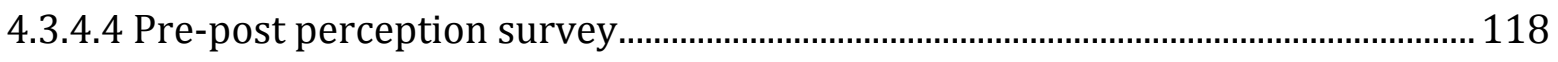

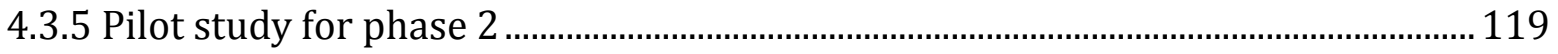

4.3.6 Participating reading lecturers (teachers) ……………………................................... 122

4.3.7 Reading textbook..................................................................................................... 123

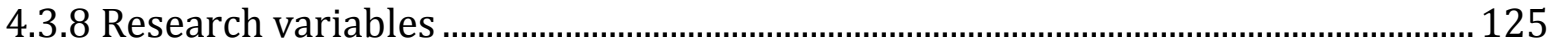

4.3.8.1 Independent variables ........................................................................................ 125

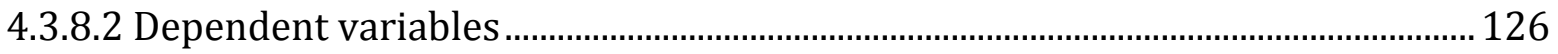

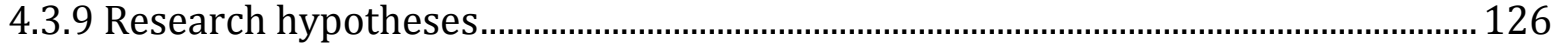

4.3.10 Threats to the research........................................................................................ 126

4.3.11 Implementation delivery and accountability ……................................................. 127

4.3.12 Methods for the CoT integration .............................................................................. 128

4.4 Data analysis ........................................................................................................... 129

4.4.1 Qualitative data analysis........................................................................................... 129

4.5 The embedded experimental design between the phases ……................................. 131

4.6 Trustworthiness …………………………………………………………………...... 132

4.7 Ethical considerations .................................................................................................... 133

4.8 The researcher's position............................................................................................. 134

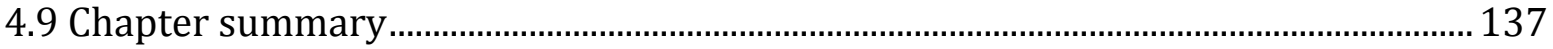

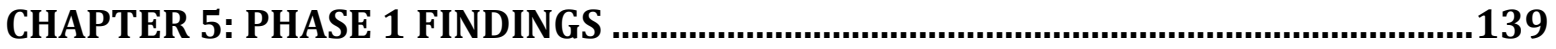

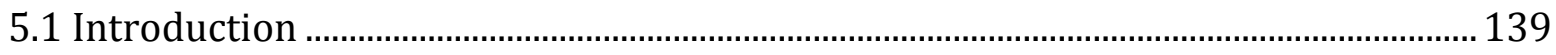

5.2 Quantitative findings ............................................................................................... 139

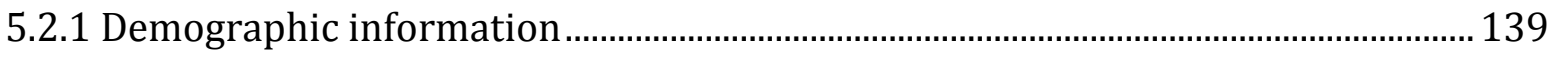

5.2.2 Perceptions of learning English reading..................................................................... 139 
5.2.3 Prior experiences in reading, learning materials, and instruction

5.3 Qualitative findings

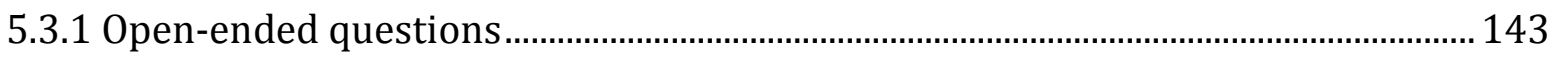

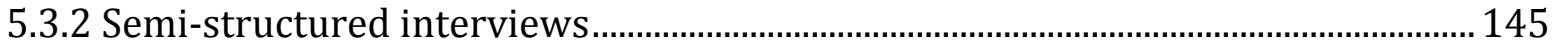

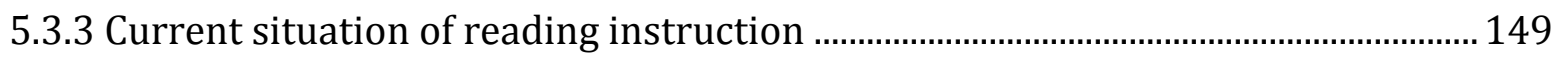

5.3.3.1 Class attendance and homework checking ............................................................. 150

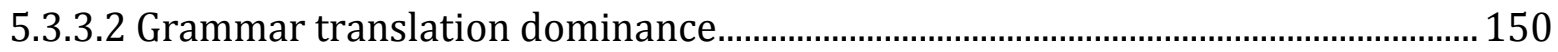

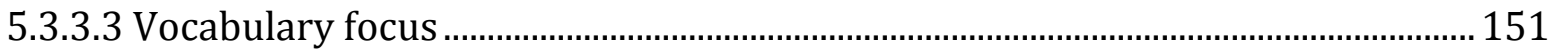

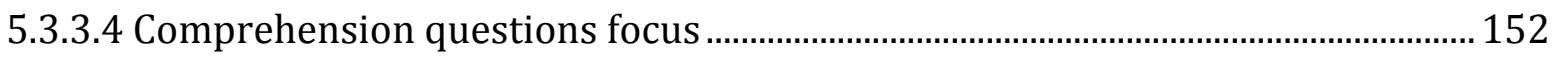

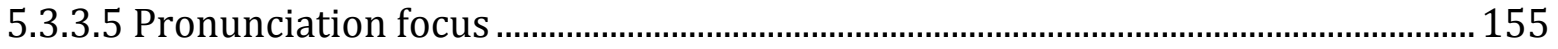

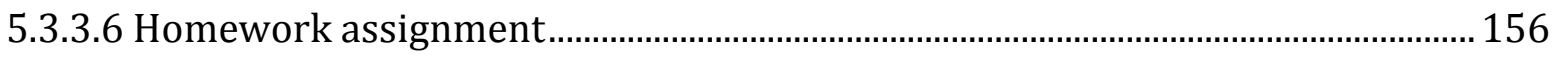

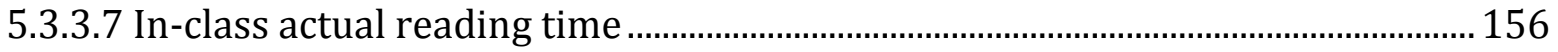

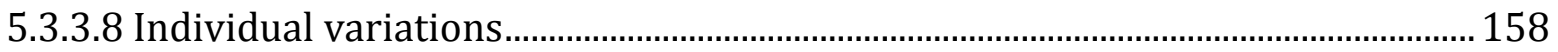

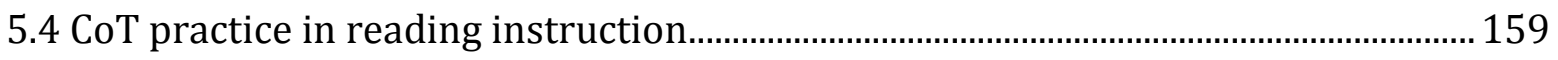

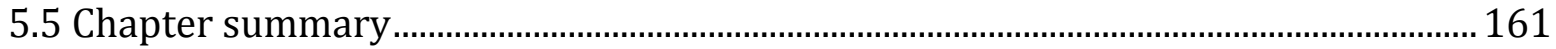

CHAPTER 6: PHASE 2 FINDINGS ................................................................................. 164

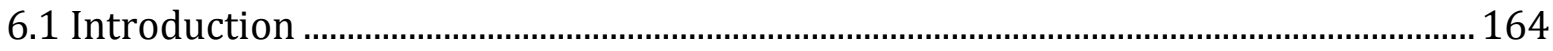

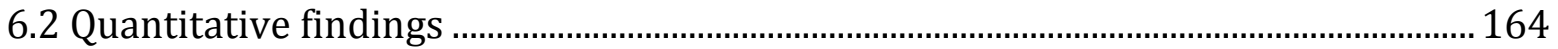

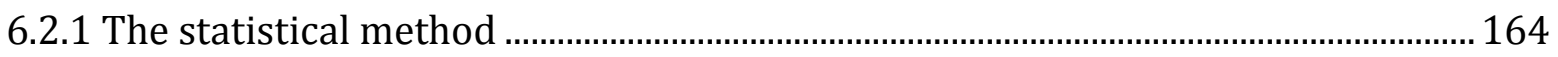

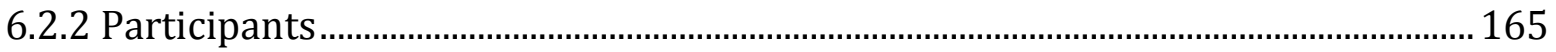

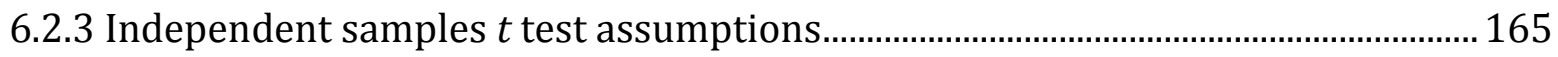

6.2.3.1 Homogeneity of variance of pre-test results ......................................................... 165

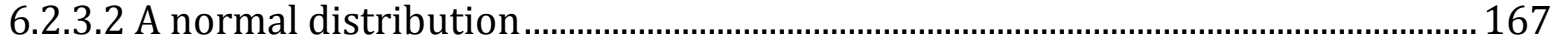

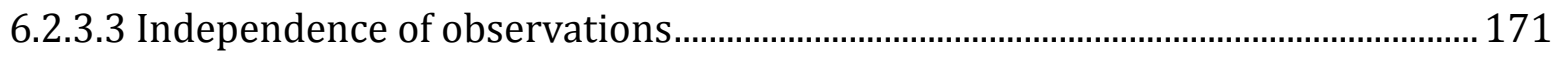

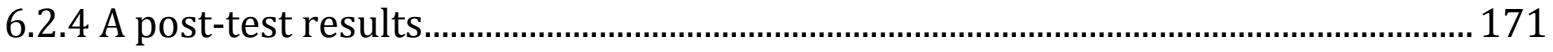

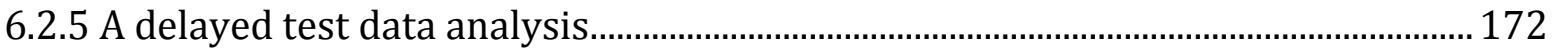

6.3 Qualitative findings in terms of student engagement................................................ 175

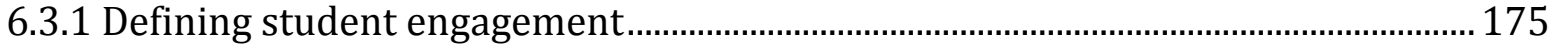

6.3.2 Student engagement and reading achievement ........................................................ 176

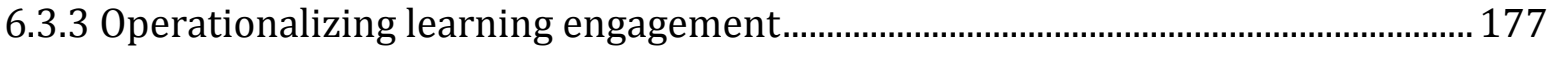


6.3.4 Emerging patterns of student engagement .............................................................. 178

6.3.5 Learning engagement in terms of cultural forces ................................................... 180

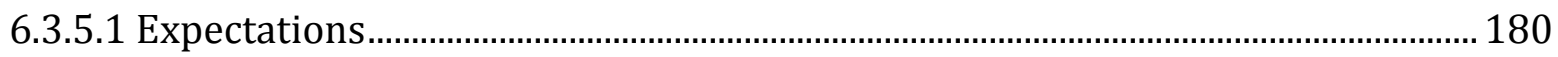

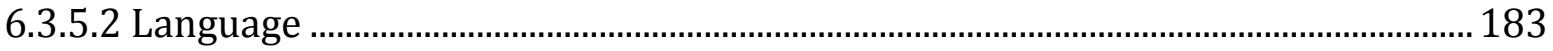

6.3.5.3 Time allocation ..................................................................................................... 186

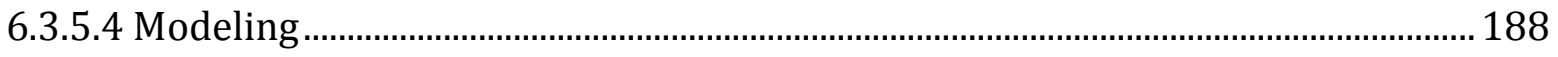

6.3.5.5 Learning opportunities, thinking routines, and interactions............................... 190

6.3.5.6 Learning environment .......................................................................................... 203

6.3.5.7 Student engagement comparison between the classes.......................................... 206

6.3.6 Learning engagement in terms of Bloom's Taxonomy............................................. 210

6.3.7 Section summary ................................................................................................ 211

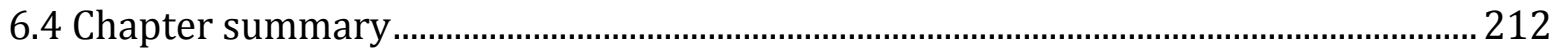

CHAPTER 7: PERCEPTIONS OF LEARNING READING ….................................................

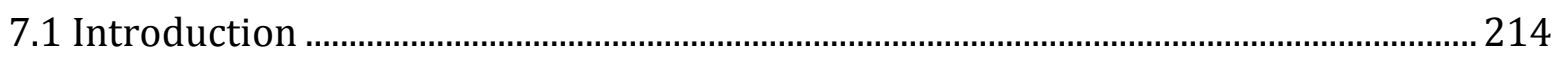

7.2 Focus group interview findings ................................................................................. 214

7.2.1 Perceptions of learning reading in general .............................................................. 215

7.2.2 Perceptions of reading learning focus …………………………………………….... 218

7.2.3 CoT promoted meaningful engagement and social interactions ............................ 220

7.2.4 CoT increased reading comprehension .................................................................... 223

7.2.5 CoT raised critical reading awareness ..................................................................... 227

7.2.6 CoT fostered reading skills and metacognitive reading strategies ......................... 230

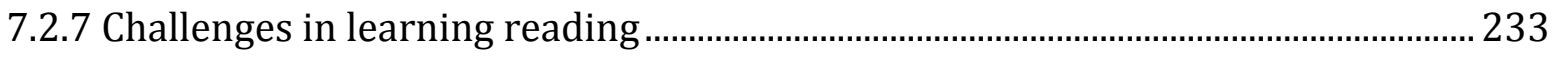

7.2.8. Participating lecturer's perceptions of the CoT implementation ............................ 234

7.2.9 Section summary ………....................................................................................... 237

7.3 Pre-post perception survey findings ………………………………………………... 238

7.3.1 Pre-perceptions of reading between the classes........................................................ 239

7.3.1.1 Perceptions of discrete language skills reading learning ...................................... 239

7.3.1.2 Perceptions of metacognitive reading learning …………………………............. 240

7.3.1.3. Pre-perceptions of reading learning experiences .................................................... 241

7.3.1.4. Pre-perceptions of learning outcomes ………………………………………….... 243 
7.3.2 Pre-post perceptions comparison findings of each class 244

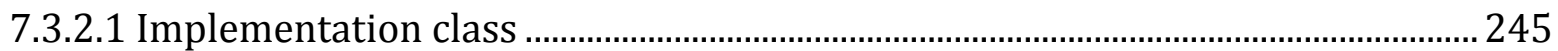

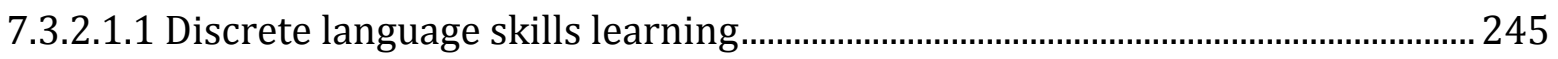

7.3.2.1.2 Perceptions of metacognitive reading learning ......................................................... 246

7.3.2.1.3 Perceptions of reading learning experiences ....................................................... 247

7.3.2.1.4 Perceptions of reading learning outcomes............................................................. 248

7.3.2.2 Control class pre-post mean scores comparison .................................................... 249

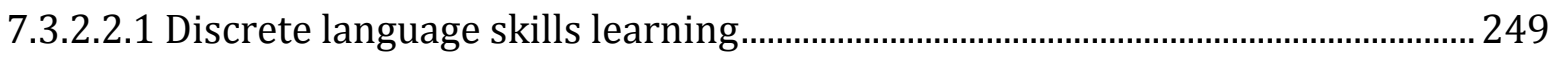

7.3.2.2.2 Perceptions of metacognitive reading learning ................................................... 250

7.3.2.2.3 Perceptions of learning experiences........................................................................ 251

7.3.2.2.4 Perceptions of reading learning outcomes........................................................ 252

7.3.3 Comparison of post survey mean scores between the classes ................................. 253

7.3.3.2. Perceptions of metacognitive reading learning ...................................................... 254

7.3.3.3 Perceptions of reading learning experiences........................................................ 255

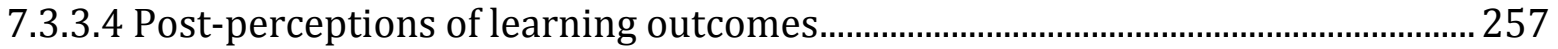

7.3.4 Qualitative findings of the pre-post perceptions........................................................ 258

7.3.4.1 Pre-service teachers' perceptions of reading learning focus .................................. 258

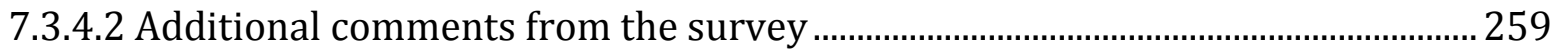

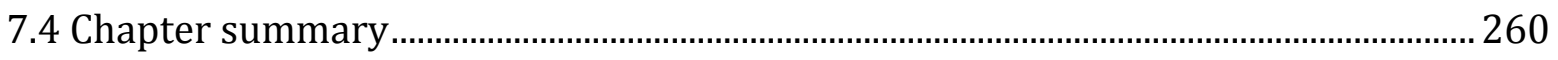

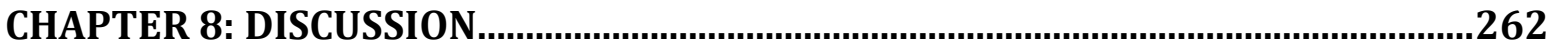

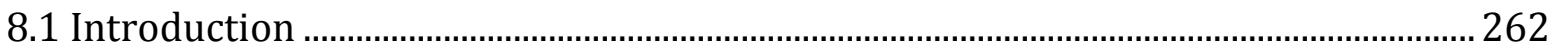

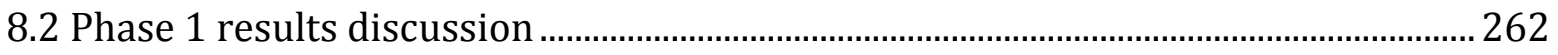

8.2.1 Pre-service teachers' prior experiences of reading and learning to read ............. 263

8.2.2 Current practices of teaching reading in Lao EFL pre-service TEPs ...................... 266

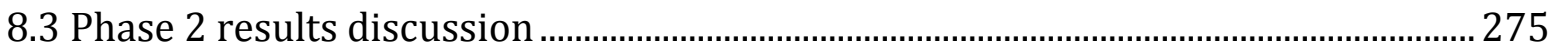

8.3.1 Reading comprehension development .................................................................... 275

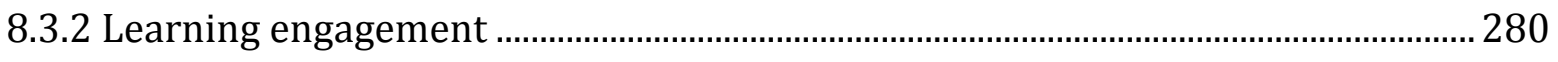

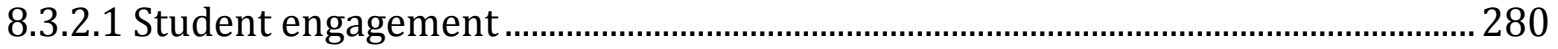

8.3.2.2 Student engagement from cultural forces perspectives ........................................ 283

8.3.2.3 Student engagement from Bloom's taxonomy perspectives................................ 287 
8.4 Lao EFL pre-service teachers' prior cognition construction of learning reading .. 288 8.4.1 Influence of BAK on prior experiences of reading learning 288

8.4.2 Cognition of reading and learning focus 289

8.4.3 Pre-service teacher cognition in terms of reading comprehension, critical reading awareness, reading skills, and metacognitive reading awareness 289

8.5 Participating lecturer's cognition and learning from a CoT-based instruction ...... 291

8.6 Pre-service teacher cognition model in action. 294

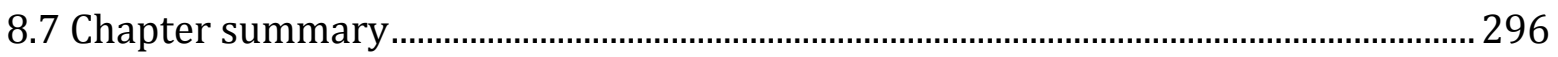

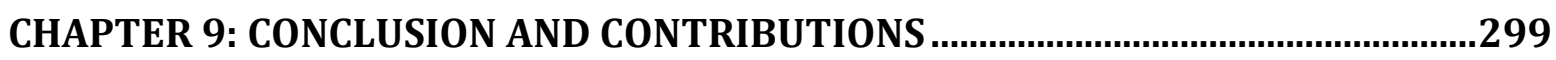

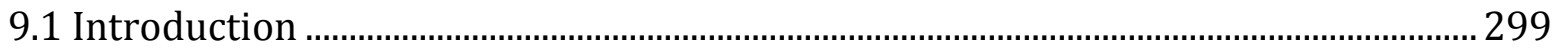

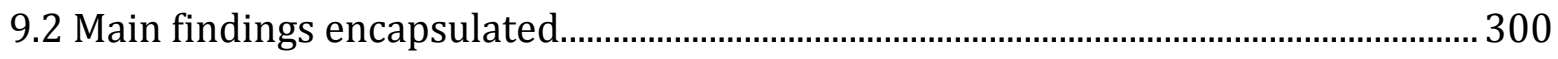

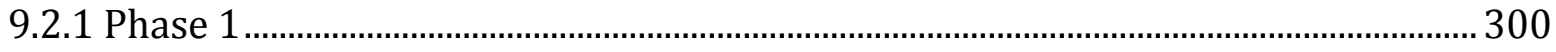

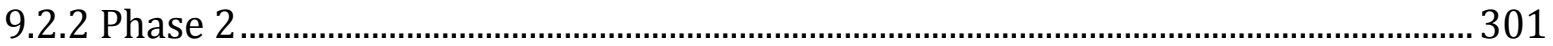

9.2.2.1 Quantitative findings summary ............................................................................. 302

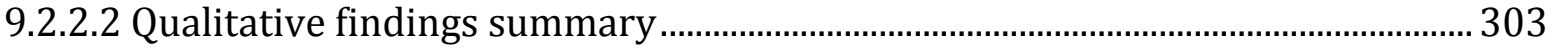

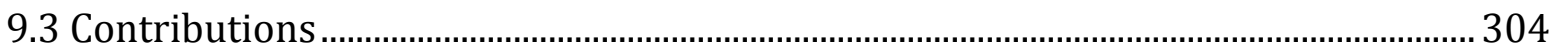

9.3.1 Theoretical contributions........................................................................................ 304

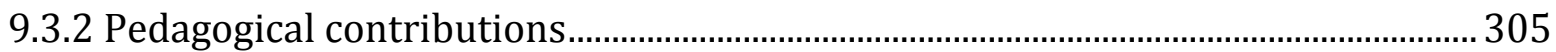

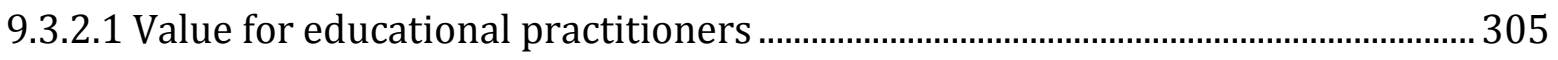

9.3.2.2 Value for EFL pre-service teachers and EFL students ........................................... 306

9.3.3. Policy Implications...................................................................................................... 307

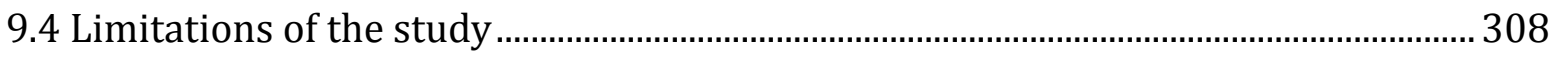

9.5 Future directions and challenges .................................................................................. 309

9.5.1 Future research directions........................................................................................ 309

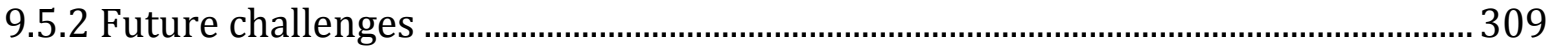

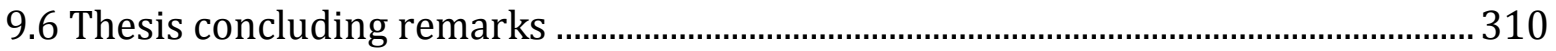

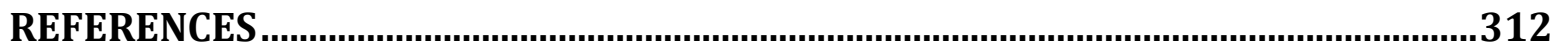

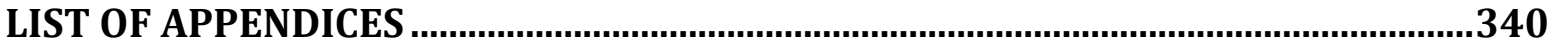

Appendix 1: Pre-service Teacher's Semi-Structured Interview Guide (Phase 1).......... 341

Appendix 2: Lecturer's Semi-Structured Interview Guide (Phase 1)................................ 342 


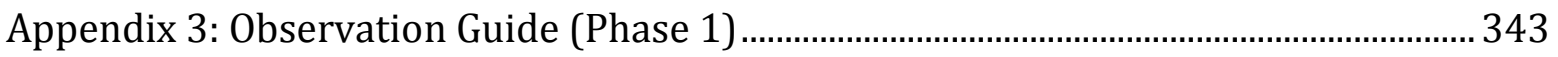

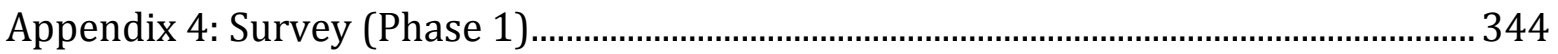

Appendix 5: Sample Reading Test Document....................................................................... 347

Appendix 6: Reading Test and Answer Key (Phase 2) .......................................................... 349

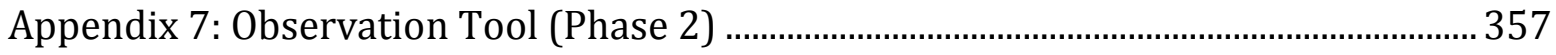

Appendix 8: Focus Group Interview Tool (Phase 2) ............................................................... 358

Appendix 9: Pre-Post Perceptions Survey (Phase 2) ............................................................... 359

Appendix 10: Sample Pre-Reading Activities from Textbook............................................. 362

Appendix 11: Sample CoT-Based Reading Lesson Plan........................................................ 363

Appendix 12: Participating Teacher's Interview Tool (Phase 2) ....................................... 365

Appendix 13: Sample Observation Transcriptions ……..................................................... 366

Appendix 14: Participating Teacher's Interview Transcriptions ........................................ 367

Appendix 15: Sample Focus Group Interview Transcriptions ............................................. 368

Appendix 16: Sample One-on-One Interview Transcriptions (Phase 1)......................... 369

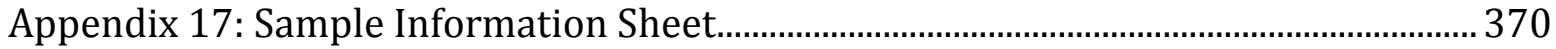

Appendix 18: Sample Consent Form .................................................................................. 372

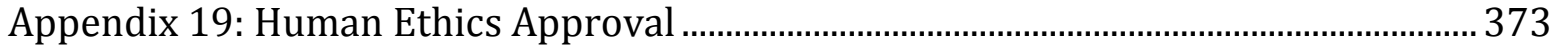

Appendix 20: Permission Letter for Data Collection ............................................................ 374 


\section{LIST OF TABLES}

Table 2. 1 Population by Ethno-Linguistic Group …................................................... 13

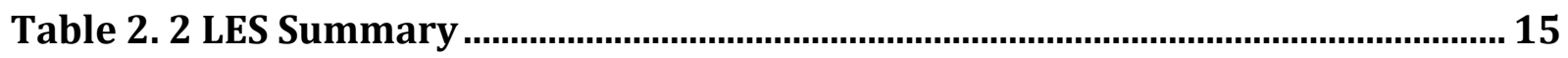

Table 2. 3 Timeframe of Curriculum Implementation ................................................. 25

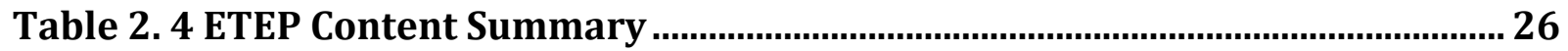

Table 3. 1 Summary of Reading Strategies and Skills................................................... 54

Table 3. 2 Dichotomies between Proficient and Poor Readers...................................... 55

Table 3. 3 Differences between Deep and Superficial Learning ................................... 67

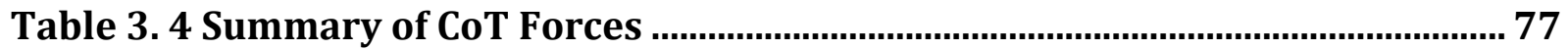

Table 3. 5 Thinking Routines Summary ….................................................................... 79

Table 3. 6 Roles of Bloom's Taxonomy in Critical Reading............................................ 87

Table 4. 1 Pre-Service Teachers' Profiles ........................................................................ 93

Table 4. 2 Reading Lecturers' Profiles ............................................................................. 94

Table 4. 3 Pre-Service Teachers' Interview Summary …................................................ 95

Table 4. 4 Reading Lecturers' Interview Summary ....................................................... 95

Table 4. 5 Classroom Observation Summary .................................................................. 97

Table 4. 6 Reliability of the Questionnaire.............................................................. 99

Table 4. 7 Summary of Document Collection.................................................................102

Table 4. 8 Phase 2 Procedures Summary...................................................................105

Table 4. 9 Vocabulary Coverage Analysis ....................................................................111

Table 4. 10 Focus Group Summary........................................................................118

Table 4. 11 Reliability Analysis Results....................................................................122

Table 4. 12 Reading Lecturers' Profiles.........................................................................123

Table 4. 13 Qualitative Analysis Procedures ............................................................131

Table 5. 1 Pre-Service Teachers' Perceptions of Learning English Reading ..........140

Table 5. 2 Prior Experiences in Reading, Teaching Materials, and Instruction .....142

Table 5. 3 Silent Uninterrupted Reading Time in Classrooms ................................157

Table 6.1 Effect Size Criteria and Interpretation ..........................................................165

Table 6. 2 Means and Standard Deviations in Each Group ..........................................166

Table 6. 3 Independent Sample $t$ Test on Pre-Test.....................................................166 
Table 6. 4 Normality of Dependent Variables ............................................................168

Table 6. 5 Means and Standard Deviations of Pre-Test and Post-Test.....................172

Table 6. 6 Results of an Independent-Sample $t$ Test on Post-Test ............................172

Table 6. 7 Means and Standard Deviations of Delayed-Test.......................................173

Table 6. 8 Results of an Independent Sample $t$ Test on Delayed-test .......................173

Table 6. 9 Summary of Pre-, Post-, and Delayed-Test between Groups ....................173

Table 6. 10 Summary of Student Engagement Patterns...............................................179

Table 6.11 Summary of Time Allocation ....................................................................188

Table 6. 12 Summary of Integrated Thinking Routines..............................................191

Table 7. 1 Reading Difficulties ......................................................................................233

Table 7. 2 A Summary of Analysis Procedures..........................................................238

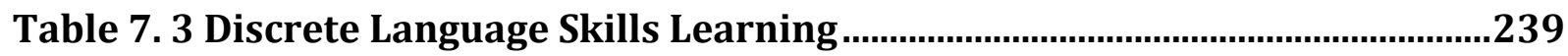

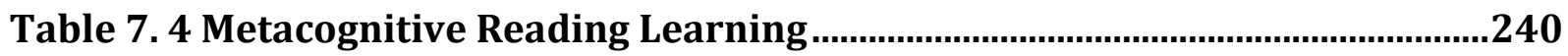

Table 7. 5 Reading Learning Experiences...................................................................241

Table 7. 6 Reading Learning Outcomes ........................................................................243

Table 7. 7 Discrete language skills Reading Learning ................................................245

Table 7. 8 Metacognitive Reading Learning ...............................................................246

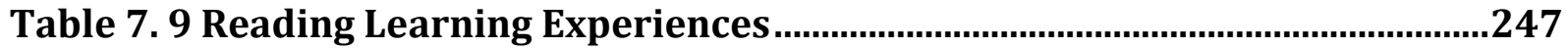

Table 7. 10 Perceptions of Reading Learning Outcomes.............................................248

Table 7. 11 Discrete Language Skills Learning ...............................................................249

Table 7. 12 Metacognitive Reading Learning .......................................................250

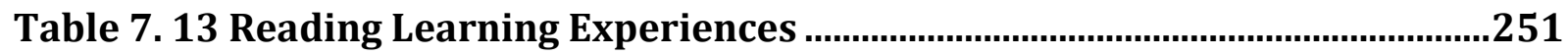

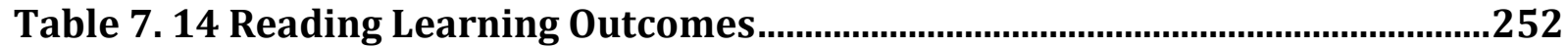

Table 7. 15 Discrete Language Skills Learning ...........................................................253

Table 7. 16 Metacognitive Reading Learning …….......................................................254

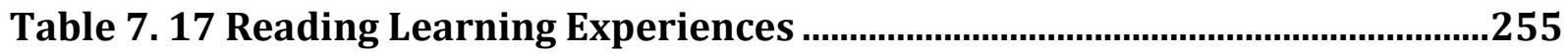

Table 7. 18 Reading Learning Outcomes.......................................................................257

Table 8. 1 Principles of GTM (Larsen-Freeman \& Anderson, 2011, p. 18) ...............263

Table 8. 2 The Extent to which Higher-order Reading Skills were Fostered ..........266

Table 8. 3 Means and Standard Deviations between the Classes ..............................276 
Table 8. 4 Reading Test Scores by the Implementation Class....................................277

Table 8. 5 Reading Test Scores by the Control Class .......................................................279 


\section{LIST OF FIGURES}

Figure 1. 1 A Visual Diagram of the Research Organization...............................................

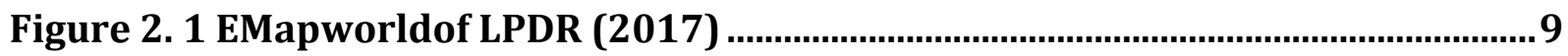

Figure 3. 1 Language Teacher Cognition Model (Borg, 2006, p. 41) ............................ 35

Figure 3. 2 The Dynamic Nature of Teacher Cognition (Macalister, 2010, p. 62) .... 38

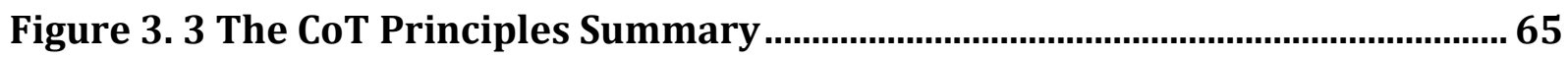

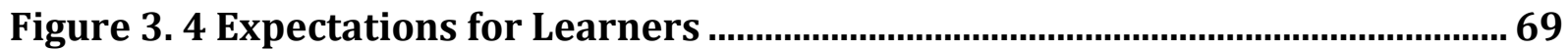

Figure 3. 5 A Summary of Language in a CoT …….................................................. 72

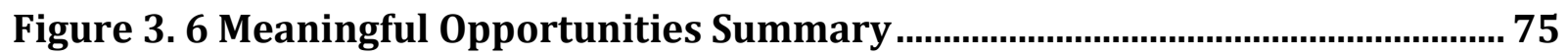

Figure 4. 1 Explanatory Quasi-Experimental Design (Creswell, 2007)....................108

Figure 4. 2 Histogram of Piloting Test Scores..........................................................113

Figure 4. 3 Normal Q-Q Plot ........................................................................................113

Figure 4. 4 Boxplot of Piloting Test Scores.............................................................114

Figure 4. 5 Focus Group Interview 2 (June 27th 2018) ..............................................117

Figure 4. 6 A CoT-Based Reading Lesson Piloting (December 29th, 2017)..............121

Figure 4. 7 A CoT-Base Reading Lesson Piloting (December 29th, 2017) ................122

Figure 4. 8 A Time Frame for Teaching Intervention ...................................................128

Figure 4. 9 An Embedded Experimental Design ..........................................................132

Figure 4. 10 Academic Workshop (April 7th, 2018) .....................................................136

Figure 4. 11 Master of Ceremony $($ May 11th, 2018) .....................................................137

Figure 6. 1 Histogram of Post-Test ....................................................................168

Figure 6. 2 Normal Q-Q Plot of Post-Test................................................................169

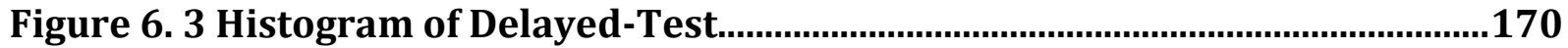

Figure 6. 4 Q-Q Plot of Delayed-Test.......................................................................170

Figure 6. 5 Profile Plots of Estimated Marginal Means between the Groups ..........174

Figure 6. 6 A Visual Diagram of Seating Arrangements ................................................204

Figure 6. 7 Students' Ideas (May 22 ${ }^{\text {nd }}$ and June 12 ${ }^{\text {th }}, 2018$ ) ........................................205

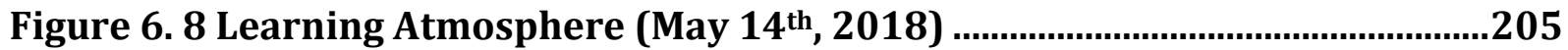

Figure 6. 9 A Comparative Reading Learning Engagement Model ............................211

Figure 8. 1 A Model of Reading Learning Engagement Process in Action................283 
Figure 8. 2 Pre-Service Teacher Cognition in Action .

.295 


\section{A GLOSSARY OF ABBREVIATIONS}

ASEAN

BAK

CLT

CoT

CT

EFL

ELT

ESL

ETEP

FED

FL

GoL

GTM

L1

L2

LDC

LES

LPDR

LPRP

LTC

MoES

NA

NUOL

PUV

SWAP

TEP

TESOL

TVET

VC
Associations of Southeast Asian Nations

Beliefs, Assumptions, Knowledge

Communicative Language Teaching

Culture of Thinking

Critical Thinking

English as a Foreign Language

English Language Teaching

English as a Second Language

English Teacher Education Programme

Faculty of Education

Foreign Language

Government of Laos

Grammar Translation Method

First Language

Second Language

Least Developed Country

Lao Education System

Lao People's Democratic Republic

Lao People's Revolutionary Party

Language Teacher Cognition

Ministry of Education and Sports

National Assembly

National University of Laos

Pedagogical University of Vientiane

Sector-Wide Approach

Teacher Education Programme

Teaching English to Speakers of other Languages

Technical and Vocational Education Training

Vientiane College 


\section{CHAPTER 1: INTRODUCTION}

\subsection{Introduction}

This chapter briefly introduces the study. Section 1.2 describes the research setting. Section 1.3 looks at the rationale for the study. Section 1.4 addresses research purposes and questions. Section 1.5 outlines the thesis organization. Section 1.6 summarizes the chapter.

\subsection{The research setting}

Lao People's Democratic Republic (L PDR) is in the process of a dynamic change that has an important influence on society at various levels, including education development (Doeden, 2014). Hunter and Yates (2002, p. 347), in the Vanguard of Globalization, warn that "globalization is only going to get stronger; if you don't get on board, you will be left behind." In an effort to keep up with global change, education reform and development are necessary for LPDR. However, to date, education reform has not improved the quality of learners' critical and lifelong learning skills due to a dominant practice of the traditional teaching method (i.e., knowledge transmission), which limits students' involvement in exploration and interaction. As Robinson (2013, p. 25) argues, "Education should be personalized to every student's talent, passion, and learning style, and creativity should be embedded in the culture of every single school". This encapsulates that education should start from the ground up, as opposed to the top down, where the goal is on critical thinking and meaningful learning. Without meaningful interaction in classroom instruction, there is no education (Robinson, 2013).

Therefore, to improve the quality of education in Lao EFL pre-service teacher education, it is important to focus on the process of learning and teaching by encouraging students to take responsibility for their own learning and developing their thinking skills. For this reason, research into this area is required to reform pre-service teacher education development. In addition, I have spent more than ten years as an English instructor, engaged in teaching English for pre-service teachers in L PDR. During this time, I have 
contemplated which teaching methods might have helped Lao EFL pre-service education move forward and keep up with the uncertainty of an ever-changing world and other countries.

In addition, the government of Laos (GoL) is attempting to revolutionize education in order to transform the country from its current status as one of the least-developed countries (LDC) by 2020 to a developing country (UNDAF 2012-2015, 2015). However, recent data show that this target has not been achieved due predominantly to extreme poverty and social and economic disparities between the urban and rural. In other words, the majority of Lao population still lacks access to basic healthcare, education, and economic opportunities. Because of these, the GoL has extended its ambition of graduating the country from the LDC status to 2024 (The $8^{\text {th }}$ National Assembly Session, 2019).

Because of the above mentioned targets, considerable attention has been devoted to the development of education and the implementation of the learner-oriented teaching method where the teachers act as facilitators. To ensure the effective use of an innovative and interactive teaching approach, teachers in L PDR are trained in how to incorporate this approach into their classroom practices. However, back in the classroom the approach is not being implemented, indicating that teachers' changes in the realm of cognition and perception of the instructional practices appear to have been slow and challenging. Thus, in order to address this and to help transform classroom practices, changes in instructional pedagogy is required.

Additionally, I have noticed this resistance to adopting new teaching approaches among teachers in the classroom. Specifically, there are factors that confound the fundamental change teachers would want to attempt in their classroom practices. Although openness to change, especially for a less-developed country like L PDR, may be crucial to increased participation in a rapidly changing world, I wonder what other factors might impact on the education reform, especially in Lao EFL pre-service teacher education. Most national 
development revolves around an education reform, particularly teacher education. In this regard, I believe that for LPDR to realize its potential as a developing nation, the same must be true. As Thepphasoulithone (2009) posits, in order for L PDR to catch up with other countries, both socially and economically, and to rise in position from one of the least developed countries in the world, the government needs to consider education as the most important factor for L PDR to help meet its socioeconomic development targets in the future.

To achieve the targets, the GoL is promoting foreign direct investment and regional and international trade. This increases the necessity for English as a main means of communication and negotiation with the outside world (Viphavanh, 2014). Therefore, developing English proficiency in the Lao population is crucial in order to help LPDR achieve its ambition in the globalized world.

As stated earlier, LES is predominantly teacher-centred and top-down. Because of this, promoting learner independence and lifelong learning skills remains challenging but crucial. The main purpose of this research is to address the issues and foster critical thinking skills in learning reading of Lao EFL pre-service teachers who have the potential to be agents of future change. Being able to read and construct meaning critically is necessary in the era of 'fake news' as people are now exposed to enormous amounts of information, often in digital form, which is not always accurate. In order to help EFL students become analytical consumers of written texts or data, it is important for reading teachers to expose them to critical thinking practices so that they can be directly influenced.

\subsection{Rationale for the study}

Ritchhart (2012) poses "What do we want the learners we teach to be like when they have finished their education?" The answers most teachers expect should include: curious, skeptical, open-minded, imaginative, strategic, metacognitive, reflective, inquisitive, responsible, independent, adventurous, inventive, flexible, risk-taking, mindful, considerate, compassionate, critical, communicative, analytical, and so forth. To 
develop these skills, learners are required to be consistently stimulated to think critically through an innovative teaching method. However, the questions to be posed here are: 1) How can teachers foster these skills in their students? 2) What methods will help teachers foster their students' thinking disposition?

The questions above have inspired me to explore the teaching approaches that are beneficial for the transformation of English instruction in the Lao EFL context. My interest and inspiration in this also stem from my personal experience as an English language learner in this context. I recall the experience of learning English at the upper secondary school level when I first started learning English. The teacher often began English lessons by writing down new words on the blackboard, asking students to repeat and remembering those words without engaging learners in using the target language with peers in the classroom. This mode of instruction was a common practice in addition to translation and explicit instruction of grammar. It was during this time that I began to experience the apprenticeship of observation (Lortie, 1975) in learning English without recognizing its long-term effects on my professional journey as a language teacher. I extensively experienced the "transmission type of teaching" (Kennedy \& Kennedy, 1996, p. 359) before I studied English education. From a language learner perspective, what I saw, experienced, and did (Borg, 2003) in classrooms during that time was the best way to master and learn the target language.

After my upper secondary school education, I was fortunate to be given a scholarship by the GoL to pursue my undergraduate degree in English teacher education at one of the most prestigious universities in L PDR. I thought that this was a great opportunity for me to develop both content and pedagogical knowledge in the target language as I was very keen to study English, hoping to be able to communicate with westerners, known as Farang, and become an influencer in the area of English teacher education. Like my upper secondary school learning experience, however, the lecturers at the teacher education programme (TEP) primarily concentrated on only discrete language features (e.g., vocabulary, grammar, pronunciation) rather than communicative and meaning- 
focused interaction. As a result, the TEP did not have a profound impact on shaping my experiences of and preconceived beliefs about learning English. This made me even more curious about what could be done to transform the teaching of English in the Lao EFL context and to seek answers to the questions posed above.

My curiosity was satisfied when I was given a scholarship to pursue a master's degree in TESOL in Australia in 2008. Before disembarking on this journey, I was required to participate in an English for Academic Purposes course at Vientiane College (VC), LPDR, as a scholarship recipient in 2007. It was at this institution that I was able to seek answers to the questions indicated previously. The teachers at VC (native speakers of English) conducted CoT-based lessons, which I found more interactive and meaningful than I had experienced in learning English in the past. The CoT-based instruction motivated students to focus on the exploration of the subject content and concept and fostered language proficiency development. It also encouraged students to use the target language in communicating ideas with classmates that resembled real-world interactions. Through my observation and experience at VC, I contemplated the

possibility of implementing a CoT in Lao EFL pre-service teacher education in order to transform the teaching of English and to shape both teachers' and students' experiences of learning and teaching English. This study emerged from my personal and professional experience of learning, teaching, and having been exposed to the CoT-based instruction. To obtain empirical data and help direct the CoT implementation in this investigation, research purposes and questions are addressed in the following section.

\subsection{Purposes and questions}

The main purposes of this study were to: 1) investigate the Lao EFL pre-service teachers' prior experiences of reading and learning to read in English;2) explore the current state of English reading instruction; 3) find out the extent to which a CoT was practiced; and 4) to determine the extent to which the CoT implementation improved Lao EFL preservice teachers' reading comprehension development, learning engagement, and perceptions of learning reading. For the purpose of this research, a CoT is defined as "a place where a group's collective as well as individual thinking is valued, visible, and 
actively promoted as part of the regular day-to-day experience of all group members" (Ritchhart, Church, \& Morrison, 2011, p. 219). This teaching method presents a divergence from the traditional lecture and teacher-oriented focus to interactive and meaningful learning. This could lead to improved levels of English as it encourages the target language use in exploring and discussing the main idea of the text in terms of reading instruction. This study consists of two phases. Phase 1 is exploratory and ethnographic while Phase 2 is a classroom-based intervention. The following central research questions are posed.

\section{Phase 1}

1. What are Lao EFL pre-service teachers' prior experiences of reading and learning to read in English?

2a. What is the current state of reading instruction in Lao EFL pre-service teacher education?

2b. To what extent is a CoT practiced in teaching reading in Lao EFL pre-service teacher education?

Phase 2

3. To what extent does the implementation of a CoT improve Lao EFL pre-service teachers' reading comprehension?

4. How do Lao EFL pre-service teachers engage in classroom-based reading in the CoT and comparison classes?

5. What are pre-service teachers' perceptions of learning reading in the CoT and comparison classes?

Detailed methodology used for addressing these central questions will be looked at and discussed in the methodology chapter.

\subsection{Organization of the thesis}

There are nine chapters in this thesis (see Figure 1.1). Chapter 1 describes the background of the study. Chapter 2 looks at the research context. Chapter 3 reviews related theories and literature. Chapter 4 addresses research methodology. Chapter 5 presents Phase 1's findings. Chapter 6 presents Phase 2's results. Chapter 7 looks at 
students' perceptions of learning reading. Chapter 8 discusses the findings. Chapter 9 concludes the thesis.

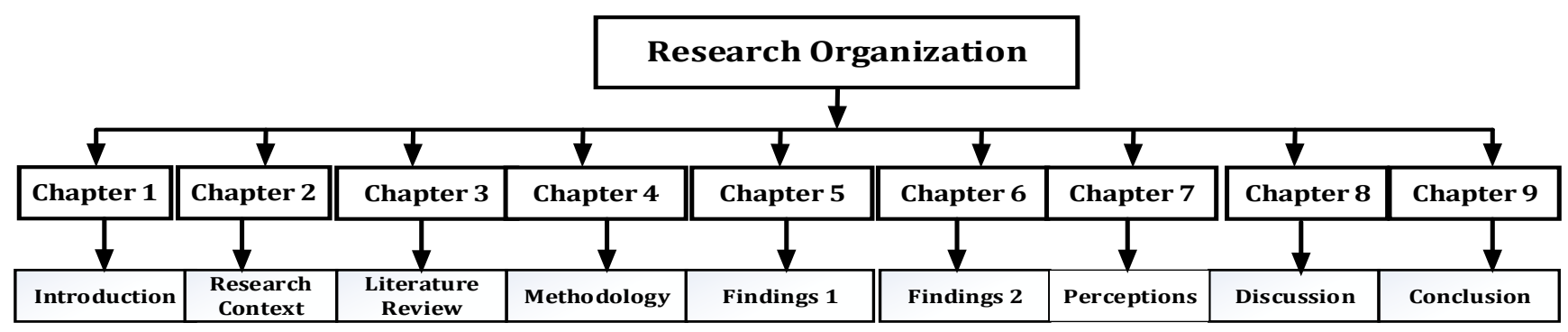

Figure 1. 1 A Visual Diagram of the Research Organization

\subsection{Chapter summary}

This chapter briefly introduced the present study. It addressed the research setting, rationale, purposes and questions, and organisation of the study. The following chapter will look at the research context to contextualise this study. 


\section{CHAPTER 2: THE RESEARCH CONTEXT}

\subsection{Introduction}

This chapter begins with geographic and demographic snapshots of the research context (section 2.2). Section 2.3 addresses the political, economic, social, and religious background. The main purpose of discussing these aspects is to provide basic but important data about the research context as this investigation is context specific. Social, economic, and cultural realities have a considerable influence on teachers' decision making and their classroom action (Borg, 2003). In addition, these data are useful for other scholars in the field to draw on when conducting research on education concerning the Lao context which is still under researched. Section 2.4 focuses on the Lao education system (LES). Section 2.5 looks at the Lao TEP. Section 2.6 specifically discusses the Lao EFL pre-service TEP. The final section (2.7) summarizes the chapter.

\subsection{Geographic and demographic snapshots}

L PDR, or Laos, is a small landlocked country in Southeast Asia. It shares borders with Vietnam, China, Cambodia, Myanmar, and Thailand (see Figure 2.1). LPDR has an area of 236,800 square kilometers, most of which is rugged and mountainous terrain, located in a tropical climate.

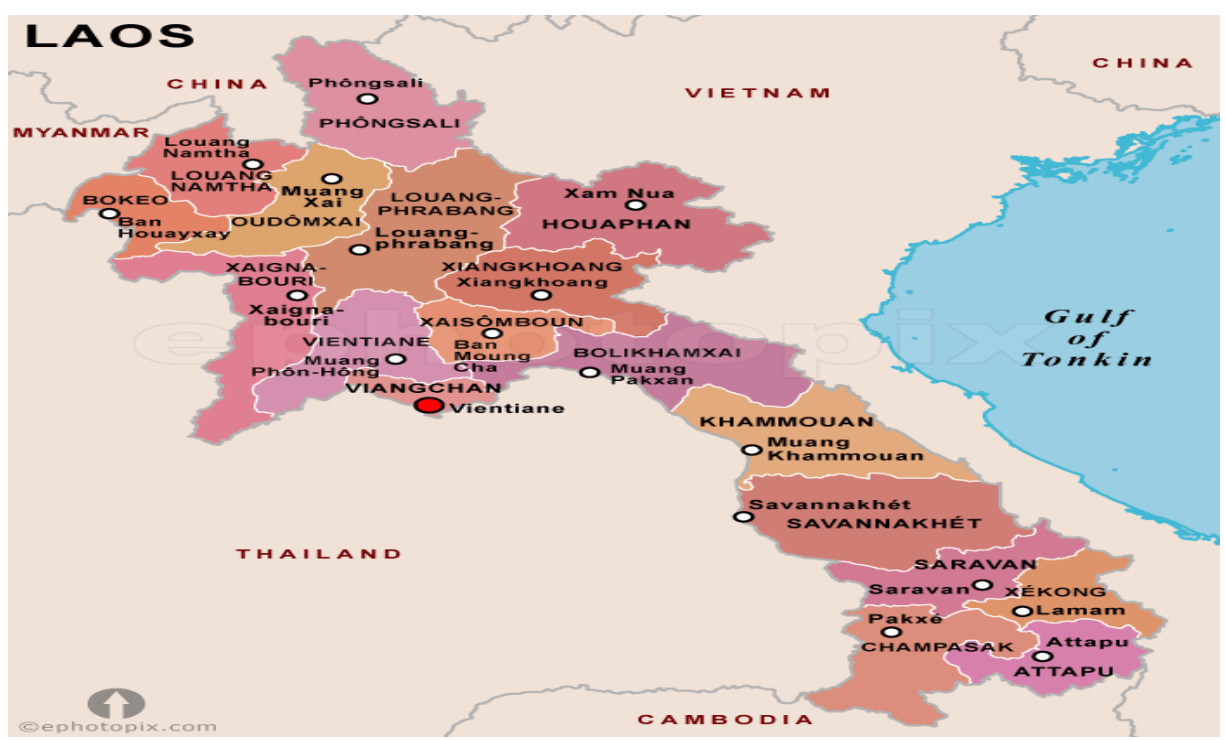

Figure 2. 1 EMapworldof LPDR (2017) 
L PDR has a population of around 7,033,809 million with 49 ethnic minorities and 84 local languages (Hayes, 2015; King \& Walle, 2010; Population Statistics, 2017). Although Lao-Tai is the official language, many ethnic groups are not able to use it effectively due to limited access to formal education. This, in turn, causes communication difficulties with other ethnic minorities and central government.

As stated in chapter 1, L PDR is attempting to graduate from being a least developed country (LDC) by 2020. To meet this goal, the GoL has been focusing on education as the building block for human resource development and poverty eradication (Lao People's Democratic Republic, 2016). However, education reform has encountered various constraints due to the social, political, economic, and religious context. Each of these will be addressed in turn in the following section. The underlying reason for taking these into consideration here is because they are regarded as "crucial determinants" (Kennedy, 1988, p. 331) of implementing an innovative teaching approach.

\subsection{The political, economic, social, and religious context}

\subsubsection{The political and institutional context}

After Pathet Lao defeated the Kingdom of Laos in 1975, LPDR became a Socialist country governed by a single party, the Lao People's Revolutionary Party (LPRP) (Doeden, 2014; Thepphasoulithone, 2009). The GoL administration consists of a head of state (the president), prime minister and ministers, and the National Assembly (NA). Because of the single party, important and central state decisions, policy development, and strategic plans are considered and determined by the Party Congress, which is held every five years. In addition, senior and high-ranking government positions are appointed by the Politburo Party Committee with the approval of the NA (Hayes, 2015). The LPRP exercises all executive power, including over education, from the central administration to lower levels: provinces and districts.

A major reform began to take place in 1986 when L PDR opened up to the outside world. At this time, the LPRP initiated a new plan, including a more decentralized administration, focusing on a new economic mechanism. The plan was proposed and 
approved by the NA to promote socioeconomic development towards a more marketoriented economy and privatization, indicating the power distribution and decisionmaking between the central and local authorities as it provided more free market opportunities and freedom of expression for all Lao citizens than had been the case previously (Adams, Kee, \& Lin, 2001; Hayes, 2015).

Currently, the GoL is in the process of implementing policies of the ninth- and tenthparty congresses of the LPRP. To achieve this goal, the GoL introduced four significant breakthroughs, known in Lao as สิ่บุภขะลุ, (Lao People's Revolutionary Party, 2016):

- thinking and imagination;

- human resource development;

- management of governance and regulation systems; and

- poverty reduction.

The thinking and imagination plan is aimed at developing future generations' creativity, problem-solving, intellect, communication, reflection, and innovation by upgrading to a more modern education system and society in general. However, it has been challenging for the GoL to develop learners' critical thinking skills due to a lack of innovative and interactive teaching pedagogy.

\subsubsection{The economic context}

As pointed out earlier, LPDR is ranked as a LDC in the world (Hayes, 2015). National economic growth has averaged $7 \%$ over the last two decades. This has raised the gross national income per capita above the level of lower-income countries to lower middleincome countries, showing a clear sign of developmental progress (Doeden, 2014; Hayes, 2015). Although there has been a gradual increase in economic development, the economic gap between the urban and rural areas remains wide. According to the Millennium Development Goals Report (Hayes, 2015), 82.6\% of poverty is in rural areas, while $17.4 \%$ is in the urban areas. Poverty disparities in LPDR are undoubtedly higher in rural areas due to limited access to educational and economic opportunities (Hayes, 2015). 
To reduce the poverty rate and achieve the social and economic development goals set, the GoL has reformed and approved several social and economic strategic plans to integrate into the regional and global community. One main achievement was that LPDR became a permanent member of Association of Southeast Asian Nations (ASEAN) in 1997 and officially became a full member of the World Trade Organization in 2013 (Manolom, Promphakping, \& Mee-Udon, 2015; Saengouthay, 2016). In addition, LPDR was integrated into the ASEAN Economic Community in 2015. The integration aimed to strengthen trade and investment in the region and with neighboring countries (Hayes, 2015). For this reason, there is an urgent need to reform education so that human resources can be developed in response to demand. The education reform, however, has encountered various difficulties due to limited financial support and a lack of qualified educational practitioners.

\subsubsection{The socio-cultural context}

As indicated earlier, LPDR is an ethnically diverse country with 49 minorities. A majority of the population (70\%) lives in rural areas. These ethnic groups are categorized into four broad language families, Table 2.1 below, (Saengouthay, 2016):

- Lao-Tai;

- Mon-Khmer;

- Chine-Tibet; and

- Hmong-Iu Mien.

Because Lao-Tai is the largest group in terms of the social and political roles, the Lao-Tai language is used as the official language and national means of communication and is enforced in formal education at all levels. The use of the Lao-Tai language as a national language aims to promote nationalism and maintain the national identity of the country. 
Table 2. 1 Population by Ethno-Linguistic Group

\begin{tabular}{llll}
\hline Language family & $\begin{array}{l}\text { No. of ethnic } \\
\text { groups }\end{array}$ & \% of population & $\begin{array}{l}\text { \% of population } \\
\text { aged 0-16 }\end{array}$ \\
\hline Lao-Tai & 8 & 64.9 & 59.8 \\
Mon-Khmer & 32 & 22.6 & 25.1 \\
Chine-Tibetan & 7 & 2.8 & 3.0 \\
Hmong-Iu Mien & 2 & 8.5 & 10.7 \\
Other & & 1.2 & 1.5 \\
\hline
\end{tabular}

Source: Saengouthay (2016)

To maintain national identity, the GoL is promoting nationalism through the preservation of cultural diversity. The term 'national identity' is officially cited in legal documents and Constitution law (Phetsiriseng, 2009). Although Laos has historically been colonized and influenced by France and the USA, culturally, its closest link is with Thailand because of having the same religion and similar beliefs despite different political and economic ideologies. To preserve its unique culture, L PDR is considered a conservative society that might be resistant to change, including education reform, in the globalized world.

\subsubsection{The religious context}

Religion plays a vital role in Lao society. Because the majority of the Lao population is Buddhist, the GoL has officially designated Buddhism as the national religion; however, Animism also co-exists alongside Theravada Buddhism. The practice of Animism is not considered a religion and has not been promoted by the GoL as it might hinder socioeconomic and educational development (Adams et al., 2001; Saengouthay, 2016). The pronouncement of Buddhism as the national religion aims to maintain the national identity. The term 'nationalism' has been continually propagated by the LPRP since 1975 to maintain peace, stability, and solidarity of LPDR (Saengouthay, 2016). Other religions (e.g. Christianity and Islam) are also practiced in LPDR although the GoL closely monitors and supervises the activities of Christian and Islamic religions as some non- 
governmental organizations have used them against government policies and educated people on politically sensitive issues: democracy and human rights.

\subsection{The educational context}

The GoL recognizes the significance of education for the country's socio-economic development. Because of this, decentralization of educational policy has been prioritized and reinforced since 2002 to foster economic growth (Lachanthaboune, Somsanith, \& Lee, 2008). The GoL's commitment to providing education for its citizens has been reflected in legal documents, the Constitution and education law. It has been stated that all Lao citizens, regardless of their ethnicity, gender, religion, and socio-economic status, have equal rights to education (Lachanthaboune et al., 2008; Phetsiriseng, 2009).

\subsubsection{Lao education structure}

The LES consists of five sectors (see Table 2.2). The first sector, pre-primary education, includes nursery and kindergarten schools. The nursery school caters for children from three months to three years old while the kindergarten school caters for children aged four to five years old. The proportion of this category is small and is restricted to the urban area. Although pre-primary education is not compulsory in LPDR, the GoL recognizes its importance as it builds children's foundational skills and ensures that all children have a smooth transition to the next level of schooling (Phetsiriseng, 2009; Saengouthay, 2016).

The second sector, general education, consists of primary, lower, and upper secondary schools (Phetsiriseng, 2009). The primary school is a five-year compulsory level for children whose ages are six or older. The primary education is important for children's transition to the next level. Learners have to pass all subjects at a satisfactory level on their leaving examination to receive a certificate of completion. The lower secondary school is a four-year level that caters for learners whose ages range from eight to eleven years old. The upper secondary school is a three-year compulsory level for learners whose ages are from eleven to sixteen years old. This level is significant because learners have to take leaving examinations so that the results can be used for the continuation of 
their vocational and professional education. Both lower and upper secondary school education levels are compulsory.

The third sector, technical and vocational education training (TVET), offers a three-year programme in various disciplines. Popular courses include English, Computer Science, and Business Management (Phetsiriseng, 2009; UNESCO, 2011). Although TVET plays a significant role in the LES, its quality is still low due to various constraints: unqualified teachers, a lack of teaching materials, and the dominant use of traditional teaching approaches.

The fourth sector, TEP, focuses on teacher professional development and training (Phetsiriseng, 2009). Currently, there are eight teacher training colleges in LPDR responsible for producing primary and lower secondary school teachers in multidisciplines. In addition, there are four university faculties of education that are offering several educational programmes (Chatouphonexay, 2013). The TEP plays a key role in developing and producing teachers in many disciplines in the LES.

The last sector, higher education, offers various programmes in the LES. First, it offers a four-year bachelor programme in the four public universities. In addition, master and doctorate programmes are offered in some faculties at these universities. These programmes are delivered in collaboration with regional and international universities located in Vietnam, Thailand, China, and Japan, to name but a few (UNESCO, 2011).

Table 2. 2 LES Summary

\begin{tabular}{|c|c|c|c|}
\hline No & $\begin{array}{l}\text { Level } \\
\end{array}$ & Duration & Remarks \\
\hline 1 & Pre-primary Education & - 3 months-5 years & Not compulsory \\
\hline 2 & General Education & - 12 years & Compulsory \\
\hline 3 & TVET & - 3 years & Not compulsory \\
\hline 4 & TEP & - 3 to 4 years & Not compulsory \\
\hline 5 & Higher Education & - 2 to 4 years & Not compulsory \\
\hline
\end{tabular}




\subsubsection{Education system administration}

As previously indicated, the GoL has absolute control over the Lao education administration. This has been recognized, legitimized, and enforced by education law and the Constitution of LPDR (Law on Education, 2007; National Assembly, 2003). In brief, the Lao education administration system consists of three levels: macro, meso, and micro and each of these will be looked at in turn.

\subsubsection{Macro level}

The macro level is administered and supervised by the GoL. It is responsible for drafting national education action plans, policy making, decision making, and administrative tasks (MoES, 2015b). These are under the supervision of the Minister of Education and Vice-Ministers of Education. To meet the socioeconomic development needs, the macro level is making every effort with education reform to ensure a higher quality. It has been stated in the education law that future generations must be cultivated with the development of intellectuality, meaning the ability to think and understand things critically and logically (Law on Education, 2007, my translation). In addition, educational policies accentuate that modern education has to foster learners' capabilities for adapting themselves to the fast-changing world for existence and survival (MacKinnon \& Thepphasoulithone, 2014).

Furthermore, the GoL's policies stress the role of teachers in developing learners' competence in content knowledge and ability to apply it in real-world situations. For this reason, there is a significant need for an instructional pedagogy that encourages learners' in-depth understanding of the subject content knowledge and application skills. On top of that, article 49 of the education law points out that it is essential to improve the quality of teacher education in LPDR (Law on Education, 2007). This, in turn, will increase teachers' competence in content knowledge and lifelong learning. In terms of the content knowledge, teachers must be equipped with a higher level of subject knowledge in order to transfer that knowledge to their learners (Law on Education, 
2007). Regarding the pedagogical knowledge, teachers must be able to apply and integrate innovative and interactive teaching methods in planning and delivering their lessons. This is to shape learners' critical thinking skills and in-depth understanding of the subject content being studied (Viphavanh, 2014). In brief, many important education goals are set for classroom practices to achieve, which might put a lot of pressure on teachers who will implement the plans and mandated curriculum.

\subsubsection{Meso-level}

This level primarily follows the macro level and Ministry of Education and Sports (MoES) is the main driver of this level. The ultimate goal of the MoES is to ensure that all government policies (macro level) are properly implemented. The MoES is also responsible for drafting education plans being proposed to the NA for further consideration and approval (MoES, 2015c). To ensure smooth implementation and practice, the MoES introduced three characteristics and five pillars of the national education in 2010. The three characteristics include:

- nationalism;

- science; and

- public ideology.

The five educational pillars are:

- intellectuality;

- good behavior;

- labor;

- physical dimension; and

- artistic education (MoES, 2015b, my translation).

Among these, the intellectual dimension is related to this study as it is intended to develop learners' critical and creative skills. For this reason, teachers at all levels are required to cultivate these skills in their learners. However, the development of these skills encounters a wide range of difficulties due to teachers' low quality, cultural and institutional constraints, and a lack of instructional strategies to implement (Kennedy, 1988; MoES, 2015b). 


\subsubsection{Micro level}

The micro level is concerned with school teachers and practical classroom instruction under the direction and supervision of the macro and meso levels (MoES, 2015c). However, many teachers encounter a wide range of teaching constraints, especially in the rural areas (MoES, 2015b). The majority of teachers still lack appropriate, interactive, and innovative teaching approaches to planning and delivering their lessons. Therefore, many education pillars and characteristics are not successfully implemented and practiced. This phenomenon might be largely attributed to the currently ineffective TEP and insufficient in-service professional development and training for teachers (MoES, 2015c). In addition, the provision of teaching materials, qualified teachers, and funding for rural schools is still relatively limited. As a result, the implementation of an innovative and interactive teaching approach remains a challenge (Benveniste, Marshall, \& Santibañez, 2007).

\subsubsection{Education sector development and reform plan}

To reform Lao education, the GoL introduced important educational frameworks and visions in 2006 and 2008 with the aim of lifting the country out of poverty by 2020 (Phetsiriseng, 2009). In this respect, six dimensions of education were introduced. These dimensions (Ministry of Education and Sports, 2008) state that Lao education reform must focus on:

- developing human resources that meet regional and international standard;

- maintaining national identity;

- encouraging social participation and collaboration in maintaining national unity;

- developing learners' intellectuality, preserving the national culture, and inspiring the spirit of peace and solidarity amongst ethnic minorities;

- building Lao citizens' capacities for better living conditions; and

- promoting teachers' status in the society.

The fourth dimension, intellectuality, is aimed at developing learners' creative and critical thinking skills. However, this dimension is just ideological and challenging to translate into action unless supported by strategies to put them into practice. 
To lift the country out of poverty by 2020, a framework for education sector development from 2008 to 2020 was introduced. This framework is associated with the previous education reform to ensure an effective implementation of the education policy (Lachanthaboune et al., 2008; Phetsiriseng, 2009). To achieve this, the MoES adopted a Sector-Wide Approach (SWAP) - an approach to international development that brings together governments, donors and other stakeholders within any sector - into the LES. The MoES received technical assistance from the Asian Development Bank (ADB) for the preparation of a SWAP. The aim was to plan and design the education framework consisting of practical policies, options, and expected targets for the LES by 2020. To ensure success, the ADB also provided financial support for basic education programmes to provide more opportunities for Lao citizens to have direct access to formal education. These programmes focused on expanding a number of schools in twenty underprivileged districts of six provinces in LPDR (Lachanthaboune et al., 2008; Phetsiriseng, 2009) rather than on teacher education development.

The education vision to 2025 and 2030 was proposed in 2015 (MoES, 2015c). The 2025 education vision focused on five important areas:

- education quality to ensure learners' morality, and critical and creative skills for higher education;

- TEP quality improvement;

- human resource development enhancement responding to socioeconomic needs;

- education management and administration focusing on capacity building; and

- physical education and sports development maintaining learners' mental and physical health (Thongphanheuangsy, 2014).

As stated, the vision stressed the importance of the development of critical and analytical thinking skills. These skills, however, are not in place in actual classroom practices.

In terms of the 2030 education vision, the GoL states that "human resource development must meet regional and international standards so that the country can sustain strong production and is, therefore, capable of contributing to socioeconomic development; 
that, the people have at least upper secondary education and have access to qualified health services and the average life span is over 75 years old" (MoES, 2015b, p. 6, my translation). In addition, the MoES points out that "by 2030 the Lao population must equally and equitably have access to quality education to be considered a qualified workforce and one that is compatible with the region and the world" (MoES, 2015b, p. 7 my translation). To achieve the goal, the MoES has focused on:

- achieving compulsory primary education;

- eradicating illiteracy among ethnic minorities by promoting lifelong learning;

- promoting basic vocational skills at all levels;

- training laborers with critical and creative skills in using information technology;

- improving education quality;

- utilizing research results to inform education development; and

- expanding arts and physical education.

Although these goals are intended, it will still be challenging to accomplish unless teacher education is actively promoted and revolutionized.

\subsection{TEP in focus}

\subsubsection{A brief history}

The TEP has a long and complex history. To better understand this, it is worth looking at it prior to the French protectorate in 1893. Lao education was carried out in temples, known as Wat, by Buddhist monks before this time. The monks not only performed religious teaching but also provided general education in reading, writing, mathematics, and traditional medicine courses. Instructional pedagogy during this period was primarily delivered through the lecture and teacher-centered approach which failed to encourage deep and critical learning. As a result, the TEP during this time was very limited in terms of quantity and quality.

When the French seized power in 1893, the practice of traditional teaching methods still existed. In 1905, there were only two formal schools in Laos: Louangprabang and Vientiane Primary schools. During this time, the French education system was introduced in Laos to serve the colonizers and elites. For this reason, teachers were 
mostly recruited from France. People who completed primary education and wanted to teach at this level required three to six months of teacher training. In 1950, the first teacher training was founded under the jurisdiction of the Secondary Education Department. The training programme offered a four-year course in some disciplines. By 1954, only five Lao nationals had graduated from the programme, which was very limited in terms of learner enrolment and quality (Chatouphonexay, 2013).

Between 1955 and 1975, Laos was divided into two territories: 1) the Kingdom of Laos and 2) the Pathet Lao (Lao country). Although the two territories had different political and economic ideologies, teacher education was still promoted. The training of primary school teachers was conducted in Vientiane (the capital city of LPDR) on the Kingdom side while this was practiced in the north of Laos on the Pathet Lao side (Chatouphonexay, 2013). Secondary school teacher training was carried out at the Pedagogical University of Vientiane (PUV) in Vientiane and in the Viengxay Pedagogical Institute in the north of Laos.

After LPDR declared independence in 1975, the PUV became the highest TEP in Laos. The TEP played an important role in training student teachers in five major areas (Can, 1991):

- Mathematics-Physics;

- Biology-Chemistry;

- Geography-History;

- Psychology-Education; and

- Languages-Literature.

The only foreign languages formally taught during this time were Russian and French. To promote the TEP, the Prime Minister of LPDR issued a decree on the establishment of the National University of Laos (NUOL) in 1996. This amalgamated 10 existing educational institutions under the administration of different ministries. As a result, PUV became the Faculty of Education (FED), one of the 13 faculties of NUOL (Thongphanheuangsy, 2014). 
However, FED has performed the same role as PUV did in terms of training upper secondary school teachers (MoES, 2015b).

The TEP has achieved an important breakthrough in terms of school infrastructure, curriculum development, and a number of graduates in the past two decades. However, existing research suggests that the TEP has not accomplished its target in terms of quality improvement and assurance due to the following predominant difficulties (Chatouphonexay, 2013):

- pre-service teachers are normally trained in a passive fashion;

- a lack of teachers' abilities and insufficient skills;

- curriculum fails to focus pre-service teachers on interactive and meaningful exploration;

- overcrowded classes and a lack of teaching materials; and

- a lack of a systematic and ongoing evaluation.

\subsubsection{Foreign languages emergence in LPDR}

As previously stated, Laos was a French colony between 1893 and 1945. During this time French was officially used as the working language for formal instruction and communication. Because of this, French gained a special status as the first foreign language in LPDR. After proclaiming independence in 1975, Russian started to gain dominance in the LES due to a change in the political ideology. For this reason, the Russian Language Department was officially founded at PUV with the aim of training preservice teachers and government officials who would be sent to study in the former Soviet Union (Chatouphonexay, 2013).

After the collapse of the Soviet Union in 1991, English became the most important language for Lao people to communicate with the western world (Bounyasone \& Keosada, 2011). Because of this, English was included as one of the compulsory subjects in primary and secondary school curriculums in addition to French (Elliott, 2014; MoES, 2015c). As the former minister of education, Viphavanh $(2014$, p. 6), states "English is required as the main foreign language at all levels of the LES to enable the country to 
better integrate into the region and the world." For this reason, the GoL is attempting to upgrade its officials at all levels. The promotion of English can be seen in recent government commitments to the establishment of English language teaching within several ministries. The GoL also provided financial support in upgrading its civil servants and allowed for the establishment of private English centers and colleges throughout LPDR (Chatouphonexay, 2013; Elliott, 2014).

\subsubsection{Tensions and constraints in Lao TEP}

As indicated earlier, one of the constraints on the development of TEP in LPDR was a lack of qualified teachers (MacKinnon \& Thepphasoulithone, 2014). Currently, many inservice teachers, especially in rural areas, lack opportunities for training to upgrade their subject content and pedagogical knowledge. Furthermore, many primary school teachers are teaching at lower or upper secondary schools without qualifications in the subject areas they are teaching. As a consequence, the teachers fail to conduct interactive and meaningful classroom instruction. For this reason, it is necessary to upgrade teachers' skills and shape their instructional experiences.

To address the challenges related to English instruction, reflective and interactive approaches were introduced. These include a learner-centered approach and communicative language teaching (Vongxay, 2013) with the aim of developing learners' problem-solving and communication skills. For this reason, teachers need to be familiar with the principles and concepts of these new teaching methods. Although being trained in how to use these methods, the teachers also had to teach in response to the assessment requirements of the syllabus which limited teachers' time and mental effort to apply interactive teaching. Moreover, many teachers trained in the learner-centered method revert to the traditional instruction, as pointed out earlier (MacKinnon \& Thepphasoulithone, 2014). In addition, a lack of in-service teacher professional development is also impeding the teaching of English. This indicates limited opportunities for teachers to enhance their teaching confidence, exchange their teaching experiences with others and share their beliefs and interests about teaching (Hausman \& Goldring, 2001). Finally, some teachers collect students' feedback at the end of their 
classes in the areas of teachers' punctuality, manners, and characteristics. Such feedback, however, might not promote meaningful learning and help transform the teaching (Hausman \& Goldring, 2001).

\subsection{English teacher education programme (ETEP) in focus}

The Lao ETEP was legitimized and recognized by the GoL (MoES, 2015b). Since the establishment of the ETEP in 1996, the curriculum has been consistently reformed and revised to keep up with socioeconomic needs and dynamic changes in the globalized world (NUOL, 2017). First, the reform took place after the foundation of the programme, which required pre-service teachers to pursue a $2+4$ programme (a two-year bridging course and a four-year English specialization course). The system was implemented from 1996 to 2003 but was discontinued due to its low credibility and quality (Bounyasone \& Keosada, 2011; National University of Laos, 2010). Second, the 0+5 system was designed and implemented to replace the previous one (2004-2009). The new programme excluded a bridging course. However, some of the bridging subjects were integrated into the English specialization subjects. Due to a lack of effectiveness and better quality, the $0+5$ programme is no longer implemented.

Third, the development of a $0+4$ system took place in 2010 . The system principally focused on English and pedagogical skills to ensure students' competence and capability in both subject content and pedagogical knowledge (National University of Laos, 2010). This programme was well-received due to its higher credibility and appropriateness. Although the $0+4$ programme was perceived as the better curriculum in terms of content knowledge and pedagogical skills, it is no longer used.

Finally, a centrally designed and mandated curriculum was replaced the previous programme. Attempts to implement this system, however, encountered various constraints and difficulties: a lack of an intensive focus on English skills, insufficient teaching materials, and a lack of pedagogical guidance (National University of Laos, 2010). More importantly, the programme does not provide a teaching method that fosters learner critical and creative thinking skills although acknowledged in the 
objectives. The primary focus of this programme is to train pre-service teachers to be able to teach various subjects (e.g. English, History, and Geography) from Mathayom 1 (grade 6) to Mathayom 7 (grade 12). Table 2.3 summarizes the time frame of the ETEP curriculum implementation

Table 2. 3 Timeframe of Curriculum Implementation

\begin{tabular}{lllll}
\hline Timeframe & $1996-2003$ & $2004-2009$ & $2010-2014$ & 2015-present \\
\hline System & $2+4$ & $0+5$ & $0+4$ & $0+4$ \\
\hline
\end{tabular}

Source: FED (2017)

It can be noted that the Lao ETEP was reformed consistently without a proper follow-up evaluation and assessment. Such reform might not have contributed to the improvement of the better quality as expected.

\subsubsection{ETEP structure, content, and philosophy}

The Lao ETEP structure and content consist of four major areas (see Table 2.4):

- general subjects;

- foundation subjects;

- English specialized subjects; and

- elective subjects.

The general subjects consist of 19 credits, which are compulsory. Learners must pass these subjects in order to complete and receive a qualification (FED, 2017). The subjects range from Lao Language to Education Technology. These subjects are intended to build pre-service teachers' general knowledge and skills in instruction. However, they are taught in L1, which is not conducive to the development of students' English skills (National University of Laos, 2010). The foundation subjects consist of 42 credits. They are intended to develop students' English in the four macro skills (listening, speaking, reading, and writing). The primary emphasis of this category is on General English.

The English specialized subjects focus on both pedagogical and English skills. Students need to take 78 credits in subjects ranging from Reading to Methodology (National 
University of Laos, 2010). Lastly, the elective subjects consist of four credits which include English and other relevant subjects.

Table 2. 4 ETEP Content Summary

\begin{tabular}{lll}
\hline Category & Credit & Focus \\
\hline General & 19 & General Knowledge of Pedagogy \\
Foundational & 42 & Building Basic English Foundation \\
Specialized & 78 & Building Pedagogical and English Skills \\
Elective & 4 & Supplementary skills \\
Total & 143 & \\
\hline
\end{tabular}

The ETEP's philosophy states that "the programme must ensure critical thinking abilities, deep learning, social responsibility, open-mindedness, and a good role model for learners" (National University of Laos, 2010, p. 3). As can be seen, the philosophical assumption of the programme covers a wide range of creative and critical thinking skills that are important in the globalized word.

In addition, the ETEP sets out important objectives that cover a wide range of learning outcomes:

- English proficiency and pedagogical competence;

- $\quad$ creative and critical skills;

- moral and social behaviors; and

- physical and mental well-being.

These objectives include important elements of the education vision and policy previously discussed. It can be noted that the ETEP has clear goals and objectives. However, it is still challenging to achieve these objectives in terms of actual classroom practices unless immediate action is taken.

\subsubsection{Current state of English instruction in L PDR}

Although there is limited research in English instruction in L PDR, research suggests several constraints affecting the English teaching in this context. According to Vongxay (2013), one of these is the use of traditional teaching methods (e.g. Grammar- 
Translation). In many Lao classroom practices, the emphasis of English teaching fails to focus learners on communication, exploration, and interaction in the target language. In addition, research suggests that the focus of teaching tends to encourage rote memorization and translation which fails to stimulate learners to use the target language to explore concepts or go beyond the surface (Souriyavongsa, Rany, Abidin, \& Mei, 2013). Another difficulty is the teacher-centered nature of the classroom. This refers to the teachers' dominance of the classroom and acting as a transmitter of knowledge which encourages learner passivity (Thongphanheuangsy, 2014). As a result, the instruction fails to reflect the social nature of the classroom interaction and collaboration (Jacobs \& Farrell, 2003).

A final constraint to be mentioned here is that some teachers have difficulty accepting learners' ideas and perspectives when conducting classroom discussions on various issues because these instructors might perceive themselves as the fount of knowledge (Vongxay, 2013). To mitigate these challenges, communicative language teaching (CLT) was introduced in 2005, aiming to create an innovative and interactive classroom. The introduction of the CLT, however, was limited by teachers' misconceptions about it, teachers' and students' low English proficiency levels, and a lack of teaching materials (MacKinnon \& Thepphasoulithone, 2014; Vongxay, 2013). These constraints will be looked at in turn when discussing the study.

\subsubsection{ETEP teaching materials}

A lack of teaching materials together with inappropriate and insufficient textbooks has had a significant impact on the quality of the ETEP in L PDR. Teaching materials refer to anything that can facilitate learning and teaching of English. As Tomlinson (2012, p. 143) states, "materials can be informative, instructional, experiential, eliciting, and exploratory." Ideally, the materials should facilitate the real nature of learning rather than teaching and should reflect all elements in the quote above.

The teaching materials for the ETEP, however, might fail to reflect all functions specified above because they are taken from commercially produced textbooks due to a lack of 
skilled textbook writers and insufficient funds to design local learning resources (National University of Laos, 2010). The problem is that these materials are produced in the Western context and, therefore, the content might not reflect the Lao EFL students' culture and setting. In addition, many teachers are overloaded with teaching hours and administrative tasks. This limits their time to adapt and develop the materials that are suitable for their students' needs (Tomlinson, 2012). The constraints undoubtedly have a significant influence on the integration of an innovative and interactive approach.

\subsubsection{ETEP physical learning environment}

The physical classroom setting plays a significant role in promoting better learning and teaching (Ramli, Ahmad, Taib, \& Masri, 2014). Ramli et al. (2014) state that learning environment refers to the surrounding conditions in which teachers and students function. These include classroom arrangement, lighting, decoration, seating management, and so forth that make up of the whole classroom (Ramli et al., 2014). To conduct interactive instruction, it is useful to have and understand the characteristics of supportive learning environments as different teaching methods require different classroom arrangements and physical spaces (Asiyai, 2014).

The physical environment of the ETEP in L PDR still lacks necessary materials although basic facilities, for instance, whiteboards, markers, tables, and teachers' desks are provided. These may not be conducive to interactive and meaningful learning to occur.

Furthermore, some classrooms need rebuilding or repairing. In addition, the Internet and technological devices: computers, LCDs, and overhead projectors are not provided (Benveniste, Marshall, \& Santibanez, 2015). These limitations affect the quality of teaching and learning.

\subsubsection{ETEP instructors}

The ETEP instructors play a crucial role in ensuring the quality of pre-service education in L PDR. The teacher is regarded as "a provider, nurturer, advocate, devotee, instructor, transmitter, and a co-worker" (Wan, Low, \& Li, 2011, p. 408). This indicates that teachers perform multidimensional tasks in their profession in addition to instruction. Currently, 
there are approximately 35 English instructors at the ETEP with a wide range of teaching experiences and educational backgrounds. The majority of them (95\%) have a master's degree in teaching English from domestic universities. In addition, the ETEP also receives a small number of American volunteer teachers each year. This provides the opportunities for pre-service teachers to be exposed to native speakers of English (National University of Laos, 2010).

Although the majority of the teachers have a master's degree in the discipline, the low quality in both English and pedagogical skills has a significant influence on the development of pre-service education in this context (MoES, 2015c). To address the issue, as indicated in chapter 1 , in-service professional training courses were conducted to foster the teachers' capabilities. The results, however, did not demonstrate effectiveness in changing actual classroom practices. This indicates that the Lao preservice education programme does not always have a big effect on shaping pre-service teachers' perceptions of teaching. This also reflects one element of the language teacher cognition (LTC) model to be discussed in chapter 3 - that; the TEP does not play its role in changing pre-service teachers' perceptions of teaching. This existing problem might be due to teachers' preconceived beliefs about language learning and teaching based on their prior experiences as learners.

\subsection{Chapter summary}

This chapter discussed various contextual factors related to the LES. These areas were addressed because they had a crucial impact on the implementation of an interactive and innovative teaching approach. They also play an influential role on shaping Lao EFL preservice teacher education and the construction of LTC. To better understand how LTC plays a direct role on language instruction; the following chapter will look at this concept prior to reviewing the reading and CoT literature respectively. 


\section{CHAPTER 3: LITERATURE REVIEW}

\subsection{Introduction}

This chapter addresses literature and empirical studies related to the present study. The chapter begins by discussing the concept of LTC in section 3.2. Section 3.3 looks at literature of reading. Section 3.4 addresses a CoT literature. The final section, 3.5, summarizes the chapter. Engagement literature will be discussed in chapter 6 (Section 6.3) when those findings are introduced.

\subsection{Introduction to LTC}

\subsubsection{Definition and origin}

LTC has been defined as "the unobservable cognitive dimension of teaching - what language teachers think, know, and believe, and the relationships of these mental constructs to what teachers do in the language teaching classroom" (Borg, 2003, p. 81). It has been noted that these mental constructs are resistant to change, even in a positive way.

LTC has emerged and received considerable interest in mainstream educational research over the last three decades (Borg, 2006; Woods, 1996). In fact, a large proportion of research has been foregrounded and conducted to support its emergence as an interesting area of investigation (Barnard \& Burns, 2012; Borg, 2006; Macalister, 2010; Wong, 2010; Woods, 1996). The development and growth of this concept can be attributed to two important factors. First, it is a recognition of teachers as "active, thinking, decision makers who play a central role in shaping classroom events" (Borg, 2006, p. 11) and it is the shift in teacher education to "constructivist, process-oriented theories of learning, teaching and teacher learning" (Crandall, 2000, p. 34).

LTC plays a very influential role in understanding what language teachers think, believe, and do in their classroom practices. As Macalister (2012, p. 99) points out, "the knowledge and beliefs that teachers hold are an important determiner of what happens 
in the classroom." Literature on LTC suggests that there are three major points to consider when exploring teachers' cognition and beliefs about learning and teaching (Borg, 2006; Ozmen, 2012; Woods, 1996). These include:

- teachers' behavior in classrooms are determined and shaped by preconceived beliefs;

- language learning and acquisition are facilitated by teachers as active players and decision-makers; and

- TEP content and structure should be shaped by empirical studies so that teacher efficiency and effectiveness can be fostered.

First, relevant literature suggests that language teachers' practices are shaped in a unique and often unpredictable way by the invisible dimension of teachers' mental lives. These have emerged from teachers' diverse personal and language learning histories, language teacher education experiences, and the specific contexts in which they do or learn to do their work (Kubanyiova \& Feryok, 2015). These experiences have a notable impact on language teachers' actions and practices in classrooms. Therefore, research in LTC needs to look at these in order to better understand and provide critical insights into the realities of language teachers' actions in classroom settings (Borg, 2006; Kubanyiova \& Feryok, 2015) so that change for the better can be made accordingly.

Second, LTC and education research acknowledge that teachers play a central role in facilitating language acquisition and learning in students (Borg, 2006; Kubanyiova \& Feryok, 2015). However, what teachers experienced and perceived as learners becomes one of the main determinants in their classroom actions and practices (Borg, 2006; Chatouphonexay \& Intaraprasert, 2014). In most educational contexts, teachers are regarded as the main drivers of learning, teaching, and change. In some societies, teachers gain higher status than others because of the social and cultural norms. These cultural norms, as pointed out in chapter 2, also play an important role in shaping classroom practices and actions. In this respect, questions worth seeking answers to are: (1) how do language teachers conduct deep and meaningful learning for their students 
despite these constraints? And (2) how can the TEP facilitate and influence those language teachers in order to change their preconceived beliefs of learning and teaching? (Kubanyiova \& Feryok, 2015). One way to address this might be through the implementation of an innovative teaching approach (e.g., a CoT) in classroom practices.

Finally, TEPs should be restructured and improved in order to re-shape pre-service teachers' perceptions of learning and teaching. Teacher education reform and development should be aligned with theoretical frameworks and empirical studies in LTC (Macalister, 2010, 2012). Research suggests that TEPs do not always play a significant influence on shaping and changing pre-service teachers' preconceived beliefs of learning, teaching, and practices (Borg, 2006; Cota Grijalva Sofía \& Ruiz-Esparza Barajas, 2013; Macalister, 2016b; Mattheoudakis, 2007; Ozmen, 2012), suggesting that more research is needed to incorporate innovative approaches into teaching TEPs in order to change language teachers' perceptions of learning and teaching.

Research into the intricate interplay between the development of teachers' beliefs and actions has provided a nuanced understanding of what was happening in classrooms. The critical argument is that if research focuses on improving teacher effectiveness and teaching performance, it is also critical to understand what accounts for thinking processes underlying teacher decision-making in terms of planning, instruction, and reflection (Woods, 1996). In addition, it is essential to explore how teacher thinking and beliefs are formed and what needs to be further done to influence those beliefs and thinking that will result in positive change so that interactive instruction can take place in the classrooms. In this respect, research in this area has two important objectives: 1) to understand how teachers' mental constructs and processes are shaped and formed; and 2) to influence these unobservable lives in order to enhance teaching effectiveness (Borg, 2006).

The issues above have led to the development of several frameworks and models attempting to make and describe connections between teachers' mental constructs and 
their actions in the classrooms (Borg, 2006; Macalister, 2012; Woods, 1996). To expand the above discussion, I will present and discuss three important models of LTC in the next section. These will be the main theoretical frameworks for the result interpretations and discussions in this study.

\subsubsection{LTC models}

Three important models of LTC (Borg, 2006; Macalister, 2010; Woods, 1996) are pertinent to explore the complex interplay between cognition and behavior. First, Woods's (1996) model provides a basic understanding of language teachers' decisionmaking processes. It synthesizes and conceptualizes both external and internal factors that shape and influence the processes and how teachers' decisions impact classroom actions (Woods, 1996). The model originates from cognitive psychology and educational research. Three elements (e.g., planning, implementation, and assessment) make up this model. The main focus of the model is the dynamic nature of the interrelation between the teachers' planning processes and their perceptions of classroom actions or behaviors (Woods, 1996). This allows researchers to apply the processes when conducting research in LTC. Additionally, he argues that teachers' actions and behaviors are determined and interpreted through a system of beliefs, assumptions, and knowledge (BAK) (Woods, 1996). The construct of BAK is proposed in an analogy to the notion of schemata, which attempts to explain teachers' thinking and behavior. BAK is similar to schemata in the sense that "knowledge, assumption, and beliefs can be posited in terms of interrelated propositions, in which certain propositions presuppose others" (Woods, 1996, p. 196). Individual teachers develop a system of BAK in a unique and structured way. Through this, researchers are able to explore "teachers' interpretative processes" (Woods, 1996, p. 213) relevant to several types of teaching actions and factors (e.g., classroom practices, curriculum or syllabus, and teaching materials). The model also reveals that it is not easy to identify the differences between mental constructs (e.g., beliefs and knowledge) as these mental lives are abstract and unobservable (Woods, 1996). 
The second model (Borg, 2006) highlights important factors that shape LTC (see Figure 3.1). The model represents the revision of the early model in 2003 reflecting an extensive review of the literature at that time (Borg, 2003).

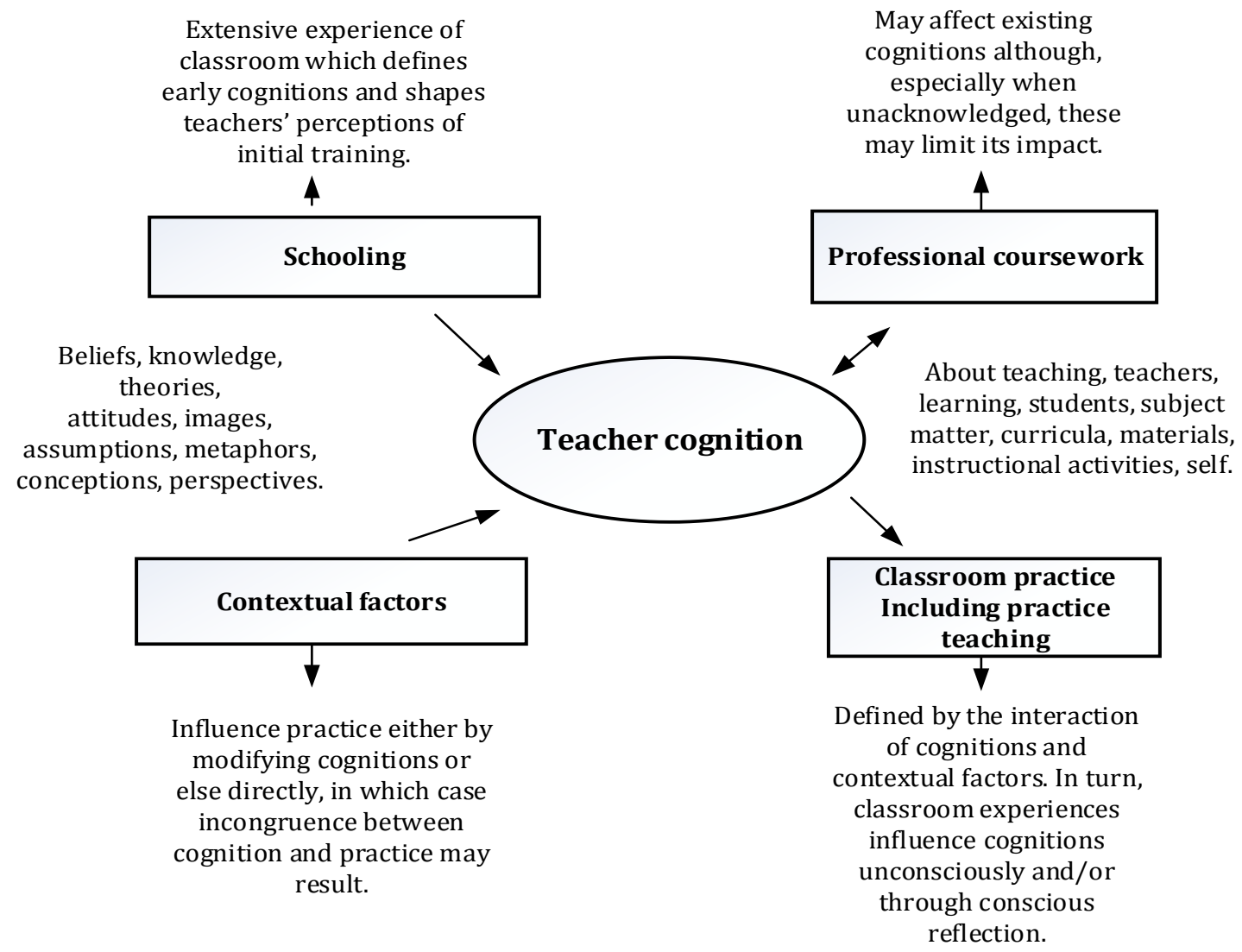

Figure 3. 1 Language Teacher Cognition Model (Borg, 2006, p. 41)

As demonstrated in the model, LTC is influenced by all aspects of work and can be used as a tool for conceptualizing research in LTC. This model was formed and synthesized based on an extensive review of literature and studies in the area (Borg, 2006). The benefit of the model is that it can be used as a framework for studies on LTC. It reveals that teacher cognition is constructed and shaped through its relationships with schooling, professional coursework, and classroom practice - in conjunction with contextual factors (Borg, 2006). These determinants are interrelated and influential to what teachers do in the classrooms. In other words, it is viewed as "a cause-effect relationship" (Macalister, 2016b, p. 60) which cannot be separated. Because of their 
influential roles in LTC construction, each of these will be briefly discussed in turn to increase our understanding of their impacts on beliefs, knowledge, prior language learning experiences, and cognition development.

First, pre-service teachers' prior language learning experiences and cognition refer to what they experienced as learners in schooling and brought to the TEP or professional development coursework. In other words, it refers to the notion of "apprenticeship of observation" (Lortie, 1975) that they have gone through during their schooling. Their memories of learning and teaching perceived as learners continue to play a significant influence on their future pedagogical and professional careers. This results in teachers performing their teaching in accordance with their pre-existing or past experiences and beliefs about language learning (Macalister, 2012).

Second, pre-service teachers' beliefs, experiences, and cognition about language teaching and learning also shape their response to, and are constructed during, professional coursework. This has become a critical issue to consider in studies on LTC. Research shows that "at the start of TEPs, students may have inappropriate, unrealistic or naïve understandings of teaching and learning" (Borg, 2006, p. 54). This implies that learners can bring all types of beliefs about learning and teaching when entering a TEP. Common beliefs that pre-service teachers brought to the TEP include learning a language is mostly a matter of: 1) learning a lot of new words, 2) learning a lot of grammatical rules, 3) intelligence, and 4) language aptitudes (Chatouphonexay \& Intaraprasert, 2014; Mattheoudakis, 2007; Peacock, 2001; Wong, 2010). This suggests that the TEP has an important role to play in changing these predominantly and common beliefs about teaching and learning a language. Changing these beliefs, however, remains difficult in many EFL TEPs.

Third, pre-service teachers' decision-making, beliefs, cognition, and knowledge during the practicum or teaching practice refer to what they experience during their teaching practices. In fact, a large body research has revealed the relationships between pre- 
service teachers' cognition and their classroom practices during the practicum (Breen, Hird, Milton, Oliver, \& Thwaite, 2001; Kuzborska, 2011; Lam, 2000). Results showed that the most common consideration of their decision-making included teaching participation, instruction management, and adaptation to the programmes. It also included their needs, their subject content knowledge, their competence, and the appropriateness of teaching methods. These components have a crucial impact on preservice teachers' cognition in addition to their preconceived beliefs (Borg, 2004). Other factors that affect their beliefs and knowledge during the practicum include: a choice of activities, materials selection, and the way they deliver their lessons. These play a greater role in shaping and conceptualizing their cognition of teaching.

Finally, teacher cognition is shaped and constructed through interaction with contextual factors. These factors can influence practices or modify early cognition of learning and teaching a language (Borg, 2006). Because of this, change in pre-service teachers' cognition during the professional coursework and the extent to which TEPs influence pre-service teachers' cognition are minimal (Pajares, 1992). Existing research has investigated the effects of TEPs on changing pre-service teachers' cognition and instructional practices (Borg, 2006). Results revealed that various variables influenced their beliefs and teaching practices. Although the results suggest some pre-existing beliefs of trainees changed after the TEP, this might have resulted from the course requirements and assessment criteria that they were required to follow (Borg, 2003). In brief, the four important factors discussed here play a major role in shaping pre-service teachers' beliefs and cognition about language learning and teaching.

Finally, Macalister's (2010, p. 62) model (see Figure 3.2) is a modified version of the Borg's model. This model includes BAK as an additional subset of the teacher cognition model, meaning that BAK is not seen as a single or isolated concept; it is recognized as an integral part of the LTC. In other words, it also plays an important role, in addition to other factors, in shaping the development of teacher cognition (Macalister, 2010). As pointed out earlier, BAK receives considerable interest in language teacher education 
research (Ellis, 2008; Horwitz, 1995; Wesely, 2012), especially in the EFL and ESL contexts. This allows researchers to explore the complex phenomenon while appreciating the dynamic nature of LTC.

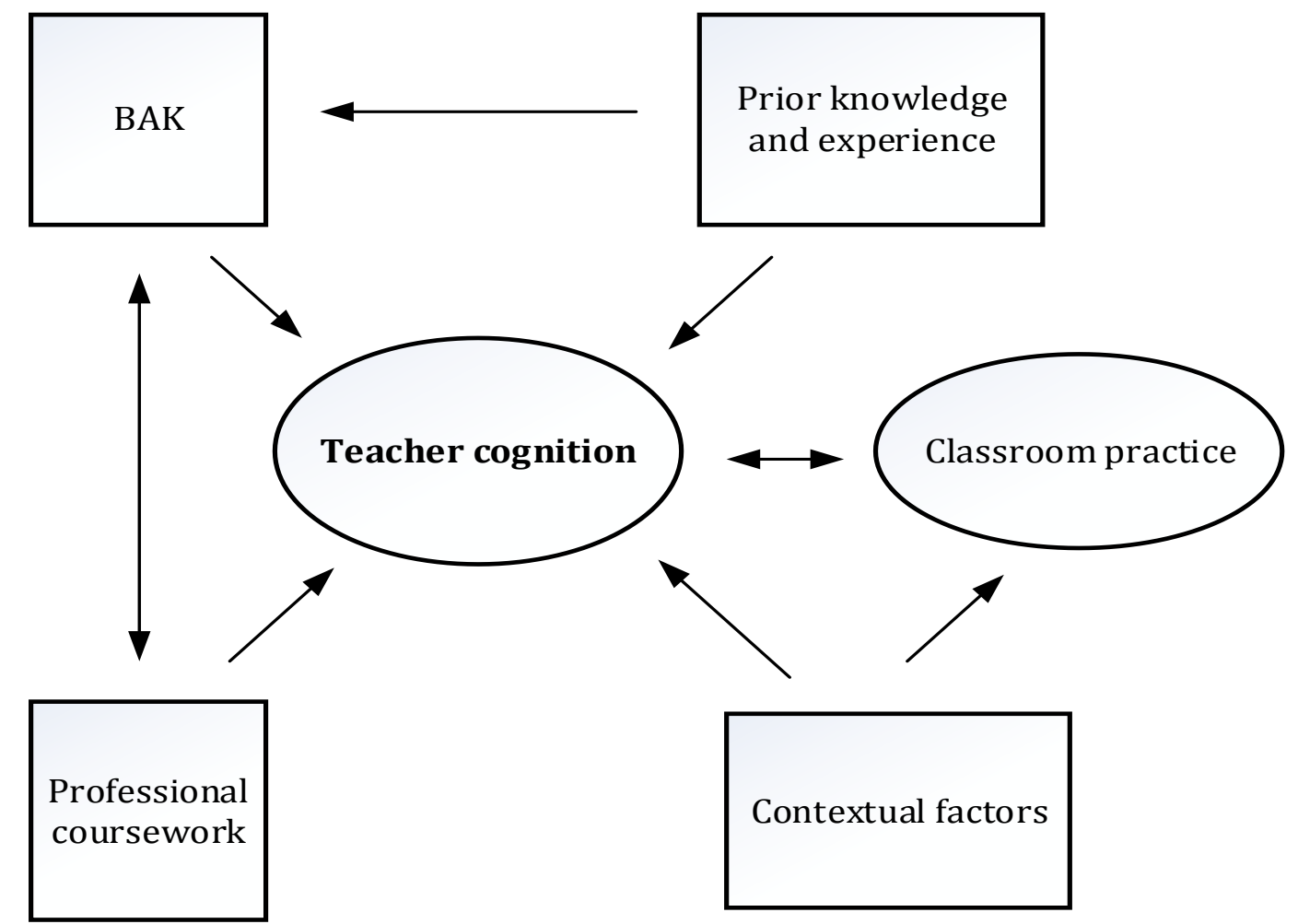

Figure 3. 2 The Dynamic Nature of Teacher Cognition (Macalister, 2010, p. 62)

All three models presented above reflect the emerging research in cognitive psychology (Vygotsky, 1978) and mainstream educational research (Woods, 1996). First, Woods' (1996) model plays an important role in LTC research because it provides the primary approach to conducting studies in the area. Second, Borg's (2006) model has demonstrated the emergence of LTC research in mainstream education over the past decades. Finally, Macalister's model is a modification of Borg's (2006) focusing on the dynamic interrelationship of teacher cognition by including BAK as an additional subset. The main contribution of this model is that it shows the interactions among the factors. 
In addition, the three models attempt to identify a dynamic relationship between the teachers' mental lives and their actions. This allows scholars to explore the interplay between teachers' preconceived beliefs and their critical impact on learners and classroom practices. Since this research focuses on pre-service teachers, it is worth looking at this to advance our understanding of how pre-service language teacher cognition is shaped and constructed.

What is interesting to note in Figure 3.2 is 'prior knowledge and experience', which seems to have replaced 'Schooling' in Figure 3.1. However, prior knowledge and experiences in this sense are shaped by a variety of factors beyond schooling or the apprenticeship of observation (Lortie, 1975). It includes early established beliefs, knowledge, and experience in life which are resistant to change even in the face of contradictory evidence (Borg, 2003). Such prior knowledge and experience are in "the form of episodically stored material derived from critical incidents in individual personal experience" (Borg, 2003, p. 86). The value of adding this element is important as cognition is shaped by not only experiences from schooling but also from their personal experiences in which they situate or live.

\subsubsection{Pre-service teacher cognition construction and change}

The construction of pre-service teacher cognition can be traced back from their primary up to teacher education experiences as learners (Borg, 2006; Ozmen, 2012). The development of their cognition and beliefs has gained relatively limited attention to date although understanding this is beneficial as erroneous beliefs might lead to ineffective classroom practices (Macalister, 2012). As stated previously, by the time learners enter the TEP, they have already experienced the apprenticeship of observation during their schooling (Lortie, 1975). Therefore, TEPs have an important role to play in shaping preservice teachers' beliefs, decisions, and practices (Pajares, 1992; Richardson \& et al., 1991) so that effective classroom instruction can be assured. In this respect, the critical question worth considering in most of the studies on pre-service teacher cognition is the extent to which the TEP results in cognitive developments and do these developments shape teachers' classroom actions and practices (Ozmen, 2012). In this regard, TEPs can 
be viewed as "change programmes, particularly in their endeavors to re-shape cognition" (Macalister, 2016b, p. 59). As pointed out earlier, however, TEPs do not play an effective role in changing pre-service teachers' beliefs, cognition, and practices of teaching (Peacock, 2001; Wong, 2010).

Although pre-service teacher cognition and beliefs about learning and teaching are categorized into several areas, there are two major ones that are considered influential in forming their BAK of learning and teaching. These include "teaching as a process of knowledge transmission and teaching as a process of knowledge construction" (Ozmen, 2012, p. 22). Research suggests that EFL Learners have extensive experience of teaching as a process of knowledge transmission in their schooling (Renandya, Lee, Wah, \& Jacobs, 1999; Vongxay, 2013). This mode of teaching is understood as a traditional and teachercentered approach in which learners play a passive role in the classroom while the teacher is the main source of knowledge and takes complete authority over the classroom (Chai, Teo, \& Lee, 2009; Ozmen, 2012). The latter, teaching as a process of knowledge construction, refers to the constructivist view of teaching. This appreciates and values "the importance of students' efforts to make sense of their experiences and teachers' role in facilitating that process" (Chai et al., 2009, p. 353). In this learning mode, learners are encouraged to engage, interact, explore concepts, and exchange ideas with their fellow classmates facilitated by the teacher. Although the two important categories provide a lens for language teachers, research suggests that most teachers apply both styles of instruction, depending on the contexts in which they live (Entwistle, Skinner, Entwistle, \& Orr, 2000; Van Driel, Bulte, \& Verloop, 2007).

In fact, previous research has investigated the cognition change of both pre-service and in-service language teachers in EFL and ESL contexts (Borg, 2003; Cota Grijalva Sofía \& Ruiz-Esparza Barajas, 2013; England, 2017; Kubanyiova \& Feryok, 2015; Macalister, 2012; Suwanarak, 2012; Xiaohui \& Li, 2011). However, results of these studies were still inconclusive in terms of confirming teachers' cognition development and change as a result of interventions and TEPs. 


\subsubsection{Empirical studies concerning pre-service English teacher cognition}

Several studies have examined and traced pre-service teacher cognition development and change (Borg, 2004; El-Okda, 2005; Kubanyiova \& Feryok, 2015; Macalister, 2012; Peacock, 2001) and the results have revealed mixed findings. The following studies are looked at because they provide critical insights into beliefs about language teaching and cognition change.

An earlier study (El-Okda, 2005) in the field established that pre-service teachers do have pre-existing beliefs about language learning and teaching when it comes to reading. The study consisted of 57 pre-service teachers. Three sets of arguments about practical teaching situations were used to collect data. Participants were asked to indicate whether items were 'right' or 'wrong'. In addition, eight informal interviews were conducted to obtain the data about issues of interest. Another data collection instrument employed consisted of three areas of beliefs: 1) literacy instruction; 2) text exploitation in reading lessons; and 3) teaching of prescribed narrative texts (stories or novels). Data were analyzed quantitatively and qualitatively. The results showed that in terms of

literacy instruction, the majority of pre-service teachers believed that it was necessary for children to be directed to learn the alphabet from the very beginning of the course as delayed literacy instruction could have a negative impact on the whole process of learning a foreign language. In addition, a model of reading provided by the teacher was useful for improving children's pronunciation and reading aloud by learners had a direct connection to pronunciation improvement. In terms of reading text exploitation, the majority of them believed that focusing on language form or structure was more important than sub-skills of the reading process. In relation to the teaching texts, the majority of them seemed to believe that reading novels and stories could develop their vocabulary and understanding of structures. It can be seen that the pre-service teachers perceived surface learning and discrete language features as the main focus of learning reading. This study, however, did not focus on changing pre-service teachers' attitudes toward teaching English. Thus, further research is needed to fill this gap. 
Another study to be discussed here was conducted in the Thai EFL context to examine pre-service teachers' beliefs about language learning and teaching (Vibulphol, 2004). Mixed- methods research was employed to collect and analyze data. The results indicated that most of the pre-service teachers believed learners who were good at English had language aptitude. In terms of difficulty, most of them believed that English was a language of medium difficulty, and the best way to learn the language was to go to an English-speaking country. They also believed that frequent exposure to native speakers of English could improve communication skills. Regarding communication strategies, most of them believed it was important for learners to use English regularly in order to enhance communicative competence. This could be achieved through listening to English TV programmes, radio, TED Talks, and other English sources. Finally, they reported the role of motivation in learning achievement. They believed that learners with high motivation tended to develop English skills faster than those who did not. The results indicate that pre-service teachers' beliefs and experiences varied widely in this context. The experiences and beliefs they held continued to play a significant role in shaping their practices and cognition. This study, however, did not look at pre-service teacher cognition development or change. This gap has been addressed by the following studies which traced pre-service teacher cognition development and change.

The subsequent study looked at how cognition changed over time as a result of the TEP. Macalister (2016b) investigated the effects of a trans-national language TEP, where the teachers spent two years studying in New Zealand, on pre-service teachers' practicum. A qualitative approach was employed to collect and analyze data. The results suggested that the pre-service teachers put their best efforts into creating interactive and innovative teaching activities for their classroom practices. Specifically, a learnercentered activity (running dictation) was observable in two pre-service teachers' teaching practices. This might be linked to their experiences as trainees in New Zealand (Macalister, 2016b). It can be noted that although TEPs attempt to influence pre-service teachers' cognitions of teaching, it remains challenging to change their preconceived beliefs and actions even in the face of contradictory evidence (Borg, 2006). In this regard, 
the conception that language TEPs as "change programmes, particularly in their endeavors to re-shape cognition" (Macalister, 2016b, p. 59), as stated earlier, remain questionable and debatable.

A final study to discuss here was carried out in Turkey to trace pre-service teachers' cognition change with regard to learning and teaching English following the TEP (Ozmen, 2012). The study aimed to: 1) identify the current status of the pre-service teachers' beliefs about language learning and teaching; 2) track the changes in the pre-service teachers' beliefs about language learning and teaching during the four years of the ELT programme; 3) explore the pre-service teachers' views of each phase of the EFL programme, and (4) to examine the influence of the EFL curriculum on their beliefs development. A mixed- methods approach was employed to collect and analyze the data. Regarding objective 1 , the results indicated that the majority of the pre-service teachers believed that learning a foreign language was mostly a matter of memorizing new words and grammatical rules. In terms of teaching, they believed that teachers were the main source of knowledge and had absolute authority in the classroom. With regard to objective 2, the results reported mixed views of learning and teaching. Some of them reported some changes in their beliefs while others were reluctant to change. In terms of objective 3 , the findings indicated that the majority of the teachers believed that the programme had a significant impact on their practicum at the end of the course. Regarding objective 4, the results suggested that the ELT programme needed modifying to meet the teachers' and students' needs. In addition, they believed that the first-year academic English courses should be replaced with some practical courses to allow them to gain first-hand experience of teaching. Finally, they reported that the intensity of learning (too many hours) in the third year was not beneficial for learning outcomes. It can be seen that although the study's results provided useful information for understanding how to change pre-service teachers' cognition of learning and teaching, it remains challenging as beliefs do not change overnight (Macalister, 2016b). For this reason, changing pre-service teachers' cognition of teaching takes considerable time and effort. 
The four empirical studies discussed above have demonstrated varied but inconclusive results of pre-service teachers' beliefs, cognition construction, and change in different contexts. While there have been no studies that focused specifically on pre-service teacher cognition development or change in the Lao EFL context, there has been one that focused on both pre-service and in-service teachers' beliefs about language learning and teaching (Chatouphonexay, 2013). The study looked at the similarities and differences of beliefs held by both categories of participants. The data were collected through a questionnaire survey. Nine hundred and sixty-two pre-service teachers and one hundred and twenty-nine in-service teachers were recruited to participate in the survey and the data were analyzed quantitatively. The results revealed that the participants perceived language-focused learning as the main feature for learning English. The findings also showed that the respondents had mixed beliefs about English learning. Even though this study provided a better understanding of students' and teachers' beliefs about learning English in this context, it did not focus on tracing cognition development and change. In addition, the data were mainly drawn on the questionnaire survey which is not enough to obtain insights into the issues of interest. Therefore, a qualitative study is required to advance our understanding of pre-service teacher cognition construction and change in this setting.

As stated in chapter 1, this research is attempting to explore the Lao EFL pre-service teachers' prior experiences of reading and learning to read, and to determine the effects of the CoT implementation on reading proficiency development, learning engagement, and perceptions of learning reading. Therefore, the following section, 3.3, addresses the literature of reading.

\subsection{Reading literature review}

This section looks at reading literature, an important part of this study. Section 3.3.1 defines reading. Section 3.3.2 discusses metacognitive reading. Section 3.3.3 looks at reading models. Section 3.3.4 focuses on reading components. Section 3.3.5 addresses 
reading comprehension strategies. Finally, section 3.3.6 looks at reading stages and pedagogical implications before turning to the CoT literature in section 3.4.

\subsubsection{Defining reading}

Many scholars have attempted to define reading. However, a critical way to define it is to engage a reader to interact with a text and ask her to think about what she is actually doing mentally (Nuttall, 1996). The answer we might get is she is cognitively constructing meaning of the text. This, however, depends largely on the reader's English reading proficiency, the reader's purpose, and the text type. A beginning reader might state that she is focusing on pronunciation or other discrete language items (e.g., vocabulary, grammar, etc.) which might not be the main focus of a proficient and better reader although these language features are important for learning reading.

To understand what reading actually means and how critical readers interact with the text, I will provide important definitions given by reading scholars in the area. First, Akarsu and Harputlu (2014) define reading as "a complex information skill in which the reader is interacting with the text in order to create meaningful discourse not just from the words and sentences but also from the ideas, memories, and knowledge aroused by those words and sentences" (p. 61). In other words, reading is a process of creating meaning in order to comprehend the writer's key message (Hudson, 2007; Medina, 2012).

Reading is also defined by Grabe (1991) as "rapid, purposeful, interactive, comprehending, flexible, and gradually developing." (p. 378). This captures several important aspects of how our mental constructs work and what is involved in reading. First, reading is rapid in a sense that a reader interacts with most materials at about "250-300 wpm" (Grabe, 2009, p. 14) in their working memory. To comprehend a text, readers need to maintain the flow of reading at this rate unless the information is new to them. This, however, depends largely on the type of text, the reader's purpose, and proficiency as previously indicated (Grabe, 2009; Weigle, Yang, \& Montee, 2013). Second, reading is purposeful because a reader has a goal before approaching the text. Having a 
clear purpose helps the reader stay focused on reading because she knows what is expected from the text (Grabe, 2009). Third, reading is interactive because it involves the reader's combined cognitive processes in order to draw meaning from the text. Interactive reading also involves using a wide range of reading skills and strategies to achieve the goal (Grabe, 2009). Fourth, reading is comprehending in a sense that a reader attempts to understand the gist of the text. In this respect, the main purpose of reading is to comprehend the main point of the text (Grabe, 1991, 2009; Macalister, 2011). Fifth, reading is flexible because a reader evaluates whether or not she is able to achieve the purpose. If not, the reader needs to flexibly apply a wide array of reading skills or strategies. These include: guessing, skimming, scanning, predicting, inferring, evaluating, analyzing, synthesizing, and making connections (Day \& Park, 2005; Hudson, 2007; Macalister, 2011; Ritchhart, 2015). Finally, reading is gradually developing because a reader needs a certain period of time and frequent exposure to various texts in order to become a competent reader (Grabe, 1991). In brief, reading is an active and interactive process. As Macalister (2014, p. 387) states, reading is "a meaning-making activity". To make meaning out of the text, a reader needs both linguistic and metacognitive knowledge (Grabe, 2009; Hellekjær, 2009; Hudson, 2007). The definitions discussed here are important as they help inform language teachers about how reading works and what is involved in meaning construction and this will be taken into consideration when interpreting the findings and discussing the research.

\subsubsection{Metacognitive reading strategy}

As stated earlier, critical and strategic readers apply various metacognitive reading strategies (Grabe, 2009) when interacting with the text (Grabe, 2009; Grabe \& Stoller, 2011; Hudson, 2007; Mokhtari \& Reichard, 2002; Nuttall, 1996). Hudson (2007, p. 112) defines metacognition as "knowledge of or regulation of cognitive endeavors". In other words, it refers to thinking about thinking (Carrell, Gajdusek, \& Wise, 1998; Flavell, 1979; Iwai, Filce, \& Ramp, 2011). The term is also defined as "the knowledge and control that we have over our cognitive processes" (Grabe, 2009, p. 222). Metacognition is important in the areas of language education and education in general. In terms of reading, two crucial terms - metacognitive awareness and metacognitive regulation - 
are often talked about (Hudson, 2007; Pintrich, 2002). Simply put, these two terms concern "awareness and control of planning, monitoring, repairing, revising, summarizing, and evaluating" (Grabe, 2009, p. 223) of reading. The terms have become the main focus of research in the reading domain since reading is, as defined earlier, a complex and interactive process that involves several strategies and skills to construct meaning from the text. Skilled readers monitor their comprehension and regulate their understanding by using metacognitive processes (Hudson, 2007; Wilson \& Bai, 2010). According to Flavell (1978), there are two important dimensions of metacognition, which have become the main focus for linguists and scholars in reading research.

The first dimension is knowledge of cognition, consisting of declarative, procedural and conditional knowledge (Hudson, 2007; Iwai et al., 2011). Declarative knowledge refers to factual knowledge (Stürmer, Könings, \& Seidel, 2013) that a reader has about a topic. This knowledge is about memorization and is referred to as the first category of the six cognitive categories in Bloom's taxonomy to be discussed in the subsequent section (Bloom, Engelhart, Furst, Hill, \& Krathwohl, 1956). Procedural knowledge is regarded as "the ability to execute action sequences to solve problems" (Schneider, Rittle-Johnson, \& Star, 2011, p. 1525). It is an awareness of thinking processes (Iwai et al., 2011; Pintrich, 2002) to deal with reading difficulty. In other words, this type of knowledge concerns reading strategies: guessing the unknown words from the context, summarizing, identifying the gist of the text (Hudson, 2007). Finally, conditional knowledge refers to why and how to apply different reading strategies or skills suitable for different reading materials. To develop conditional knowledge, learners need to employ both declarative and procedural knowledge (Hudson, 2007; Iwai, 2011; Tsai, 2005).

The second dimension is the regulation of cognition (Hudson, 2007). In reading, the reader is able to plan, monitor, and control their cognitive processes while interacting with the text (Grabe, 2009; Hudson, 2007; Schraw \& Moshman, 1995). The learner can be exposed to these qualities by engaging in planning (Carrell, Wise, \& Gajdusek, 1998; 
Grabe, 2009), monitoring comprehension, and evaluating their reading achievement when learning reading so that she can become a better reader.

\subsubsection{Reading models}

Reading models are shaped by a large body of research (Grabe, 2009; Hudson, 2007). A model is defined as "a representation of the psychological process that comprises a component or set of components involved in human text comprehension" (Goldman, Golden, \& van den Broek, 2007 as cited in Grabe, 2009, p. 83). In other words, it refers to a cognitive construct that consists of a set of components related to learning and an understanding of a text (Hudson, 2007). In this regard, three significant models (e.g., bottom-up, top-down and interactive) of reading are addressed in this section (Grabe, 2009; Grabe \& Stoller, 2011; Hudson, 2007; Padberg, 1997).

First, the bottom-up model refers to the process of learning by focusing on letters, words, phrases, and sentences (Nuttall, 1996; Padberg, 1997). Grabe (2009, p. 89) states that the bottom-up model is "a mechanical process in which the reader decodes the ongoing text letter-by-letter, word-by-word, and sentence-by-sentence". In other words, this model works in a linear procedure in which basic information is processed or digested first before a deeper or higher level of comprehension is acquired. In this respect, the bottom-up model is less automatic in the sense that text is processed in small pieces. These pieces are then integrated into readers' mental process and knowledge (Hudson, 2007; Padberg, 1997). Although this model is considered less effective than the top-down model, it is still useful for language learning and use and should be only a small part of the reading course (Nation, 2007).

Second, the top-down model is regarded as the reader's ability to make sense of the text using a higher-level process of metacognitive reading strategies (Grabe, 2009; Nuttall, 1996). In this respect, a reader interacts with the text by activating her prior knowledge and applying critical reading strategies in order to construct meaning. Making inferences is one main feature of this model as it reflects the interactive process in that the reader uses the clues or her experiences to figure out what is conveyed in the text (Grabe, 
2009). In brief, readers do not read word for word but reading in this sense is the interaction between thought and language (Grabe, 2009; Hudson, 2007; Padberg, 1997).

Finally, the interactive model is a combination of the bottom-up and top-down (Hudson, 2007; Nuttall, 1996; Padberg, 1997). This model, as its name suggests, focuses on the interaction between the reader and the text, which takes place in a cyclical fashion. This means that the reader's schemata, content knowledge, and knowledge of features of the text itself have a significant impact on the assignment of meaning to the text (Grabe, 2009). Because reading, as pointed out earlier, is a complex and interactive process, it is worth cultivating these skills in learners to help them construct meaning from the text more efficiently and become better readers (Padberg, 1997). The stance taken in this thesis is that reading proficiency is better achieved when attention is given to meaningfocused learning and not just to language features. Although language-focused learning has a place in teaching reading, it should be a small part of the course. As Nation (2009a) states, "there are lots of ways of making language-focused learning a part of the course, but the teacher needs to be careful that this does not take up more than 25 percent of the total course time" (p. 2). This will be reflected throughout the study when looking at the CoT implementation effects on reading comprehension development.

In language classrooms, the main focus of instruction should be the interactive model as it involves all aspects of reading skills (Grabe \& Stoller, 2011; Hudson, 2007). What makes this model unique is that it does not only require the reader to process and apply social and cultural knowledge, but also require her to understand the social interaction beneficial for comprehension development (Hudson, 2007). The models introduced here play an important role in the classroom practices as they can help inform classroom teachers in designing their lessons (Grabe \& Stoller, 2011).

\subsubsection{Reading components}

Reading scholars have identified reading components in order to help inform language teachers and their classroom practices. I will discuss six major components of reading 
introduced by the scholars in the area (Grabe, 2009; Grabe \& Stoller, 2011; Hudson, 2007), which include:

- automatic recognition skills;

- vocabulary and syntactic knowledge;

- formal discourse structure knowledge;

- content or background knowledge;

- synthesis and evaluation skills or strategies; and

- metacognitive knowledge and monitoring skills.

First, automatic recognition skills refer to the ability to recognize linguistic features (orthographic, phonological, semantic, and syntactic) when interacting with texts. In reading, automaticity is the accuracy and speed with which the reader is able to achieve the task through unconscious recognition of the linguistic features (Grabe \& Stoller, 2011). The importance of automatic recognition is acknowledged in the area of language education in terms of reading-fluency development and its contribution to comprehension (Grabe, 1991, 2009; Hudson, 2007), playing an important role in helping the reader construct meaning and identify linguistic features (Schadler \& Thissen, 1981). Most of the time, readers need these skills to help facilitate their reading.

Second, vocabulary and syntactic knowledge is concerned with a basic but important aspect of reading ability. To be able to construct meaning, readers need to employ a certain level of word meanings and syntactic information (Grabe \& Stoller, 2011). It has been acknowledged that vocabulary and syntactic knowledge become available after acquiring automatic recognition skills and are employed by readers to enhance their comprehension (Grabe, 2009). In this regard, a major predictor for comprehension is semantic knowledge. If readers fail to cognitively identify words in the text, it is challenging for them to extract meaning (Grabe, 2009). Semantic knowledge can be developed in learners by engaging them in exploring concepts (Grabe, 2009) and participating in meaning-focused output activities (Boutorwick, 2017; Nation, 2007). Specifically, syntactic knowledge refers to readers' abilities to identify how words are combined and assembled to form sentences (Cain, 2007; Morvay, 2012). Research 
suggests that syntactic awareness has a close link with reading comprehension (Cain, 2007; Hashemi \& Borhani, 2014) since meaning is conveyed through language structure, combination, and assembly. To develop this knowledge in learners, language teachers should expose them to a textual analysis and identification of ideas represented in the text (Grabe, 2009; Ritchhart et al., 2011).

Third, formal discourse structure knowledge refers to knowledge of text organization. In other words, it is viewed as the "knowledge structures or basic rhetorical patterns in texts" (Grabe, 2003, p. 10). This is useful for reading comprehension and research evidence suggests that formal discourse structure knowledge is perceived as one of the important predictors of reading comprehension (Grabe, 2009; Grabe \& Stoller, 2011; Jiang, 2012; Kobayashi, 2002). Text writers use this knowledge to organize information in a coherent manner in academic texts. Most texts are structured in various forms: comparison-contrast, cause-effect, problem-solution, classification, description (Grabe, 1991). Proficient readers tend to make use of the text structures to help them construct meaning (Grabe, 2009). In terms of classroom practices, learners should be directed to develop this knowledge so that comprehension can be better fostered in them. For this reason, "pedagogical efforts should be made to raise students' awareness of these discourse structures" (Jiang, 2012, p. 85). One way to achieve this might be through using graphic organizers that represent the discourse structures of the text. In this regard, the interrelationships among ideas and patterns of the text can be visually demonstrated to learners (Grabe, 2000; Jiang, 2012).

Fourth, content and prior knowledge refer to what readers already have or know before interacting or processing new information in the text (Grabe, 2009). A large body of research has acknowledged the importance of content and prior knowledge in reading comprehension (Bit Na \& Yusun, 2017; Fisher \& Frey, 2010; Grabe, 2009; Johnston, 1984; Nation \& Macalister, 2010; Pritchard, 1990). Readers with considerable content and background knowledge of the topic are able to read more flexibly and efficiently than those who do not. Because of this, learners should be encouraged to activate and 
build on their prior knowledge when learning reading. As Fisher and Frey (2010) posit, 'teachers can increase students' comprehension by building connections between new content and what students already know" (p. 62). This type of knowledge can be fostered through both direct experiences (e.g., experimentation, fieldtrips) and indirect experiences (e.g. observations, stimulations, and interactions). Additionally, prior knowledge can be enhanced by reading a wide range of materials and topics (Fisher \& Frey, 2010).

Fifth, synthesis and evaluation skills or strategies refer to the ability to compare and evaluate new ideas while interacting with the text (Grabe, 2009). In this regard, fluent and skilled readers not only attempt to understand the writer's key message, but also evaluate the textual information and compare it with other sources (Grabe, 1991). This allows them to "evaluate the information; take a position with respect to the author's intentions; and decide whether or not the information is useful" (Grabe, 1991, p. 381). What is important for classroom practices is that teachers need to incorporate activities that foster synthesis and evaluation skills in learners so that they can become better readers. One way for developing these skills is to integrate interactive and meaningful activities (e.g., identifying claims, making connections, etc.) into actual classroom practices.

Finally, metacognitive knowledge and monitoring skills, as indicated in section 3.3.2, are defined as the ability to self-monitor and regulate cognition (Baker \& Brown, 2002; Carrell, Pharis, \& Liberto, 1989; Flavell, 1979; Grabe, 2009). Regulation of cognition refers to "metacognitive activities that help control one's thinking or learning" (Schraw \& Moshman, 1995, p. 335). In this respect, there are three major skills: planning, monitoring, and evaluation. These three skills play a considerable role in reading comprehension and are worth discussing. First, planning refers to the "selection of appropriate strategies and the allocation of resources that affect performance" (Schraw \& Moshman, 1995, p. 354). In reading, planning is important and there are various steps involved: making predictions before reading, arranging time, and using reading 
strategies. Second, monitoring skill refers to readers' awareness of enabling text understanding and performance. In other words, it refers to one's self-awareness of how to monitor the process of making meaning. Finally, evaluation refers to the ability to assess the outcomes and regulate the processes of reading. For instance, the reevaluation of one's own reading goals and objectives is important for reading comprehension development (Schraw \& Moshman, 1995). Literature suggests that proficient readers tend to use metacognitive skills more often than poor readers when interacting with a text (Grabe, 1991; Hudson, 2007; Pintrich, 2002). The six reading components discussed above are important for reading comprehension and classroom practices. Therefore, it is useful for language teachers to focus students' attention on these when it comes to reading instruction.

\subsubsection{Reading comprehension strategies and skills}

Reading strategy refers to "the reader's deliberate, goal-directed attempts to control and modify their efforts to decode text, understand words, and construct meaning of the text" (Afflerbach \& Cho, 2009, p. 69). Hudson (2007) defines reading strategy as "any interactive process that has the goal of obtaining meaning from connected text and reading skills operate within the context of such reading strategies" (p. 107). These definitions suggest that reading strategies are intentional techniques in making sense of the text. The term strategy signifies our mental constructs that are different from “traditional skilled-based reading” (Grabe, 2009, p. 220).

Since skill and strategy are used interchangeably, it is important to differentiate them. Skill is concerned with automaticity (unconsciousness) while strategy refers to the intention to achieve the goal (Grabe, 2009). Because of this, reading skills are not explicitly defined but implied, whereas strategies are defined explicitly. Although skills

are not defined explicitly, Paris, Wasik, and Turner (1991, p. 611) point out that reading skills are "informational processing techniques that are automatic, whether at the level of recognizing grapheme-phoneme correspondence or summarizing a story. Skills are applied to a text unconsciously for many reasons, including expertise, repeated practice, compliance with directions, luck, and naïve use". The ability to automatically recognize 
reading components, as stated earlier, can be understood as reading skills. In regard to classroom practices, reading strategies and skills can be fostered in pre-reading, duringreading, and post-reading stages as revealed in Table 3.1 below (Grabe, 2009; Hudson, 2007; Medina, 2012; Paris et al., 1991).

\section{Table 3. 1 Summary of Reading Strategies and Skills}

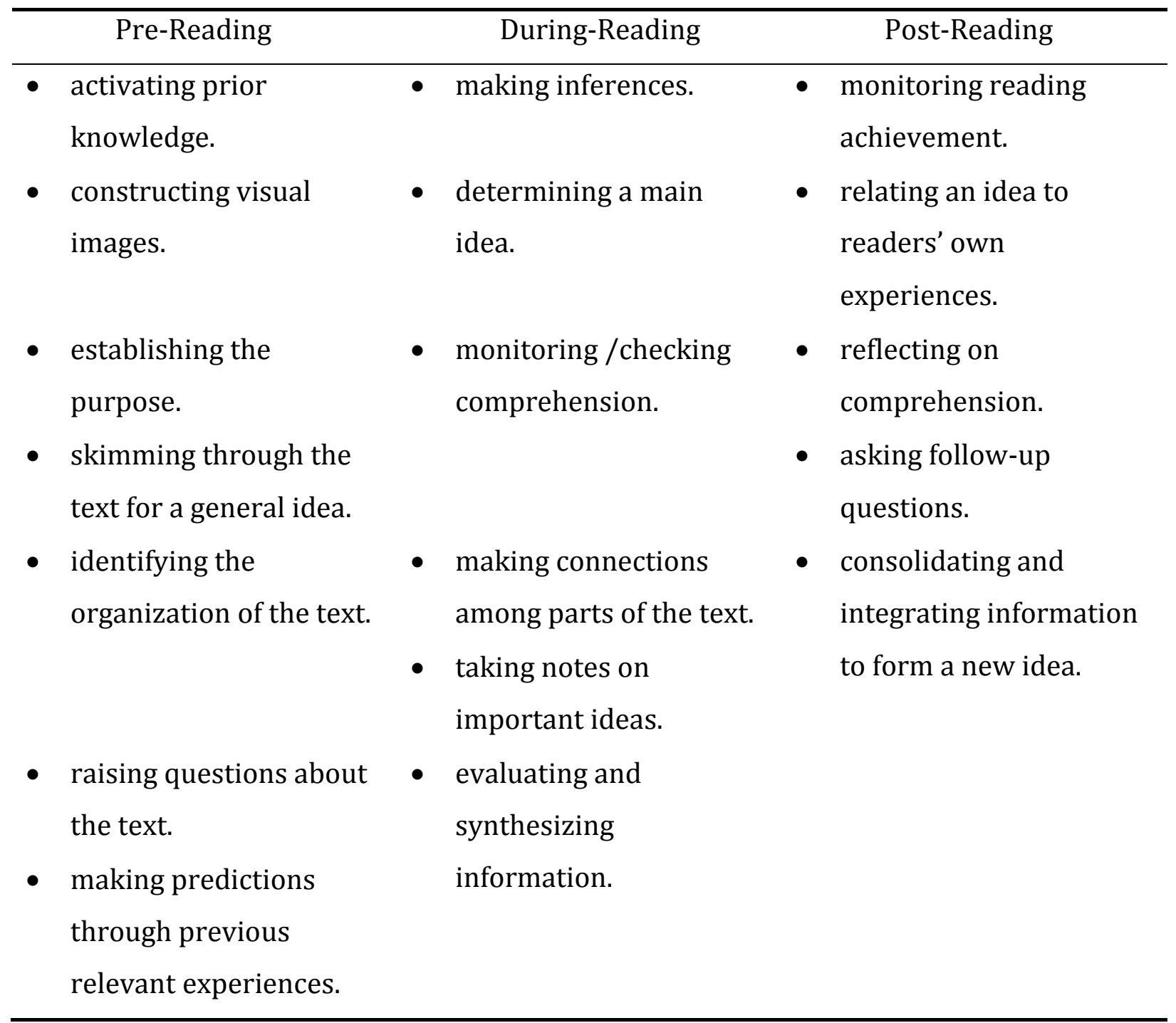

Proficient and poor readers employ different reading strategies and skills when interacting with text (see Table 3.2). This difference can be seen within the three reading stages (Akarsu \& Harputlu, 2014; Duke \& Pearson, 2008; Grabe, 2009; Hudson, 2007; Irvin, 1990; Pang, 2008; Vellutino, 2003). 
Table 3. 2 Dichotomies between Proficient and Poor Readers

\begin{tabular}{|c|c|}
\hline Proficient readers & Poor readers \\
\hline \multicolumn{2}{|c|}{ Before-Reading } \\
\hline $\begin{array}{l}\text { - } \text { activate or construct prior } \\
\text { knowledge of the subject before } \\
\text { interacting with the text. } \\
\text { - } \text { are aware of their reading purposes. } \\
\text { - } \text { apply a wide range of strategies to } \\
\text { build foundations and focus their } \\
\text { complete interest on reading. } \\
\text { - skim the text first to get an overview } \\
\text { - } \text { of ideas and layout. } \\
\text { iny to visualize information to help } \\
\text { increase their understanding. }\end{array}$ & $\begin{array}{l}\text { - jump into reading without } \\
\text { - } \text { considering the topic. } \\
\text { - } \text { knowledge about the topic. } \\
\text { - think of reading as words to words } \\
\text { - } \text { translation. }\end{array}$ \\
\hline
\end{tabular}

During-Reading

- give their complete attention to the reading comprehension tasks.

- constantly monitor their understanding.

- underline or circle key information to help locate main ideas.

- attempt to get back on track when losing concentration.

- associate meaning with symbols.

- use metacognitive awareness to plan, monitor, and evaluate their comprehension and accuracy.

- guess the meaning of the unknown words or phrases from the context.
- lack an awareness to monitor their comprehension.

- lack an ability to control their emotion and anxiety.

- fail to use cognitive and metacognitive strategies.

- $\quad$ seldom use any of the fix-up strategies when lacking concentration.

- try to translate every word instead of constructing the overall meaning from the context.

- read at the same rate no matter what. 
- try not to panic when not

understanding a part of the text.

- adjust a reading speed and rate

according to the task.

\begin{tabular}{|c|c|}
\hline \multicolumn{2}{|c|}{ Post-Reading } \\
\hline $\begin{array}{l}\text { - } \text { assess if they have achieved their } \\
\text { - } \text { reading purposes and why. } \\
\text { purpose. } \\
\text { - } \text { ask relevant questions to further } \\
\text { seek clarification and evidence. } \\
\text { - } \text { value the reading experience and } \\
\text { relate ideas to the real-world } \\
\text { situation. }\end{array}$ & $\begin{array}{l}\text { - are not sure what they have read } \\
\text { and/or understood. } \\
\text { - fail to use follow-up comprehension } \\
\text { skills and strategies. } \\
\text { - fail to monitor or assess their } \\
\text { reading accomplishments. } \\
\text { - fail to seek relevant information to } \\
\text { help understand the meaning of the } \\
\text { text. }\end{array}$ \\
\hline
\end{tabular}

In brief, proficient readers tend to apply more higher-order or metacognitive reading strategies than poor readers who fail to read strategically to construct meaning as they start reading without careful planning, monitoring, and evaluating (Grabe \& Stoller, 2011; Iwai, 2011).

\subsubsection{Reading stages and pedagogical implications}

A reading stage can be understood as a series of actions taken to achieve a reading purpose (Grabe, 2009; Hudson, 2007). In this regard, a stage can be understood as a complex and cognitive action of decoding words or sentences in order to draw meaning from the text (Hudson, 2007; Iser, 1972). In other words, readers need a series of steps to construct meaning, communicate ideas, and share information through reading (Breznitz, 2006; Fernandez-Toledo \& Salager-Meyer, 2009; Tennent, 2015). These stages need to be introduced to students to help them read strategically. Reading scholars introduce reading stages which are crucial for their pedagogical implications. These include: pre-reading, while-reading, and post-reading (Grabe, 2009; Hudson, 2007; Hughes, 1989). 
First, the pre-reading stage involves activating prior knowledge, setting goals, making predictions, and asking relevant questions about the topic (Grabe, 2009; Hudson, 2007). The purpose of this is to help learners generate and activate their existing knowledge about the topic so that they can relate it to what is to be read. Second, the during-reading stage is related to the act of meaning construction using various reading strategies and skills (Grabe \& Stoller, 2011). This requires readers to use both linguistic knowledge and metacognitive strategies to successfully extract meaning of the text (Grabe \& Stoller, 2011). Finally, the post-reading stage focuses on comprehension monitoring. This includes making connections, extending and challenging ideas, discussing main ideas, debating the concepts, and writing a summary (Grabe, 1991; Hudson, 2007). The stages presented here are significant procedures for developing reading comprehension in learners. These will be used when implementing the CoT.

Based on literature discussed above, a number of implications for ESL and EFL reading instruction can be established. These pedagogical values offer not only beneficial guidance for shaping and developing reading programmes but also contribute to classroom practices (Grabe, 2009). The following are examples of pedagogical implications for reading instruction (Grabe, 2009; Hudson, 2007; Kheirzadeh \& Tavakoli, 2012):

- large and adequate vocabulary recognition practices;

- explicit language instruction for learners to move through the target language threshold;

- the benefit of graphic representations for comprehension practice;

- the necessity of discourse organization principles;

- the importance of metacognitive awareness and strategy learning;

- the importance of reading fluency and automaticity practice;

- the role and significance of extensive reading and broad exposure to L2 texts;

- the importance of reading and writing integration in academic settings; 
- the need to apply content-based reading instructions (e.g., concept exploration through the target language use) and;

- The importance of motivation

To better understand these, it is worth commenting on each briefly. Points 1 and 2 reflect research on reading processes as reading development is associated with a large recognition of words and reasonable structural knowledge. Points 3 and 4 concern working with text types, especially academic texts, to which learners might not have sufficient exposure (Grabe, 2009; Pressley, 2006). Point 5 indicates the need to develop strategic readers in relation to a strategy focus. This is one of the useful features for reading comprehension development, especially in academic situations. Points 6 and 7 highlight the role of reading fluency, suitable reading rates, automaticity, and rich exposure to L2 or foreign language materials (Krashen, 2004). Point 8 focuses on the relationship between reading and writing, and the need to develop skills crucial for linking reading and writing. As a result, this aspect helps facilitate reading comprehension (Hudson, 2007). Points 9 and 10 stress the important role of contentbased language learning and motivation in reading instruction. This plays an important role in enhancing learners' reading comprehension. Content-based language teaching provides a useful framework for L2 reading instruction (Grabe, 2009; Hudson, 2007).

In conclusion, this section looked at reading literature. It addressed reading definitions, metacognitive reading, reading components, reading strategies and skills, and reading stages and pedagogical implications. These are important aspects for classroom teachers should consider when teaching reading. The following section will look at the CoT literature.

\subsection{CoT literature review}

Prior to discussing the CoT approach I used, it is worth acknowledging the usefulness of the other teaching approaches in the area as there is no single perfect approach to teaching a language. One of these is the genre approach which is widely practiced in contexts such as Australia and Indonesia (Ghufron, 2016; Martin, 2008). My interest, as indicated in chapter 1 , in the CoT teaching approach stemmed from my personal 
experience of being exposed to the CoT and its benefits in shaping classroom culture and fostering language proficiency. It can be integrated directly into classroom practices where curriculum and textbooks are centrally mandated, which is challenging for the researcher and the teachers to change these teaching materials.

As indicated in the previous section, one important way to address the challenges in reading instruction in the Lao EFL context and beyond might be through the implementation of a CoT. Section 3.4.1 defines the CoT. Section 3.4.2 looks at the origin of the CoT. Section 3.4.3 discusses the relationships among critical and creative and a CoT. Section 3.4.4 addresses the principles and cultural forces of a CoT. Section 3.4.5 looks at thinking routines in focus. In this study, thinking routines are chosen for teaching intervention of reading. Section 3.4.6 focuses on the emergence of CoT-related studies in the L1 context. Section 3.4.7 reviews CoT-related studies in the L2 and EFL contexts. Section 3.4.8 discusses the CoT pedagogical implications. Finally, section 3.4.9 summarizes the chapter.

\subsubsection{Defining a CoT}

As a reminder, a CoT is defined as "a place where a group's collective as well as individual thinking is valued, visible, and actively promoted as part of the regular, dayto-day experience of all group members" (Ritchhart et al., 2011, p. 219). The definition encapsulates several important aspects of collaborative and interactive learning. For this reason, it is worth understanding what the definition delineates.

First and foremost, the term a place refers to any location (e.g., in a museum, a school library, etc.) where a group of learners comes together to undertake learning (Ritchhart et al., 2011). Second, the phrase a group's collective as well as individual thinking refers to the social interaction between an individual and a group in developing thinking. For our thinking to become critical, it must be challenged by others. Furthermore, what we are able to achieve as a group in terms of problem solving, decision making, and understanding is usually far greater than what can be achieved by the individual alone (Ritchhart et al., 2011). Although there are examples of individual success, human 
accomplishments have relied on the efforts of groups more frequently. As stated by a creativity expert, Robinson (2010), deep and meaningful learning occurs in groups where interaction and collaboration are promoted and valued. Learners should not be separated or isolated if we want to establish a learning community where the ultimate goal is collaboration.

Third, the subsequent part of the CoT definition points out that thinking must be valued, visible, and actively promoted. In a CoT environment, the individual thinking is considered an enterprise of the learning. Our thinking can be valued, visible, and promoted through explaining, articulating, and exchanging ideas. These can be achieved through the use of questioning, documenting, and thinking routines, which will be discussed in the subsequent sections of this part (Ritchhart et al., 2011). However, for thinking to be truly valued, it has to be well articulated and identifiable.

Fourth, the definition points out that a CoT is regarded as part of the regular day-to-day experience. This echoes what Vygotsky $(1978$, p. 88) posits, "Children grow into the intellectual life around them." To develop thinking in children or learners, it is important that they are encouraged to think regularly as part of their daily lives and interactions. In other words, learners should be exposed to a wide range of thinking-learning environments where they are consistently encouraged to develop their thinking (Ritchhart et al., 2011).

Finally, the key aspect of the CoT definition is of all group members. In a CoT-learning environment, every learner's thinking is valued and visible. Every single student is encouraged to engage in exchanging ideas, considering perspectives of the others, and forming their own arguments. This allows the learner's ideas and thinking to be respected by members of the group and the teachers (Ritchhart et al., 2011). It can be seen that the CoT definition covers various aspects of interactive and collaborative teaching. This definition should be seen as "a goal for educators to work toward rather than a state that is ever perfectly achieved" (Ritchhart et al., 2011, p. 221). 
A CoT is also defined by Pohl (2012) as "a supportive environment in which specific factors work together in a synergetic fashion to bring about and reinforce the enterprise of productive thinking in a critical, creative and caring sense" (p. 8). The definition captures significant points. First, a CoT aims to promote a supportive environment to foster learners' thinking dispositions in exploring concepts being studied. Second, a CoT also intends to expose learners to a wide range of thinking dispositions in a respectful and safe environment.

It can be noted that the definitions above appear to suggest that the CoT approach focuses on face to face interaction rather than online discussion platforms. This makes sense in many EFL contexts, including LPDR where the majority of the students still lack access to stable and fast internet connections at home or classrooms due to financial and economic constraints with which they associate.

\subsubsection{Origin of a CoT}

The CoT concept was introduced in 2002 (Ritchhart, 2002). It has received considerable attention in many educational contexts over the past decades; mainly in western countries (e.g. the Netherlands, Australia, and the USA) in mainstream education. The underlying success of the CoT is its practicality and applicability in terms of developing learners as powerful thinkers in a globalized world. To support its roles and values in classroom instruction and practices, many textbooks have been written and published regarding this concept over the decades. In 2002, Ritchhart published a textbook called Intellectual Character, which provides principles for deep and meaningful learning. It is about what remains as a result of student life in schools (Ritchhart, 2002). In 2011, Ritchhart and his colleagues at Harvard Graduate School of Education, USA, published a textbook called Making Thinking Visible. The book provides significant tools (thinking routines) for developing learners' thinking dispositions. Thinking routines can be used in both L1 and L2 contexts to cultivate a culture of thinking in learners (Ritchhart et al., 2011). In 2015, Ritchhart published another textbook called Creating Cultures of Thinking: The 8 Forces We Must Master to Truly Transform Our Schools. This publication 
provides a comprehensive insight into how teachers can transform the passive classroom environment into an active, engaging, and interactive learning environment (Ritchhart, 2015).

\subsubsection{Relationships among critical and creative thinking and a CoT}

In order to better understand the relationship between critical and creative thinking and a CoT, it is worth discussing each aspect before drawing a conclusion. Critical thinking (CT) is defined by many scholars in mainstream educational research (Ennis, 1993) as "reasonable reflective thinking focused on deciding what to believe or do" (p. 180).

The definition captures many important aspects. First, it states that CT is reasonable, which indicates that what we decide to believe or do is "governed by general methods and standards and because it demands that we have good reasons for our decisions" (Hunter, 2014, p. 44). CT is also reflective in the sense that "thinking about a problem at several levels or forming several different angles all at once, because it sometimes requires thinking about what the right method is to answer or solve some thinking about a problem at some problem" (Hunter, 2014, p. 44). Another definition of CT is "the art of analyzing and evaluating thinking with a view to improving it" (Paul \& Elder, 1992, p. 44). In this respect, CT is regarded as self-directed, self-disciplined, self-monitored, and self-corrective thinking. It requires rigorous standards of excellent and mindful command of their use. It entails effective communication, problem-solving abilities, and a commitment to overcoming our negative egocentrism and socio-centrism (Paul \& Elder, 1992). CT requires evaluative and analytical skills in order to form a critical judgment towards the issues being proposed. CT is also defined as "the process by which we test claims and arguments and determine which have merit and which do not" (Ruggiero, 2011, p. 19). In other words, CT refers to the procedures of testing claims or arguments in order to critically evaluate them. In classroom practices, it is not easy to develop this skill in learners. It may be achieved in two different ways. First, it can be enhanced by embedding it into subject content through language of thinking, discussions, interactions, and problem-solving activities (Marin \& Halpern, 2011). This approach is preferred by many educational practitioners as it encourages learners to contemplate beyond surface 
learning. Another way of developing CT in learners is the explicit instruction designed for specific skills and disciplines (Marin \& Halpern, 2011). To achieve this, however, it is important for teachers to plan their lessons carefully and logically.

Creative thinking is seen as the different side of the same coin of CT. Mumford, Medeiros, and Parlow (2012) define creative thinking as the ability to generate innovation. In other words, it is divergent because it attempts to create something new and unique while CT is convergent. In this sense, CT refers to the ability to judge claims or arguments while creative thinking refers to innovative capacity. These two terms, however, cannot be separated as they need some elements of each to make a sound decision and promote innovation (Mumford et al., 2012).

How are CT and creative thinking related to a CoT? As indicated earlier, a CoT is "a place where a group's collective as well as individual thinking is valued, visible, and actively promoted as the regular, day-to-day experience of all group members" (Ritchhart et al., 2011, p. 219). In this respect, learners experience school as a learning venue where thinking is consistently promoted through the exploration and discussion of concepts or ideas being presented. Additionally, learners are encouraged to use a wide range of meta-strategic thinking skills: "analytical thinking, critical thinking, creative thinking, and caring thinking" (Pohl, 2012, p. 88). These internal constructs can be viewed as the outcomes of a CoT (Ritchhart, 2011a). In other words, a CoT is the concept and method that aim to develop all types of thinking skills necessary for the development of strategic and critical learners.

\subsubsection{CoT principles and cultural forces}

\subsubsection{Principles}

Ritchhart and Perkins (2005) introduce six principles (see Figure 3.3) of the CoT that teachers should consider when planning CoT-based lessons in order to foster interactive and meaningful learning. 
First, the possession of thinking skills is not sufficient for learners. They should be encouraged to use those skills for their good thinking to emerge and develop (Ritchhart, 2015). Learners must have the disposition to use their abilities in various situations. In this regard, teachers must foster learners' inclination to think and awareness of occasions for thinking as well as their thinking skills. This will lead to the enhancement and development of critical and creative thinking skills (Ritchhart, 2015).

Second, enhancing critical thinking skills and understanding of subject content knowledge is a social endeavor, occurring in a cultural context. As Vygotsky (1978, p. 88) states, "children grow into the intellectual life of those around them." In this respect, learners' thinking is promoted through interactions with people around them. They need exposure to different points of view "within the constant interplay between the group and the individual" (Ritchhart, 2015, p. 315). This reflects the real-world situation where interactions play an important role in the exploration of concepts and ideas (Ritchhart, 2015). In the CoT-learning setting, the chief goal is to foster a learning community that provides more opportunities for learners to communicate and exchange ideas. This allows them to understand other people's perspectives and to reinforce their own vision (Ritchhart, 2002).

Third, a CoT fosters deep and meaningful learning through the culture of the classroom (Ritchhart, 2015). In this regard, the culture of the classroom does not only direct learners to learning, but also draws their attention to meaningful engagement and interaction. Ritchhart (2015, p. 315) points out that "the messages sent through the culture of the classroom communicate to students what it means to think and learn well." These messages are important for students to learn and think critically.

Fourth, the CoT intends to make learners' thinking visible. Even though thinking cannot be seen under normal conditions, because people often think with little awareness of how they think, this can be promoted through a CoT (Ritchhart, 2015). To make learners' thinking visible to themselves and others, Ritchhart et al. (2011) suggest using thinking 
routines. Thinking routines are tools, structures, and patterns, which teachers regularly use to make learners' thinking visible.

Fifth, a CoT requires a variety of teaching sources and materials and is facilitated by the use of external tools to "download" or "distribute" one's thinking (Ritchhart, 2015, p. 315). These include papers, computers, images, written texts, tape recorders, projectors, films, objects, audio-visual aids, and other materials to document ideas and thoughts. These tools are used to help learners think beyond the surface and engage in deep and meaningful interactions (Ritchhart, 2015).

Finally, a CoT requires cooperation between teachers and educational institutions. In order for a CoT to emerge, teachers and schools need to develop "a professional community" (Ritchhart, 2015, p. 315). This provides an opportunity for teachers to exchange ideas about instruction, promote rich discussion of issues related to their career and pave the way for future professional development (Ritchhart et al., 2011). The six principles discussed are important and will be taken into consideration when planning reading lessons for the intervention and discussion of the findings.

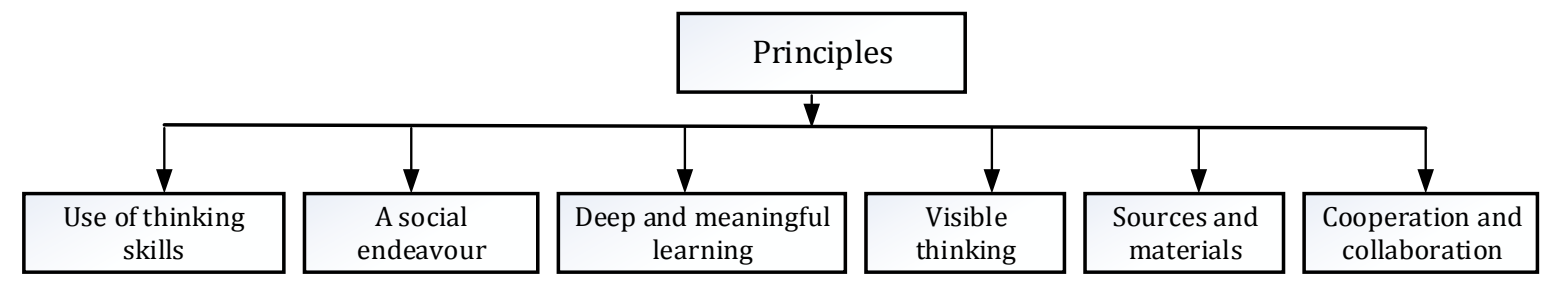

Figure 3. 3 The CoT Principles Summary

\subsubsection{Cultural forces}

\subsection{Definition}

Ritchhart (2015) defines cultural forces as "the shapers of classroom cultures" (p. 6). In other words, they are approaches to transforming school and classroom cultures. The classroom culture can be defined as "a group of people enacting a story. The story concerns the relationship between teachers, students, and the act of learning. Everyone 
is a player in this story, acting in a way that reinforces the story and makes it reality" (Ritchhart, 2015, p. 21). As stated in chapter 2, school and classroom cultures are influenced by the social, historical, cultural, educational, and political context in which the teachers and students situate. These contextual factors continue to have a profound impact on introducing innovations and how teachers and students perceive and value learning and teaching (Jurasaite-Harbison \& Rex, 2010; Kennedy, 1988). In some contexts, teachers have more freedom to adapt their lesson plans and use different approaches to delivering the lessons. In the other extreme (e.g. LPDR), teachers might be required to follow the mandated curriculum, which limits their flexibility and innovation in planning their lessons. This has become standard practice, which is difficult to change. There are eight cultural forces of a CoT: expectations, language, time, modeling, opportunities, thinking routines, interactions, and environment (Ritchhart, 2015). Each of these will be looked at in turn.

\subsection{Expectations}

Expectation refers to "a set of strong beliefs surrounding future outcomes and anticipated results" (Ritchhart, 2015, p. 37). In other words, it refers to our requirements that need to be fulfilled by others or something that we expect to happen in certain situations or actions. Expectations here refer to teachers' expectations for students, not of students. Five sets of beliefs for teachers' expectations (see Figure 3.4) will be looked at.

First, learners should be encouraged to focus on meaningful learning rather than the mere completion of the work (Ritchhart, 2015). In a work-oriented classroom, learners are asked to focus on work completion instead of a deep and meaningful exploration. However, in a learning-oriented classroom, learners are stimulated to explore concepts in a critical and meaningful way. In addition, both learners and teachers work together to achieve the goals of learning beyond the surface level (Ritchhart, 2015).

Second, teachers should expect to teach for understanding or knowledge construction rather than for knowledge transmission as pointed out in section 3.2.3. The terms 
knowledge and understanding are commonly used in education. However, they are ambiguous and may lead to confusion. According to Ritchhart (2015, p. 47), knowledge refers to "the accumulation and storage of facts, procedures, and skills." In other words, it refers to possession, storage, and retrieval of information, which is not adequate for lifelong learning. In contrast, understanding is viewed as "going beyond merely processing a set of skills or a collection of facts in isolation; rather, it requires that our knowledge be woven together in a way that connects one idea to another" (Ritchhart, 2015, p. 47). In this respect, understanding focuses on exploring a concept from different angles, making connections, challenging ideas, and applying what is learned in new and novel situations.

Third, encouraging deep as opposed to surface learning is another important set of beliefs about expectations for students. The terms deep and surface have a specific feature (Ritchhart, 2015). As indicated earlier, "deep learning is more about understanding and the surface approach more about memorization" (Hamm \& Robertson, 2010, p. 592). Characteristics of deep and surface learning are summarized in Table 3.3.

Table 3. 3 Differences between Deep and Superficial Learning

\begin{tabular}{lll}
\hline \multicolumn{1}{c}{ Deep learning } & \multicolumn{1}{c}{ Superficial learning } \\
\hline - $\begin{array}{ll}\text { goes beyond mere knowledge or } \\
\text { what is needed for evaluation or }\end{array}$ & - & explores information just to \\
assessment; & complete the assessment or work; \\
- $\quad$ asks why, not just how; & - $\quad$ asks the how and what rather than \\
- $\begin{array}{ll}\text { finds evidence to support claims; } \\
\text { attempts to understand and satisfy }\end{array}$ & - $\quad$ uses information given; \\
curiosity and personal interest. & focuses on memorization and rote \\
\hline
\end{tabular}

The fourth set of beliefs about expectations for students aims at encouraging independence, as opposed to dependence. Rose-Duckworth and Ramer (2009) define 
independence as "learners are internally motivated to be reflective, resourceful, and effective as they strive to accomplish worthwhile endeavors when working in isolation or with others - even when challenges arise, they persevere" (p. 2). Developing learner independence is important for classroom practices in order to develop lifelong learners (Ritchhart, 2015). Therefore, classroom instruction should promote learner-oriented skills and independence; learners take care of their own learning. Too much control over the learners might result in learner passivity and complete dependence upon the teachers. In the end, this may result in learners' being insufficiently resilient when difficulties and challenges emerge and a decline in creativity and innovation (Ritchhart, 2015).

The final set of beliefs about expectations for students is to foster a growth mind-set as opposed to a fixed mind-set. The goal of education is to sharpen and broaden learners' vision (Kelley \& Sharif, 2005). Learners with a fixed mind-set are more likely to give up when encountering difficulties and often regard themselves as lacking talent or abilities. They may avoid experimenting with new things and seeking help or advice to overcome challenges. They accept defeat and label themselves a failure instead of attempting to learn (Kelley \& Sharif, 2005). In contrast, learners with a growth mind-set reflect the reality of learning. They seek the opportunities to explore, ask for clarification, suggestions, and feedback. They see learning as an ongoing and interactive process (Ritchhart, 2015). The five sets of beliefs about expectations for students discussed here are useful for classroom teachers to consider in order to transform their classroom cultures. 


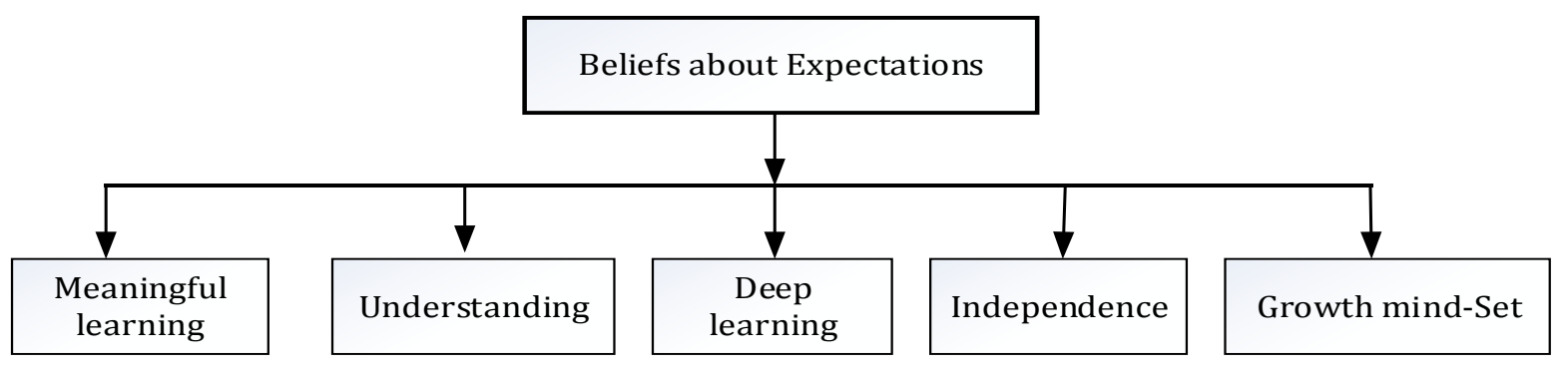

Figure 3. 4 Expectations for Learners

\subsection{Language}

Language plays a major role in developing deep and meaningful learning and shaping students' thinking. Ritchhart (2015) defines language as "the system of communication used by a community to negotiate shared meaning and build group coherence and understanding around ideas, behaviors, and actions" (p. 61). Ritchhart (2015) argues there are seven types of language (see Figure 3.5) that can be used to promote and facilitate deep and interactive learning.

First, language of thinking refers to the language that directs learners to specific cognitive and metacognitive acts. It facilitates an understanding of written input and also helps production of oral communication skills (Wang \& Shih, 2011). In addition, it stimulates metacognitive thinking. In this respect, language of thinking not only helps us review what we have done or the products of our thoughts but also helps us monitor the processes we used to generate those products (Ritchhart, 2015). This reflects the notion of metacognition discussed in section 3.3.2 in terms of monitoring and regulating one's thoughts. For example, when reading we monitor our comprehension (Ritchhart, 2015) and the language of thinking contributes to this process. Thus, learners should be encouraged to wonder, think, imagine, monitor, generate ideas, and theorize concepts through the language of thinking. As Vygotsky $(1978$, p. 78) attests, "the child begins to perceive the world not only through its eyes but also through its speech. And later it is not just seeing but acting that becomes informed by words." 
Second, language of community refers to the use of language to include every member of the group in exploring and engaging in class activities. The main purpose of this language is to create a learning community where every member is consistently stimulated to cooperate and share their ideas rather than compete. As Vygotsky (1978) states, intellectual property is developed through interactions and shaped by language of inclusion and cooperation. Examples of language of community include pronouns such as we, our, and us (e.g., we're going to identify claims represented in the text). This indicates that the instructor is involved with the class in teaching, learning, and thinking (Ritchhart, 2015).

Third, language of identity refers to the use of language to make learners value the benefit of the topic being learned (Ritchhart, 2015). A main problem that exists in teaching is that "many teachers tend to teach a subject in terms of its elements, pieces, topics, and so on rather than engaging students in authentic activities" (Ritchhart, 2015, p. 74). This has been called aboutitis (Perkins, 2009). Language of identity is a tool to address aboutitis and make learners see themselves as members of the discipline. It encourages learners to assume roles in subjects or topics being studied (e.g., writers, reporters, poets, authors, etc.). However, this does not mean that learners become experts in these roles and subject areas because the teachers call them that one day. Language conveys intention and cues behavior. Through this language use, learners come to realize that the purpose of real learning is about acquiring thinking abilities and acting as members of the discipline (Ritchhart, 2015).

Fourth, language of initiative refers to the language that encourages "agency" (Ritchhart, 2015, p. 76) which requires actions in learners to perform the learning activities or tasks. Learners must take the agency of their own learning through teachers' facilitation. However, the question is 'how does language shape or develop initiative?' To achieve this, teachers need to use the language that directs students' attention. Teachers should 
help learners clarify, identify, plan, and consider the possibility of courses of actions (Ritchhart, 2015).

Fifth, language of mindfulness refers to the teacher's language that aims to show openness and maintain flexibility so that new ideas and learning styles can be developed (Ritchhart, 2015). Mindfulness is viewed as "an open, flexible state in which new categories and possibilities can more easily be created" (Ritchhart, 2015, p. 78). An example of this type of language is the use of conditional language like might or may. This is to avoid absoluteness that might shut down a discussion or conversation. In this respect, there might be things that are absolute (there are black and white answers). However, research suggests the benefit of using conditional language in making learners think critically instead of just absorbing what is being transmitted to them (Herrenkohl \& Guerra, 1998).

Sixth is language of praise and feedback. Praise, on the one hand, refers to compliments on what is done well. This type of feedback might not be meaningful for learners and may discourage them from going below the surface. Research evidence suggests that the use of language of praise did not effectively motivate learners to become the agents of their own learning (Ritchhart, 2015; Ritchhart et al., 2011). As Harris and Rosenthal (1985, p. 377) state, "This kind of feedback is not informative to the student; consequently, it may have no impact on the child beyond the realization that he or she got the answer right or wrong." Feedback, on the other hand, refers to the act of providing 'information about students' learning, performance, knowledge, or understanding and is often referred to as one of the most powerful sources of influence on student learning" (Lee, 2017, p. 4). It is more encouraging, instructional and informative to learners' future learning than praise. As Ritchhart (2015) notes, language of feedback plays an important role in guiding future learning. For feedback to be motivating, however, it has to be specific, descriptive, and informative (Harris \& Rosenthal, 1985). 
Finally, language of listening refers to the powerful way we show respect for and interest in our learners' thinking. Effective or active listening plays an important part in daily communication for both listeners and speakers (Ritchhart, 2015). As Ames, Maissen, and Brockner (2012, p. 345) posit, "effective listening may help individuals better understand the context in which their influence attempts transpire, thereby enabling them to tailor their persuasive behavior to that context." In many classrooms, however, teachers and students might ignore the importance of effective listening, which might result in failure to foster meaningful learning. Figure 3.5 is a summary of language of thinking.

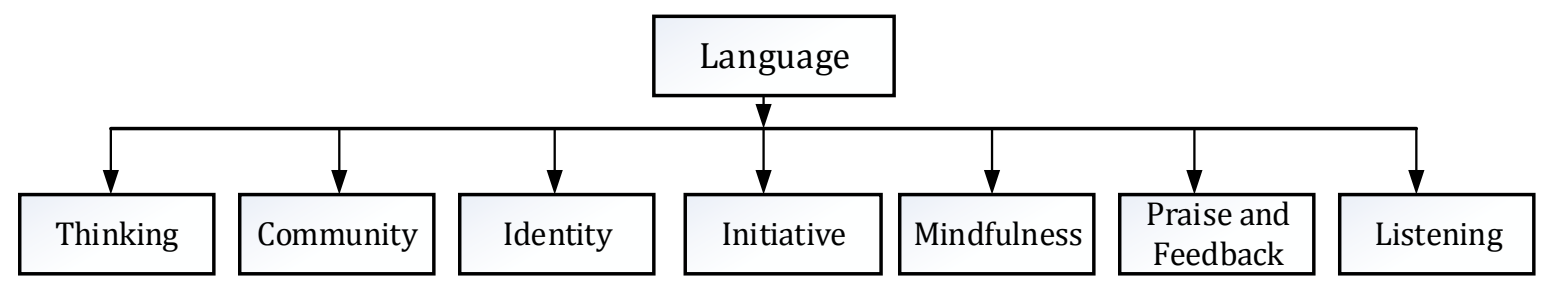

Figure 3. 5 A Summary of Language in a CoT

\subsection{Time}

Time in the context of teaching refers to what teachers allocate, assign, or use to accomplish the learning goals (Ritchhart, 2011a, 2015). A number of important ideas on time management to facilitate classroom instruction will be discussed in this regard. First, the teacher must recognize time as a key statement of his or her values. This means time spent on building a learning community, and deep and meaningful interaction should be sufficient and appropriate (Perkins, 2009). In addition, the teacher must learn to prioritize time for learners' interactive learning and academic success. Allocating suitable time to engage learners in exploring rather than sitting back waiting to be spoon-fed is critical for classroom actions (Gettinger \& Walter, 2012).

Although time management is important, it is not easy for teachers to achieve as they encounter many constraints in their teaching contexts (e.g., test deadlines, curriculum requirements, etc.). However, teachers should ask themselves: What learning outcomes 
do they want their students to take away from their year with them? Once teachers have clear purposes, they should prioritize time to achieve those purposes. Finally, sufficient and appropriate time for learners to participate, engage, and reflect on what is being explored is beneficial. Learners need sufficient time to process their thoughts. This can be achieved through writing down a few ideas, talking to their peers, and activating their background knowledge before contributing to the group discussions. In other words, where teachers' time management allows for learners to understand what has been learned is significant for learning success (Ritchhart et al., 2011). It is also useful for teachers to recognize the importance of time space after initiating questions and tasks. Ritchhart (2015, p. 103) regards this as "wait time". As Feng (2014) states, thinking time after initiating questions is crucial for learners. However, many teachers might ignore "wait time" after asking questions in their classroom practices.

\subsection{Modeling}

Ritchhart (2015, p. 115) defines a model as "a system or thing used as an example to follow or imitate." In other words, it refers to the act of displaying and demonstrating for others to emulate. Modeling plays a considerable role in shaping learners' perceptions of learning and teaching because what teachers think, believe, and do has an impact on learners (Borg, 2006). As a classroom culture shaper, modeling might be explicit or implicit (Ritchhart, 2015). The former refers to visible procedures or processes that students can practically learn from. The latter refers to teachers' actions or behaviors as classroom patterns for learners to absorb from (Ritchhart, 2015). In this sense, teachers need to consider the following models when teaching (e.g., learning and thinking, making thinking visible to learners, demonstrating independent learning, interactive modeling, etc.). These models are important for developing strategic lifelong learners (Shein \& Chiou, 2011) and have an influential role on learners' learning styles (Marshall, 1991).

\subsection{Opportunities}

Opportunities refer to "a set of conditions or circumstances that make it possible to do or achieve something" (Ritchhart, 2015, p. 139). As a shaper of the classroom culture, they allow learners to explore concepts and ideas being learned. In a CoT learning 
environment, the main center of attention is on the creation of powerful learning opportunities which promote engagement and understanding (Perkins, Tishman, Ritchhart, Donis, \& Andrade, 2000). To achieve this, teachers should focus on the following elements: novel application, meaningful inquiry, effective communication, and perceived worth (Ritchhart, 2011a).

Novel application is viewed as the ability to apply skills and knowledge learned in a new context; the synthesis level. This requires learners to organize, interpret, problem-solve, and evaluate subject content which allows skills or knowledge to be enhanced and sharpened (Bloom et al., 1956). Meaningful inquiry refers to the development of understanding and lifelong learning. Learners must be required to learn new ideas and concepts to sharpen their vision. This does not only help learners get good or top grades, but also exposes them to something new and beneficial (Ritchhart, 2015). Effective communication refers to precise, focused, and meaningful messages so that the recipient comprehends the key meaning (Sharifirad, Rezaeian, Jazini, \& Etemadi, 2012). Effective communication in a CoT encourages learners to find evidence, articulate their thoughts, and make clear connections between ideas (Ritchhart, 2015). Finally, perceived worth refers to what learners are asked to work on. This must be of great value for their time and commitment. In fact, the purpose of a lesson does not have an important impact on creating learners' perception of worth. It relies on the teacher to integrate the learning task into a larger context suitable for the goal of learning (Ritchhart, 2015). Therefore, what is being studied in the classroom should promote deep engagement and interaction. This has a direct link to the learners' academic achievements while disengagement might lead to poor and surface learning (Shernoff et al., 2016). Figure 3.6 summarizes elements of learning opportunities. 


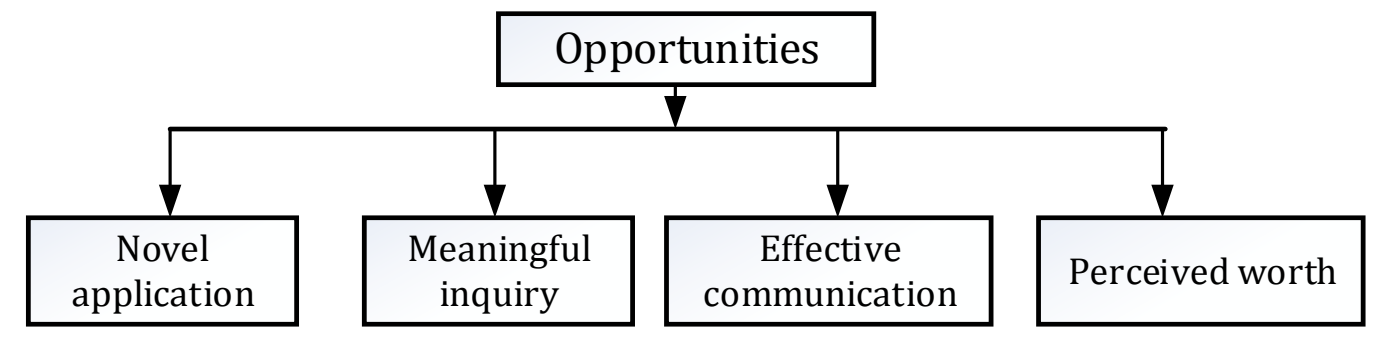

Figure 3. 6 Meaningful Opportunities Summary

\subsection{Thinking routines}

Ritchhart (2015, p. 171) defines a routine as "a sequence of actions designed to achieve a specific outcome in an efficient and productive manner." In other words, it refers to any procedure, process, or pattern of action that is used repeatedly and normally to manage and facilitate the accomplishment of specific goals or tasks. In terms of instruction, a routine can be thought of as what teachers and students repeatedly do to achieve the goal of learning. Learning or teaching routines can be both passive and interactive, depending on the social, cultural, educational, and political context as discussed in chapter 2 . In this study, thinking routines can be defined as "the tools, structures, and patterns of behavior" (Ritchhart et al., 2011, p. 45). As a classroom culture shaper, thinking routines play a considerable role in promoting deep and meaningful learning. The definition captures important aspects of the classroom cultures. Thinking routines are the tools because they are learning activities that teachers can apply to or integrate into their classroom practices. This means that a teaching method does not fit all learners' needs as they have different styles of acquiring the knowledge and concepts. In addition, different topics might need a different approach to teaching to meet the students' learning fashions (Ritchhart, 2015). Taking this notion into account when planning a lesson might have a notable impact on learners' performance and their learning outcomes (Ritchhart, 2015).

Thinking routines as structures refer to the procedures or steps taken to deliver a lesson. These structures act as "natural scaffolds that can lead students' thinking to higher and 
more sophisticated levels" (Ritchhart, 2015, p. 47). Additionally, they become a learning pattern for the whole class or small group discussions if used repeatedly (Ritchhart, 2001). The final key term worth discussing here is patterns of behavior. For thinking routines to become a classroom culture or pattern, they must be employed and used regularly. Through regular practice, learners internalize key messages about how real learning is taking place (Ritchhart, 2015). The routines are not designed to elicit specific answers but to uncover students' nascent thinking about the topic. In this respect, learning involves both absorbing others' ideas and uncovering one's own ideas as the starting point to understand the subject content knowledge (Ritchhart et al., 2011).

\subsection{Interactions}

Interactions are important drivers of classroom transformation. It is defined as "the dynamic phenomenon that emerges when two or more objects have an effect on one another" (Ritchhart, 2015, p. 199). As a classroom culture shaper, interactions help establish the basis for relationships between teachers and students and students and students (Ritchhart, 2015). The primary goal of classroom interaction is for learners to show respect for and to value others' contributions in a spirit of collaboration (Mount, 2006; Ritchhart \& Perkins, 2008). In a CoT, the interaction between teachers and students shows respect for, and interest in, one another and cultivates thinking development for both the individual and the group (Ritchhart, 2015). Effective and meaningful interactions might be enhanced through sharing ideas, meaningful feedback, identified roles, initiating good questions, creating new patterns of discourse, and through empowering disenfranchised learners, and engaging all learners of all levels (Ritchhart, 2015).

\subsection{Environment}

Environment refers to "surrounding conditions or influence in which a person operates" (Ritchhart, 2015, p. 227). Learning environment can reflect whether deep or critical learning is taking place. The physical space in which learning is situated includes: a design, a setup, displays, furnishings, and so forth (Scrivener, 2012). The physical environment has a significant impact on interactions, behaviors, and learning outcomes 
as it can hinder or motivate the work of the group and/or the individual. This indicates that a suitable arrangement of the classroom space might facilitate and cultivate meaningful and interactive learning. Meaningful learning is the consequence of interactions facilitated by various factors, including physical and emotional environments (Ritchhart et al., 2011). Emotional environment includes safe and friendly atmosphere, which is important for collaborative learning to occur. Table 3.4 below summarizes cultural forces.

Table 3. 4 Summary of CoT Forces

\begin{tabular}{lll}
\hline No. & Cultural forces & Description \\
\hline 1 & Expectations & Expectations for learners, not expectations of \\
& learners (e.g. classroom will be about learning & rather than the mere completion of work and \\
& merely accumulating enough points to score a \\
& top grade). \\
& Classroom language that promotes deep and \\
& higher-order thinking. Language that draws \\
& learners' attention to explore concepts and \\
& & engage in interactive discussions. \\
& Appropriate and sufficient time for an in-depth \\
& Time allocation & exploration and discussion of the concepts. \\
& Modeling & Teachers act as learners and risk takers. \\
& Showing learners that teachers are passionate \\
& about a topic, interested in ideas, engaged as \\
& learners, reflective, and deliberative. \\
& Purposeful opportunities for collaboration, \\
& interactions, discussions, and reflection. \\
& Opportunities & opportunities that allow learners to challenge \\
& misconceptions push learners to clarify a \\
& position, and to consider different perspectives. \\
&
\end{tabular}




\begin{tabular}{|c|c|c|}
\hline 6 & Thinking routines & $\begin{array}{l}\text { Tools, structures or patterns of behaviors that } \\
\text { shape the classroom learning fashion and } \\
\text { interactions. }\end{array}$ \\
\hline 7 & Interactions & $\begin{array}{l}\text { Meaningful, engaging participation and } \\
\text { collaboration in learning and discussing } \\
\text { concepts with others. }\end{array}$ \\
\hline 8 & Environment & $\begin{array}{l}\text { A physical environment that fosters the } \\
\text { interactive, explorative, and collaborative } \\
\text { learning. }\end{array}$ \\
\hline
\end{tabular}

Source: Ritchhart (2015).

As stated earlier, I chose the thinking routines (the sixth cultural force) for teaching intervention of reading in Phase 2 of the present study. I chose these because they are the shapers of classroom culture and can be directly integrated into classroom practices to address the issues of the top-down national educational system and passive and surface learning. Therefore, the following section will specifically look at this in detail. However, this does not mean that the other forces will be ignored. They will provide the framework for the analysis of student engagement, which will be presented in Chapter 6 .

\subsubsection{Thinking routines in focus}

Thinking routines, the product of years of research and classroom practices focusing on the development of learners' thinking and understanding of the topic, were developed by Harvard Project Zero researchers and revised several times to ensure workability (Perkins, 2009; Ritchhart, 2015; Salmon, 2008a; Salmon, 2008b; Stuart \& Deluse, 2009). Ritchhart (2015) divides thinking routines into three major groups (see Table 3.5):

- routines for introducing and exploring ideas;

- routines for synthesizing and organizing ideas; and

- routines for digging deeper into ideas.

First, routines for introducing and exploring ideas refer to what teachers usually and repeatedly use at the beginning of their lessons to activate learners' background knowledge or generate ideas about the topic before the process of inquiry commences (Ritchhart, 2015). In reading instruction, it is important for teachers to draw learners' 
attention to the topic as learning involves not only remembering but also thinking about concepts relevant to and represented in the text. Second, routines for synthesizing and organizing ideas, are intended to assist learners to initiate exploration, make connections, and identify issues (Ritchhart et al., 2011). Through these routines, learners are stimulated to evaluate, organize, summarize and form arguments with reasons and evidence. Finally, routines for digging deeper ideas direct learners to explore deeper and go below the surface learning and consider the complexity of issues and concepts. Through these routines, learners are encouraged to critically analyze and discuss concepts by considering the underlying assumptions (Ritchhart et al., 2011). In terms of pedagogical implications, thinking routines can be integrated into teaching any course or skill to push learners to think critically and connect ideas to their real-life situations or experiences.

Table 3. 5 Thinking Routines Summary

\begin{tabular}{|c|c|c|}
\hline Routine & Key tenets & Description \\
\hline \multicolumn{3}{|c|}{ Routines for Introducing and Exploring Ideas } \\
\hline See-Think-Wonder & $\begin{array}{l}\text { Describing, interpreting, and } \\
\text { wondering. }\end{array}$ & $\begin{array}{l}\text { Good with ambiguous or } \\
\text { complex visual stimuli. }\end{array}$ \\
\hline Zoom In & $\begin{array}{l}\text { Describing, inferring, and } \\
\text { interpreting. }\end{array}$ & $\begin{array}{l}\text { Variation of the first one } \\
\text { using only portions of an } \\
\text { image. }\end{array}$ \\
\hline $\begin{array}{l}\text { Think-Puzzle- } \\
\text { Explore }\end{array}$ & $\begin{array}{l}\text { Activating prior knowledge, } \\
\text { wondering, and planning. }\end{array}$ & $\begin{array}{l}\text { Good at the beginning of } \\
\text { a unit to direct personal } \\
\text { or group inquiry and } \\
\text { uncover current } \\
\text { understandings as well as } \\
\text { misconceptions. }\end{array}$ \\
\hline Chalk Talk & $\begin{array}{l}\text { Uncovering prior knowledge, } \\
\text { ideas, and questioning. }\end{array}$ & $\begin{array}{l}\text { Good for open-ended } \\
\text { discussion for all } \\
\text { learners. }\end{array}$ \\
\hline 3-2-1 Bridge & Activating prior knowledge, & Works well when \\
\hline
\end{tabular}


questioning, distilling, and

making connections through

metaphors.

Compass Points

The Explanation

Game
Decision making, planning, and discovering personal reactions.

Observing details and building explanations. students have

background knowledge

on the unit being studied.

Elicits learners' ideas and

interactions to a

proposal, plan, or

possible decision.

Good for identifying

claims and explaining

them in order to build up

deep understanding.

\begin{tabular}{|c|c|c|}
\hline \multicolumn{3}{|c|}{ Routines for Synthesizing and Organizing Ideas } \\
\hline Headlines & $\begin{array}{l}\text { Summarizing, capturing the } \\
\text { heart. }\end{array}$ & $\begin{array}{l}\text { Quick summaries of the } \\
\text { bigger ideas or what } \\
\text { stand out. }\end{array}$ \\
\hline $\begin{array}{l}\text { CSI: Color, Symbol, } \\
\text { Image }\end{array}$ & $\begin{array}{l}\text { Capturing the heart through } \\
\text { metaphors. }\end{array}$ & $\begin{array}{l}\text { Non-verbal routine that } \\
\text { forces visual connections. }\end{array}$ \\
\hline $\begin{array}{l}\text { Generate-Sort- } \\
\text { Connect-Elaborate: } \\
\text { Concept Maps }\end{array}$ & $\begin{array}{l}\text { Uncovering and organizing prior } \\
\text { knowledge of identified } \\
\text { connections. }\end{array}$ & $\begin{array}{l}\text { Highlights the thinking } \\
\text { steps of making an } \\
\text { effective concept map } \\
\text { that both organizes and } \\
\text { reveals one's thinking. }\end{array}$ \\
\hline $\begin{array}{l}\text { Connect-Extend- } \\
\text { Challenge }\end{array}$ & $\begin{array}{l}\text { Making connections, identifying } \\
\text { new concepts, and raising } \\
\text { questions. }\end{array}$ & $\begin{array}{l}\text { Deals with new } \\
\text { information in whatever } \\
\text { form represented in a } \\
\text { text. }\end{array}$ \\
\hline $\begin{array}{l}\text { The 4Cs (Connect, } \\
\text { Challenges, } \\
\text { Concepts, Changes) }\end{array}$ & $\begin{array}{l}\text { Connection making, identifying } \\
\text { key concepts, raising questions, } \\
\text { and considering implications. }\end{array}$ & $\begin{array}{l}\text { A text-based routine that } \\
\text { identifies key points of } \\
\text { complex text for } \\
\text { discussion. }\end{array}$ \\
\hline
\end{tabular}


The Micro Lab Focusing on attention, analyzing, Can be integrated with

Protocol

I used to

Think.....Now I

Think..... and reflecting.

Reflection and metacognition. other routines to prompt discussion and reflection.

Helps learners to reflect on how thinking has shifted and changed over time.

\begin{tabular}{|c|c|c|}
\hline \multicolumn{3}{|c|}{ Routines for Digging Deeper into Ideas } \\
\hline $\begin{array}{l}\text { What Makes You } \\
\text { Say that? }\end{array}$ & Reasoning with evidence. & $\begin{array}{l}\text { A question that is } \\
\text { intended to push learners } \\
\text { to think deeper and } \\
\text { support their ideas with } \\
\text { evidence. }\end{array}$ \\
\hline $\begin{array}{l}\text { Circle of } \\
\text { Viewpoints }\end{array}$ & Perspective taking. & $\begin{array}{l}\text { Identification of } \\
\text { perspectives around an } \\
\text { issue or problem. }\end{array}$ \\
\hline Step Inside & Perspective taking. & $\begin{array}{l}\text { Stepping into a position } \\
\text { and talking or writing. }\end{array}$ \\
\hline $\begin{array}{l}\text { Red Light, Yellow } \\
\text { Light }\end{array}$ & $\begin{array}{l}\text { Monitoring, identifying of bias, } \\
\text { and raising questions. }\end{array}$ & $\begin{array}{l}\text { Used to identify possible } \\
\text { errors in reasoning, over- } \\
\text { reaching by authors, or } \\
\text { areas that need to be } \\
\text { questioned. }\end{array}$ \\
\hline $\begin{array}{l}\text { Claim-Support- } \\
\text { Question }\end{array}$ & $\begin{array}{l}\text { Identifying generalizations, } \\
\text { theories, reasoning with } \\
\text { evidence, and making } \\
\text { counterarguments. }\end{array}$ & $\begin{array}{l}\text { Can be used with text or } \\
\text { as a basic structure for } \\
\text { deeper thinking. }\end{array}$ \\
\hline Tug-of-War & $\begin{array}{l}\text { Perspective taking, reasoning, } \\
\text { identifying complexities. }\end{array}$ & $\begin{array}{l}\text { Identifying and building } \\
\text { both sides of an argument } \\
\text { or tension/dilemma }\end{array}$ \\
\hline
\end{tabular}


Sentence-Phrase- $\quad$ Summarizing and distilling.

Word
Text-based protocol

aimed at eliciting what a

reader found important

or worthwhile; used with

discussion to look at

themes and implications.

Source: Ritchhart (2015).

\subsubsection{Emergence and related studies of a CoT in L1 Context}

As pointed out earlier, the CoT concept has experienced an increased interest over the last two decades. In fact, there is volume of research that serves to support its emergence as a unique area of investigation in mainstream education (Ritchhart, 2000, 2015; Ritchhart et al., 2011; Ritchhart, Perkins, \& Turner, 2007; Tishman, Perkins, \& Jay, 1995). This is due to its benefits and impact on developing learners' thinking dispositions and deepening their content knowledge understanding. For this reason, empirical studies concerning the cultivation of a CoT have been investigated in L1 in areas such as: Mathematics, Arts, Sciences, Museum Education, and Social Sciences (Ritchhart, 2015; Ritchhart et al., 2011). To support its emerging research in L1, the following studies are looked at as examples.

First, Linck (2012) investigated the effects of thinking routine application on students' thinking awareness in four global competencies: 1) recognition of perspectives at the onset, 2) investigation of the world beyond their immediate environment, 3) communication of ideas effectively with diverse audiences, and 4) taking actions to improve conditions. The study also attempted to explore the extent to which frequent exposure to thinking routines impacted the development of empathy and deep understanding of others. Participants were 18 third graders. Two female teachers were involved in the implementation of the thinking routines. A pre-post survey questionnaire, observations, and reflective diaries were employed to collect data. The results revealed that frequent exposure to thinking routines could develop and cultivate learners' disposition to recognize diverse perspectives and enhance the development of 
empathy and deeper understanding of others in relation to the four global competencies (Linck, 2012). The study, however, did not include a control group to compare the results. It also focused on the internal thought process, which was difficult to assess as thinking is invisible.

Another study was carried out in Australia to investigate the effects of a CoT on students' metacognition thinking about thinking (Ritchhart, Turner, \& Hadar, 2009). Concept maps were employed as metacognitive tools to explore learners' knowledge or understanding of the topics. Two hundred and thirty-nine primary and secondary school students were recruited to participate in the study. Pre-post concept maps were used to measure learners' thinking about thinking in terms of four types of responses: associative (general comments), emotional (affective comments), strategic (surface or deeps strategies), and meta (the nature of understanding and conceptualizations of building knowledge). Data were analyzed qualitatively, and the results revealed the benefits of the CoT implementation in promoting and fostering learners' conception of thinking and their meta-strategic knowledge. Although the study highlighted the benefit of a CoT in broadening learners' thinking skills, it is useful to critique some aspects of the study design. The study did not include a control group to compare the results. Furthermore, the improvement of learners' conceptual thinking might have resulted from their maturity after a year of participating in the study. In other words, the issue of maturity should have been taken into consideration when designing and interpreting a longitudinal study.

\subsubsection{Related studies of a CoT in L2 and EFL contexts}

A number of studies have been conducted to investigate the effects of a CoT implementation on L2 and EFL learners' language development and learning engagement.

First, Hooper (2016) conducted a study to determine the effects of thinking routines implementation on students' academic writing ability in supporting arguments with evidence. The study aimed to seek answers to the question "Will the number of 
participants engaging in academic writing who support their arguments with evidence increase after applying thinking routines in class?" Ninety-four second-year EFL students at a Japanese university were recruited to participate in the study for fourteen weeks. Data were collected through pre-post essay writing. Results indicated a large increase in a number of participants who were able to support their arguments with evidence in essay writing after the intervention. The result suggested that the implementation of a CoT was beneficial for the development of learners' ideas and arguments crucial for academic essay writing practices. Although the study provided a new insight for language teachers to consider using a CoT, the design of the study might not reflect the experimental research paradigm (e.g., more tightly controlled or quasi-experimental design). In addition, the researcher implemented the thinking routines himself, which might be difficult to mitigate biases and subjectivity which may affect the internal reliability of the research.

Bias and subjectivity, however, were reduced in another study by Majida Mohammed Yousef (2016) who conducted a qualitative study to determine the impact of the CoT implementation on ESL students' engagement and inquiry skills development. Six ESL teachers and five students from two private schools in Palestine voluntarily participated in this action research. Prior to the implementation, the participating teachers were trained how to integrate thinking routines in their lesson plans. The study was carried out in one semester (five months) and focused on General English. Data were collected through direct classroom observations, videotaping, students' and teachers' written and oral reflections. The results showed that the implementation of thinking routines helped increase students' participation, engagement, and interaction. Classroom activities were more interactive, meaningful, and learner driven than in the past. Students benefited from collaborative thinking and thought beyond the facts and rote memorization. The study, however, reported some challenges related to the implementation of thinking routines for both teachers and learners. For the teachers, the challenges were an extra effort as they were not familiar with this teaching method while the main difficulty that learners encountered was their English proficiency. The study provides a comprehensive 
insight into the pedagogical implications of a $\operatorname{CoT}$ in promoting engagement and interaction but it did not focus on a language skills development (e.g., reading).

However, a language development was focused on by Salmon (2008b) who examined the CoT effects on young learners' language development. This qualitative research was conducted in two early childhood bilingual settings in Florida, USA. Most of the participants were exposed to Spanish in their home and community and mostly to English at school. Six bilingual teachers participated in this action research and data were collected through videotaping, teachers' documentation and discussions with the teachers. The research lasted six months and the findings revealed that learners were more confident to express themselves naturally in both English and Spanish. However, it was evident that learners externalized their thoughts in Spanish when they were pushed to think through thinking routines. They were also able to exchange ideas in English during large group activities. This indicates that the use of thinking routines was to promote L1 use in the child which can then be transferred to L2. Although the study demonstrated the benefits of thinking routines on enhancing learner language development (e.g., reading proficiency), it did not determine the effects of thinking routines on particular language skills and did not include a control group.

While the CoT has its advocates in other areas of investigation, there is a lack of empirical studies to show its impact on developing EFL pre-service teachers' language skill development, learning engagement, and their cognition of learning and teaching construction. Therefore, further research is needed to fill this gap and to contribute to the area of the CoT in language teacher education. To understand how the CoT potentially helps contribute to interactive and meaningful learning, the following section will look at this.

\subsubsection{CoT pedagogical implications in reading}

As indicated in reading literature, the main purpose of reading in the real world is not about word by word translation; it is the process of constructing meaning from a written text (Macalister, 2011). Learners should, therefore, be directed to make sense of what 
they read so that they might become better and critical readers in their professional and social interactions with written text. As pointed out earlier, an important way to develop this might be to engage learners in exploring ideas and concepts through the thinking routines (Ritchhart, 2015). Another pedagogical implication of a CoT is that it potentially assists learners in developing their metacognitive reading strategies and skills. As defined earlier, metacognition refers to higher-order thinking which involves active control over the cognitive processes engaged in learning (Hartman, 1998; Hudson, 2007). Given the important role of metacognitive learning strategies, attempts were made to categorize a taxonomy of thinking (Flavell, 1979; Wilson \& Bai, 2010).

Well-known scholars in this area are Bloom and his colleagues who created taxonomy of thinking development, consisting of three significant educational domains: 1) cognitive, 2) affective, and 3) psychomotor (Bloom et al., 1956). Among these, the cognitive domain is concerned with developing thinking skills in learners. Research suggests that the cognitive domain is significant for developing critical readers because it involves the development of intellectual capabilities (see Table 3.6) crucial for learning outcomes and reading comprehension (Irfan \& Shelina, 2016; Surjosuseno \& Watts, 1999). In this respect, this domain includes the recall or recognition of specific facts, procedural patterns, and concepts that serve in the development of thinking abilities. There are six categories of the cognitive domain, (see Table 3.6) ranging from lower-to higher-order thinking (Bloom et al., 1956). This framework will be used as criteria for the student engagement analysis to be presented in chapter 6 . 
Table 3. 6 Roles of Bloom's Taxonomy in Critical Reading

\begin{tabular}{lll}
\hline Category & Description & Critical reading \\
\hline Knowledge & Memorization & Facts/numbers \\
Comprehension & Understanding & Points of view \\
& & /interpretation \\
Application & Using ideas in new situations & Implication/application \\
Analysis & Breaking down claims into components & Conclusion, supporting \\
& and showing their relationships & statement, evidence \\
Synthesis & Forming new ideas & Assumption/construction \\
Evaluation & Judging the ideas against criteria set & Relevant/irrelevant \\
& & argument \\
\hline
\end{tabular}

In conclusion, this section focused on the notion of the CoT. Specifically, it looked at the definition, origin, relationships among critical and creative and a CoT, principles and cultural forces, thinking routines in focus, studies related to the CoT, and Bloom's taxonomy framework. The theory and framework here will be used as a basis for this study's discussion.

\subsection{Chapter summary}

This chapter has addressed three important contributors to the present study: LTC, reading literature, and a CoT. These theories will continue to be key elements for discussion throughout the remainder of this thesis. To seek answers to the central research questions posed in Chapter 1, the following chapter will look at the methodology adopted for the present study. 


\section{CHAPTER 4: METHODOLOGY}

\subsection{Introduction}

A number of issues and gaps were pointed out in the previous chapter. These were identified while reviewing the concept of LTC, reading literature, and a CoT. These issues and gaps reflect:

- the lack of research into the current state of reading instruction in the Lao EFL pre-service education context;

- the lack of an in-depth understanding of pre-service teachers' cognition in learning reading, especially in the EFL pre-service teacher education context; and

- the lack of an investigation of the effects of the CoT implementation on reading comprehension development, learning engagement, and perceptions of learning reading.

Thus, this research does not only attempt to address the issues and fill the gaps but also to contribute to the areas of LTC, EFL reading instruction, and a CoT by focusing on an indepth investigation into pre-service teachers' learning. This chapter details the methodology employed to address the aforementioned issues and gaps and to seek answers to the central research questions indicated in chapter 1 . Since this research has two phases, I look at the methods used to achieve each phase. Section 4.2 discusses the research methodology for phase 1 . Section 4.3 addresses the research methodology for phase 2. Section 4.4 looks at data analysis. Section 4.5 addresses an embedded experimental design between the phases. Section 4.6 addresses research trustworthiness. Section 4.7 focuses on ethical considerations. Section 4.8 justifies the researcher's position. Section 4.9 summarizes the chapter.

\subsection{Methodology for phase 1}

\subsubsection{Research questions}

This phase aimed to seek answers to the following research questions: 
RQ1: What are Lao EFL pre-service teachers' prior experiences of reading and learning to read in English?

RQ2a: What is the current state of reading instruction in Lao EFL pre-service teacher education?

RQ2b: To what extent is a CoT practiced in teaching reading in Lao EFL preservice teacher education?

\subsubsection{Design for phase 1}

The design of this phase is driven by the research purposes and questions indicated above (Patton, 1990). To reach data saturation and obtain an in-depth understanding of the issues, I adopted a qualitative method plus an element of a quantitative approach (Creswell, 2007). Specifically, the design here draws on important elements of exploratory and ethnographic research (Creswell, 2007; Croker, 2009; Dörnyei, 2007; Mackey \& Gass, 2005). This in turn ensures the credibility, dependability, conformability, and transferability (Mackey, 2016; Nowell, Norris, White, \& Moules, 2017), which will be addressed in section 4.6 (Trustworthiness) of this chapter. In the next section, I present the rationale supporting this design and paradigm.

\subsubsection{Exploratory research}

Exploratory research is defined as an investigation into an issue that is not clearly defined and empirically studied. It is conducted to provide a better understanding of the existing issue, which is worth further discovering and the results are used as empirical data for a follow-up action (Stebbins, 2001). It is often regarded as a grounded approach to answer questions like what, why, and how. The adoption of this paradigm was to seek empirical evidence of the current state of reading learning and instruction in Lao EFL pre-service education where there is very limited research and data to work on. As Stebbins (2001, p. 66) posits, "researchers explore when they have little or no scientific knowledge about the group, process, activity, or situation they want to examine but nevertheless have reason to believe it contains elements worth discovering". While it may sound a little challenging to explore an issue about which there is very limited information, I used several methods to help figure out the best research design and data 
collection. Specifically, I used two main sources of data collection methods to achieve the objectives of this investigation: qualitative plus a small scale of quantitative (Punch, 2009), to collect both primary and secondary data to the issues of interest. The primary data includes survey, semi-structured interviews, and classroom observations while the secondary data includes related literature, documents (e.g., curriculums, course syllabuses, test documents), online sources (e.g., education and university websites), and reports (e.g., national education reports). The two sets of data allowed me to obtain an insight into the issue under investigation. In addition to an exploratory study, phase 1 design also reflects important characteristics of ethnographic research.

\subsubsection{Ethnographic research}

In chapter 2, I argued that the social, political, educational, and cultural contexts (Palfreyman, 2015) played an influential role on shaping teachers' and students' prior experiences of learning and determining the application of innovative methods in Lao pre-service teacher education. I also believe that the Lao EFL pre-service teachers' mental lives and cognition are shaped by the dynamic interactions and experiences of the TEP and the world around them (Creswell, 2007). Concerning this, investigating Lao pre-service teachers' prior experiences of language learning and teaching without considering contextual factors is impossible as this research is context specific. This reflects important elements of ethnographic research.

Ethnographic research has evolved and been developed from the area of Anthropology (Dörnyei, 2007; Heigham \& Sakui, 2009) and the emergence of this approach in language teacher education and applied linguistics has resulted from its central role in developing an in-depth understanding of language teaching and learning situations in an authentic setting (Palfreyman, 2015; Starfield, 2015). It is regarded as a qualitative data collection approach. As Creswell (2007) posits, "Ethnographic research is a qualitative design in which the researcher describes and interprets the shared and learned patterns of values, behaviors, beliefs, and language of a culture-sharing group" (p. 68). Culture in this sense refers to beliefs, values, and behaviors of the teachers and students in a particular learning situation (Heigham \& Sakui, 2009). The discussion and employment of 
ethnographic research here is to help inform the results, interpretations, and the discussion of the issues under investigation from a wide range of qualitative perspectives (Mackey \& Gass, 2005; Palfreyman, 2015). This allowed me to produce a detailed and comprehensive description of the issues being investigated. In addition, data collection instruments (e.g., classroom observations and interviews) also reflected the important principles of ethnographic research (Starfield, 2015). I was able to gather rich information through triangulation of sources which aims for "thick description" and seeks to "unearth and piece together participants' own perspectives and values" (Palfreyman, 2015, p. 146) that form their beliefs and prior experiences of learning and teaching reading.

\subsubsection{Participants}

There were two categories of participants for this phase: pre-service teachers and reading lecturers (teachers). The two groups allowed for diverse perspectives on the issues. In this regard, ten pre-service teachers (see Table 4.1) and six reading lecturers (see Table 4.2) were recruited for semi-structured interviews, using a purposive sampling method (Dörnyei \& Taguchi, 2010; Teddlie \& Yu, 2007). The pre-service teachers were selected based on the following characteristics. First, they were adult students with a wide range of English-learning experience, ensuring potentially comprehensive insights into the issues of interest. Second, they had a large amount of exposure to reading learning during their schooling. It was assumed that most of them had experience of reading since grade 6 (lower secondary school).

The lecturers were selected using the following criteria. First, they had to have served as English instructors in the programme for at least three years. Second, they had to have at least two years of reading instruction experience. Finally, they were recruited on a voluntary basis so that they were not exploited in this regard.

The underlying reason for utilizing the purposive and criteria sampling method was because this research focused on an in-depth exploration of the phenomenon of interest (Dörnyei \& Taguchi, 2010; Patton, 1990). For this reason, participants who met these 
criteria were invited to participate in this study. In addition, the purposive sampling method allows for convenience and accessibility (Palinkas et al., 2015) while permitting the researcher to examine the issues of interest deeply.

In addition, 129 pre-service teachers were invited to complete a survey questionnaire regarding prior experiences of reading and learning to read in English to gain a wider picture of the issues being investigated (Creswell, 2007; Onwuegbuzie \& Leech, 2007). All respondents were informed of my permission to administer the questionnaire. This will be addressed in section 4.7 (Ethical consideration).

Table 4. 1 Pre-Service Teachers' Profiles

\begin{tabular}{ccccc}
\hline $\begin{array}{c}\text { Participant } \\
\text { code }\end{array}$ & Gender & Age & Years at ETEP & Semester/year \\
\hline P1 & Male & 23 & 4 & $1 / 2017$ \\
P2 & Female & 22 & 4 & $1 / 2017$ \\
P3 & Female & 19 & 2 & $1 / 2017$ \\
P4 & Female & 20 & 2 & $1 / 2017$ \\
P5 & Female & 19 & 2 & $1 / 2017$ \\
P6 & Male & 21 & 3 & $1 / 2017$ \\
P7 & Male & 18 & 1 & $1 / 2017$ \\
P8 & Male & 23 & 4 & $1 / 2017$ \\
P9 & Male & 22 & 4 & $1 / 2017$ \\
P10 & Female & 19 & 1 & $1 / 2017$ \\
\hline
\end{tabular}


Table 4. 2 Reading Lecturers' Profiles

\begin{tabular}{clccc}
\hline $\begin{array}{c}\text { Participant } \\
\text { Code }\end{array}$ & Gender & $\begin{array}{c}\text { Teaching } \\
\text { experience }\end{array}$ & $\begin{array}{c}\text { Reading teaching } \\
\text { experience }\end{array}$ & Qualifications \\
\hline P1 & Female & 3 & 3 & MA.TEFL \\
P2 & Male & 18 & 5 & MA.TEFL \\
P3 & Male & 7 & 7 & MA.TEFL \\
P4 & Male & 14 & 7 & MA.TEFL \\
P5 & Female & 13 & 12 & MA.TEFL \\
P6 & Female & 9 & 9 & MA.TEFL \\
\hline
\end{tabular}

\subsubsection{Instruments}

\subsubsection{Semi-structured interview}

Semi-structured interviews (see Appendix 1) were conducted with pre-service teachers to gather data concerning their prior experiences of reading and learning to read in English. The interviews were conducted in November 2017. In terms of the prior experiences of reading, I conducted 10 one-on-one semi-structured interviews (see Table 4.3) to seek answers to RQ1. The interviews were conducted in the participants' L1 to ensure that they were able to exchange ideas meaningfully regarding the issue under research. They were also allowed to use English if they wished to. 
Table 4. 3 Pre-Service Teachers' Interview Summary

\begin{tabular}{ccc}
\hline Participant code & Date & Duration \\
\hline P1 & $13^{\text {th }}$ November 2017 & 16:25 minutes \\
P2 & $13^{\text {th }}$ November 2017 & 26:02 minutes \\
P3 & $14^{\text {th }}$ November 2017 & 28:25 minutes \\
P4 & $14^{\text {th }}$ November 2017 & $15: 48$ minutes \\
P5 & $14^{\text {th }}$ November 2017 & $32: 04$ minutes \\
P6 & $15^{\text {th }}$ November 2017 & $24: 31$ minutes \\
P7 & $15^{\text {th }}$ November 2017 & $23: 42$ minutes \\
P8 & $16^{\text {th }}$ November 2017 & $17: 22$ minutes \\
P9 & $16^{\text {th }}$ November 2017 & $19: 56$ minutes \\
P10 & $17^{\text {th }}$ November 2017 & $20: 17$ minutes \\
\hline
\end{tabular}

I also conducted 6 one-on-one semi-structured interviews (see Appendix 2) with the reading lecturers to seek answers to $R Q s 2 a \& 2 b$, the current state of reading instruction and the extent to which a CoT was practiced in Lao EFL pre-service teacher education. The interview was conducted in the participants' L1 in accordance with their wishes. Again, they could use English if they wished to do so. Interviews lasted from 17 to 30 minutes. Table 4.4 is a summary of the lecturers' interviews.

Table 4. 4 Reading Lecturers' Interview Summary

\begin{tabular}{ccc}
\hline \multicolumn{1}{l}{ Code } & Date & Duration \\
\hline P1 & $1^{\text {th }}$ December 2017 & 21:12 minutes \\
P2 & $1^{\text {th }}$ December 2017 & 29:57 minutes \\
P3 & $1^{\text {th }}$ December 2017 & 24:15 minutes \\
P4 & 18 $^{\text {th }}$ December 2017 & 17:02 minutes \\
P5 & 19th December 2017 & 21:32 minutes \\
P6 & 19th December 2017 & 27:23 minutes \\
\hline
\end{tabular}

An interview can be defined as an interaction or conversation that has a particular purpose. An interview is not only a matter of asking and answering questions regarding 
the issue being researched, but is also a method for investigating participants' beliefs, perceptions, and experiences of a particular issue (Kasper, 2015; Richards, 2009). These were semi-structured interviews which allow "the use of a written list of questions as a guide, while still having the freedom to digress and probe for more information" (Mackey \& Gass, 2005, p. 173). Semi-structured interviews permit the researcher to explore an indepth understanding of the phenomenon under study (Alshenqeeti, 2014; Richards, 2009). I opted for this type of interview because it enabled me to examine participants' prior experiences of learning and teaching reading in a flexible and meaningful manner. I was able to ask follow-up questions in order to dig deeper into the issues being looked at. All interviews here were recorded, transcribed, and translated into English for further analysis (see Appendix 16: Sample)

\subsubsection{Direct classroom observation}

To gain a deeper insight into the current state of reading instruction and the extent to which a CoT was practiced, six reading classes were observed. I opted for the observation because it allowed me to experience and see the reality of what happened in the classroom. As Cowie (2009) notes, "observation is the conscious noticing and detailed examination of participants' behavior in a natural setting" (p. 166). Through this, I was able to interact informally with the pre-service teachers and lecturers prior to, and after, the observations. Profiles regarding the classes and schedules are presented in Table 4.5 below. To ensure effective observation, an observation protocol (see Appendix 3) and audio-recording devices were used to support the field notes. This provided a means for data triangulation and corroboration gathered through the semi-structured interviews and survey questionnaire. During the observations, I acted as a nonparticipant observer (Cowie, 2009) to mitigate my influence on both the lecturers (teachers) and pre-service teachers. To minimize the impact of my presence, I arrived at the classroom five to ten minutes before the class commenced to set up the audiorecording devices and arrange my seat. The devices were placed at the back of the room so that the lecturers and pre-service teachers did not feel distracted. 
Table 4. 5 Classroom Observation Summary

\begin{tabular}{|c|c|c|c|c|}
\hline Date & Duration & Topic & $\begin{array}{c}\text { Teacher } \\
\text { code }\end{array}$ & Year/semester \\
\hline $28^{\text {th }}$ Nov 2017 & $57: 42$ minutes & $\begin{array}{l}\text { Urban } \\
\text { planning }\end{array}$ & $\mathrm{P} 1$ & $4 / 1$ \\
\hline 29th Nov 2017 & 92:23 minutes & Life in the city & $\mathrm{P} 2$ & $2 / 1$ \\
\hline 29th Nov 2017 & $82: 27$ minutes & $\begin{array}{l}\text { Today's } \\
\text { technology }\end{array}$ & P3 & $3 \mathrm{~B} / 1$ \\
\hline 27th Dec 2017 & 50:08 minutes & Tourist sites & P4 & $1 / 1$ \\
\hline $21^{\text {st }}$ Dec 2017 & $94: 19$ minutes & $\begin{array}{l}\text { The Pirate } \\
\text { business }\end{array}$ & P5 & $2 / 1$ \\
\hline $22^{\text {nd }}$ Dec 2017 & $85: 56$ minutes & Sports & P6 & $3 \mathrm{~A} / 1$ \\
\hline
\end{tabular}

There are certain advantages and disadvantages of observation that need to be pointed out (Creswell, 2013). In light of its merits, as stated above, observation is beneficial because it allows the researcher to collect non-verbal data and provides the opportunity to gather rich data on the participants' social, behavioral, and emotional interactions in a natural setting (Mackey \& Gass, 2005). In terms of its caveats, observation does not allow the researcher to know the inner motivation of the participants' actions or interactions in learning. For this reason, I employed other data collection methods (e.g., semistructured interviews and survey) to triangulate the data.

\subsubsection{Questionnaire}

As stated in section 4.2.2.3, the questionnaire (see Appendix 4) was administered to 129 pre-service teachers to seek a wider picture of their prior experiences of reading and learning to read. According to Brown (2001), "a questionnaire is any written instrument that presents respondents with a series of questions or statements to which they are to react by writing out their answers or selecting from among existing answers" (p. 6). A questionnaire has many advantages in the classroom-based study. First, it allows the researcher to collect a large quantity of data to answer the research question (Mackey \& Gass, 2005; Yongqi Gu, 2016). Second, it is more economical and practical than the other 
data collection instruments (e.g. interviews and observations) as it can be easily administered in a short period of time and through many forms: email, phone, and in person (Combe \& Davidson, 2015). Finally, data from the questionnaire can be easily analyzed using descriptive or inferential statistics like SPSS (Mackey \& Gass, 2005). For these reasons, a questionnaire was used in addition to other data collection instruments stated above.

In terms of its disadvantages, a questionnaire does not allow the researcher to probe responses; it is a structured instrument (Combe \& Davidson, 2015). It does not provide the opportunity for respondents to qualify their choice of responses, which often does not result in rich data. To mitigate this, I included an open-ended section at the end of the survey to allow the respondents to add and justify their attitudes, feelings and experiences toward the issues being asked (Meadows, 2003). Another issue is respondent literacy (Combe \& Davidson, 2015). Respondents might not be able to read or understand well in the target language (English), which might result in a lack of reliable data obtained. To minimize this, I translated all items into the respondents' L1. To ensure the accuracy and reliability of my translation, I followed Meadow's (2003) translation process called "the forward-backward translation procedure" (p. 569). This process was used to ensure the reliability and retain the semantic equivalence of each item after translation. In this respect, I first carried out the forward translation from the target language to respondents' native language. A competent bilingual instructor then back translated from the respondents' L1 to the target language. The main purpose for this was to compare the equivalence between the two versions in terms of the intended meaning. Through this process, minor adjustments (e.g., rewording) were made.

All items in this questionnaire were adapted from two existing questionnaires. The two questionnaires are Beliefs about Language Learning (Horwitz, 1988) and Metacognitive Awareness of Reading Learning Strategies (Mokhtari \& Reichard, 2002) as "utilizing existing questionnaires that have been widely used and been shown to be reliable and valid" (Meadows, 2003, p. 564) is good practice. All items were revised following guiding 
principles of experts via their publications (Horwitz, 1988; Meadows, 2003; Mokhtari \& Reichard, 2002; Mokhtari \& Sheorey, 2002) in the area of FEL and ESL reading instruction. For the purpose of my research, only slight rewording was required. For instance, an original item states 'Learning a language is mostly a matter of learning a lot of new words.' The modified version is 'Learning a lot of new words is important for learning English reading'. The adaptation did not affect intended meaning of the item.

In addition, prior to its administration, it was piloted with a group of participants who had similar characteristics to the participants of the main study (Combe \& Davidson, 2015; Meadows, 2003). After piloting, a reliability analysis using SPSS (Version 25) was performed. The results (see Table 4.6) revealed that the questionnaire reached acceptable reliability, Cronbach's alpha $\alpha=0.861$, suggesting that all of the items are worthy of retention. Specifically, the reliability analysis included the Reliability Statistics (Cronbach's Alpha $(\alpha=.861)$ and Cronbach's Alpha based on Standardized Items (0.857).

Table 4. 6 Reliability of the Questionnaire

\begin{tabular}{ccc}
\hline \multicolumn{3}{c}{ Reliability Statistics } \\
\hline Cronbach's Alpha & Cronbach's Alpha Based on Standardized Items & No. of Items \\
.861 & .857 & 24 \\
\hline
\end{tabular}

In addition, I also examined each of the 24 items by looking at its means and standard deviations. The results showed that $23(M=3.00-3.96)$ of the 24 items are tapping into the same concept, suggesting that all items are worth retaining. Because the survey was adapted, I expected high reliability. As indicated above, the result of the reliability analysis was .861, suggesting that the reliability of the instrument was satisfactory as the acceptable values of Alpha ranges from "0.70 to 0.95" (Tavakol \& Dennick, 2011, p. 54). The survey administration took around 15 to 20 minutes and all respondents were informed of my permission to collect data (see Appendix 20: Permission Letter for Data Collection). 


\subsubsection{Document analysis}

According to Bowen (2009), document analysis is "a systematic procedure for reviewing or evaluating documents - both printed and electronic (computer-based and Internettransmitted material" (p. 27). It is regarded as one of the qualitative methods in eliciting meaning, gaining understanding, and developing empirical knowledge (Atkinson \& Coffey, 1997; Bowen, 2009). The documents collected for this study include: curricula, syllabuses, reading lesson plans, and reading tests (see Table 4.7) and these are often conflated within education (Nation \& Macalister, 2010; Woods, Luke, \& Weir, 2010). The main differences between the documents are:

- curriculum refers to a wide or more general guideline of education, allowing me to analyze the goal, objectives, and philosophy of the curriculum mandated by MoES;

- syllabus refers to the aim, content, and method of a particular subject (Nation \& Macalister, 2010), allowing me to have a closer look at the reading materials in relation to what is conducted in the classroom;

- reading lesson plan refers to a detailed sequence of a unit around a specific theme a teacher designs for the successful learning outcome (Farrell, 2002); and

- reading test paper is a document designed by the reading instructors which are often recognized as a reflection of their classroom practices. In particular, the test content reflects what happened in the classroom.

Document analysis has both advantages and disadvantages (Bowen, 2009). In terms of its merits, it is:

- an efficient method because it is less time consuming than other methods since it requires data selection rather than data collection;

- sometimes easy to find and locate since documents are available in the public domain;

- cost-effective as documents are less costly than the other research methods;

- not obtrusive or reactive as it is not affected by the research process;

- stable, documents are not affected by the investigator's presence; 
- exact as the inclusion of exact names, references, etc. makes documents advantageous; and

- rich in providing a wide range of events, time, and settings.

Although there are many advantages to using document analysis, it is important to also acknowledge the limitations of this method, which are:

- inadequate detail; they are produced for some purposes other than research;

- sometimes low retrievability; difficult to access as they may be blocked or not allowed; and

- biased selectivity; they might be aligned with corporate policies and particular organizations (Bowen, 2009).

To minimize the limitations, I collected data from different sources through different methods related to the issues of interest as data triangulation to validate findings (Cohen, Manion, \& Morrison, 2007). In addition, although document analysis has its limitations, its advantages clearly outweigh the limitations (Bowen, 2009). Table 4.7 summarizes documents collected.

Four sets of documents were collected and analyzed as complementary data in support of data triangulation (see Appendix 5: Reading Test Document). Documents are socially constructed products that are published, shared and used in socially organized ways (Atkinson \& Coffey, 1997; Cohen et al., 2007). For this reason, documents might not serve the research purposes. To address this, I embraced Scott's (1990) criteria for assessing the quality of documents:

- authenticity (legitimacy and legality of the document);

- credibility (error and distortion free);

- representativeness (writer's presentation); and

- meaning (concise and clear evidence).

They were treated as authentic sources because, in most cases, they were signed by the designated authorities (e.g., minister of education, academic committee, and instructors) and added to the official records of the TEP. They were revised by several experienced educational practitioners in the area of language teacher education prior to final official 
approval, which ensured credibility. The four sets of documents represent a wide range of related ideas and issues (representativeness) and provided meaningful and comprehensible evidence to the issues being looked at. The results of the analysis here will be augmented with the findings of the other instruments mentioned above (Balwant, Birdi, Stephan, \& Topakas, 2018; Bowen, 2009).

Table 4. 7 Summary of Document Collection

\begin{tabular}{llc}
\multicolumn{1}{c}{ Documents } & No. of documents \\
\hline 1. Curricula & 4 \\
2. Reading course syllabuses & 3 \\
3. Reading lesson plans & 10 \\
4. Reading test papers & 10 \\
\multicolumn{2}{c}{ Total } & $\mathbf{2 7}$ \\
\hline
\end{tabular}

Although documents are seen as a rich data source, it is important for the researcher to examine them critically (Bowen, 2009). In this respect, I established the meaning of the documents and their contributions to the issues under investigation by paying attention to the process of skimming, examining, and interpreting. This process integrates both content analysis and thematic analysis (Bowen, 2009). Specifically, the four sets of documents were analyzed separately first before integrating the findings and drawing a conclusion in relation to the issues under investigation. In terms of the curriculum documents, I focused on their philosophy and objectives to see whether they included the notion or a statement of critical thinking. Regarding the course syllabus and reading lesson plan, I first analyzed their objectives to see the key aspects of expected learning outcomes set. Second, I examined learning activities designed to engage learners in interacting with the text and peers and the extent to which these activities reflected their objectives in terms of critical thinking practices. For the reading test document, I first identified types of test components, i.e. what the tasks require candidates to do. Then, I focused on the extent to which the comprehension questions are meaningful and require critical thinking skills. By focusing on these, I was able to draw a conclusion and identify the gap between policy and classroom practices. 


\subsubsection{Pilot study for phase 1}

Before the main study, I conducted two pilot studies. One was in Wellington and the other was at the TEP in LPDR. Pilot studies are beneficial in terms of identifying strategies and methods adopted to collect the data (Mackey \& Gass, 2005; Mckay, 2006) pretesting particular research instruments. As Baker (1988) notes, pilot studies are often employed to pilot research data collection instruments in the preparation for the main study. Another advantage is that it can give advance warning regarding weaknesses in a proposed project (Mackey \& Gass, 2005). In brief, pilot studies help address a wide range of logistical issues related to the main study.

The first pilot study that took place at Victoria University of Wellington (VUW) included two main activities:

- Observations: I observed the teaching of reading in three English Proficiency Programme classes at the School of Linguistics and Applied Language Studies to practice my observation and note-taking skills. To ensure the effectiveness of my observations, I used an observational protocol. This allowed me to focus on the issue under investigation and;

- Interviews: I piloted five one-on-one interviews, three with ESL teachers (August 15, 2017) and two with students (August 17 and 21, 2017). One of the interviews was conducted in Lao language.

The second pilot study was conducted in LPDR with a group of pre-service teachers who had similar characteristics to the participants of the main study. The pilot study included: two pre-service teachers interviews, one reading lecturer interview, one reading class observation, and the administration of the questionnaire.

Through piloting, I learned several important aspects of conducting research. First, the pilot studies helped me shape my observation and note-taking skills, which was important to ensure the quality of data collection in the main study (Cohen et al., 2007). Second, I realized that sometimes I had to re-order the interview questions so that I was able to maintain the flow of the conversation coherently and logically. For instance, I 
swapped Question 5 with Question 4. Third, I learned that I had to clarify my interview questions to the participants so that they knew how to answer them in an insightful manner (Creswell, 2013). For instance, when piloting the semi-structured interview with a reading lecturer, she was struggling to understand Question 5 that asks: 'Tell me a typical successful reading lesson you conducted'. To help the lecturer understand the intended meaning, I modified the question by stating 'Can you give an example of your effective reading lesson and why?' Fourth, I learned that the pilot studies helped me practice my listening skills to the participants' accounts, stories, and beliefs about the areas of interest. Last, while listening to the participants' stories, I was able to practice my interruption skills, manage my interview time, maintain a focus, and ask follow-up questions in an appropriate manner so that I was able to seek answers relevant to the research questions from them.

\subsection{Methodology for phase 2}

\subsubsection{Design for phase 2}

As stated earlier, phase 2 of this research is aimed at determining the extent to which the CoT implementation improves Lao EFL pre-service teachers' reading comprehension, learning engagement, and perceptions of learning reading. As a reminder, research questions asked:

RQ3: To what extent does the implementation of a CoT improve Lao EFL preservice teachers' reading comprehension?

RQ4: How do Lao EFL pre-service teachers engage in learning reading in the CoTbased and comparison classes?

RQ5: What are Lao pre-service teachers' perceptions of learning reading in the CoT- based and comparison classes?

The design of this phase (see Table 4.8) was informed and shaped by the research purposes and research questions (Patton, 1990). Additionally, the design reflects the underlying philosophical assumptions adopted to achieve the intended purposes and to overcome weakness believed to have a significant impact on the research. For this 
reason, phase 2 adopted an explanatory mixed-method and quasi-experimental design (Ivankova \& Creswell, 2009), meaning that the qualitative findings help explain and justify the quantitative results (Creswell \& Clark, 2007) of the intervention.

Table 4. 8 Phase 2 Procedures Summary

\begin{tabular}{|c|c|c|c|c|c|c|c|c|}
\hline \multirow[t]{2}{*}{$\begin{array}{c}\text { Intact } \\
\text { classes }\end{array}$} & \multicolumn{2}{|c|}{$\begin{array}{c}\text { Pre- } \\
\text { implementation }\end{array}$} & \multicolumn{2}{|c|}{$\begin{array}{c}\text { During- } \\
\text { implementation }\end{array}$} & \multicolumn{4}{|c|}{ Post-implementation } \\
\hline & 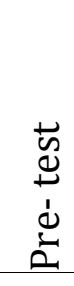 & $\begin{array}{l}\overrightarrow{0} \\
\stackrel{0}{0} \\
0 \\
\dot{0} \\
\vdots\end{array}$ & 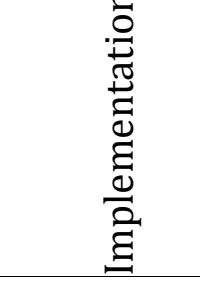 & $\begin{array}{l}0 \\
0 \\
.0 \\
0 \\
0 \\
0 \\
0 \\
0 \\
0\end{array}$ & $\begin{array}{l}\vec{\Delta} \\
\stackrel{\Delta}{\Delta} \\
\dot{\Delta} \\
0 \\
0\end{array}$ & 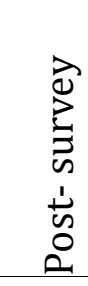 & $\begin{array}{l}\overrightarrow{0} \\
\stackrel{0}{0} \\
0 \\
0 \\
0 \\
\frac{\sigma}{0} \\
\frac{0}{0}\end{array}$ & 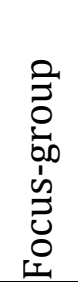 \\
\hline 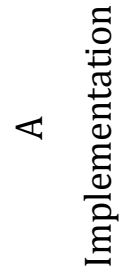 & 01 & Q1 & $\begin{array}{l}\text { X1 } \\
\text { COT-based }\end{array}$ & OB1 & 02 & Q2 & 03 & FG1 \\
\hline 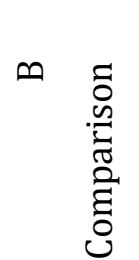 & 01 & Q1 & $\begin{array}{l}\mathrm{X} 2 \\
\text { Normal }\end{array}$ & OB1 & 02 & Q2 & 03 & FG1 \\
\hline
\end{tabular}

As the table shows, the implementation includes a CoT-based reading instruction (X1) and normal reading instruction (X2). This means that the CoT-based instruction serves as the intervention while normal instruction serves as the comparison. The preintervention includes the administration of a pre-test (01) and a pre-survey (Q1). During the implementation, the two intact classes were observed (OB1) to obtain insights into how pre-service teachers engaged in learning and what they experienced in the classroom. The post-implementation includes the administration of an immediate posttest (02), a post-survey (Q2), and a delayed-test (O3). In addition, focus group interviews (FG1) were also conducted with both intact classes to seek their perceptions of learning reading. The post measures were conducted to compare the results and see if there was 
any significant difference between the classes in terms of the issues under research. The delayed-test was conducted two weeks after the immediate post-test to measure comprehension retention. The implementation included two learning-sessions of 90

minutes per week over 13 weeks. This matched against the control class. The implementation class's schedule was on Tuesdays and Fridays (13:00-14:30 pm) while the control class was on Tuesdays and Wednesdays (10:00-11:30 am).

\subsubsection{Rationale for explanatory mixed methods design}

When I designed this phase, I asked myself important questions regarding its methods. The questions included:

- What underlying methods and theoretical foundations should I employ to answer the central research questions?

- What could be done to investigate the issues of interest that makes it almost impossible to examine from a single method?

With these questions in mind, I realized that it was important to draw answers from multi-voices to lend insights into the issues in order to consider a suitable research design and method (Natalia \& Greer, 2015). For this reason, I employed an explanatory mixed quasi-experimental method, the quantitative and qualitative combination as demonstrated in Table 4.8. There are five main reasons for the adoption of this method. First, it allowed me to triangulate and seek corroboration of data (Mackey \& Gass, 2005) from various sources (lecturers and pre-service teachers) and use several data collection instruments (e.g., testing, observing, interviewing, surveying). Second, it allowed me to seek clarification of the results from various perspectives or explanations. Third, it opened up the opportunity for me to further discuss the results from one method to help inform the findings and discussions of the other. Fourth, it allowed me to initiate attempts to discover a new teaching perspective. Finally, it helped me expand the scope and range of inquiry through using different methods for different purposes (Creswell \& Clark, 2007; Natalia \& Greer, 2015).

The mixed-methods research was taken in this phase to provide a much more detailed picture of what was investigated. In this regard, the advantage of the quantitative 
method is that it allowed me to obtain results through a statistical analysis (e.g. test and survey questionnaire), which a qualitative method would not achieve (Creswell, 2007). However, the limitation of the quantitative method is that it is not able to examine the issue more deeply (Creswell, 2013; Seliger \& Shohamy, 1989). For this reason, I employed qualitative methods to compensate what a quantitative analysis might not be able to fully explain, such as the reasons why and how pre-service teachers develop or fail to improve their reading comprehension and what they thought about learning reading after the implementation (Brown, 2015).

In carrying out a mixed-methods design, it is useful to understand its key principles in terms of its strands, including:

- timing;

- weighting; and

- mixing (Creswell \& Clark, 2007; Johnson, Teddlie, \& Tashakkori, 2012).

First, timing refers to the sequence of collecting and analyzing qualitative or quantitative data. To achieve this, I followed what Ivankova and Creswell (2009, p. 138) call "concurrently-collecting and analyzing both quantitative and qualitative at the same time." Specifically, qualitative methods like observations (Natalia \& Greer, 2015) were conducted during the 13-week implementation to investigate how pre-service teachers engaged in learning reading, and to see what they experienced in the classroom as intended by the lesson plans (Natalia \& Greer, 2015). This also allowed me to identify common patterns of pre-service teachers' interaction. Focus group interviews were conducted after the implementation. This sequence of data collection allowed me to gather data in a systematic way.

Second, weighting refers to "the relative importance or priority given to each type of data" (Ivankova \& Creswell, 2009, p. 138). In this phase, a greater emphasis was placed on the qualitative data determined by the research questions, data collection methods, data analysis, and the sophisticated learning situation. In this respect, results were interpreted based on data integration to draw a final conclusion (Creswell, 2013). 
Finally, mixing refers to how two methods (e.g., qualitative and quantitative) are integrated within a study (Ivankova \& Creswell, 2009). In this regard, mixing was conducted during data collection and the interpretation of results. Mixing was driven and informed by the research's purposes, which aimed to explain the quantitative results obtained before the qualitative results (Ivankova \& Creswell, 2009). Therefore, integration occurred at the data interpretation stage, when the results from two data sets were compared and backed each other up (Creswell \& Clark, 2007). With this in mind, I combined an explanatory approach with elements of triangulation methods. Figure 4.1 presents a visual diagram of this design (Creswell, 2013).

\begin{tabular}{|c|c|c|}
\hline Quantitative & Qualitative & Interpretation \\
\hline 1 & 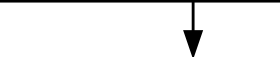 & 1 \\
\hline $\begin{array}{ll}\text { - Implementation } \\
\text { - Inferential } \\
\text { Statistical } \\
\text { Analysis }\end{array}$ & 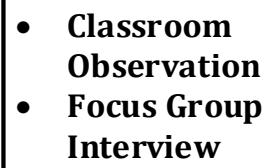 & $\begin{array}{l}\text { Interpretation based } \\
\text { on quantitative and } \\
\text { qualitative results }\end{array}$ \\
\hline
\end{tabular}

Figure 4. 1 Explanatory Quasi-Experimental Design (Creswell, 2007)

\subsubsection{Participants (pre-service teachers)}

Participant recruitment for this phase was determined by the research purposes, design, and contextual factors (Woodrow, 2014). In this respect, two intact classes of intermediate pre-service English teachers were recruited. One of the classes was assigned to the implementation group while the other class was taught as normal. The comparison class had 31 pre-service teachers $(n=31)$ and the experimental class had 30 pre-service teachers $(n=30)$. The ages of the participants ranged from 18 to 25 and their English proficiency was intermediate. The two classes were recruited based on the following reasons. First, they had been in the TEP for at least three years. Second, the participants' native language was Lao so that there may not have been much difference 
in terms of their exposure to English language input outside of the classroom (Mackey \& Gass, 2005). Finally, they were future teachers (lecturers) who might impart new teaching skills gained from the intervention to their future students and apply in their classroom practices.

\subsubsection{Instruments}

\subsubsection{Reading test}

To measure the participants' baseline data of English reading proficiency, the International English Language Testing System (IELTS) general reading sample test (IELTS, 2017) was administered (see Appendix 6). This type of a proficiency test is unlikely to be encountered by pre-service teachers in this context. The IELTS general reading module is internationally recognized in terms of its reliability and validity in assessing candidates' English reading capability. The general reading module is mainly used to assess language ability of the candidates who intend to work in or migrate to a country where English is the means of communication (Cambridge University Press, 2006). For this reason, research has been conducted to determine its validity and reliability. In 2012, 24 IELTS general reading training test modules were piloted, and the Cronbach's alpha was used to measure the internal consistency of the test items. The results revealed that the tests had sufficient and meaningful reliability values with "an average alpha of .91" (Taylor \& Weir, 2012, p. 29), which was satisfactory.

In this research, six IELTS general reading sample texts were taken from different IELTS (IELTS, 2017) for measuring participants' English reading proficiency. The texts included extracts from the areas of notices, advertisements, leaflets, newspapers, instruction manuals, books, and magazines. These represent a wide range of reading texts that reflect real-world situations (Cambridge University Press, 2006). Reading text one aims to test candidates' ability to locate and recognize particular pieces of information conveyed in the text through true, false, or not given comprehension questions. As discussed in the reading and CoT literature (Grabe, 2009; Grabe \& Stoller, 2011; Ritchhart, 2015; Ritchhart et al., 2011), students need to skim the text in order to understand what the author intends of the text. To perform this, students are required to 
evaluate the true, false, or not given statements through thinking, comparing and applying a critical evaluation before deciding on the answer.

Reading text two aims to test students' capability in locating and understanding precise information or ideas represented in the text through short answer comprehension questions. This type of question also aims to test students' ability to read the text to understand the overall meaning, identify keywords, think of possible synonyms of keywords that form the gist. Reading text three is intended to test students' ability to recognize the main idea of the text through matching headings, i.e., meaning-focused questions, as students need to draw a conclusion based on what they read before deciding. Passage text four, sentence completion, focuses students on locating and identifying detailed and specific information in the text. It also aims to test students' ability to paraphrase, understand synonyms, and construct meaning of the text.

Reading text five, multiple choice questions, intends to test students' ability to identify specific points and meaning of the text. The final reading text aims to test students' ability to understand the main idea of paragraphs through summary comprehension questions. This also tests students' capability to recognize words (e.g., nouns, verbs, adjectives, phases) that are suitable for gap completion. The reading test used here intends to measure not only students' ability to apply metacognitive reading strategies but also to construct meaning of the text (Grabe, 2009; Ritchhart, 2015).

Although the reading test has its merits and credibility in measuring students' reading comprehension as stated earlier, it is important to ensure that the test is appropriate to the students' English proficiency (Hamza, 2006) in terms of the lexical coverage (i.e., the percentage of known words in a text). Since the target candidates of the test were year three pre-service English teachers, it was assumed that their proficiency was at an intermediate level (K1-K3 words: 1000-3000). Despite other factors that determine reading comprehension, vocabulary knowledge is one factor that contributes to an understanding of the text (Nation \& Ming-Tzu, 1999). A large volume of research has 
been conducted to identify the proportion of the lexis in a text that a reader needs to know in order to read for comprehension (Hu \& Nation, 2000; Laufer \& RavenhorstKalovski, 2010; Schmitt, Jiang, \& Grabe, 2011), and the previous and current agreement is between 95\% and 98\% (Laufer, 1989; Nation, 2006; Prior, Goldina, Shany, Geva, \& Katzir, 2014; Schmitt et al., 2011). To estimate participants' vocabulary knowledge, the reading texts were analyzed using Lextutor and the results are illustrated in Table 4.9.

Table 4. 9 Vocabulary Coverage Analysis

\begin{tabular}{|c|c|c|c|c|c|c|}
\hline Texts & Criteria & $\begin{array}{l}\text { Words in } \\
\text { text }\end{array}$ & K1: 1000 & K2: 2000 & K3: 3000 & $\begin{array}{l}\text { Cumulative } \\
\text { percent }\end{array}$ \\
\hline \multirow[b]{2}{*}{1} & \multirow{3}{*}{$95-98 \%$} & 250 & 182 & 46 & 6 & \\
\hline & & $\%$ & $(72.80 \%)$ & (18.40\%) & $2.40 \%$ & $93.60 \%$ \\
\hline \multirow{3}{*}{2} & & 227 & 175 & 21 & 8 & \\
\hline & \multirow[t]{2}{*}{$95-98 \%$} & $\%$ & $77.09 \%$ & $9.25 \%$ & $3.52 \%$ & $89.86 \%$ \\
\hline & & 225 & 158 & 34 & 15 & \\
\hline 3 & \multirow[t]{2}{*}{$95-98 \%$} & $\%$ & $70.22 \%$ & $15.11 \%$ & $6.67 \%$ & $92.00 \%$ \\
\hline \multirow[b]{2}{*}{4} & & 192 & 145 & 16 & 10 & \\
\hline & \multirow[t]{2}{*}{$95-98 \%$} & $\%$ & $75.52 \%$ & $8.33 \%$ & $5.21 \%$ & $89.06 \%$ \\
\hline \multirow[b]{2}{*}{5} & & 129 & 108 & 9 & 33 & \\
\hline & \multirow[t]{2}{*}{$95-98 \%$} & $\%$ & $83.72 \%$ & $6.98 \%$ & $15.14 \%$ & $90.70 \%$ \\
\hline \multirow[b]{2}{*}{6} & & 318 & 270 & 34 & 10 & \\
\hline & $95-98 \%$ & $\%$ & $84.91 \%$ & $10.69 \%$ & 3.14 & $98.74 \%$ \\
\hline
\end{tabular}

Based on the results above, it can be noted that most of the reading passages (except reading passage 6) were quite challenging for the participants as lexical coverage fell below the criteria set above: reading text 1 (93.60\%), reading text 2 (89.96\%), reading 
text $3(92.00)$, reading text $4(89.06 \%)$, reading text $5(90.70 \%)$, and reading text 6 (98.74\%). As a reminder, the analysis here did not reveal students' actual reading comprehension. It is used as a means of estimating a relationship between students' lexical knowledge and vocabulary coverage in a text. Although the test may have been challenging for the participants, the researcher remained optimistic that the CoT implementation would help students improve reading comprehension.

In addition, the test was piloted with a group of 52 pre-service teachers (participants) who had similar characteristics to the participants of the main study to measure its reliability through a normality test. I ran this because it was assumed that for most parametric tests to be reliable, the test scores must be approximately normally distributed (Woodrow, 2014). In this respect, the test scores were computed using SPSS version 25 (Bachman \& Palmer, 1996). As a criterion, the Skewness and Kurtosis values should be somewhere in the span of -1.96 to +1.96 . The Shapiro-Wilk test p-value (Shapiro \& Wilk, 1965) should be above .05. In addition, the histogram, normal Q-Q plot and Box plot should visually indicate that the test scores are approximately normally distributed (David \& Lori, 2011). However, it does not have to be perfectly normally distributed. The results of the analysis revealed that the test scores were approximately normally distributed as the Skewness and Kurtosis values fell into the criteria set (Skewness $=.795$; Kurtosis $=.705$ ), suggesting that the test scores were skewed and kurtotic for all pilot participants. In addition, Shapiro-Wilk was above the $p$-value set ( $p$ $=.16$ ). It was assumed that the test scores were approximately normally distributed. In addition, the histogram (see Figure 4.2) shows that the test has the approximate shape of a normal curve. 


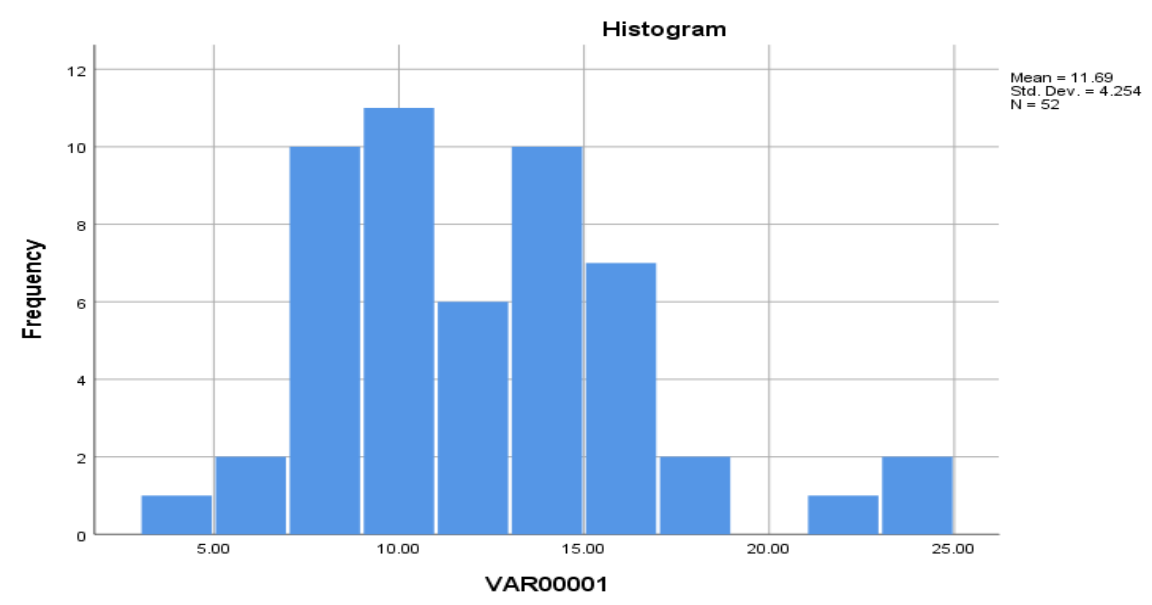

Figure 4. 2 Histogram of Piloting Test Scores

In addition, I also looked at the normal Q-Q plot of the pilot test scores (see Figure 4.3). It shows that the dots were along the line despite two outliers. This means that there was an approximate distribution.

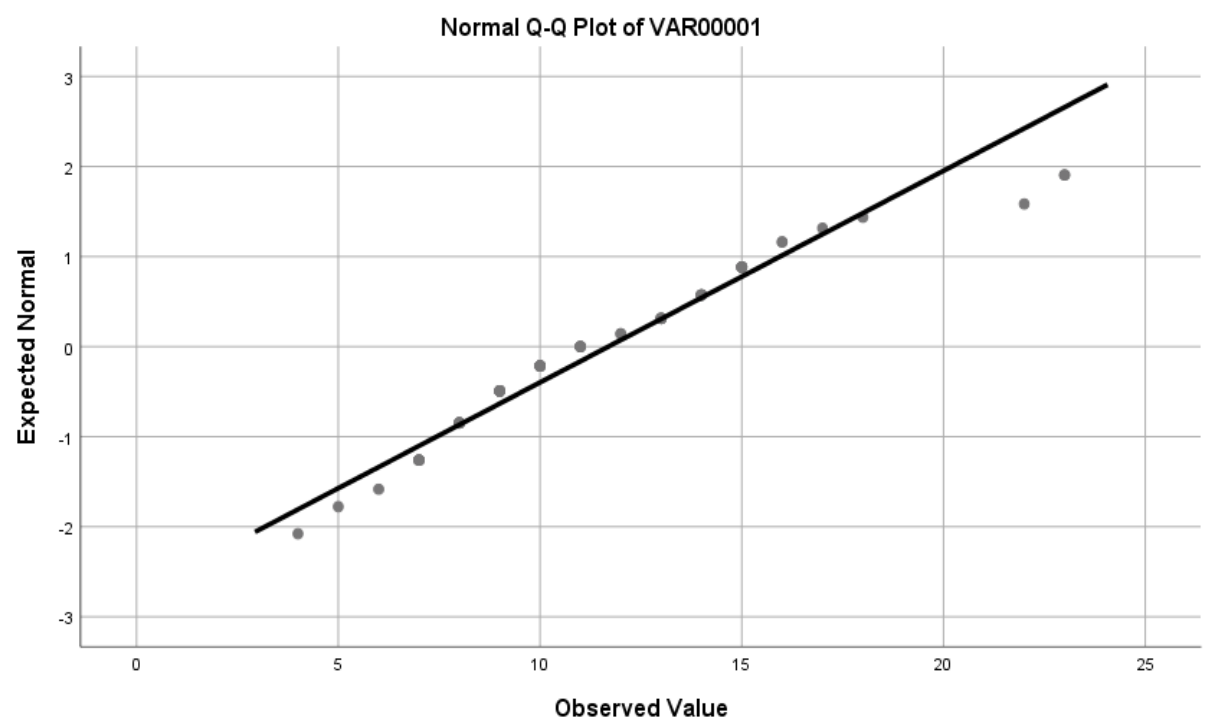

Figure 4. 3 Normal Q-Q Plot

In terms of the boxplot, the analysis shows that the pilot test scores were approximately normally distributed (see Figure 4.4). In this respect, most pilot participants scored between 9 and 14, except participants 41 and 47 who scored 23. This happens in classroom-based research because it was impossible to randomly select pilot 
participants who had the same proficiency level. However, the analysis suggested that the test is good because most pilot participants, despite different proficiency level, scored similarly (between 9 and 14). Since this test was approximately normally distributed, it was not necessary to re-examine the test items and the test reliability was reassured.

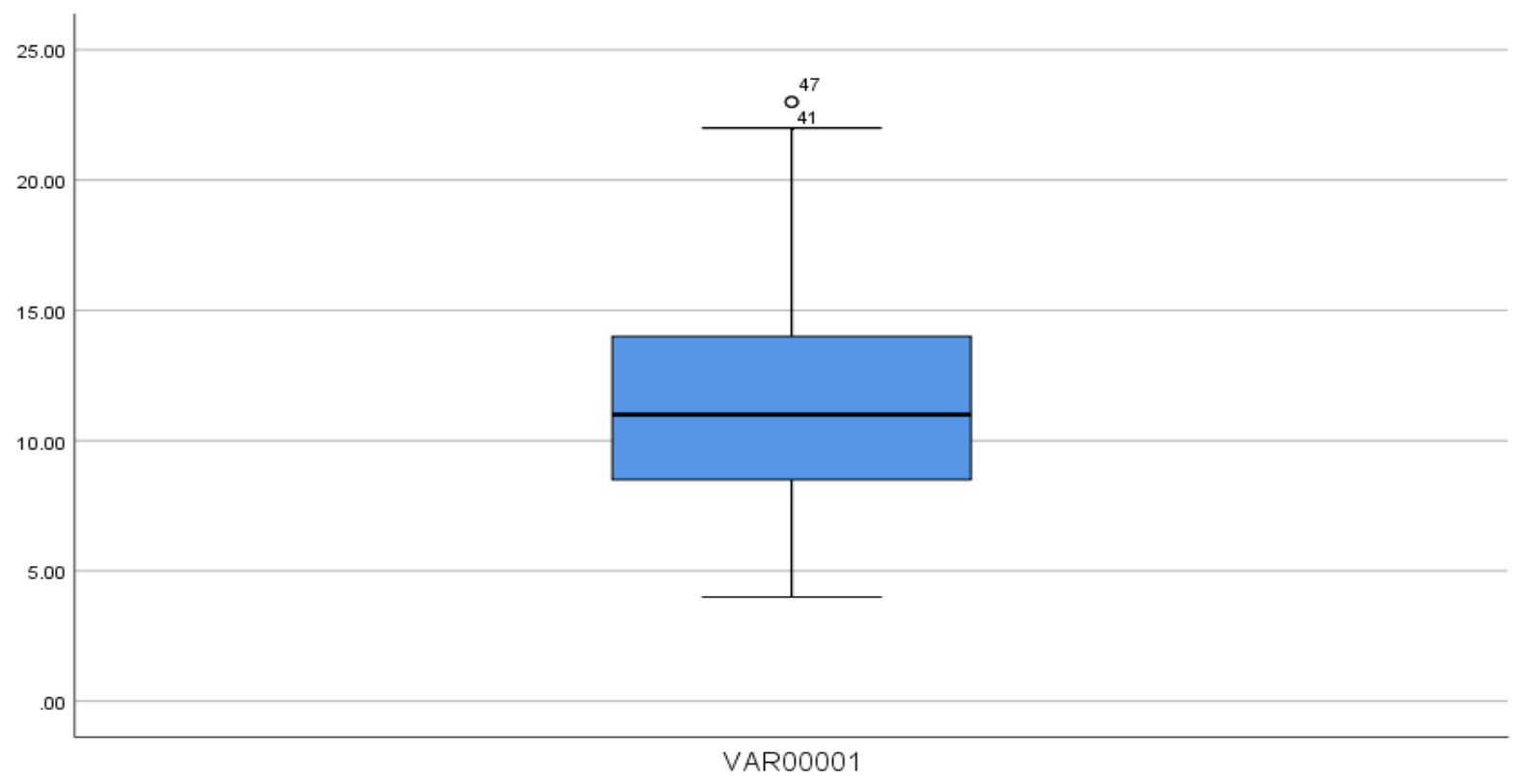

Figure 4. 4 Boxplot of Piloting Test Scores

The mean score ( $M=11.69$ out of 34$)$ of the test revealed that it was quite challenging for the participants. This reflects the results of the Lextutor analysis indicated above. This, however, did not pose any internal threat to the reliability of the text. To minimize the effects of the pilot test on the pre-and post-test, the results were not revealed to the participants.

\subsubsection{Direct classroom observation}

As indicated in Table 4.8, direct observations were also conducted with the two classes. The underlying reasons for utilizing observation were, as pointed out earlier, because it:

- enables me to experience the actual learning interaction and engagement of the students in the implementation and comparison classes; 
- is an inductive way of obtaining data;

- helps me explore things that might be omitted in interview or testing; and

- allows me to access participants' values and personal knowledge in actual classroom interaction (Cohen, Manion, \& Marrison, 2011).

To ensure the quality of observation, I adopted three techniques (Borich, 2011) for direct classroom observations: an observation protocol, audio recording devices, and field notes. The observation protocol was designed to focus on important aspects of student engagement and interaction in relation to the research questions (see Appendix 7). It included important elements of the eight cultural forces (Ritchhart, 2015) and some reading principles discussed in the literature chapter (Grabe, 2009; Hudson, 2007). Audio-recording devices were used to support the field notes in case important information was missed. Field notes are important for data collection - they are a means of collecting data. I wrote the field notes up as soon as possible after observation as this provided "fresher and more detailed recollections" (Emerson, Fretz, \& Shaw, 2011, p. 40) of the data collected. This was also used for classroom observation notes in phase 1. All observations were transcribed for further analysis right after the observation was done (see Appendix 13: Sample)

\subsubsection{Focus group interview}

As pointed out in section 3.4.2, focus group interviews were conducted to investigate pre-service teachers' perceptions of learning reading. Focus group interview is sometimes called group discussion, group interview, or focus group (Cohen et al., 2007; Krueger \& Casey, 2009). It refers to a number of people forming a group to discuss particular problems, issues, or phenomena under research. It focuses on "communication between research participants in order to generate data" (Kitzinger, 1995, p. 299). This means that focus group interviews do not involve the researcher asking each participant to respond to a question. Instead, it focuses on encouraging participants to interact, talk, and share ideas with one another about the issues of interest (Kitzinger, 1995). Although there is no specific size for a focus group interview, Bloor, Frankland, Thomas, Robson, and Stewart (2001) suggest that the maximum size for focus group discussion ranges from four to eight. In addition, literature suggests that the adequate number of focus 
groups to reach data saturation is three to six (Acocella, 2012). A focus group interview can be "highly structured, semi-structured, or unstructured" (Punch, 2009, p. 147). In my research, the semi-structured focus group was used as a guide (see Appendix 8). This allowed me to follow a set of questions while maintaining the nature of the focus group during the group discussion (Creswell, 1994; Patton, 1990).

Using the focus group interview has the following advantages. First, a focus group interview encourages participation from participants who are reluctant to share ideas in a one-on-one interview. Second, a focus group interview helps participants uncover, justify, and clarify their ideas in ways that are unlikely to be achieved in one-on-one interviews. Third, it allows the researcher to experience different forms of communication used by participants in daily interactions. Through this, I was able to understand the dynamic nature of interaction in a focus group discussion because participants' perceptions or attitudes are not entirely encapsulated in reasoned responses to direct questions but in natural interactions (Kitzinger, 1995).

Despite its advantages, a focus group interview has limitations, which should be taken into consideration when adopting (Patton, 1990). Literature suggests that a focus group interview might prevent individual members whose perspectives are different from expressing them (Cohen et al., 2011). As a result, important pieces of data might be omitted. To minimize this, I focused on management and facilitating skills essential for effective focus group discussion and participation (Krueger \& Casey, 2009).

To ensure a smooth and effective focus group discussion, I reserved a quiet room at the TEP. As a focus group moderator, I set up recording devices, arranged a round table and seats for each participant, prepared name tags, and provided some water for them (see Figure 4.5). When participants arrived, I offered them water prior to the commencement of the interview. This created a relaxing and friendly environment. In addition, to facilitate smooth and efficient interaction, I followed Krueger and Casey's (2009) suggestions and standard introduction. Specifically, I first welcomed the participants, 
introduced myself and provided additional reasons why they were invited to participate in the interviews. Second, I briefly re-introduced an overview of my research to them and assured them that the results of the discussion would be used for the purpose of my research only. Third, I explained some ground rules by pointing out there were no right or wrong answers; only different ideas and sharing. The participants were also informed that recording devices were used to support my field notes, rules for mobile phones, and other relevant issues were also made clear to the participants. This allowed me to establish a friendly atmosphere with the participants so they would feel more comfortable sharing their insights and experiences of the issues under investigation (Krueger \& Casey, 2009).

Once all participants understood the processes, group discussion commenced. The discussion was conducted in Lao, the participants' native language. This was to ensure that they were able to provide insights, experiences, and perceptions about learning reading adequately. This, however, did not mean that they could not use English. All focus group interviews were transcribed and translated into English (see Appendix 15: Sample). Table 4.10 summarizes the focus group interviews.

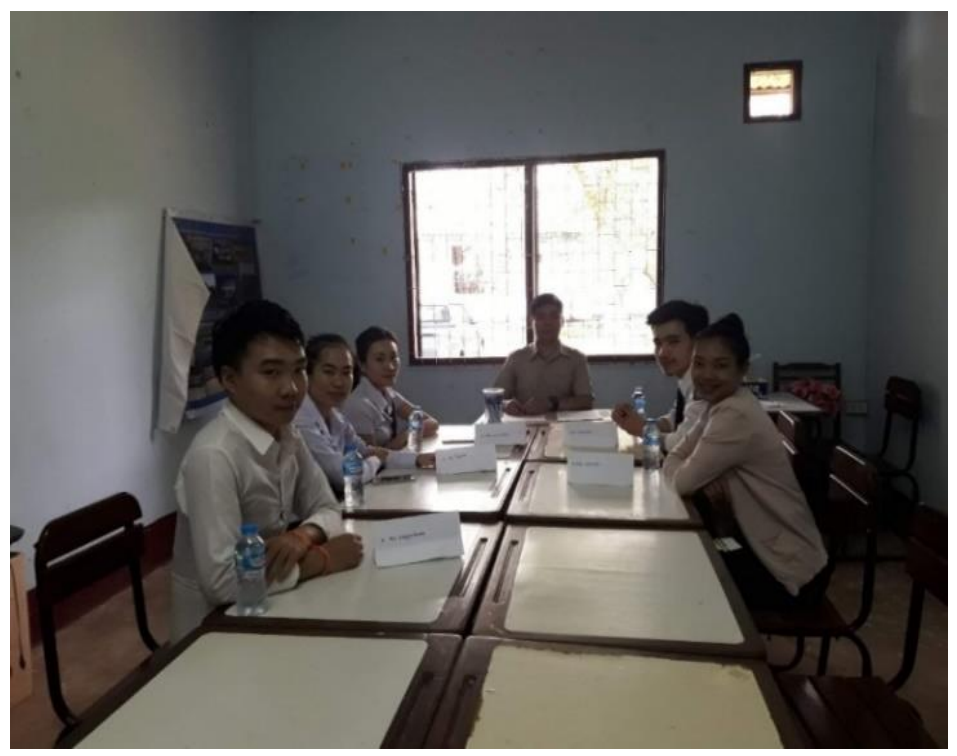

Figure 4. 5 Focus Group Interview 2 (June 27 ${ }^{\text {th }}, 2018$ ) 
Table 4. 10 Focus Group Summary

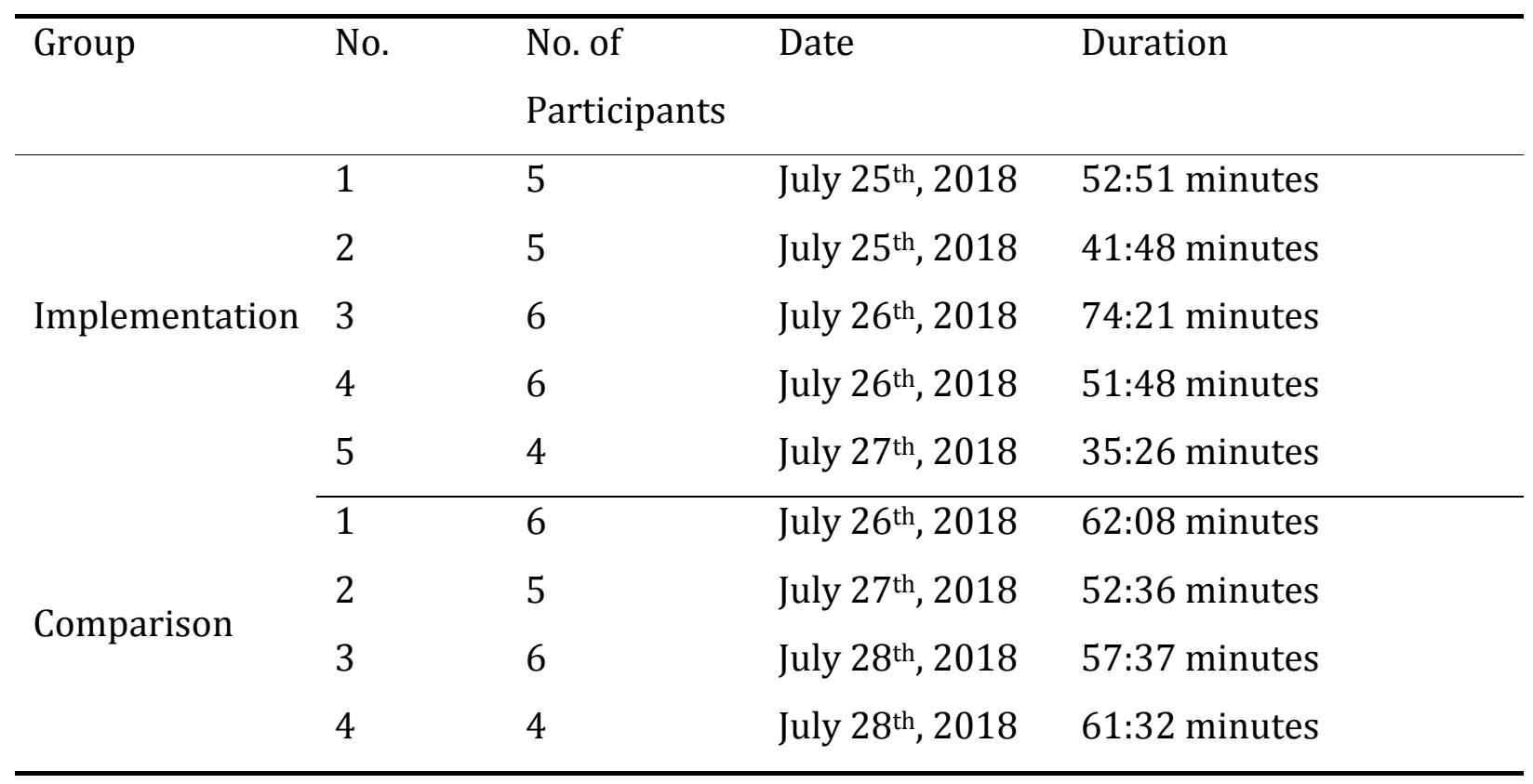

When transcribing the focus group interviews, the participants were labeled P1, P2, P3, and so forth. In this regard, each P number refers to a particular participant who took part in the group discussion. The underlying reason for using this was to help the researcher or reader of this thesis distinguish each participant easily in each group as this form of interview is dynamic. In addition, the assignment of the $\mathrm{P}$ code here was to protect the participant identity (ethical considerations) so that they could not be identified. Through this technique, I was able to analyze each focus group participant's insights or perceptions regarding the issues of interest in a systematic and easy manner while considering ethical issues.

\subsubsection{Pre-post perception survey}

A pre-post perception survey (see Appendix 9) was also administered to both groups to compare their perceptions of learning reading before and after the implementation. The items were adapted from an existing questionnaire of beliefs about language learning because of their relevance to the issue under investigation (Horwitz, 1988). To ensure respondents' clear understanding, the survey was translated into the participants' L1. I used the same process as stated in section 4.2.3.3 for ensuring translation accuracy. Through this process, minor adjustments were made. 


\subsubsection{Pilot study for phase 2}

As stated in phase 1's methodology, the main purpose of piloting was to collect feedback about research instruments and to fine-tune them prior to the main study (Dörnyei \& Taguchi, 2010). Pilot studies were conducted with the students who had similar profiles to the participants of the main study (Baker, 1988). In this phase, all research instruments: reading test, focus group interview, CoT reading lesson, and pre-post perception were piloted. The piloting included:

- one focus group interview was conducted on December $12^{\text {th }}, 2017$ with a group of five pre-service teachers in the programme. This allowed me to modify and revise my research tools before the main investigation. To ensure the pilot's effectiveness and smooth flow, I followed group discussion procedures discussed in section 4.3.4.3;

- two CoT-based reading lessons were piloted with a group of 35 students on December 29th, 2017 (one conducted by the researcher and the other by the participating teacher);

- one pre-post perception survey questionnaire was piloted with a group of 65 students at the programme; and

- one reading test was piloted as stated in section 4.3.4.1 above.

Through piloting, I learned several important and useful things. In terms of the focus group interviews, I learned whether the interview protocol was intended to seek answers to the issue under investigation. Second, I learned that I had to combine some of the questions that had the same purposes so that participants did not have to repeat the answers. For instance, the original version states 'Do you think the reading activities promoted your engagement or participation? Why? Why not? And To what extent were you engaged in learning reading?' The combined version is 'Do you think the reading activities conducted in your reading class promoted engagement or participation? If yes, to what extent? If no, why?' Third, I learned that I sometimes needed to add an opinion phrase instead of asking a direct Yes/No question so that participants were encouraged to express their ideas concisely. For instance, the original version states 'Have your critical reading skills improved as a result of the reading class? Have your reading skills or 
strategies developed or improved as a result of the reading class? Why? Why not?' The additional version is 'Do you think your critical reading skills have improved as a result of the reading class? Do you think your reading skills or strategies have developed or improved as a result of the reading class?' Fourth, I learned that I had to explain some phrases to the participants to ensure they captured the intended meaning although the interview was conducted in the native language of the participants. For instance, when I asked them about 'critical reading skills', most of the pilot participants did not understand what it meant to read critically. This might have been due to a lack of exposure to such ideas and focus in classroom practices. To address this, I had to explain and give an example to ensure that they captured the intended meaning of the phrase (e.g. critical reading refers to the act of analyzing, evaluating, judging, and thinking about the claim or idea to draw a conclusion) when interacting with the text. Finally, I learned that I had to dig deeper into ideas of the participants when they provided surface answers by further asking the 'Why'. This allowed me to gain deeper insights into the issue under study.

In order to ensure effective implementation, I piloted a CoT-based reading lesson (see Figure 4.6). The main purpose of the pilot was to detect what worked or did not work well so that an improvement could be made prior to the main study. To ensure the intervention class teacher understood of the CoT-based reading lesson and instruction presentation, I invited the participating teacher to observe me conducting a CoT-based reading lesson. The piloted lesson lasted 90 minutes as a normal teaching schedule indicated in the curriculum.

Through piloting, I learned important and useful lessons. Firstly, I had to combine some of the activities to make the lesson more cohesive and smoother. For instance, the original procedure/version of the lesson states ' $T$ asks students to share ideas about the accessories with the whole class by having them follow the guided questions. The revised version is 'Students exchange ideas by asking, clarifying, and explaining the meaning of the concept words written down on the Chalk Talk papers.' Secondly, I had to be flexible in 
terms of time allocation to each activity due to the dynamic nature of the classroom environment and student interactions. For instance, the lesson plan indicates that ' 30 minutes is allocated to a pre-reading activity'. In the actual classroom practice, however, the learning activity required much more time than stated because the students were not able to complete the activity within the given time. Finally, I learned that I had to skip some comprehension activities in the textbook by encouraging students to work from home because these activities focus students on discrete language skills (e.g., grammar and vocabulary). After piloting, I had a discussion with the participating teacher regarding the implementation of, and flexibility in, presenting the CoT-based lessons. Through discussing, I learned that the teacher was clear and understood about the CoTbased reading lesson and implementation.

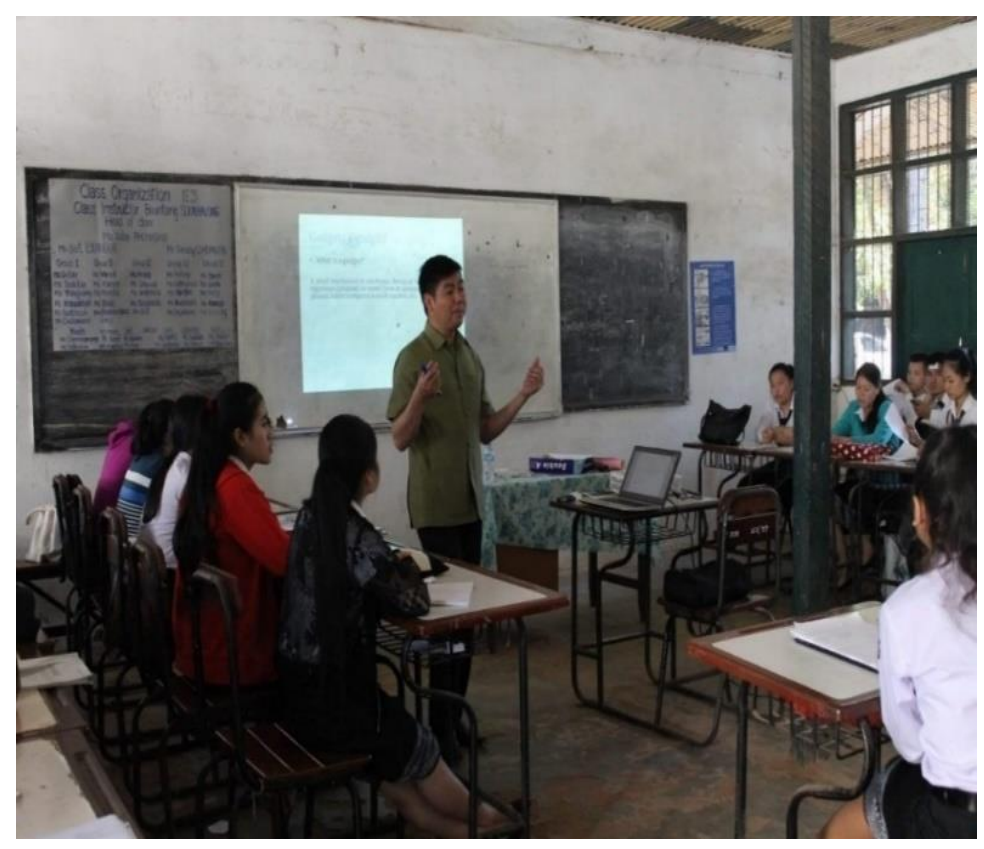

Figure 4. 6 A CoT-Based Reading Lesson Piloting (December 29th, 2017)

To ensure that the participating teacher was clear and able to conduct the lesson, I invited him to pilot a CoT-based reading lesson on the same day (December 29th, 2017) with a group of students who had similar characteristics to the participants of the main study (see Figure 4.7). Through piloting and discussing with the teacher, we (the researcher and teacher) learned that the delivery went well according to the lesson plan procedures. The teacher understood the steps of the lesson although there was a need 
for flexibility in terms of time management. In addition, through my observation of the participating teacher's pilot, I noticed that students were able to follow and engage in learning activities well although this was new to them.

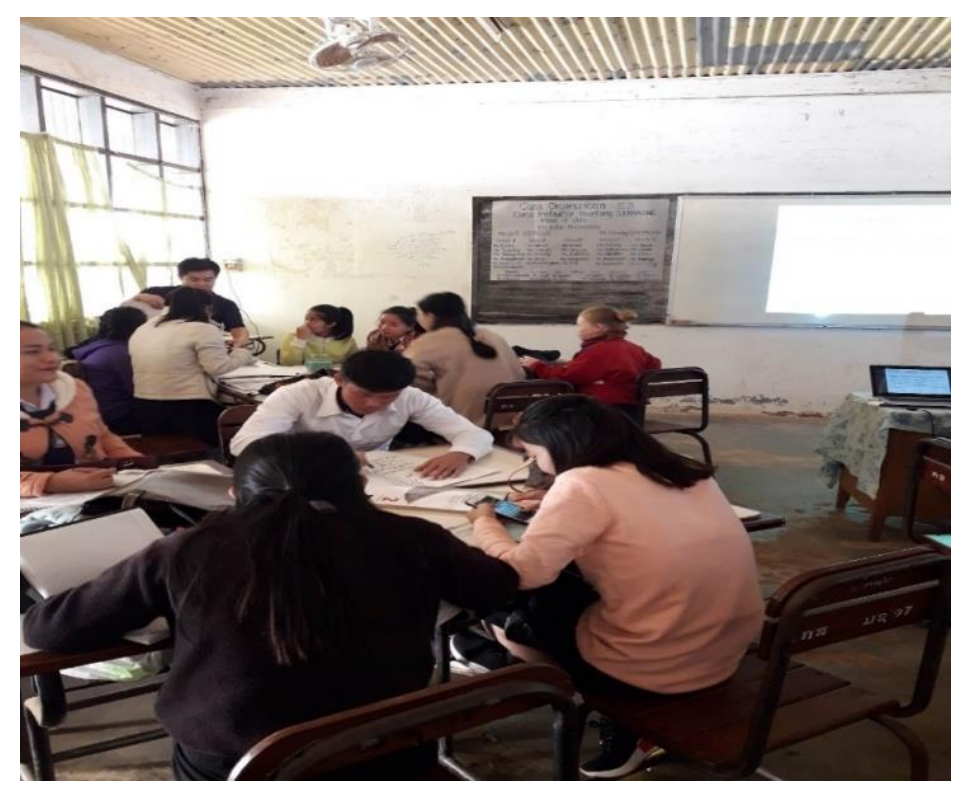

\section{Figure 4. 7 A CoT-Base Reading Lesson Piloting (December 29th, 2017)}

I piloted the pre-post survey with a group of 65 students in the programme. The pilot study was intended to examine the survey reliability. The acceptable reliability through the result of Cronbach's alpha coefficient should be above 0.7 (Woodrow, 2014). This, however, depends on the number of items and sample size. The pilot data were analyzed using SPSS version 25 and the results of Cronbach's alpha was .875, indicating that the survey was reliable and measured the same construct (see Table 4.11).

Table 4. 11 Reliability Analysis Results

\begin{tabular}{ccc}
\hline Cronbach's Alpha & Cronbach's Alpha Based on Standardized Items & No. of Items \\
\hline .875 & .875 & 31 \\
\hline
\end{tabular}

\subsubsection{Participating reading lecturers (teachers)}

One important aspect of the experimental design that should be taken into consideration is the role of the researcher in the research (Barber, 1973; Creswell \& Clark, 2007; 
Mackey \& Gass, 2005). This might lead to subjectivity or bias in the research findings. To minimize this, two reading lecturers (known as teachers in the Lao EFL context) were invited to participate in this study. As Barber (1973) points out, research studies would be less biased if the implementer and the researcher are not the same person. To ensure the lecturers' homogeneity in terms of content and pedagogical knowledge, I took the following characteristics into consideration when recruiting them (see Table 4.12). First, they must have a master's degree in teaching English. Second, they must have served as English instructors on the TEP for more than five years. Finally, they must have taught English Reading Subject for at least two years. Based on their profiles, it was assumed that these two lecturers had similar characteristics in terms of teaching experience and qualifications. They were invited to participate in this phase, following the information sheets and informed consent forms given to them. The implementation class lecturer (A) was also invited to participate in the interview to seek his view of the CoT implementation in teaching reading (see Appendix 12) and the interview was transcribed for analysis (see Appendix 14: Sample).

Table 4. 12 Reading Lecturers' Profiles

\begin{tabular}{clccc}
\hline Code & Gender & Teaching Experience & $\begin{array}{c}\text { Reading teaching } \\
\text { Experience }\end{array}$ & Degree \\
\hline $\mathrm{A}$ & Male & 10 years & More than 3 years & M.A TEFL \\
$\mathrm{B}$ & Female & 14 years & More than 4 years & M.A TEFL \\
\hline
\end{tabular}

\subsubsection{Reading textbook}

Textbooks play an important role in education. However, there has been an ongoing debate regarding the necessity of using textbooks and their effects on students' achievement (Menkabu \& Harwood, 2014). In some contexts, the textbook serves as the main source of language input. In other situations, the textbook might be used as a supplementary teaching material. There are some advantages and disadvantages (Richards, 2001) of using a textbook. In terms of merit, a textbook can:

- provide a syllabus for a programme;

- help standardize instruction; 
- provide a variety of learning sources;

- save teachers' time;

- support non-native teachers; and

- be attractive to both teachers and students.

However, a textbook might:

- not contain authentic language (fail to represent real life situations);

- fail to reflect students' needs;

- limit teachers' skills in developing innovation; and

- be costly for both teachers and students in some contexts.

The reading textbook (Essential Reading 2) used in the Lao EFL pre-service TEP is a commercial publication (McAvoy, 2008). For this reason, some of the content is not locally meaningful and many of the passages are not contextualized; there is "a lack of cultural relevance of much of the content" (Macalister, 2016a, p. 59). In addition, many of the learning activities are not specifically intended to engage students in an in-depth exploration of the main gist of the text. There are 12 chapters in this material, focusing on a wide range of topics (i. e., Culture Shock, Urban Life, and Sports) and each chapter has the same pattern and sequence of learning activities. The intended audience of the textbook is the general lower to upper intermediate language learner.

To better understand this, it is worth evaluating part of the material so that adaptation can be made. Chapter 11 (Sports: Past and Present) was taken as an illustrative example. The reading texts and learning activities designed for the three stages of reading instruction (Grabe, 2009; Hudson, 2007) were evaluated by comparing them with the level of thinking indicated in the CoT principles (Ritchhart, 2015) and with Bloom's taxonomy framework discussed in chapter 3.

In terms of the pre-reading activities, there is a lack of attempts and meaningful activities to activate students' prior knowledge of the topic (see Appendix 10). The first activity, sentence completion, focuses students on learning grammatical knowledge instead of activating students' background knowledge of the topic to be read. The second activity, 
word elimination, focuses on vocabulary knowledge rather than encouraging students to discuss issues related to the topic being learned. The two pre-reading activities fail to reflect the routines for Introducing and Exploring ideas discussed in section 3.4.5 of the literature chapter (Ritchhart, 2015). In addition, when compared with Bloom's taxonomy, the two activities could be categorized as the first level, Knowledge, since they focus on factual information (Bloom et al., 1956).

In terms of the while-and post-reading stages, four reading comprehension activities are included, aiming to develop students' reading comprehension. The first comprehension activity, matching a heading with each of the newspaper articles, focuses on interpreting the main ideas of the short articles. This activity is meaningful as it reflects the second category of thinking routines discussed in the CoT theories, requiring students to identify information and key ideas (Ritchhart, 2015). In comparing with Bloom's taxonomy, the activity falls into the second level, Comprehension, as it focuses students on meaning construction. In regard to comprehension activities 2, 3 and 4, the main goal of these is to focus students' attention on discrete language features. For instance, in line 3 of the reading text, another way of saying, 'to get stronger' is...This indicates that the main purpose of learning reading is just a matter of paying attention to bottom-up processes (e.g., vocabulary and grammar). Yet this is insufficient for the development of strategic and better readers. Therefore, it is necessary to develop these skills in students and this might be achieved through the implementation of a CoT as it requires innovation in terms of instructional pedagogy.

\subsubsection{Research variables}

\subsubsection{Independent variables}

Independent variables are viewed as factors or predication variables. The independent variables of this explanatory quasi-experimental design are the CoT and traditional teaching methods. 


\subsubsection{Dependent variables}

The dependent variables of this research are the effects (expected outcomes) of the independent variables (Mackey, 2016; Punch, 2009), including pre-service teachers':

- reading comprehension;

- learning engagement; and

- perceptions of learning reading.

In this research, dependent variable bullets one and three above were used to test the hypotheses since they involved quantitative data (test scores and questionnaire). The dependent variable point two above could not be tested using a statistical package because it involves qualitative data.

\subsubsection{Research hypotheses}

Hypotheses of research refer to the expected results of the intervention, the independent variables (Punch, 2009). Thus, the research-hypotheses are shaped and informed by the research questions and data collection methods. To test this, two null research hypotheses that involved quantitative data were formulated:

$\mathbf{H}_{\mathbf{0 1}}$ : Reading comprehension will not be significantly different for pre-service teachers with a CoT-based instruction compared to those without it.

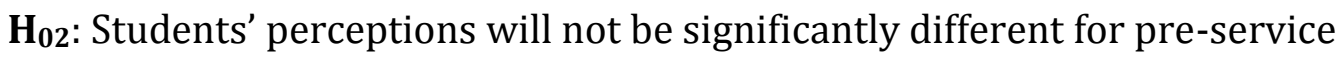
teachers with a CoT-based instruction from those without it.

These are not expected results of the CoT implementation. However, positive learning outcomes are assumed to happen for pre-service teachers who are exposed to a CoTbased learning in order to reject the null hypotheses.

\subsubsection{Threats to the research}

The influence of extraneous variables is less powerful in an EFL setting than an ESL context due to the amount of the target language input to which participants are exposed out-of-class (Mackey \& Gass, 2005; Seliger \& Shohamy, 1989). Therefore, the design of this research serves to mitigate the effects of these variables on the research. In addition, the main threat to the internal validity is the possibility of group differences on the post- 
test due to pre-existing differences of the intact classes, rather than the effects of the implementation (Creswell \& Clark, 2007). To reduce this, independent sample $t$ tests were employed to ensure class comparability in terms of reading proficiency. This helps mitigate the threats on this research so that its reliability was assured (Woodrow, 2014).

\subsubsection{Implementation delivery and accountability}

To ensure an effective and smooth delivery of the CoT implementation, two briefing sessions of 90 minutes each concerning the CoT were conducted for the implementation class teacher (December 12th, 20017 ). This allowed the teacher to understand the underlying theories and principles of the CoT. Furthermore, issues related to the implementation were taken into consideration after discussing with the instructor to ensure implementation effectiveness. In addition, I collaborated closely with the implementation class teacher in planning and implementing the lessons during this process (see Appendix 11: Sample Lesson plan). This allowed me to hear the instructor's voice in relation to the implementation.

As indicated earlier, this phase was conducted in the second semester (February to July 2018) of the academic year 2018. It lasted 16 weeks, with the first week for orientation or pre-intervention, thirteen weeks (2-14) for the teaching intervention, and the last two weeks (15-16) for the post-intervention: post-test, delayed-test, focus group interviews, and survey administration (see Figure 4.8). Two ninety-minute session lessons per week were conducted as indicated in the curriculum. In total, 26 CoT-based reading lessons were implemented. 


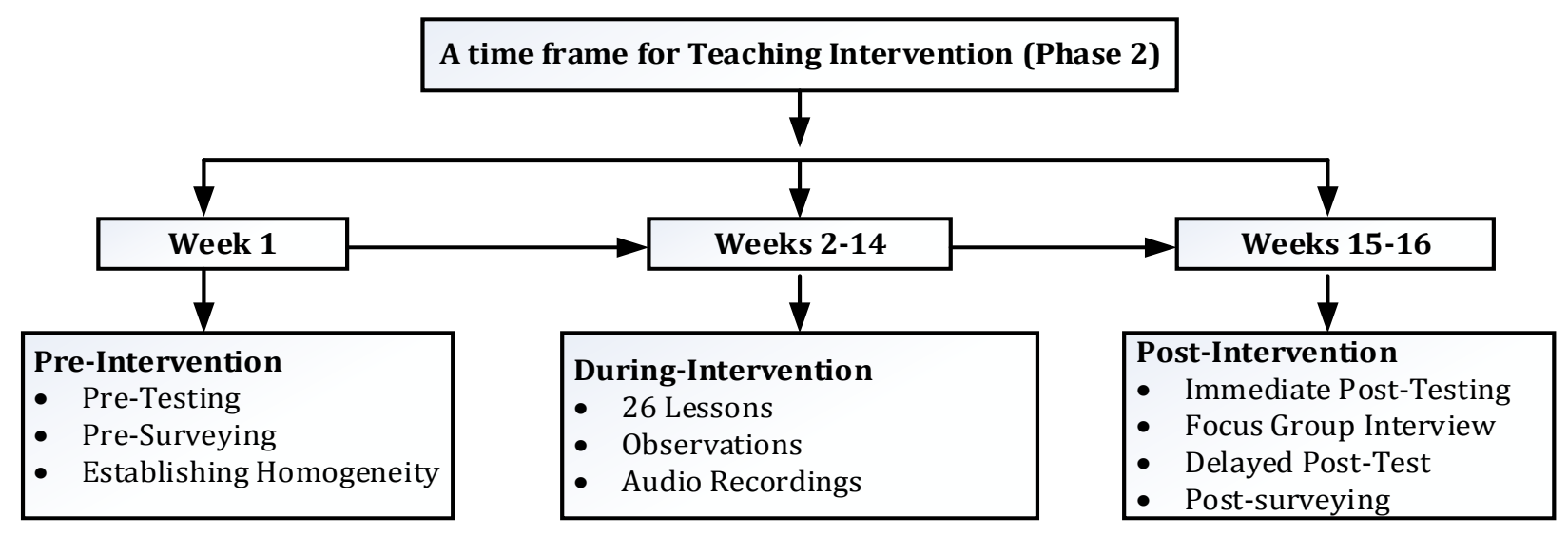

Figure 4. 8 A Time Frame for Teaching Intervention

\subsubsection{Methods for the CoT integration}

To conduct the CoT-based reading instruction, several thinking routines (activities) were integrated into the three stages of reading instruction: pre-reading, while reading, and post-reading (Grabe, 2009; Ritchhart, 2015). Thinking routines for the pre-reading stage aim to activate students' prior knowledge, draw their attention to, and help create mental pictures of the topic to be read. Thinking routines for the while-reading stage are intended to assist students to construct meaning and develop critical reading skills and strategies. Through this, students are encouraged to explore ideas, identify patterns of the text, justify the key message, analyze and evaluate the author's intended purpose represented in the text (Grabe \& Stoller, 2011; Ritchhart et al., 2011). Thinking routines for the post-reading stage aim to reinforce comprehension by having students answer meaningful comprehension questions and make connections from what they have read to their existing experiences. Through regular exposure to a CoT-based reading learning, students are consistently encouraged to think critically and meaningfully about the topic. As Ritchhart et al. (2011) state, deep and meaningful learning is:

- a result of thinking;

- as much a collective endeavor as it is an individual process;

- provisional, incremental, and evolving in nature;

- continual, focusing on uncovering the complexity of ideas; and 
- an active process that entails getting personally involved.

\subsection{Data analysis}

Although this research has two phases, data analysis is confined and discussed in the same section. In this respect, I will address how qualitative data were analyzed as the quantitative data analysis was stated in phase 1.

\subsubsection{Qualitative data analysis}

As mentioned earlier, a thematic and content analysis was used to analyze the qualitative data. This enabled me to reduce, organize, code, and summarize a large volume of data inductively (Ellis \& Barkhuizen, 2005; Krippendorff, 2004; Mackey \& Gass, 2005). It also enabled me to examine the emerging themes and patterns according to the literature review (Drisko \& Maschi, 2016). Since language teacher education research is dynamic, I was mainly inductive in coding the research data in order to examine themes and seek answers pertinent to the research questions (Mackey, 2016; Mackey \& Gass, 2005). However, this did not mean that new insights and themes that were not derived from the research questions or literature review were not taken into consideration.

Thematic analysis is "a method for identifying, analyzing, and interpreting patterns of meaning (themes) within qualitative data" (Clarke \& Braun, 2017, p. 297). By employing this, I was able to summarize, identify and interpret significant features of the data directed by the research questions in relation to the issues being looked at (Clarke \& Braun, 2017; Nowell et al., 2017). As Maguire and Delahunt (2017, p. 335) note, "a good thematic analysis interprets and makes sense of the data". In brief, this analysis allowed me to interpret and explain the intended meaning of what was said and shared by the participants that reflected what they experienced.

There is no perfect method in analyzing qualitative data in any type of research. However, to draw on its strengths and lessen its weaknesses, I followed Creswell and Clark's (2007) procedures regarding five stages of the qualitative data analysis (see Table 4.13). First, I prepared data, data preparation, by converting the raw data into a 
form crucial for further analysis. In this respect, I listened to the recordings several times before transcribing to check my understanding (Creswell, 2013). This allowed me to identify content and emerging themes related to the research questions. In terms of the field notes, I looked closely for emerging themes or patterns related to the issues by rechecking the transcriptions and field notes for accuracy and correctness. Second, I explored data, data exploration, by closely examining and reading through them several times to develop a general understanding of the database (Creswell \& Clark, 2007). Further, I recorded my initial thoughts by writing short memos in the margins of the transcripts. "The memos are typically short phrases or ideas written in the margins of transcripts or field notes" (Creswell \& Clark, 2007, p. 131). This allowed me to form a broader set of data (i.e., themes or codes).

Third, I analyzed the data, data analysis, in relation to the research questions and literature review. I began this by coding the data, dividing the text into small units and assigning a label to each unit (Creswell \& Clark, 2007). In this respect, I grouped evidence from the data into codes before categorizing them into broader themes. As Creswell and Clark (2007) note, "coding is the process of grouping evidence and labeling ideas so that they reflect increasingly broader perspectives" (p. 132). Fourth, I presented the results, presentation, in a summary form and statement. In this respect, results were presented in terms of the themes or patterns that emerged from the analysis. When presenting the results, I kept in mind that generating a convincing discussion from the emerging themes or categories was important (Creswell \& Clark, 2007; Ivankova \& Creswell, 2009). To achieve this, I followed Creswell and Clark's (2007) strategies in presenting convincing results. These include conveying subthemes or subcategories, citing specific quotes, and utilizing different sources of data and literature to cite multiple items of evidence. Finally, I validated the data, data validation, to ensure that the results provided were accurate, reliable, and credible. I followed Creswell and Clark's (2007) strategies for data validation through data triangulation. Specifically, the results of this research were triangulated with several other sources (e.g. interviews, observations, recordings, survey, tests, and field notes) to ensure accuracy and 
reliability. This allowed me to identify and summarize emerging themes and results objectively (Creswell \& Clark, 2007).

Table 4. 13 Qualitative Analysis Procedures

\begin{tabular}{cl}
\hline \multicolumn{1}{c}{ Procedures } & \multicolumn{1}{c}{ Description } \\
\hline 1. Data preparation & $\begin{array}{l}\text { Organizing documents and all data, transcribing, and } \\
\text { preparing the data for a further analysis. }\end{array}$ \\
2. Data exploration & $\begin{array}{l}\text { Reviewing data through transcribing, writing memos, and } \\
\text { organizing themes, codes, or patterns. } \\
\text { Coding data, assigning labels to codes or patterns, grouping } \\
\text { codes into themes, categories, interrelating themes to small } \\
\text { 3. Data Analysis }\end{array}$ \\
& $\begin{array}{l}\text { Presenting findings or discussing of themes or categories, } \\
\text { including visual models, figures, and tables emerged from } \\
\text { data analysis. } \\
\text { Data triangulation. }\end{array}$ \\
& \\
\hline
\end{tabular}

\subsection{The embedded experimental design between the phases}

An embedded design (see Figure 4.9) is defined as "a mixed-methods design in which one data set provides a supportive, secondary role in a study based primarily on the other data types" (Creswell, 2007, p. 67). The adoption of this design was driven by the research questions, data collection methods, data analysis, and procedures of the research (Creswell \& Clark, 2007). As Creswell and Clark (2007) assert, "the premises of this design are that a single data set is not sufficient, that different questions need to be answered, and that each type of question requires different types of data" (p. 67). This design is particularly beneficial and appropriate when mixing qualitative data with quantitative data (Creswell \& Clark, 2007). This research adopted what Creswell and Clark (2007, p. 68) call "the Embedded Experimental Model." 
In this design, qualitative data plus a small element of quantitative data collected before the implementation, phase 1 , was used to lay the foundation for phase 2 . The collection of qualitative data (e.g., observations) during the implementation aimed to investigate how students engage in learning reading. Finally, the use of a qualitative method (e.g., focus group) after the implementation was to find out students' perceptions of learning reading in two different instructional methods (Creswell \& Clark, 2007). The results were then integrated and discussed based on literature review and empirical studies.

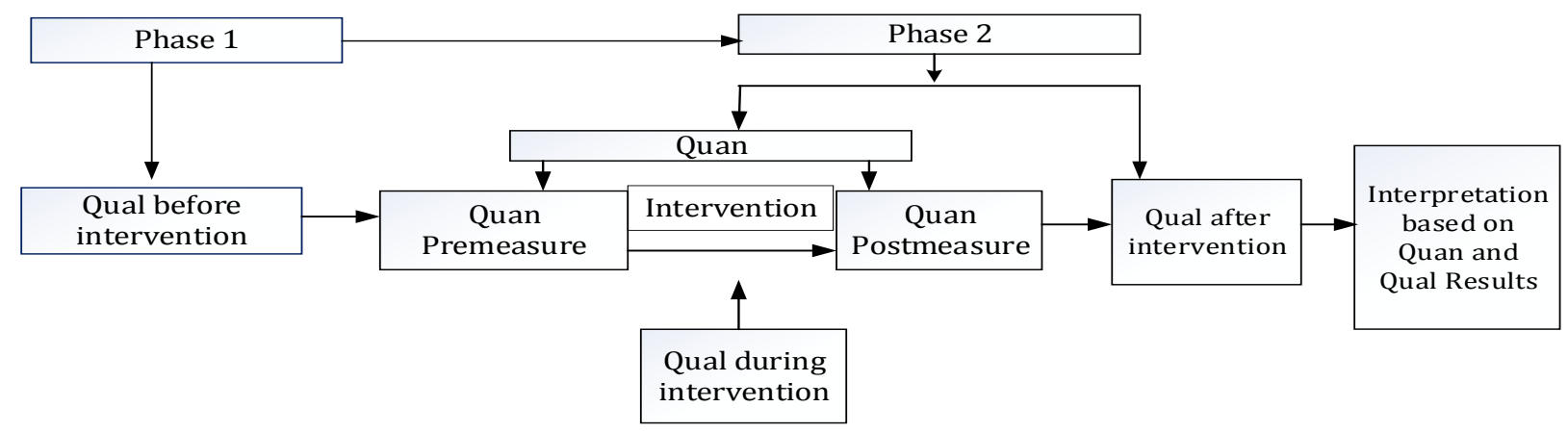

Figure 4. 9 An Embedded Experimental Design

\subsection{Trustworthiness}

When addressing research trustworthiness, it is critical to discuss the notion of reliability and validity (Golafshani, 2003). The terms reliability and validity are used to mean different things in quantitative and qualitative paradigms (Golafshani, 2003). In quantitative research, reliability refers to "replicability or repeatability of results or observations" (Golafshani, 2003, p. 598). According to Woodrow (2014), "reliability refers to the consistency of the results and how sure readers can be of the replicability of the research" (p. 25). In other words, similar results can be obtained if the study were carried out again in a similar context or circumstance. Validity is defined as "the appropriateness, correctness, and usefulness of the specific inferences researchers make based on data they collect" (Woodrow, 2014, p. 30). It concerns the extent to which research instruments allow the researcher to seek data to answer the research questions (Creswell, 1994; Golafshani, 2003). It is regarded as whether or not the instrument 
measures what it is supposed to measure. In this research, the construct validity of the reading test was established through a distinctive approach to validation suggested by Purpura, Brown, and Schoonen (2015), which is content-based evidence validity. Content-based evidence validity refers to the inclusion of knowledge, skills, and abilities that represent the content of language in the test (Purpura et al., 2015). To ensure the reading test validity, different types of comprehension questions were included, as stated in the reading test section.

In qualitative research, reliability is commonly referred to as credibility, conformability, consistency, dependability, and transferability (Golafshani, 2003). These terms define the quality of research. Good qualitative research has the purpose of "generating understanding" (Nordström, 2001, p. 551). In contrast, validity refers to the processes and intentions of particular research methodologies and projects. Although the term is not commonly employed in qualitative research, many qualitative methodologists have recognized its importance in helping measure and check the research quality (Creswell \& Miller, 2000; Golafshani, 2003). To ensure the trustworthiness of my research, multiple data sources (e.g., students, teachers, documents, etc.) and multiple data collection methods (e.g., observation, interview, focus group interviews, etc.) were employed for data generation and saturation (Woodrow, 2014). This data triangulation corroborates and improves the overall credibility, dependability, conformability, and transferability of the research (Lincoln \& Guba, 1985). The volume of data collected afforded greater credibility in interpreting and concluding the research findings. During data collection, a research journal was used as a means of keeping track of the many important aspects, situations, and components of the research I experienced in the fieldwork. This allowed me to reflect on my own journey and circumstance at different stages of my research (Punch, 2009).

\subsection{Ethical considerations}

In this study, various ethical issues were considered to ensure that the research participants' physical, emotional, and social health was protected (Woodrow, 2014). As Ivankova and Creswell $(2009$, p. 88) state, "ethical practices involve much more than 
merely following a set of static guidelines, such as those provided by professional associations." An ethical issue is something a researcher needs to be aware of and to take into consideration at all stages of her research journey. To ensure that my research participants were not exploited or harmed in anyway, I applied for human ethics and approval was given by the University Human Ethics Committee of VUW on the $30^{\text {th }}$ of May 2017 (see Appendix 19: approval number: 24391). Since the research location is the Lao EFL pre-service TEP, initial communication with the research participants was made following the approval. In addition, I started to recruit participants for the first phase as soon as I arrived in LPDR in November 2017. Once my research participants were identified and recruited, I requested an opportunity to meet them face-to-face to establish a good rapport with them so that would feel more comfortable providing data related to the issue under investigation. In addition, information sheets were given out and informed consent forms were sought from the participants on a voluntary basis (see Appendixes $17 \& 18$ ). This ensured that all participants were protected and not obliged to participate in the study.

Regarding the comparison group, I acknowledge that both the students and teacher missed the opportunity to be exposed to the CoT approach during the implementation. They were not, however, being denied any component of their usual teaching, and arguably the risk of compromised learning outcomes was greater for the intervention class, which was trying something new. In the event that the CoT approach was found to be effective, the implementation class students and teacher could share their experience of the CoT practices once this thesis was completed. In addition, conducting teaching methodology workshops for English teachers could also address this so that the other teachers can be informed.

\subsection{The researcher's position}

As an insider, it was not easy to constrain my influence on the participants with whom I worked during my data collection. An insider refers to "the member of a specified group and collectivity or occupant of a specified social status" (Merton, 1972, p. 21). I used to work and teach English in this context for more than 10 years. Having shared the 
learning and teaching experiences with the study participants positioned me in the role of the "insider" and as such offered me three main advantages, "easier entrée, a head start in knowing about the topic, and understanding nuanced reactions of participants" (Berger, 2015, pp. 222-223). However, my relationships with the participants had the potential to impact the research process. Therefore, it is important to reflect on my positionality during this process so that the influence can be mitigated.

First, I addressed my position with the participants regarding my research and motivations for collecting the data. As Bourke $(2014$, p. 7) points out, "addressing the issues of motivations with participants has the potential to foster greater openness between participants and the researcher". I shared with them my interest, motivation, and benefits in conducting this study. This was also to establish trust and be open to the participants so that they felt more comfortable sharing their insights and experiences of the issues with me. They expressed that being a lecturer myself, I was able to better understand and represent their experiences and struggles than a non-lecturer researcher.

Second, I assumed a number of different roles at the research location. As Mackey and Gass (2005) state, the role of the researcher is never that of simply collecting data but involves multiple roles that can influence how data is collected and interpreted and that can risk posing ethical dilemmas. Although my primary role was researcher, I was also invited to participate in both academic and extracurricular activities. I was party to workshops and academic meetings with the lecturers (see Figure 4.10). I was also invited to participate in several extracurricular activities, including being a master of ceremony for an English-speaking contest (see Figure 4.11). This allowed me to establish a good rapport and trust with the participants and observe many other factors that might have had important impacts on the development of pre-service teacher education in this context. In other words, I came to the office almost every day as a full-time-lecturer and planned a weekly schedule concerning observations, interviews, lesson planning, and other related data collection matters, allowing me to observe the types of activities 
undertaken by the teachers and students, to seek assistance and clarification relevant to my research, to share ideas, and to discuss issues related to English language teaching in general. I was also available to answer lecturers' questions or assist them informally if necessary.

In addition, to minimize my deeply held beliefs of the interpretation results, initially, I did not commit to only one system or issue under study. I, instead, considered the issues from different perspectives before drawing a conclusion. Second, I did not "see the world as an absolute unity" (Creswell, 2007, p. 13) when presenting the results of my study. I considered different approaches to collecting, corroborating, and analyzing data in order to obtain a comprehensive understanding of the issues from multiple perspectives. Third, I focused on what and how this research was conducted to remind myself of subjectivity (Cherryholmes, 1992; Murphy, 1990). Lastly, I kept in mind that research in language teacher education is always operated in "authentic, social, historical, political and other contexts" (Creswell, 2007, p. 23) as stated in chapter 2. Hence, I witnessed a dynamic relationship influencing classroom practices.

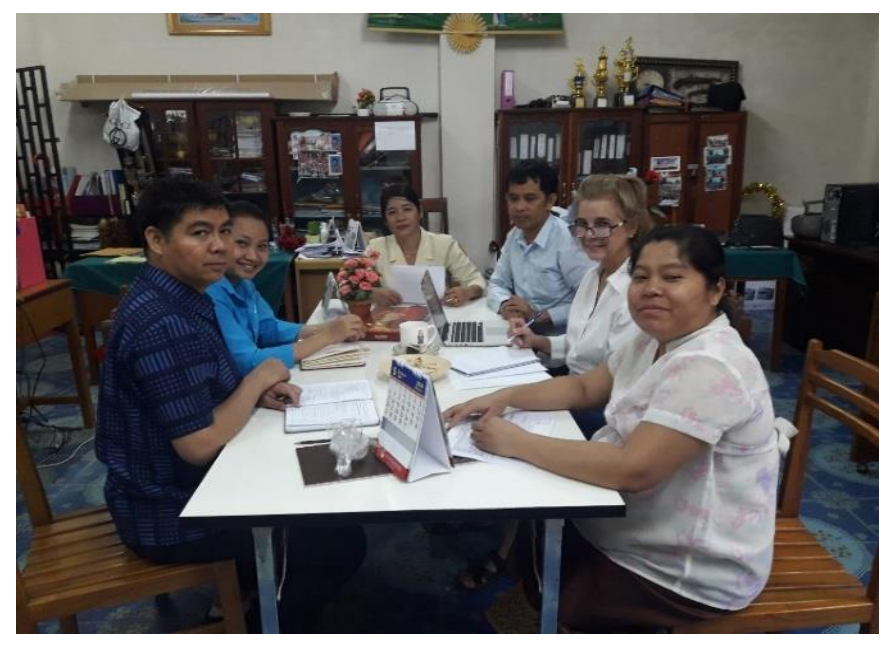

Figure 4. 10 Academic Workshop (April 7th 2018) 


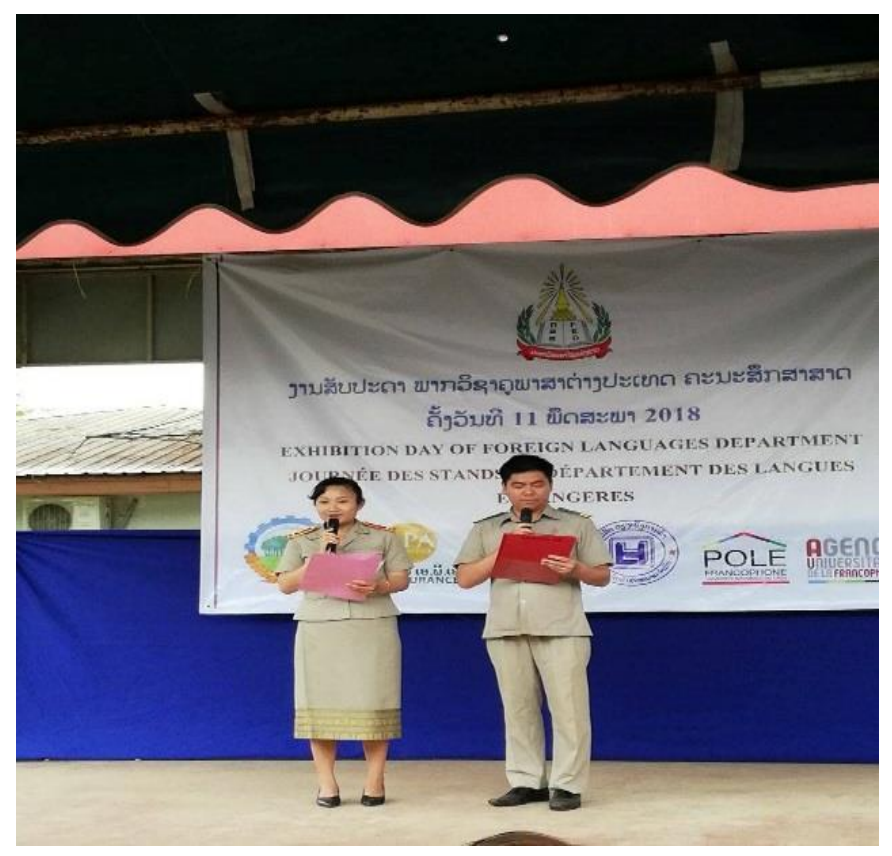

Figure 4. 11 Master of Ceremony (May 11 $\left.1^{\text {th }}, 2018\right)$

\subsection{Chapter summary}

This chapter discussed theoretical and methodological frameworks employed to seek answers to the research questions. It looked at both the quantitative and qualitative methods used to explore answers to the research questions and provided the rationale for utilizing a mixed-method design. Reasons for the data analysis, research methods, research participants, research variables, methods for integrating a CoT, ethical considerations, research trustworthiness, and researcher's positionality were also presented. The subsequent chapters (5 to 7) will present the findings of the present study. 


\section{CHAPTER 5: PHASE 1 FINDINGS}

\subsection{Introduction}

The previous chapter described the research methods and methodology employed to seek answers to the research questions in both phases. There are two sets of data in this chapter: quantitative and qualitative. Section 5.2 presents the quantitative findings and section 5.3 reports the qualitative results based on the open-ended questions and the semi-structured interviews. Section 5.4 summarizes the chapter.

\subsection{Quantitative findings}

In section 4.2.3.3, I pointed out that a questionnaire was used to seek the wider picture of the pre-service teachers' prior experiences of reading and learning to read and to triangulate the data. In this regard, three subsections will be presented according to the questionnaire arrangement. Section 5.2.1 describes the pre-service teachers' demographic information. Section 5.2 .2 reports the pre-service teachers' perceptions of learning English reading. Section 5.2.3 describes the pre-service teachers' prior experiences of reading, materials use, and instruction at the TEP.

\subsubsection{Demographic information}

This section reports the main findings of the demographic data. The analysis revealed that $60(47 \%)$ of the 129 participating pre-service teachers had been learning English for more than four years, that 111 (86\%) of them thought that English reading was very important; and that 74 (57\%) of them also rated their reading ability as satisfactory. The data indicated that the pre-service teachers had a wide range of English learning experiences and perceived reading as an important skill. This should be considered by the lecturers when planning and delivering their lessons to facilitate interactive and meaningful learning for their students.

\subsubsection{Perceptions of learning English reading}

This section of the questionnaire consisted of 10 items. A 5-point Likert-scale was used with categorizations as follows: "1" strongly disagree, "2" disagree, "3" neither agree nor 
disagree, "4" agree, and "5" strongly agree. As stated in the methodology chapter, descriptive statistics (SPSS version 25) were used to analyze the data. The means $(M)$ on the Likert-scale responses are presented in Table 5.1. The standard deviations (SD) for the perceptions ranged from 0.66 to 0.85 , all under 1.00 . The mean scores are ranked from the highest to the lowest.

Table 5. 1 Pre-Service Teachers' Perceptions of Learning English Reading

\begin{tabular}{|c|c|c|}
\hline Description & $M$ & $S . D$ \\
\hline $\begin{array}{l}\text { 1. Learning a lot of new words is important for learning } \\
\text { English reading. }\end{array}$ & 4.45 & 0.66 \\
\hline $\begin{array}{l}\text { 2. Pronouncing words or sentences correctly is } \\
\text { important for learning English reading. }\end{array}$ & 4.38 & 0.69 \\
\hline $\begin{array}{l}\text { 3. Translating from L2 to L1 is important for learning } \\
\text { English reading. }\end{array}$ & 4.33 & 0.76 \\
\hline $\begin{array}{l}\text { 4. Reading out loud is important for learning English } \\
\text { reading. }\end{array}$ & 4.26 & 0.87 \\
\hline $\begin{array}{l}\text { 5. Constructing meaning is important for learning } \\
\text { English reading. }\end{array}$ & 4.22 & 0.71 \\
\hline $\begin{array}{l}\text { 6. Answering comprehension questions is important } \\
\text { for learning English reading. }\end{array}$ & 4.19 & 0.79 \\
\hline $\begin{array}{l}\text { 7. Learning grammatical rules is important for learning } \\
\text { English reading. }\end{array}$ & 4.08 & 0.85 \\
\hline $\begin{array}{l}\text { 8. Summarizing the main idea of a text is important for } \\
\text { learning English reading. }\end{array}$ & 3.98 & 0.81 \\
\hline $\begin{array}{l}\text { 9. Monitoring or evaluating comprehension is } \\
\text { important for learning English reading. }\end{array}$ & 3.96 & 0.77 \\
\hline $\begin{array}{l}\text { 10. Developing critical thinking skills about a reading } \\
\text { topic is important for learning English reading. }\end{array}$ & 3.93 & 0.74 \\
\hline
\end{tabular}

For all but items 8 to 10, the means for items on the Likert-scale survey were 4.00 and over, suggesting that the pre-service teachers "agreed" that each statement was 
important for learning English reading. Interestingly, the three highest ranking means (items 1-3) perceived by the students all related to a bottom-up reading approach, paying attention to individual words, pronunciation (item 2) and translation (item 3) in learning English reading. In other words, they focused on the system of language instead of critical reading skills and a meaning-construction focus. The fourth-high ranked mean (item 4) seemed to be related to reading aloud, typically focused on pronunciation, which is related to the elements of the grammar translation method.

Another important point is that the three lowest ranked perceptions (items 8-10) are related to the level of comprehension development and critical reading skills. The means show that the pre-service teachers were not sure about the significant role of critical reading skills development. One of the possible reasons for the low means here is that they were not regularly engaged in practicing these aspects in the classroom instruction. It can be noted that they did not seem to regard learning reading as comprehension development. What is also worth considering about the remaining three items (items 57) was that they seemed to perceive item 5, meaning construction, as one of the important features for learning reading. This, however, was not practiced in the actual classroom practices as the observational data revealed.

The results of the quantitative data analysis reflect the pre-service teachers' perceptions of reading that were shaped through their personal and school experiences as discussed in the chapter 3.

\subsubsection{Prior experiences in reading, learning materials, and instruction}

The fourteen items in this section used a 5-point scale as follows: "1" never, "2" very rarely, "3" sometimes (50\%), " 4 " very often, and " 5 " always. The mean scores on the

frequency responses are presented in Table 5.2. The standard deviations for the experiences ranged from 0.87 to 1.04 . In this section, the respondents were required to refer to the reading courses they had experienced during the TEP. 
Table 5. 2 Prior Experiences in Reading, Teaching Materials, and Instruction

\begin{tabular}{|c|c|c|c|}
\hline Item & Description & $\bar{M}$ & $S . D$ \\
\hline 1. & $\begin{array}{l}\text { The teacher established a safe and respectful environment for } \\
\text { meaningful interaction in learning reading. }\end{array}$ & 3.68 & 0.89 \\
\hline 2. & $\begin{array}{l}\text { The teacher encouraged students to think about the concept } \\
\text { represented in the text when teaching reading. }\end{array}$ & 3.48 & 0.92 \\
\hline 3. & $\begin{array}{l}\text { I used various sources (e.g., online website, newspapers, } \\
\text { magazines, etc.) in addition to reading the textbooks used in the } \\
\text { class. }\end{array}$ & 3.35 & 0.98 \\
\hline 4. & $\begin{array}{l}\text { The teacher used reading materials suitable to my English } \\
\text { proficiency. }\end{array}$ & 3.29 & 0.90 \\
\hline 5. & $\begin{array}{l}\text { The teacher used assessment practices aligned with planned } \\
\text { goals or actual instruction. }\end{array}$ & 3.27 & 0.89 \\
\hline 6. & $\begin{array}{l}\text { The teacher provided meaningful or effective consultation to } \\
\text { students regarding learning reading. }\end{array}$ & 3.27 & 1.03 \\
\hline 7. & $\begin{array}{l}\text { The teacher focused students on constructing meaning of the } \\
\text { text. }\end{array}$ & 3.26 & 0.87 \\
\hline 8. & $\begin{array}{l}\text { A balance existed in the reading lesson between teacher- } \\
\text { initiated and student-initiated tasks. }\end{array}$ & 3.26 & 0.93 \\
\hline 9. & $\begin{array}{l}\text { The teacher designed and included extra activities (e.g., } \\
\text { retelling the text content, sequencing the events, short } \\
\text { summary, debates, presentations, etc.) for students to do after } \\
\text { reading to further increase understanding of the text. }\end{array}$ & 3.21 & 0.99 \\
\hline 10. & $\begin{array}{l}\text { The teacher provided a clear explanation about the skills or } \\
\text { strategies to be used in reading. }\end{array}$ & 3.16 & 1.01 \\
\hline 11. & $\begin{array}{l}\text { The teacher activated students' prior knowledge of the topic } \\
\text { before reading. }\end{array}$ & 3.11 & 0.87 \\
\hline 12. & $\begin{array}{l}\text { In addition to textbooks, the teacher also used other } \\
\text { supplementary reading materials to expose students to } \\
\text { different text types. }\end{array}$ & 3.03 & 0.88 \\
\hline
\end{tabular}




\begin{tabular}{llll}
\hline 13. & The teacher asked students to summarize what they read. & 2.98 & 1.04 \\
14. & I read various types of texts (e.g., novels, reports, & 2.88 & 0.96 \\
& advertisements, etc.) to develop my reading skills or capacity. & &
\end{tabular}

For all items, except items 13 and 14, the means on the frequency were over 3.00. This indicates that the participants sometimes had an experience of the activities represented in each statement. The mean scores reveal that none of the activities were universally experienced by the pre-service teachers. They were occasionally exposed to such reading activities in this context. What is to note here is that the mean of item $1(M=3.68)$ showed that the teacher seemed to have been successful in establishing a rapport with the students, which is important for a safe and friendly environment to occur. Another important point was that while there was inconsistency between items 3 and 14; 14 having the lowest mean score might suggest that the students did not do a lot of reading outside the classroom. These data provide a global picture of the issue under investigation. To gain an insight into what the participants thought about their prior experiences of reading and learning to read in English, a qualitative perspective from the open-ended question sections and semi-structured interviews will be presented in the following section.

\subsection{Qualitative findings}

As pointed out in 4.2.2, exploratory and ethnographic methods were used to seek answers to research questions. Section 5.3.1 presents the results of open-ended questions. Section 5.3.2 reports the findings of semi-structured interviews. Section 5.3.3 describes the current situation of reading instruction. Finally, section 5.3.4 reports the extent to which the CoT was practiced in this context.

\subsubsection{Open-ended questions}

As indicated in section 4.2.3.3, the open-ended section of the questionnaire allowed respondents to add further ideas. The questionnaire has two open-ended question sections which are about their perceptions of learning English reading. Fourteen out of 129 respondents provided additional comments. Although this provides limited data to 
work with, three main themes emerged from the data. First, 4 of the 14 mentioned that the teacher should read the text aloud and clearly when teaching English reading. For instance, participant 35 stated:

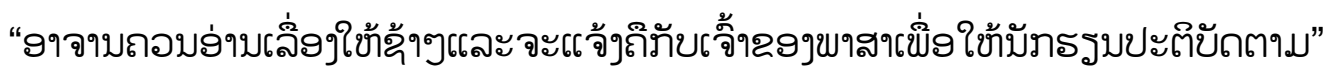

[The teacher should read the text aloud slowly and clearly as native speakers of English so that the students can imitate the accent]

This reflects their perceptions represented in item 2 (Table 5.1), concerning pronouncing words or sentences correctly as important for learning English reading ( $M$ $=4.38, S D=.68$ ). Second, 3 of the 14 said that the teacher and students should use more English during the reading class. For instance, participant 66 stated:

“างบเอิ้าขาสางังภึถใข้าขูายเอลาสงบอ่าบเปับสิ่งจำเปับ และสำถับ"

[Speaking in English a lot when teaching reading is important and necessary]

A final theme to take into consideration in this regard was the need for translation when learning reading. The other ones expressed a need for translation of the text into L1. For instance, participant 31 stated:

"ยาภใช้างจาบแปเลิ่งตเปับพาสาลาใใท้ขूายๆ"

[I want the teacher to translate the text into Lao more]

The second section addresses prior experiences of reading, materials, and instruction (section 3 of the questionnaire) and general comments from 13 of the 129 respondents. 5 of the 13 mentioned that the teacher should engage and motivate the students more during the reading class. Participant 64 stated:

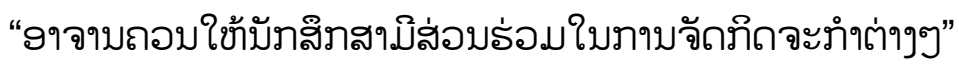

[The teacher should engage students in learning activities]

Another theme was the lack of a summarizing focus on the main idea of the text after reading. Participant 96 stated:

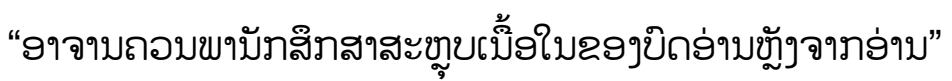

[The teacher should have students summarize the main point of the text after reading] 
This is reflected in the mean score of item 13 (Table 5.2) that the teacher asked the students to summarize what they $\operatorname{read}(M=2.98, S D=1.04)$; there was a lack of such experiences in classroom practice.

\subsubsection{Semi-structured interviews}

Ten semi-structured interviews with pre-service teachers were conducted in December 2017. The interviews focused on aspects of the participants' prior experiences of reading and learning to read. These include: years of learning English, motivation for learning it, prior experiences in reading and learning to read on the TEP, reading materials, challenges in learning reading, and other issues related to RQ1.

In regard to the length of time learning English, the ten interview participants had from six to ten years of English learning and with regard to their motivation for learning English, seven of them stated that they learned it because it was important for communicating with foreigners, in addition to employment opportunities. The other reasons for learning English included: English is an international language and the participants' interest in learning it.

When asked about their prior experiences of reading in general, four main themes emerged. One related to the grammar translation method. Of the ten pre-service teachers who participated in the interviews, nine of them stated their prior experiences in reading were reading easy texts and translation of words or texts into L1. As participant 4 stated:

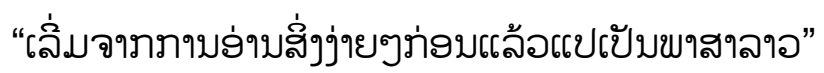

[I started from reading simple and easy stories or texts first and translate them into Lao]

This reflects the perceptions of learning reading (item 3, Table 5.1), which states that translating from L2 to L1 is important for learning English reading $(M=4.33, S D=.67)$. Another important theme was a pronunciation, oral fluency, and intonation focus. A majority $(80 \%)$ of the participants pointed out that reading and pronouncing words 
correctly, and correct intonation were the main focuses of learning English reading. As participant 5 stated,

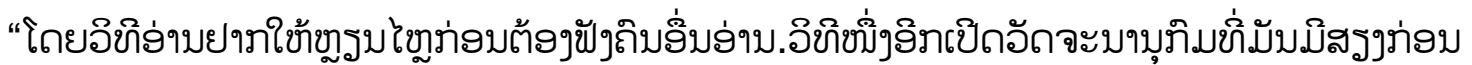

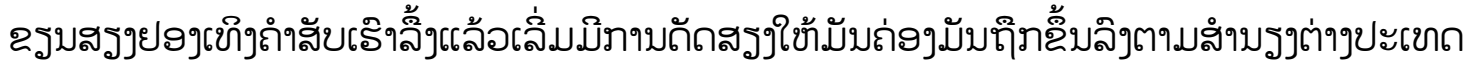
ขั่เอ้̆ๆ"

[Yes, I focus on reading fluency first. I have to listen to the other people read first. Another way is to check the pronunciation of words up in a dictionary. I write the sound of the words above them. When I am familiar with how words sound, I adjust my accents according to native speakers]

This experience also reflects the pre-service teachers' perceptions of learning reading presented in Table 5.1, item 2: Pronouncing words or sentences correctly is important for learning English reading $(M=4.38, S D=.69)$. Furthermore, seven of the ten participants reported that vocabulary was another central focus for learning English reading. Participant 4 stated:

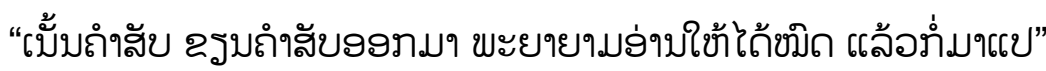

[I focus on vocabulary. I jot down new words, try to read and translate them]

This is a reflection of item 1 of the survey questionnaire introduced in Table 5.1, which states that learning a lot of new words is important for learning English reading $(M=$ $4.45, S D=.66)$. The last theme that emerged is related to the use of a dictionary in learning reading. More than half $(60 \%)$ of the participants expressed that when encountering the unknown words, they stopped and looked them up in a dictionary instead of applying reading skills or strategies to construct meaning of the text.

In terms of the pre-service teachers' prior experiences in learning to read on the TEP, several important themes emerged from the interview data. The first was related to the application of a grammar translation method in teaching reading. The ten participants interviewed reported that the teacher first asked them to read the text aloud and then translate it into L1. Participant 1 said: 


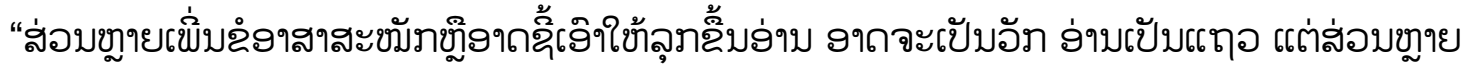
จะย่าบเปับอัภ แล้อแปเปับลาอ"

[Most of the time, the teacher calls volunteer students to stand up and read aloud paragraph by paragraph and then translate them into Lao]

This also reflects the perceptions stated in item 3 of Table 5.1 that translating from L2 to L1 is important for learning English reading. The second theme was about answering comprehension questions. $90 \%$ of the participants stated that the teachers asked them to focus on finding answers to comprehension questions after the reading and translating stage. Participant 8 stated:

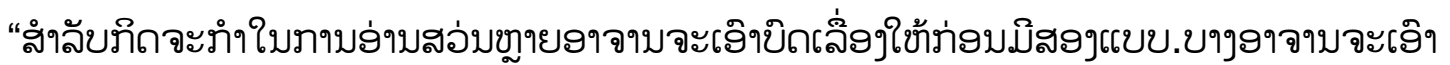

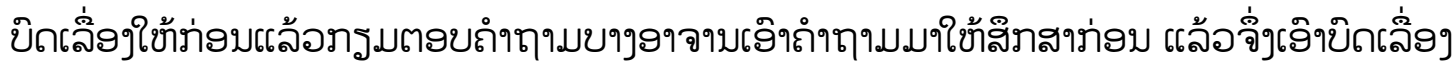
ใช้อ่าบตอบถำฤๆม"

[There are two types of reading activities. Some of the teachers provide a reading text for the students to study first before answering the comprehension questions. Other teachers provide comprehension questions for the students to study first before giving the reading text to the students to answer the questions]

This reflects the perception of learning English reading represented in item 6 (Table 5.1) concerning answering comprehension questions is important for learning English reading $(M=4.19, S D=.79)$. What is interesting to note here is that while this reflects variable practice, it was not evident in the classes observed.

The third theme was related to vocabulary and phonological focus associated with intonation, reading fluency, stress and accent practices. Nine (90\%) of the ten participants interviewed mentioned that the teacher asked them to identify difficult words and read out loud to see who had the perfect accent and read correctly and clearly. As stated by participant 5 ,

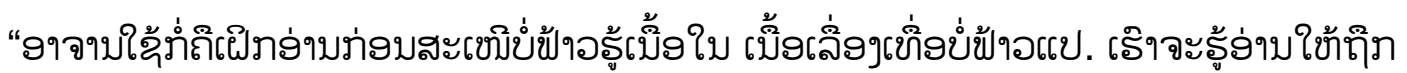

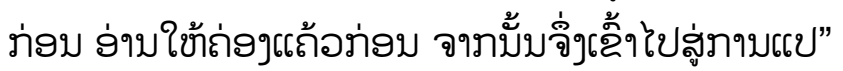

[The teacher first asks the students to read the text correctly without worrying about the main idea of the text. The teacher ensures that the students are able to read the text correctly and fluently before translating] 
This reflects the perceptions of the pre-service teachers that pronouncing words or sentences correctly is important for learning English reading (item 2, Table 5.1). Other themes that emerged include: use of textbooks only, individual activities, and use of a dictionary. These suggest that the teacher relied heavily on the textbooks instead of incorporating or integrating other reading sources. In terms of the text summary, only two participants reported that the teacher asked them to summarize or identify the main ideas of the text after reading. This reveals a lack of a focus on meaning-construction development, which is the main goal of learning reading.

When asked about the reading textbook (reading materials), $80 \%$ of the participants stated that the textbook was appropriate to the students' English background. Participant 5 stated:

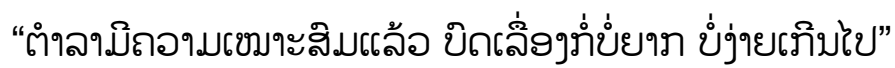

[The textbook is appropriate. The reading passages are neither easy nor difficult]

However, what teachers did in class and how teachers delivered the lessons seemed to have an important effect on students in learning to read in English. Another important theme was a lack of extra reading sources. $30 \%$ of the participants pointed out that there were no supplementary materials to help facilitate learning or support the textbooks used. This reflects the results of the survey questionnaire presented in Table 5.2 (item 14 ) that the students had very limited materials to read $(M=2.88, S D=.96)$. The final theme was related to the pattern of the textbooks. In this respect, $20 \%$ of the participants stated that the pattern of the activities in the textbooks was boring because they had the same layout.

In terms of the challenges in learning reading, $80 \%$ of the participants stated that vocabulary was the main difficulty in learning reading. An example of this is a quote from participant 2 who stated:

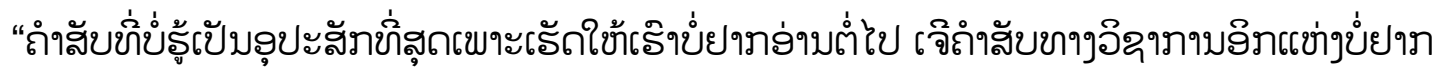
่่าบเขาะข่่ยๆภอ่าบภะเลิยปะไอ้” 
[Vocabulary is the main issue that demotivates me in reading. When reading and encountering academic words, they stop me from continuing to read]

This suggests that vocabulary was one of the key determinants in constructing meaning of the text. Other important themes that emerged on the topic of the challenges include incorrect pronunciation (40\%), lack of English background knowledge (30\%), failure to construct meaning of the text (30\%), lack of reading skills or strategies $(20 \%)$, and translation (20\%). This might reflect the reality that some of these aspects (meaning construction and reading skills or strategies) were not in place in teaching reading in this context.

When asked about the main focus of learning reading, the participants pointed towards correct pronunciation (50\%), vocabulary (40\%), translation (20\%), and understanding (20\%). All of these reflect their experiences and perceptions stated in the survey questionnaire. As the findings revealed, the quantitative and qualitative data were useful in answering RQ1 and the results from both quantitative and qualitative data were congruent.

In summary, the overall picture of the Lao EFL pre-service teachers' prior experiences in reading and learning to read in English was learning discrete language knowledge: vocabulary, pronunciation, and translation. In other words, they had an experience of grammar translation, rather than reading skill development.

\subsubsection{Current situation of reading instruction}

As a reminder, RQ2a asked:

What is the current state of English reading instruction in Lao EFL pre-service teacher education?

As stated in the methodology chapter, six classroom observations and six semistructured interviews were conducted. In addition, documents (e.g., curriculum, course syllabus, lesson plans, and reading test papers) related to reading instruction were collected for data triangulation. In this section, the results from the six direct classroom 
observations will be presented first and then supported by the interview data and the document analysis.

The findings demonstrated that the main focus of reading instruction in this context was on grammar translation, involving deliberate attention to language features (pronunciation, vocabulary, and grammar rather than comprehension development). These include: class attendance and homework checking, grammar translation, vocabulary focus, comprehension questions-oriented focus, pronunciation, homework assignment, and in-class actual reading time. Each of these will be discussed at in the following subsections.

\subsubsection{Class attendance and homework checking}

One of the recurring patterns or themes that emerged from the observational data was checking students' class attendance and reviewing homework prior to the lesson development. The main reason behind this practice was because class attendance accounted for $10 \%$ of the student assessment. This was stated in the assessment criteria of the curriculum as pointed out in chapter 2. Another reason was that checking students' attendance and presence might be the best way for the teachers to maintain their classroom authority. As indicated in the curriculum, if a student fails to attend twothirds of the total classes without a reasonable justification in the reading course within a school term, she is not allowed to sit the semester or final examination. This means that he or she fails the subject and is required to retake it in the following semesters.

\subsubsection{Grammar translation dominance}

Another main theme derived from the analysis was having students read texts aloud and translate them into L1. Five of the six reading classes observed used this method in their instructional practices. This reflects the dominant use of the traditional teaching method of grammar translation. Results from the interview data analysis were also congruent with the observational evidence. For instance, one of the interview participants (reading lecturer) stated: 


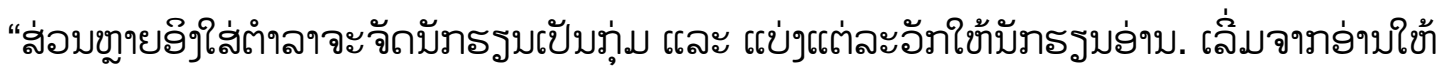

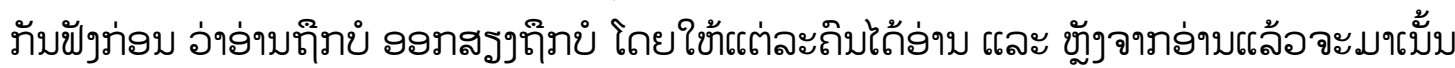
ใส่ภาบเป และ สุถข้าย รำบั้บใส่ถำสับ"

[Most of the time, I primarily follow the textbook. I divide the students into groups and assign them one or two paragraphs to read. Members of each group take turns reading aloud by focusing on pronunciation. After reading, I have them translate the text into Lao and finally focus on new vocabulary]

The result was not surprising since the Lao EFL lecturers still followed a traditional rote memorization mode of instruction while critical reading skills, deep and meaningful learning, self-regulation, and meaning construction were not in place. The findings also reflect the notion of the 'apprenticeship of observation' (Lortie, 1975) discussed in chapter 3. In other words, the current state of reading instruction and preconceptions of teaching held by both pre-service teachers and lecturers in this context was largely shaped by the attitudes, beliefs, and styles that they had developed through their experience of teacher-centered education during their teacher education lives and experiences as learners. This also reflects the survey findings for RQ1 that pre-service teachers viewed translation as one of their important reading learning experiences. These learning experiences are often resistant to change, even change for the better.

\subsubsection{Vocabulary focus}

Another important theme/pattern derived from the observational data was a vocabulary focus. As one of the discrete linguistic knowledge features, vocabulary received considerable attention in reading instruction in this context. Five of the six reading classes observed focused pre-service teachers primarily on reviewing difficult words prior to and after reading the text. The finding also reflects what was found in the six teacher interviews. For instance, one of the participants indicated that:

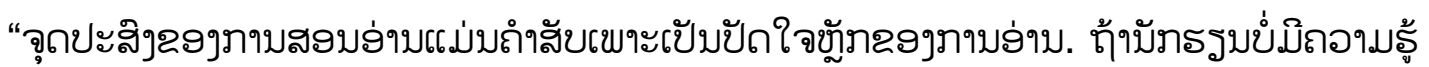

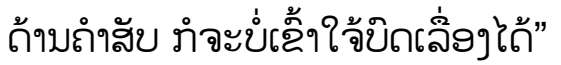

[The main focus of reading instruction is vocabulary because it is an indispensable part of reading. If students lack vocabulary knowledge, it is impossible for them to understand the text] 
Although vocabulary plays an important role in reading comprehension, meaning construction should be the focal focus of classroom practice. If vocabulary has to be one of the important components in teaching reading, it should be taught within the context in which it has to be used, rather than in isolation, so that a contextualized meaning of the word can be acquired effectively by the students. One of the important reasons why vocabulary was frequently targeted was that the reading test components appeared to include a vocabulary feature (see Appendix 5). The results of the reading test papers analysis also revealed that each test paper included direct testing of vocabulary knowledge. For instance, one of the question types in a reading test required students to: 1) Match the words in column A with their meanings in column B and 2) Choose the best word for each sentence. In other words, a vocabulary focus has become one of the significant aspects of learning and teaching English reading in this context due to the vocabulary-oriented testing culture.

Another reason was that reading lecturers might assume that once pre-service teachers were equipped with sufficient vocabulary knowledge, they would know how to read strategically or automatically. This assumption has become a challenging issue because students with good vocabulary knowledge may still fail to construct meaning of the text. As stated in section 3.3, reading is an interactive and complex process that involves the reader with the text (Grabe, 2010). In other words, reading is a meaning-construction process that requires a reader's prior knowledge and may include word-by-word decoding, but this differs from the grammar translation practices in the class where there is no attention to meaning construction. Therefore, to successfully make sense of a text, a reader needs not only linguistic knowledge but also practical interaction with the reading text.

\subsubsection{Comprehension questions focus}

What is also interesting in the observational and interview data is the role of answering comprehension questions in the textbook and going over the answers with the students. This practice was common in the six reading classes observed. In addition, the six teachers interviewed also stated that answering comprehension questions was one of 
the main features of teaching and learning reading. For instance, one of the participants stated that:

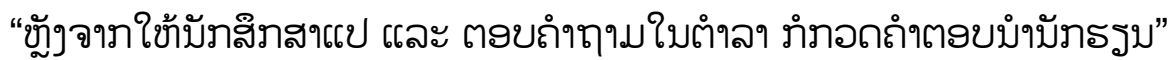

[After having students translate the text and answer the comprehension questions, I go over the answers with them]

As pointed out in chapter 2, one of the main reasons the lecturers only followed the comprehension questions in the textbook was that they had multiple tasks to deal with, which affected their lesson planning preparation. As one of the teachers stated:

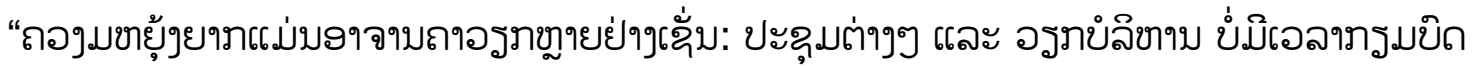
สอบปิธเต่ไปตามตำด “

[The main challenge is that the teachers have a lot of work to do, for instance, meetings and administrative affairs, not enough time to prepare lessons. I just follow the textbook]

Through my observation and attachment during data collection at the research site, it was obvious that the teachers were required to participate in not only teaching but also administrative work (e.g., Women's Union, Youth Union, Trade Union, Party matters, meetings, etc.). Because of this, following the comprehension question exercises given in the textbook might be one of the better solutions in teaching reading as it saves the teachers' time and effort.

Although comprehension questions are beneficial for reading instruction, not all of them help the students interact with the text meaningfully. Through my evaluation of the reading comprehension questions and activities the teachers used during their reading classes, it was obvious that many of the questions focused students on linguistic features (e.g., vocabulary, grammar, etc.) or literal comprehension. This type of question can be answered explicitly and directly from the text without critical thinking and metacognitive reading strategies as discussed in section 4.3.7. For instance, one of the question types was about the meaning of up to 50 other students (turn 01 of Extract 5.1). This was immediately followed by another question about the meaning of travelling around (turn 05). 
Extract 5.1

$01 \mathrm{~T}$ แปอ่าฉ้งยบ่่เฉ้้ใจ [It means that I don't understand]. Next, number 7: In lines 37 and 38 of the reading text, what does up to 50 other students mean?

02 Ss [Different groups of students call out the answers to the question].

- $\quad$ B. more than 50 students.

- C. exactly 50 students.

- A. 50 students or less.

$03 \mathrm{~T} \quad$ Up to means not over but exactly. It means up to or less.

04 Ss Oh. The letter $\mathrm{A}$ is the correct answer [LAUGHS].

$05 \mathrm{~T} \quad$ Yes. The correct answer is the letter $a$. How about number 8? In lines 46 and 47 of the reading text, which phrase means travelling around?

06 Ss On the move.

07 T Yes. I agree. Number 9: Which phrase shows that Hilary's father is not sure about if university podcasts are a good thing or not?

As can be seen, this type of question required students to directly identify answers represented in the text; this fails to foster deep and meaningful interaction with the reading text. It also tends to lead to Initiation-Response-Evaluation (IRE) sequences (Walsh, 2011). Although the IRE is commonly practiced in classrooms all around the world, the controlled turn-taking tends to limit student-student interactions and to limit opportunities for students to develop communicative competence since their role is reduced to one of responding to teacher questions. This also suggests that classroom interaction is goal-oriented in the sense that the teacher is the only person who establishes goals and sets the agenda for instruction without considering the students' needs. This teacher-prepared and teacher-delivered lesson tends to focus on the conveyance of factual information and literal recall from the students. As a result, this orientation influences not only the teaching approach adopted but also the language used to accomplish the goals.

In addition, when going over the answers with the students, there was a lack of meaningful interaction between the teachers and students because the teacher only checked whether the answers given by the students were right or wrong according to the answer key without having the students strategically identify and interact with the 
reading text and with one another. This can be seen in Extract 5.2. For instance, the teacher asked the students to call out the answer (turn 01). One of the students stood up and said: "Make" (turn 02). "Correct all?" asked the teacher (turn 03). The students said: "Yes" (turn 04).

\section{Extract 5.2}

01 T Number 1: My parents.......me do my homework every evening.

02 S1 Make

03 T Correct all?

04 Ss Yes.

The teachers asked the students to take turns answering the questions and then gave scores for their participation. To promote meaningful interaction and active engagement in creating meaning of the text, a discussion of the right and wrong answers should be fostered during this process. However, the reading teacher should be aware that too much emphasis on comprehension questions could result in student boredom. This reflects what Day and Park (2005, p. 68) refer to as "death by comprehension question syndrome". In other words, the use of comprehension questions should be appropriate for a course of reading instruction.

\subsubsection{Pronunciation focus}

A further practice found in the data was the practice of reading aloud with a pronunciation focus. Three of the six reading classes observed had the students stand up and read the text aloud one by one. This practice also reflects the results of the interviews as five of the six teachers stated that correct pronunciation of words or sentences was one of the central focuses in teaching reading. For instance, participant 3 stated:

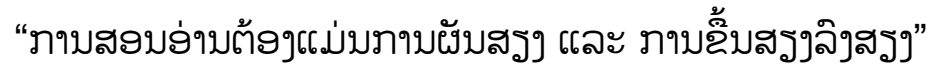

[The main focus of teaching reading is pronunciation and intonation]

This practice encouraged students' passivity in learning reading because its primary focus was on discrete language skills rather than comprehension development. One of the possible explanations for this might be that the reading lecturers believed that once students had gained confidence and knowledge in reading aloud and correct 
pronunciation, they would know how to interact with the text strategically and meaningfully. This perception is inaccurate since students who are good at pronunciation may still struggle to construct meaning from the text effectively. Although taking turns to read aloud might help develop reading fluency and correct pronunciation of words or sentences, the main goal of teaching reading, as pointed out earlier, should be meaning construction and critical reading skills development.

\subsubsection{Homework assignment}

Another common pattern that emerged from the observational data was homework assignment. The six reading class teachers observed ended their lessons by giving homework. One likely reason for doing this was that, as indicated in the assessment criteria, homework is worth $10 \%$ of the student assessment. Although this was stated in the curriculum, homework should contribute to an increased understanding of reading and encouragement of effective learning. Through my observation, the most common types of homework the teachers assigned were answering comprehension questions in the textbook. Many of these question types, as stated earlier, did not encourage active and meaningful reading. Homework that required critical reading skills and meaning construction was not designed and integrated into reading instruction. As a result, preservice teachers tended to be given homework that required more rote memorization practice and literal comprehension rather than meaning construction. Vocabulary exercises taken from the textbook tended to dominate the homework given. For instance, the fourth reading teacher assigned his students homework that focused on word collocation and sentence completion with a phrase from the previous exercise.

\subsubsection{In-class actual reading time}

Another pattern that emerged from the six classroom observations was the limited silent, uninterrupted reading time in classes (see Table 5.3 below). It can be seen that only 13 minutes (observations 1 and 3) out of seven hours were used for silent, uninterrupted reading time in the six classes. Such in-class reading time was relatively weak and insufficient in promoting meaning-focused interaction and active engagement with the reading text. This suggests that the teacher did most of the talking during 
reading classes. The majority of time was spent on reviewing and explaining new vocabulary, reading aloud, translating the text, and checking comprehension questions as previously pointed out. Silent uninterrupted reading time in class is important for speed reading, comprehension promotion, and fluency development, which result in fostering readers' confidence (Nation, 2009c). Therefore, this practice should be encouraged in order to develop better readers.

Table 5. 3 Silent Uninterrupted Reading Time in Classrooms

\begin{tabular}{|c|c|c|}
\hline$\overline{\text { Observation }}$ & Silent uninterrupted reading time & Remarks \\
\hline $1(57: 42)$ & 9 minutes & $\begin{array}{l}\text { The teacher was sitting at his desk and } \\
\text { waiting for the students to finish. }\end{array}$ \\
\hline $2(92: 23)$ & No reading time in class & $\begin{array}{l}\text { The teacher asked the students to read } \\
\text { the text beforehand. }\end{array}$ \\
\hline $3(88: 27)$ & 4 minutes & $\begin{array}{l}\text { Too short to construct meaning of the } \\
\text { text within } 4 \text { minutes. }\end{array}$ \\
\hline $4(50: 08)$ & No reading time in class & $\begin{array}{l}\text { The teacher asked the students to read } \\
\text { the text beforehand }\end{array}$ \\
\hline $5(94: 19)$ & No reading time in class & $\begin{array}{l}\text { The teacher asked the students to read } \\
\text { the text beforehand }\end{array}$ \\
\hline $6(85: 56)$ & No silent reading time in class & $\begin{array}{l}\text { The teacher asked the students to stand } \\
\text { up and read aloud one by one in class } \\
\text { (10 minutes). }\end{array}$ \\
\hline Total: 7:79 & 13 minutes & Very limited in-class reading time. \\
\hline
\end{tabular}

When asked about difficulty in teaching reading, the six lecturers stated pre-service teachers' low and diverse English backgrounds, lack of teaching materials, lack of internet access, pronunciation issues in students, insufficient vocabulary knowledge in students, irrelevance of reading texts to the student's context, the classroom physical environment, and the teacher workload in teaching and dealing with other tasks contributed to reading instruction difficulty. These had important effects on facilitating interactive and innovative reading instruction in the Lao EFL pre-service TEP. When 
asked about how they addressed the issues mentioned, the lecturers pointed out paying attention to lesson plan preparation by using their private internet access, assigning more work to students to do, having good students help weak students, and giving different reading texts to different groups of students to read.

\subsubsection{Individual variations}

While the seven central patterns/themes represented the current state of reading instruction and reflected teachers' voices in Lao EFL pre-service teacher education, there were three variations relating to the current practice of reading instruction in this context. One was having the students tell stories of their own preferences and translate them into L1. The main focus of this was to encourage the students to read texts or stories for enjoyment. To achieve this, the teacher set criteria for the students to follow, which included: selecting easy local novels or stories, summarizing the main points of texts, and giving the morals of the stories or reading texts. After these processes, the students were required to share what they read with their classmates through telling it in the class. This practice appeared to be a form of extensive reading. Extensive reading is important because it is regarded as one of the meaning and fluency-focused development strands (Nation, 2009b) that should be promoted during a course of reading instruction. This variation was mentioned by one teacher who pointed out that one of her best lessons was having the students tell the stories of their own selection. This participant said:

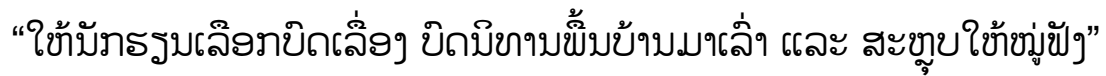

[I have the students select and tell easy local stories of their own preferences and summarize the main points]

This practice reflects a degree of teacher freedom in incorporating different teaching activities into actual classroom practices although the primary source of reading instruction activities is provided in the textbook. However, each student was only required to read and report on one text or story and so the quantity requirement for extensive reading was not present. 
Another practice in one of the reading classes was having students work in groups to justify why they agreed or disagreed with the questions in the textbook. This type of task required the students to support their ideas with reasons which were useful in terms of pushing them to think deeper about their answers. For instance, one of the questions asked: What do you think is more important: to be beautiful or to have a nice personality? This type of question was useful because the students were encouraged to think about their answers in relation to the idea represented in the text they had read. This task, possibly, should have been conducted prior to reading the text in order to activate the students' background knowledge of, and to promote, active engagement in the topic.

A final variation that emerged from the observational data was a grammar focus. Two reading classes observed focused the students on grammar in addition to the other language features. Although grammar plays an important role in reading comprehension, it should be taught meaningfully in a reading course. In other words, attention given to grammar should help the students interact with, and create meaning of, the text more strategically. One of the grammatical features on which the teacher focused was a conditional sentence. The teacher asked the students to complete the sentences with their opinion using the structure learned. This type of learning activity failed to support the students to construct meaning of the reading text.

To sum up, the results of direct classroom observations, interviews and reading-test analysis revealed that the current state of reading instruction in Lao EFL pre-service education was still dominated by a traditional method of grammar translation and a discrete language skill focus. What the pre-service teacher experienced in their preservice education appears to reinforce the assumption and beliefs about teaching reading through the apprenticeship of observation. In the next section, I will look at answers to RQ2b by drawing on evidence from all sources of the data as pointed out in the research design in chapter 4 .

\subsection{CoT practice in reading instruction}

As posed earlier, RQ2b asked: 
To what extent is a CoT practiced in teaching reading in Lao EFL pre-service teacher education?

To answer the question, the qualitative data analysis drew upon direct classroom observations, semi-structured interviews, and document analysis. As a reminder, a CoT is defined as "a place where a group's collective as well as individual thinking is valued, visible, and actively promoted as part of the regular, day-to-day experience of all group members" (Ritchhart et al., 2011, p. 219). This definition indicates the important role of promoting students' thinking and interactive engagement in the process of learning.

The results from the observational and interview data revealed that there was a lack of the CoT practice in teaching reading in Lao EFL pre-service teacher education, suggesting that, as stated earlier, Lao EFL pre-service education was highly oriented toward discrete language items (e.g., pronunciation, vocabulary, grammar). Given this conclusion, it would be very easy to infer that the Lao pre-service TEP ignored the importance of a CoT. However, by drawing on a documentary analysis, a slightly different picture emerged. First, the results from the curriculum document analysis revealed that their objectives included a statement related to the notion of a CoT. For instance, a $12+4$ curriculum objective stated:

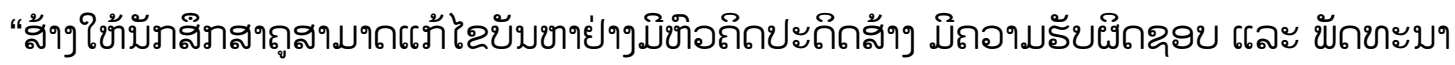
ถอามรู้ ถองมสามาถฉองติบใบดะบาถิถ"

[This curriculum aims to equip pre-service teachers with creative ideas, problemsolving skills, accountability, knowledge development, and capacity-building skills in the future]

This statement acknowledges the significant potential role of the CoT in TEPs in LPDR. In addition, the results from an analysis of reading-course syllabuses showed that their objectives included activities focusing on activating prior knowledge before reading and summarizing the main idea of reading texts. For instance, one of the reading-course syllabus objectives stated:

"After learning this subject, students will be able to predict, skim, scan and summarize the main idea of the text." 
This statement indicates the importance of developing strategic and fluent readers in the course of reading instruction, the aim of a CoT. In terms of lesson plan analysis, the results also revealed that three of the ten lesson plans aimed to focus students on summarizing the main ideas of the text as indicated in the following extract.

\section{Extract 5.3}

Teacher name Teacher B

Subject Reading

Unit $8 \quad$ Two cities

Topic London's Chinatown

Objectives - Students will be able to read and summarize main points of the text.

- Students will be able to read the text to find their difficult words.

The results of the document analysis reflect that the important potential role of a CoT in the process of learning and teaching English reading was acknowledged in the curriculum policy and objectives of the course syllabuses and some lesson plans. This also reflects what was pointed out in chapter 2 in terms of the government breakthroughs and education pillars. What was found in the documents, however, failed to be reflected in the actual classroom practices observed in this study.

\subsection{Chapter summary}

This chapter presented the results of phase 1. It specifically reported on pre-service teachers' prior experiences of reading and learning to read in English, the current state of reading instruction, and the extent to which a CoT was practiced in this context. The results were drawn from semi-structured interviews, survey, observations, and document analysis. The findings show that pre-service teachers experienced extensive practice of discrete language features and the current state of reading instruction was predominantly dominated by use of grammar translation and discrete language skills, which were insufficient for the development of better and critical readers. The results also revealed that the CoT practice was not in place in teaching reading although it was acknowledged in government and education policy. In other words, there was a gap between language teacher education policy in terms of a CoT and actual practices. To 
create a bridge to link to the policy and practice, the CoT was implemented and the results are presented in the following chapter. 


\section{CHAPTER 6: PHASE 2 FINDINGS}

\subsection{Introduction}

As stated in section 4.3, a quasi-experimental design and mixed methods research were employed to seek the answers to phase 2's research questions. The aim was to understand the issues from multiple and integrated perspectives (data triangulation). Section 6.2 addresses the quantitative findings (reading proficiency development). Section 6.3 looks at the results of the qualitative data analysis (learning engagement). Finally, section 6.4 summarizes the chapter before turning to pre-service teachers' perceptions of learning reading in chapter 7 .

\subsection{Quantitative findings}

The statistical approach to examining the effects of the CoT implementation on preservice teachers' reading comprehension is addressed in section 6.2.1. The employment of the statistics was to test independent and dependent variables as stated in section 4.3.8. Section 6.2.2 looks at descriptive statistics of participants. Section 6.2.3 deals with independent sample $t$ test assumptions. Section 6.2.4 presents a post-test data analysis. Section 6.2.5 addresses delayed post-test results before addressing the qualitative findings in section 6.3.

\subsubsection{The statistical method}

As a reminder, RQ3 of phase 2 asked:

To what extent does the CoT implementation improve Lao EFL pre-service teachers' reading comprehension?

To determine an appropriate statistical option, a statistical consultation was sought from the School of Mathematics and Statistics of Victoria University of Wellington (October 17th, 2018). Following the consultation, an independent sample $t$ test was used to compare the mean scores between the classes (Green \& Salkind, 2011; Pallant, 2013). As Green and Salkind (2011) state, "independent sample $t$ tests are used to analyze data 
from different types of studies, including quasi-experimental studies" (p. 175). The $t$ test assesses whether the mean value of the test variable (score) for one group differs significantly from the mean value of the test variable for the comparison group (Pallant, 2013). To achieve this, the Statistical Package for the Social Sciences (SPSS version 25) was used to run the test (Green \& Salkind, 2011).

In addition, effect size analysis (Cohen's $d$ ) for the $t$ test was performed (Cohen, 1988). As reminder, the criteria for interpreting the effect size result are outlined in Table 6.1:

Table 6.1 Effect Size Criteria and Interpretation

\begin{tabular}{ll}
\hline Range & Interpretation \\
\hline $0.20-0.40$ & Small or no significance \\
$0.50-0.70$ & Medium \\
0.80 or over & Large /strong \\
\hline
\end{tabular}

\subsubsection{Participants}

As stated in section 4.3.3, two classes of EFL pre-service teachers were recruited to participate in this intervention. One of the classes was randomly assigned to the implementation group and the other class was assigned to the comparison group. Fortunately, none of the participants failed to complete the pre-test, immediate post-test, delayed test, and pre-post perception survey.

\subsubsection{Independent samples $t$ test assumptions}

Before conducting independent sample $t$ tests, it is important to check a number of assumptions. These include: 1) homogeneity of variance, 2) normal distribution, and 3) independence of observations (Pallant, 2013). Each of these will be tested and discussed in the following sub-sections.

\subsubsection{Homogeneity of variance of pre-test results}

As pointed out in section 4.3.4.1, to measure both group participants' English reading baseline prior to the CoT implementation, a reading test was administered. The test scores from both groups were analyzed using an independent sample $t$ test to detect a 
preexisting difference between the two groups in terms of their English reading proficiency. The results of the test were not revealed to the participants to avoid an internal threat to the research. To test homogeneity of variance of the pre-test, the following null hypothesis was formulated:

$\mathbf{H}_{\mathbf{0}}$ : The mean pre-test score does not differ between the implementation group and the comparison group.

If the mean score of the two groups was significantly different, this assumption was violated and the use of the independent sample $t$ test was not appropriate. Table 6.2 below presents group statistics concerning mean scores and standard deviation.

Table 6. 2 Means and Standard Deviations in Each Group

\begin{tabular}{llcc}
\hline Group & $\mathrm{N}$ & $\mathrm{M}$ & $\mathrm{SD}$ \\
\hline Implementation & 30 & 13.17 & 4.42 \\
Comparison & 31 & 14.03 & 4.23 \\
\hline
\end{tabular}

As can be seen, although the mean score of the comparison group was slightly higher than the implementation group, the result of the Levene's test of equality of variance and independent sample $t$ test (see Table 6.3) yielded no difference in terms of the pre-test score analysis, $t(59)=.781, p=.438$. This was also confirmed in the effect size analysis result where there was no significant difference between the two groups in terms of their reading proficiency $(d=0.19)$. It can be said that the pre-test scores maintained significantly equal variances in both groups as there was not enough statistical evidence to reject the null hypothesis stated above. Therefore, the assumption of homogeneity of variance was met and the use of an independent sample $t$ test is appropriate (Pallant, 2013).

Table 6. 3 Independent Sample $t$ Test on Pre-Test

\begin{tabular}{lllll}
\hline & $\mathrm{t}$ & $\mathrm{df}$ & Sig. (2-tailed) & Mean difference \\
\hline Pre-test & .781 & 59 & .438 & .866 \\
\hline
\end{tabular}


Since the homogeneity of variance assumption was met, it is important to discuss a normal distribution of dependent variables (post-test and delayed-test scores) for each group and at each time.

\subsubsection{A normal distribution}

This assumption means comparing two independent groups on a continuous outcome (the post-test and delayed-test score). This test is one of the assumptions that need to be met before running an independent sample $t$ test. Normality of a continuous distribution is evaluated using a Shapiro-Wilk test in this study (Green \& Salkind, 2011). To meet the statistical assumption of normality, the Shapiro-Wilk (the $p$-value) should be above.05. If the Shapiro-Wilk result is below.05, an independent sample $t$ test should not be conducted on continuous variables that violate the assumption of normality. The following figures (Figures 6.1 to 6.4), present the distributions of the two dependent variables (the post-test and delayed-test of both groups). The histograms and Q-Q plots of the immediate post-test and delayed-test below show that there are approximate normal distributions of the test scores between the two groups as there are approximately normal curves and the pattern of dots in the plot lie close to straight lines.

This means that the immediate post-test and delayed-test scores are approximately normally distributed, suggesting that the use of an independent sample $t$ test was appropriate.

In terms of the Shapiro-Wilk test, the results indicated that the dependent variables (post- and delayed-test scores) were approximately normally distributed (see Table 6.4) as both $p$-values are above $.05\left(p_{1}=.239\right.$ and $\left.p_{2}=.061\right)$. The results revealed that there were approximate normal distributions from the dependent variables of the two groups. Therefore, the assumption of normality on dependent variables was met. 
Table 6. 4 Normality of Dependent Variables

\begin{tabular}{lccc}
\hline \multicolumn{3}{c}{ Tests of Normality } \\
\hline & \multicolumn{3}{c}{ Shapiro-Wilk } \\
\cline { 2 - 4 } Statistic & $\mathrm{df}$ & Sig. \\
Post-Test & .975 & 61 & .239 \\
Delayed-Test & .963 & 61 & .061 \\
\hline
\end{tabular}

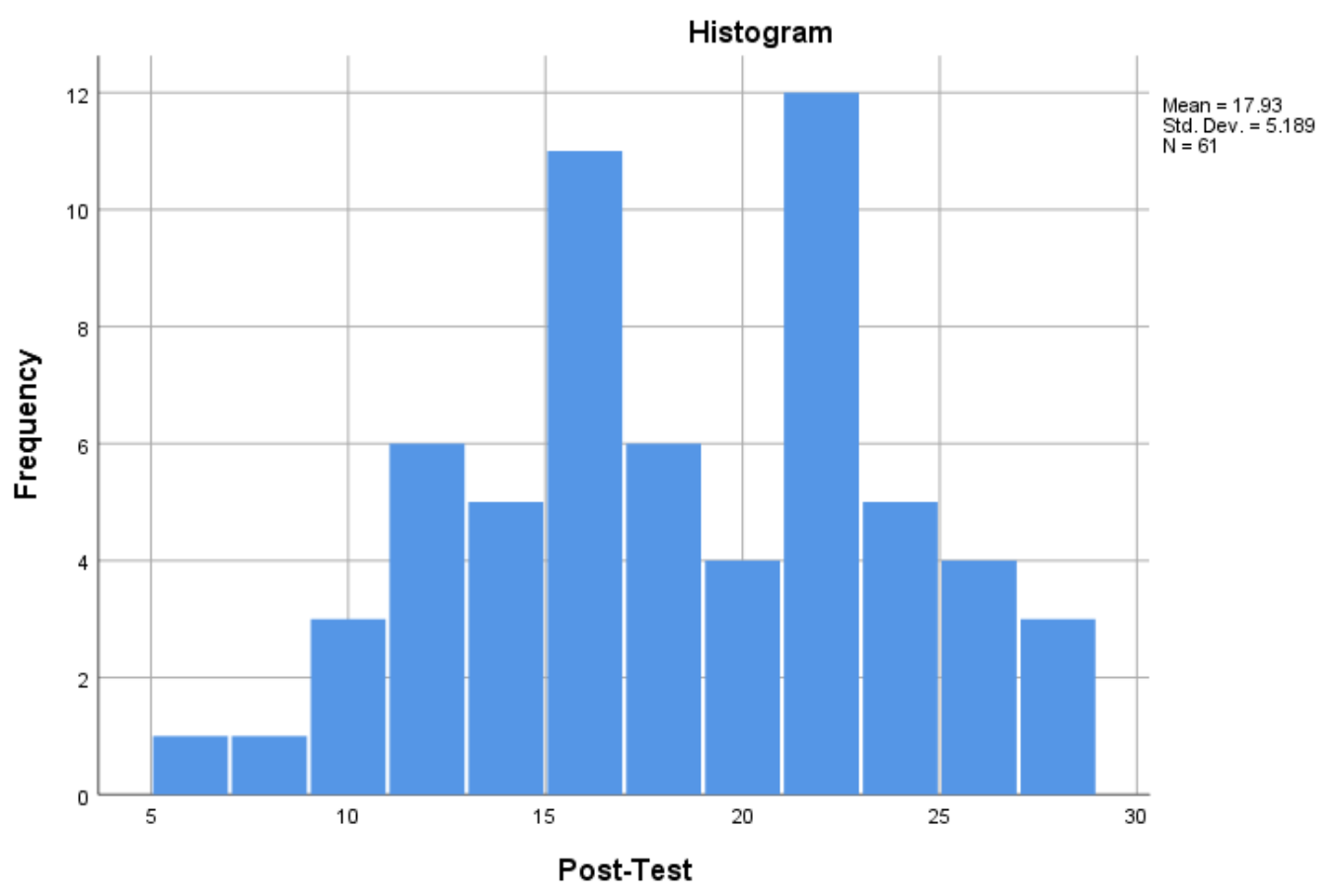

Figure 6. 1 Histogram of Post-Test 


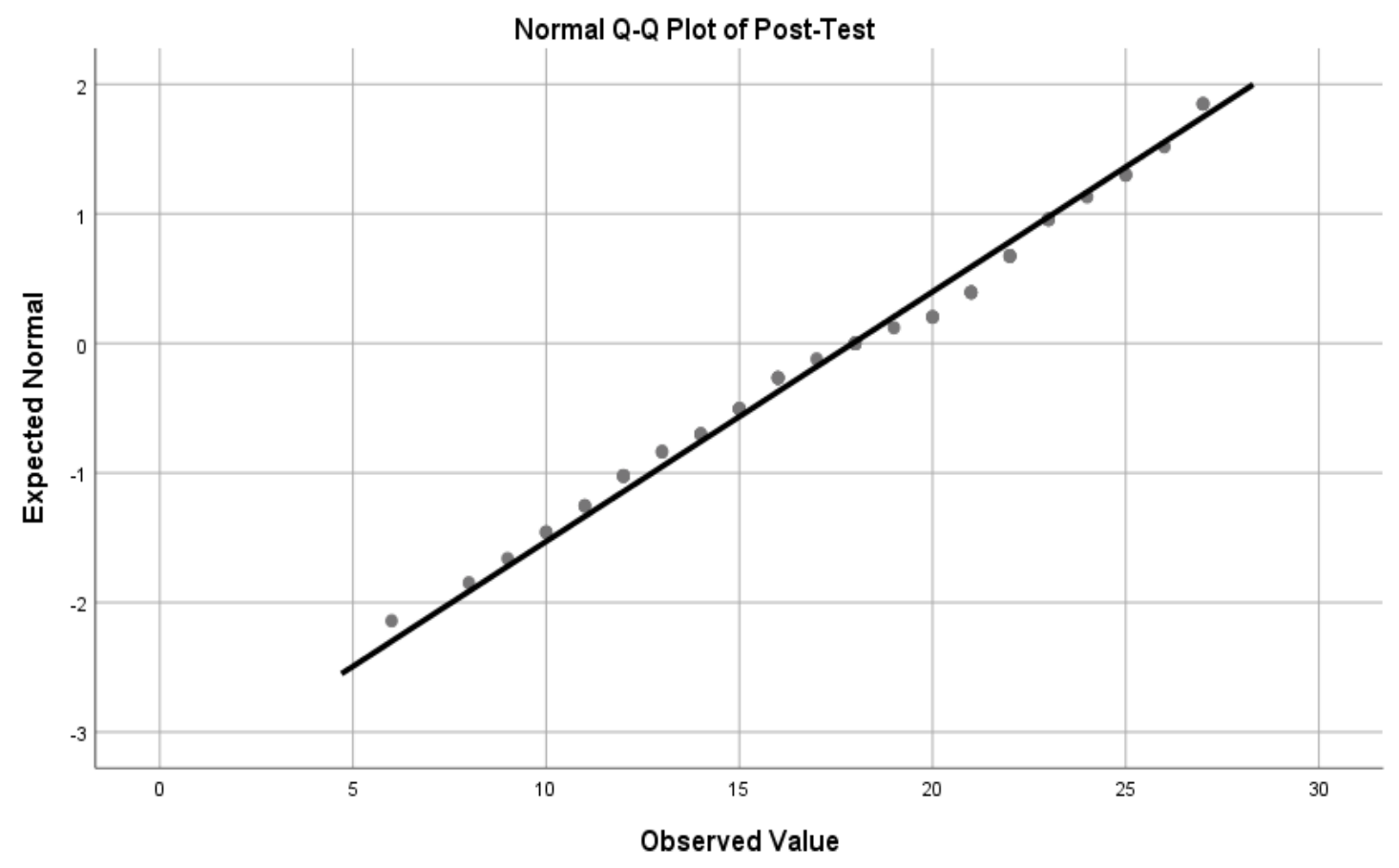

Figure 6. 2 Normal Q-Q Plot of Post-Test 


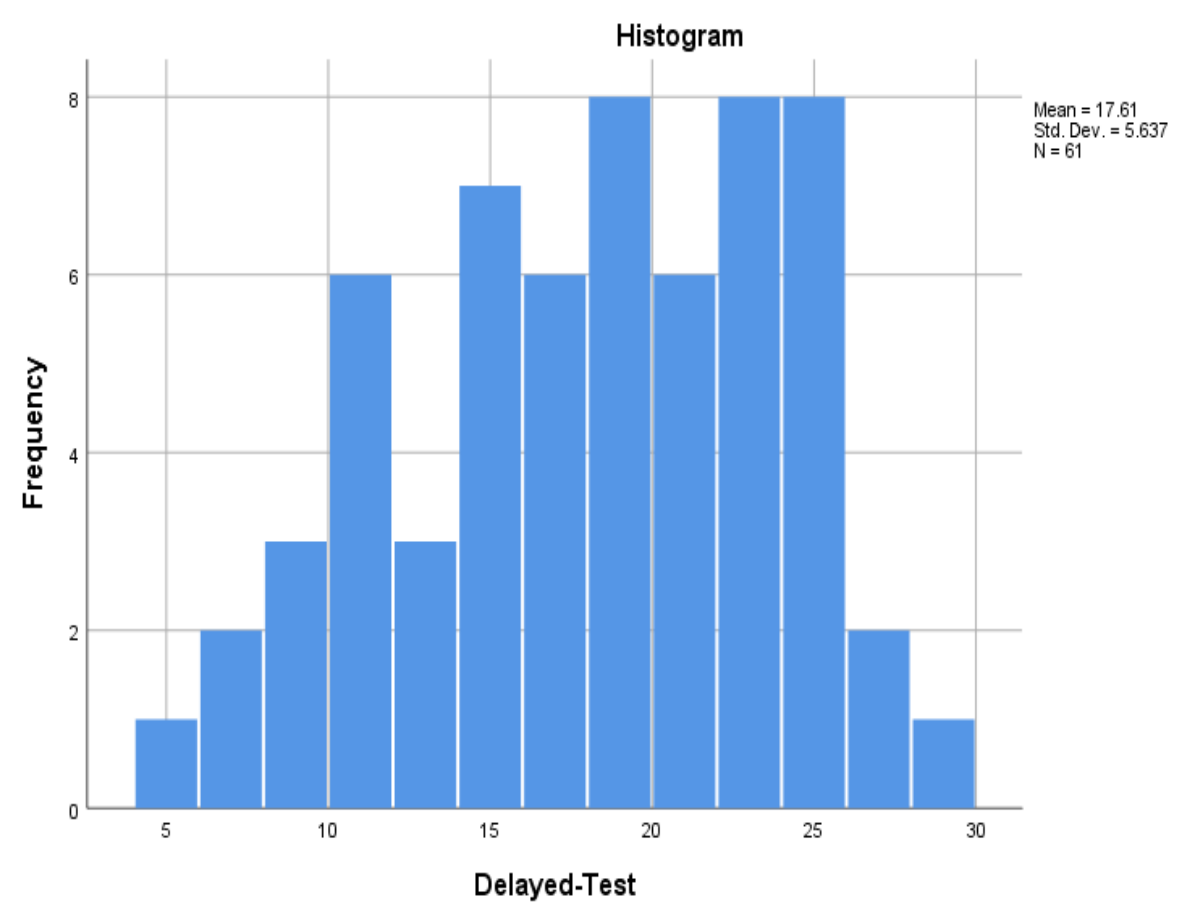

Figure 6. 3 Histogram of Delayed-Test

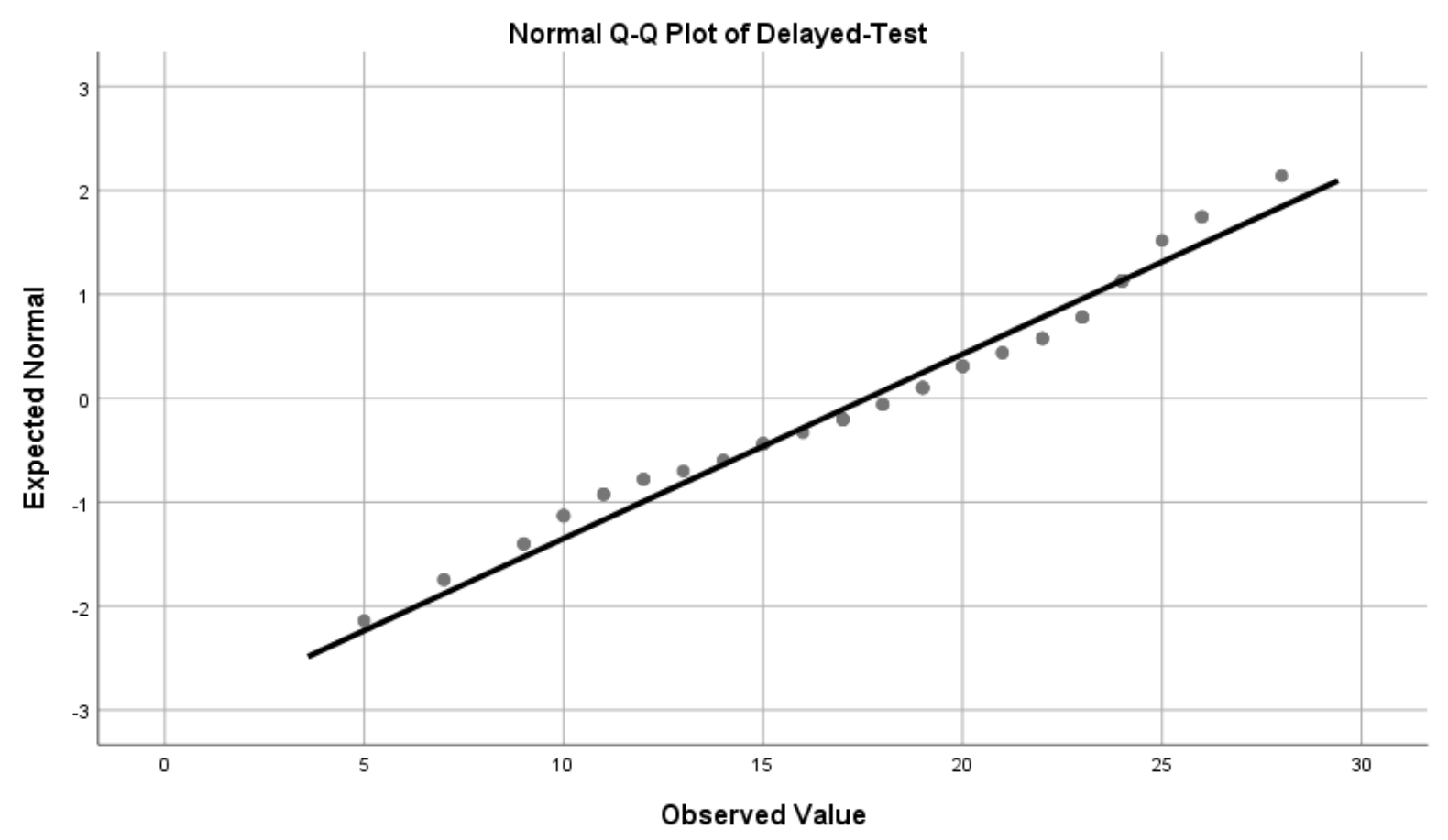

Figure 6. 4 Q-Q Plot of Delayed-Test 
Since normality was performed and the assumption was met, it is worth looking at independence of observations assumptions before conducting an independent sample $t$ test on the results of the immediate post-test and delayed-test.

\subsubsection{Independence of observations}

This assumption means that scores of each person or case are assumed to be counted only once. As Pallant (2013, p. 222) points out, "scores cannot appear in more than one category or group, and the data from one subject cannot influence the data from another". In this study, scores from participants are independent of others (Field, 2005) since there are two independent groups exposed to different independent variables (a CoT versus a traditional method of instruction). In addition, each participant was seated at a table each when taking the pre-, post-, and delayed-test to minimize the possibility of cheating. Therefore, it can be said that this assumption was met and the use of an independent sample $t$ test is appropriate in this aspect. Once all assumptions underlying independent sample $t$ tests have been met, analysis of the post-test and delayed-test scores can proceed.

\subsubsection{A post-test results}

A post reading test (same as the pre-test) was administered to both groups immediately after the implementation (June 20 $0^{\text {th }}, 2018$ ). Given the gap between the pre- and post-test and the fact that students did not receive feedback on the pre-test, the likelihood of the pre-test affecting the post-test results is discounted. As a reminder, the null hypothesis stated:

$\mathbf{H}_{01}$ : Reading comprehension will not improve for pre-service teachers with a CoTbased instruction compared to those without it.

An independent sample $t$ test was performed to test this hypothesis and the results are presented in the following section. In this regard, the first dependent variable was the immediate post-test mean scores. Table 6.5 presents the mean and standard deviation of 
the post-test and Table 6.6 outlines the results of the independent sample $t$ test used to test the hypothesis stated above.

Table 6. 5 Means and Standard Deviations of Pre-Test and Post-Test

\begin{tabular}{lccccc}
\hline Group & $\mathrm{N}$ & \multicolumn{2}{c}{ Pre-Test } & \multicolumn{2}{c}{ Post-Test } \\
\cline { 3 - 6 } & & $\mathrm{M}$ & $\mathrm{SD}$ & $\mathrm{M}$ & $\mathrm{SD}$ \\
\hline Implementation & 30 & 13.17 & 4.42 & 20.30 & 4.15 \\
Comparison & 31 & 14.03 & 4.23 & 15.65 & 5.11 \\
\hline
\end{tabular}

Table 6. 6 Results of an Independent-Sample $t$ Test on Post-Test

\begin{tabular}{lllll}
\hline & $\mathrm{t}$ & $\mathrm{df}$ & Sig. (2-tailed) & Mean difference \\
\hline Post-test & 3.894 & 59 & .000 & 4.655 \\
\hline
\end{tabular}

As Table 6.5 shows, there was a significant effect of the CoT implementation on the preservice teachers' reading comprehension, $t(59)=3.894, p=.000<.05$. The effect size was $(d=1.01)$, indicating a strong effect of the CoT. There was a significant difference between the two groups on the post-test mean scores. Therefore, there was enough evidence to reject the null hypothesis and conclude that after the 13-week CoT implementation, the experimental group outperformed the comparison group. To gain an insightful explanation into this improvement, results of qualitative data will provide further evidence to this in section 6.3 and chapter 7.

\subsubsection{A delayed test data analysis}

To measure pre-service teachers' reading comprehension retention and to confirm the immediate post-test results, a delayed-test (same as the pre-and immediate post-tests) was administered to both groups (July 4th 2018 ) two weeks after the immediate posttest. It was conducted just two weeks after the immediate post-test as the participants were about to take their summer break. To compare the scores, an independent sample $t$ test was run. The mean and standard deviation of the test are presented in Table 6.7. 
Table 6. 7 Means and Standard Deviations of Delayed-Test

\begin{tabular}{llcccc}
\hline Group & $\mathrm{N}$ & \multicolumn{2}{c}{ Post-Test } & \multicolumn{2}{c}{ Delayed-Test } \\
\cline { 3 - 6 } & & $\mathrm{M}$ & $\mathrm{SD}$ & $\mathrm{M}$ & $\mathrm{SD}$ \\
\hline Implementation & 30 & 20.30 & 4.15 & 20.57 & 4.17 \\
Comparison & 31 & 15.65 & 5.11 & 14.74 & 5.42 \\
\hline
\end{tabular}

As can be seen, the mean score of the delayed test of the experimental group remained relatively stable compared to the immediate post-test while the comparison group's delayed-test mean score was slightly lower. To see whether the mean score of the two groups was statistically significant, the analysis of an independent sample $t$ test was performed and the results are presented in Table 6.8.

Table 6. 8 Results of an Independent Sample $t$ Test on Delayed-test

\begin{tabular}{lllll}
\hline & $\mathrm{t}$ & $\mathrm{df}$ & Sig. (2-tailed) & Mean difference \\
\hline Delayed test & 4.687 & 59 & .000 & 5.825 \\
\hline
\end{tabular}

It can be indicated that there was a significant difference in the delayed-test mean score between the two groups, $t(59)=4.687, p=.000<.05$ and there was a strong effect size $(d=1.19)$ Therefore, there was enough statistical evidence to confirm the results of the immediate post-test and conclude that the CoT implementation improved pre-service teachers' reading comprehension. Table 6.9 summarizes the mean scores and standard deviations of the pre-, post-, and delayed-test between the groups.

Table 6. 9 Summary of Pre-, Post-, and Delayed-Test between Groups

\begin{tabular}{lccccccc}
\hline Group & $\mathrm{N}$ & \multicolumn{2}{c}{ Pre-Test } & \multicolumn{2}{c}{ Post-Test } & \multicolumn{2}{c}{ Delayed-Test } \\
\cline { 2 - 8 } & & $\mathrm{M}$ & $\mathrm{SD}$ & $\mathrm{M}$ & $\mathrm{SD}$ & $\mathrm{M}$ & $\mathrm{SD}$ \\
\hline Implementation & 30 & 13.17 & 4.42 & 20.30 & 4.15 & 20.57 & 4.17 \\
Comparison & 31 & 14.03 & 4.23 & 15.65 & 5.11 & 14.47 & 5.42 \\
\hline
\end{tabular}

Figure 6.5 below visualizes the estimated marginal means of the two groups under each time point. As can be seen, the implementation group outperformed the comparison group in terms of reading comprehension development after the CoT implementation. 


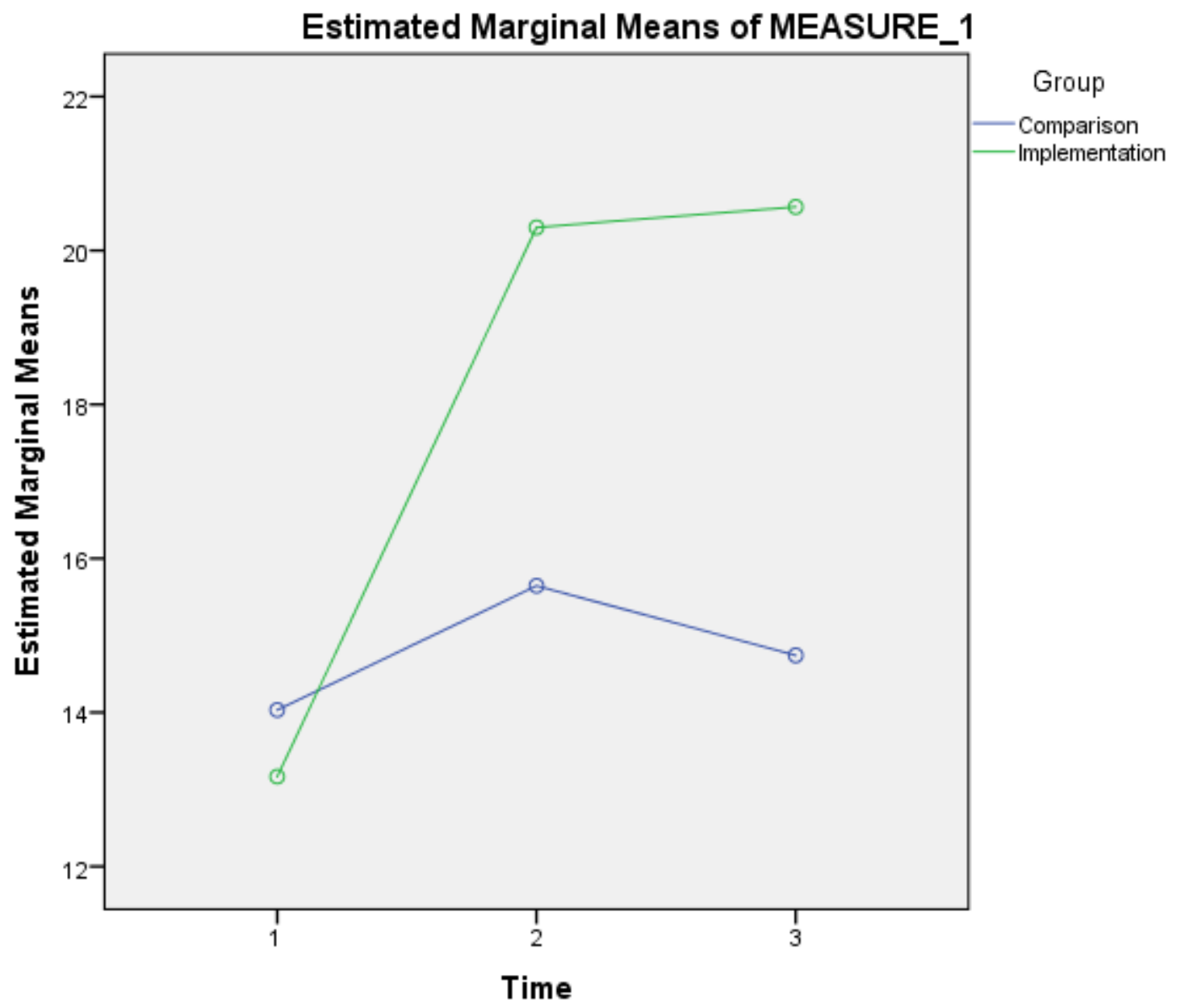

Figure 6. 5 Profile Plots of Estimated Marginal Means between the Groups

In conclusion, the goal of the quantitative analysis was to find out whether the CoT implementation improved Lao EFL pre-service teachers' reading comprehension. The statistical results indicate that the experimental group experienced a significant improvement in the immediate post-test, and this remained stable in the delayed-test compared to the control group. This means that integrating a CoT into teaching English reading benefited Lao EFL pre-service teachers. Further explanations relating to proficiency development will be drawn from the focus group interview results in chapter 7. The following section will look at the results of reading learning engagement from direct classroom observations. 


\subsection{Qualitative findings in terms of student engagement}

As stated in the previous section and chapter 4, a qualitative method was used to triangulate data. Furthermore, it was intended to seek critical insights into the issues that could not be answered through the statistical numbers. Although the statistical results in the previous section revealed the evidence of a CoT's effectiveness on reading comprehension development, these results should be double checked through another approach before accepting the findings. RQ4 asked:

How do Lao EFL pre-service teachers engage in classroom-based reading in the CoT and comparison classes?

As indicated in the literature chapter, engagement theory will be discussed in this section to help readers understand how it was measured and analyzed. Section 6.3.1 looks at the definition of student engagement. Section 6.3.2 addresses student engagement and reading achievement. Section 6.3.3 details the operationalization of learning engagement. Section 6.3.4 presents the emerging patterns of student engagement. Section 6.3.5 focuses on student engagement in terms of the cultural forces. Finally, section 6.3.6 presents student engagement in terms of Bloom's taxonomy.

\subsubsection{Defining student engagement}

The term student engagement is widely used and discussed in education due to its influential role in fostering learning outcomes and academic achievement (Fredricks, 2004; Ng \& Brendan, 2017). Thus, understanding its meaning and related dimensions is beneficial. Guthrie, Wigfield, and You (2012, p. 601) define engagement as "involvement, participation, and commitment to some set of activities". In other words, it refers to students' dedication to completing learning tasks or activities facilitated by the teacher in order to achieve specific learning outcomes. Student engagement can be fostered through a wide variety of learning activities: individualized or collaborative (Philp \& Duchesne, 2016), depending on the teacher. Student engagement is also viewed as "a state of heightened attention and involvement, in which participation is reflected not only in the cognitive dimension, but in social, behavioral, and affective dimensions as 
well" (Philp \& Duchesne, 2016, p. 52). Since these dimensions are important, it is worth discussing them briefly for this purpose.

Cognitive engagement is an act of thinking in learning that cannot be seen or touched but can be indicated in terms of questioning, exchanging ideas, reasoning, making an evaluation, or giving explanations. It can also be demonstrated by phrases such as I think, by causal connectives such as because and by questions (Philp \& Duchesne, 2016, p. 5). Based on this, I was able to examine such indicators when analyzing the observational data and measuring what students experienced in the classroom. Social engagement refers to the act of working or interacting with others through participating in learning activities. This can be seen through collaboration and interaction among members of the learning community (Storch, 2002). Behavioral engagement is primarily concerned with the amount of time that students actively spend on tasks or interactions in order to achieve the learning outcomes. It can be measured by observing the students' efforts applied to tasks and compliance with classroom rules or norms (Fredricks, 2004; Fredricks \& McColskey, 2012). Affective or emotional engagement refers to students' feelings or reactions to the learning activities, which include: interest, boredom, happiness, anxiety, feeling of belonging to the learning community to name a few (Fredricks \& McColskey, 2012).

It can be seen that student engagement encompasses a myriad of factors and dimensions (Darr, 2012) and keeping these in mind is helpful when it comes to analyzing student engagement. It is also important to look at its role in learning, particularly for this study in reading.

\subsubsection{Student engagement and reading achievement}

As stated in the literature chapter, reading is a complex and interactive process that requires a reader's effort, attention, interaction, and engagement to cognitively construct meaning of the text based on visually encoded information (Grabe \& Stoller, 2011; Koda, 2007). Research has highlighted the benefits of engagement to learning gains and academic achievement (Guthrie, 2004; Guthrie \& Cox, 2001; Guthrie et al., 2012). As 
Christenson, Reschly, and Wylie (2012) point out, engagement helps increase comprehension and achievement in learning because it fosters students' effort, attention, and energy. These qualities are important for meaning construction since reading, as stated, is a complex and cognitive process (Grabe \& Stoller, 2011).

In addition, engagement enhances motivation, skills use, and social interactions (Guthrie et al., 2012; Ritchhart et al., 2011). Student motivation includes "goals, intrinsic and extrinsic motivation, values, self-efficacy, and social motivation” (Guthrie et al., 2012, p. 603). These facets stimulate students to use their cognitive dispositions to attend to, or construct meaning of the text. Skills use refers to "students' multiple cognitive processes of comprehending, self-monitoring, and constructing their understanding and beliefs during reading" (Guthrie et al., 2012, p. 603). These characteristics are helpful and should be taken into consideration when analyzing learning engagement data. Social interactions, as stated earlier, refer to collaboration in the learning community among group members in achieving the learning goals. This in turn fosters students' comprehension and develops a sense of community learning (Guthrie et al., 2012). In brief, student engagement plays a key role in learning processes and outcomes and should be promoted during a course of instruction including reading to develop better and critical readers.

\subsubsection{Operationalizing learning engagement}

In order to measure student engagement, a number of steps were followed to seek answers to the research question. First, all observational data and field notes were transcribed and analyzed using thematic analysis as pointed out in the methodology chapter. Second, the emerging themes or patterns were measured using CoT forces as discussed in the literature review. The primary reason supporting the adoption of these forces is because they are the shapers or transformers of a passive classroom culture to a more interactive and meaningful learning orientation (Ritchhart et al., 2011). By following this, I was able to provide insights into what was intended to be fostered and what students experienced in the classroom in relation to learning reading between the two classes. Finally, the Bloom's Taxonomy framework discussed in section 3.4.8 was 
employed to measure the level of student engagement and what they experienced in the classroom (Bloom et al., 1956). I begin by introducing major themes or patterns of student engagement, followed by the results of measurement in terms of the cultural forces and finally Bloom's Taxonomy.

\subsubsection{Emerging patterns of student engagement}

Based on the lesson plans and observation data analyses, it was found that student engagement patterns differed considerably between the classes (see Table 6.9). This was expected because the implementation class had lesson plans designed to promote interactive and meaningful learning. However, what was intended in the lesson plans was not always what students experienced in the classroom. In the implementation class, the most common pattern was activating prior knowledge in the pre-reading stage. Activating students' background knowledge of the topic has beneficial effects on comprehension because it provides a framework for making connections to what students already have with new information or concepts to be read (Kostons \& Werf, 2015; Perlazzo \& Sypnieski, 2018). This also allowed them to use their content schemata in constructing meaning of the text.

Another intended pattern was silent reading and meaning construction, which was fostered during the while-reading stage. Research has pointed out that comprehension is fostered and enhanced when students read silently, as opposed to reading aloud (Hiebert \& Daniel, 2018; Jiang, 2015; Mano \& Guerin, 2018). What was also evident in the implementation class was that it was intended that pre-service teachers answer meaningful comprehension questions (e.g., summary completion, short answer questions, identifying paragraph purposes, etc.). Meaningful comprehension questions refer to questions that focus students' attention on meaning construction, analysis, synthesis, and evaluation (Bloom et al., 1956). This allowed them to apply skills or strategies learned and use higher-order thinking while interacting with the text and with peers. This reflects engagement roles in enhancing skills use discussed in section 6.3.2. 
Another intended student engagement pattern was connecting new knowledge to existing knowledge or information. This allowed students to broaden their perspectives and think beyond the immediate context (Ritchhart et al., 2011). A final expected student engagement pattern was collaborative learning. This was evident during the 13-week observation. It offered significant affordances for the students to cooperate toward a joint objective, which resulted in interactive and meaningful learning (Turner, Christensen, Kackar-Cam, Trucano, \& Fulmer, 2014). Research has pointed out that when students work productively in groups, they develop positive attitudes toward their peers and meaningfully engage in understanding content (Johnson \& Johnson, 1989; Roseth, Johnson, \& Johnson, 2008). This contrasted with the comparison class where common patterns of student engagement focused on discrete reading features, telling stories, reading aloud, translating, answering literal comprehension questions, vocabulary and grammar focus, and individualized learning. These patterns also reflect the results of prior reading learning experiences presented in chapter 5 and the concept of 'apprenticeship of observation' (Lortie, 1975) stated in the literature chapter. While these play a role in learning reading, they are still insufficient for the development of better and analytical readers. Table 6.10 below summarizes engagement patters.

\section{Table 6. 10 Summary of Student Engagement Patterns}

\begin{tabular}{ll}
\hline \multicolumn{1}{c}{ Implementation class } & \multicolumn{1}{c}{ Comparison class } \\
\hline 1. activating prior knowledge of topics; & 1. telling stories and translating; \\
2. silent reading and meaning & 2. reading aloud and translating \\
construction; & texts; \\
3. answering meaningful & 3. answering literal \\
comprehension questions; & comprehension questions; \\
4. making connections and reflecting on & 4. discrete language skills learning; \\
ideas learned; and & and \\
5. cooperative learning. & 5. individualized learning. \\
\hline
\end{tabular}

It can be noticed that student engagement patterns differed in a number of important ways as intended by the lesson plans designed to promote interactive learning in the 
implementation class. To gain a deeper insight into how these patterns reflected and represented what students experienced in learning reading in both classes, section 6.3.5 will look at this in terms of the cultural forces.

\subsubsection{Learning engagement in terms of cultural forces}

As stated in section 3.4.4.2, CoT cultural forces are viewed as the shapers for classroom transformation. As a reminder, the eight forces include: expectations, language, time allocation, modeling, opportunities, thinking routines, interactions, and learning environment.

\subsubsection{Expectations}

As pointed out in the literature chapter, expectation here refers to the expectation for students, not of students. In other words, it refers to the expectation that learning will be deep and meaningful as outcomes instead of mere completion of work (Ritchhart et al., 2011). In this respect, the results showed that the way in which expectations were established differed considerably between the classes. In the implementation class, the expectations for students were clearly set and intended to foster active learning. The most common expectation that was evident was encouraging students to activate prior knowledge of the topic through a variety of thinking routines before interacting with the text. Students' prior-knowledge activation is essential for acquiring new knowledge and has an important function in comprehension (Fisher \& Frey, 2012; Stahl, Sinatra, \& Gregory, 1991). This was intended to equip students with ease in extracting meaning and evaluating the text. Another common expectation was stimulating students to construct meaning of the text. This was evident in every lesson using the Claim-Support-Question (96\%) and Compass Point (4\%) thinking routines. As stated earlier, the ultimate goal of reading instruction is comprehension. Without this, reading has not been achieved. As Pardo (2004) points out, comprehension is "a process in which readers construct meaning by interacting with the text through the combination of prior knowledge and previous experience, information in the text, and the stance the reader takes in relationship to the text" (p. 272). As the definition demonstrates, many factors are involved in constructing meaning. Keeping these in mind is helpful when it comes to 
teaching reading. Other means of expectations set included: seeking evidence, making connections, collaborative learning, and developing critical reading skills. Examples of these can be seen in Lesson 18's objectives as follows and another example can be seen in Appendix 11:

- activating prior knowledge of the topic;

- summarizing the main ideas of the text and paragraphs;

- identifying key information; and

- developing ideas by focusing on the substance of the text and new words.

These features of expectations were clearly established and implemented in the implementation class. An example of what students experienced in meaning construction is demonstrated in Extract 6.1 below. Prior to sharing the main claim of the text, students were asked to read silently and write down the main point and supporting evidence in English. This allowed them to use the target language in exchanging ideas on the issue being focused on.

\section{Extract 6.1}

01 S1: What do you think the main claim of the text is and why?

02 S2: I think the main idea of the text is about the popular.... of extreme sports.

03 Ss: Hmm [Nodding heads].

04 S1: What's the supporting evidence? What makes you say that?

05 S2: Because .... I think the main evidence is stated in lines 8 and 9 of the reading text [S2 reads from text: Indeed, extremes sports, or alternative sports as other people to call them, attract people of all ages, including parents with their children]. This means that alternative sports are popular.

06 S3: I agree because it is talking about the popularity of alternative sports or extreme sports. People choose to do them over the traditional ones.

07 S4: I have the same idea because the main point of it is about the famous of extreme sports as people become interested in doing these. The phrase 'attracts people of all ages' shows how these sports are very interesting to do.

08 S5: แ่่มละ [Yes, that's right]. It is about the popularity of these sports.

09 S6: It is very popular and many people are playing them now. For example, people come to Vangvieng [a city in Laos] to do hot air balloon rides and zip line.

10 S5: Hmm. I want to try some of these but I don't have enough money [LAUGH].

11 S1: Yeah. I think you guys are right because the text is talking about the popularity of the ... alternative sports or extreme sports you call them.

12 S5: Yeah, I agree. So, what should we say when summarizing the main idea of the text? We need to summarize it in our own words, right?

13 Ss: Yeah. 
14 S6: I think it should be 'popularity of extreme sports'. How does it sound?

15 S2: Not bad. I think it should be 'the popularity of extreme sports'.

16 S3. Yeah. That sounds better. Agree?

17 Ss: Yeah.

(Observation 18: May 4th 2018)

As the extract shows, student interactions reflect many important features of the expectations set in Lesson 18 above and learning engagement dimensions discussed in section 6.3.1. The six students exchange their ideas in terms of extracting meaning of the text and identifying key evidence or information in support of their ideas. In turn 02, S2 exchanges his ideas regarding meaning of the text with his peers by pointing out the key term 'the popular of...extreme sports' and in turn 05 he provides evidence in support of his position by referring to lines and information in the text. This effort reflects behavioral engagement discussed in 6.3 .1 as he is doing his best to achieve the purpose. In turn 07, S4 (She) provides further information to support her ideas by pointing out a keyword 'attract people of all ages' which is stated in the text. In turn 12, S5 (he) reflects the summary skills by referring back to what he has learned in terms of meaning construction and seeking confirmation from his peers. This reflects skills use in extracting meaning of the text. These qualities of engagement also reflect social interaction where students interacted and exchanged ideas while working in groups. What is also interesting is that the extract reflects important features of cognitive engagement. This can be demonstrated in turns 02 and 05 where S2 uses 'I think' and 'because'.

This differed considerably from the comparison class where expectations for deep and meaningful engagement were seldom set as seen and reflected in the following patterns: telling stories, vocabulary, grammar, reading out loud, and translating texts. This type of preparation for the activity was found in $90 \%$ of the comparison class. Extract 6.2 below illustrates what students experienced in reading aloud and translating the text.

Extract 6.2

01 T: Paragraph 1? Who will start reading and translating first?

02 S1: I will start first. [The student is reading the paragraph aloud and translating it into the L1 as follows]. 
My main problem is that I lose all sense of time. I have no idea how long I've been playing for. The café windows where I play are covered up, so I don't know what time of day it is. I play for hours and hours, sometimes until the morning - and then I have to go school and feel terrible. I try to concentrate on my lectures, but all I really want to do is carry on playing the game! One player here in Shanghai killed another player because he stole, then sold, his cybersword so I realize it's bad.

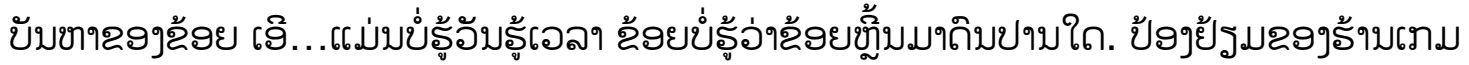

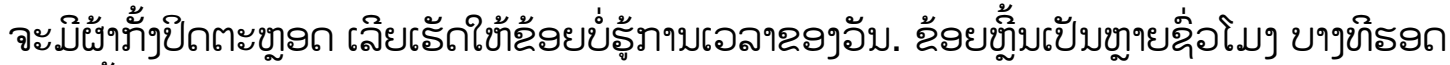

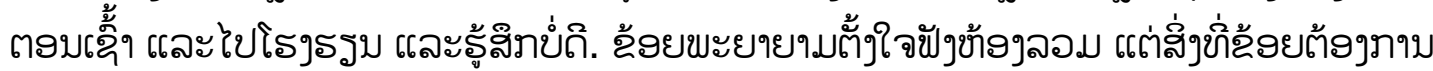

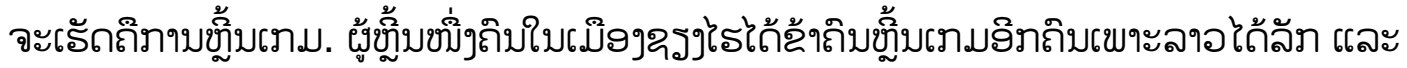

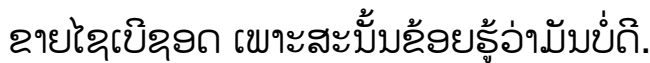

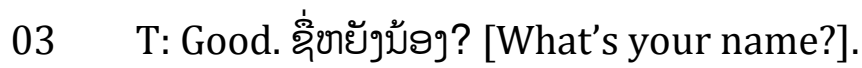

04 S1: My name's Kor.

05 T: Good job! Let's move to next paragraph. [The same pattern is continued for the subsequent paragraphs].

(Observation 6: April 19th, 2018)

Extract 6.2 above clearly reveals that the teacher's expectations of student engagement were mostly a matter of reading aloud and translating the text, as opposed to comprehension and critical reading development. In turn 01, the teacher expects the student to just complete reading aloud and translating. In turn 02 , the student reads the paragraph out loud and translates it into L1. In this sense, reading learning is a matter of mere completion of work, which encourages learning passivity as discussed in phase 1's results. In addition, this form of engagement reflects a lack of cooperative learning which is not adequate for the development of critical readers. What is also worth commenting on is in turn 01, the teacher asks who is able to read and translate first. This reflects an important element of the behavioral classroom rules or norms.

\subsubsection{Language}

As pointed out in the literature chapter, classroom language plays a significant role in fostering meaningful learning outcomes. Meaningful learning outcomes refer to enhanced comprehension and active participation in order to achieve the learning goal. This also helps to shape pre-service teachers' perceptions of learning and transform the passive classroom environment into an active learning community. Language in this sense refers to the teacher language that directs students' attention to engage in 
exploring ideas represented in the text and thinking beyond what is focused on. This stimulates them to evaluate, analyze, interpret, and give reasons towards their positions of issues being studied (Bloom et al., 1956; Ritchhart, 2015). It also reflects the important characteristics of cognitive engagement discussed in section 6.3 .1 because the teacher language use fostered thinking and encouraged students to expand their ideas. In this respect, the results showed that classroom language differed considerably between the classes. In the implementation class, the use of classroom language was oriented to a meaningful exploration of ideas and critical reading. An example of this can be seen in Extract 6.3 below, where the teacher encourages students to think beyond the context of what they have read through a Connect-Extend-Challenge thinking routine after meaning construction.

\section{Extract 6.3}

01 T: How does the idea or information about bloggers in the classroom connect to ideas you have or you already knew or learned in the past?

02 S1: Connect?

03 S2: It's connected.

$04 \mathrm{~T}$ : ผ่งมบขขอาเจ้้จรู้ร่รอภับ blog จั่งใด? [Did you know anything about blogs before learning this?]

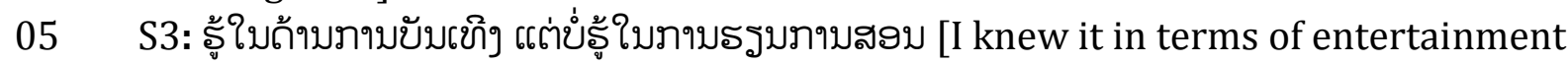
but not in education].

06 T: How about extending, what new ideas have you learned from this topic? The new idea. Did you get some ideas about this topic?

07 S4: Resources.

08 S5: I will learn how to use it in my daily life.

09 S6: ใด้ใช้เปขับปะโขทยถ แขบบางบเฉัดขาลิ้บ [Instead of using it for enjoyment, I will use it for - better beneficial purposes].

10 Ss: [CLAP HANDS].

11 T: Use it in a better and beneficial way. Any ideas? What new thinking have you learned in today's lesson?

12 S7: ไถ้ถำสับใช่ม [Lots of new words].

13 T: New words. How about concepts or ideas? You can find resources in the blog. Do you think the resources in the blog will be related to your field?

14 S8: No.

15 T: Why in learning and teaching? Why?

16 S9: In some fields?

17 T: In some fields, some areas? What do you want from the blog?

18 S10: We can create our own blogs. 
19 T: And how about challenges? So we have talked about this. What challenges have come up into your mind about the topic?

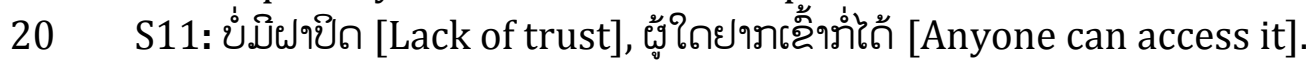

21 T: Hmm, no privacy.

22 S12: ภะฏ there is password.

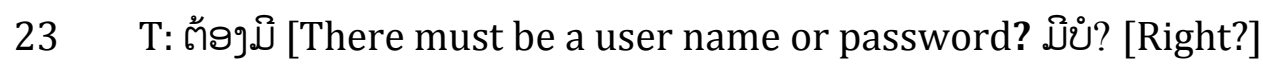

24 Ss: ปิงจจาม [Yes, there are].

25 S13: เล้อแต่เจ้้า299จะเปิถแบอใด สาขาละบะบฆู์ส่อบติอ [It depends on the blog owner, whether he wants it to be public or private].

26 S14: ปับภะถ้ายถ๊ [It is like Facebook].

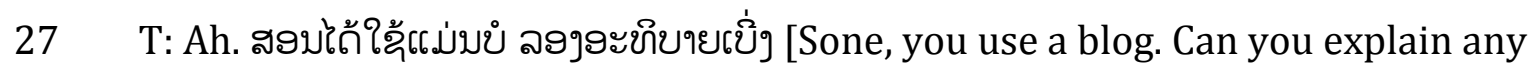
challenge?]

28 S15: ข้งจะเปับโถสะบาเฉาเอิ้ามๆ [Lots of interrupting ads].

29 T: Annoying right? Intrusive, interrupting ah and .... easy for other websites to interrupt or intrude.

30 S16: Virus also as well.

31 T: Virus also.

(Observation 15: April 6 ${ }^{\text {th }}$ 2018)

As can be seen, classroom language used by the teacher reflects several important features of Language of Thinking as discussed in the literature review. In turns $01,06,11$, $13,15,19$, and 27 , the teacher asks students critical questions in order to engage them in sharing and expressing ideas of what they have read about Bloggers in the classroom. This was intended to encourage students to think deeper and develop reasoning skills in addition to meaning construction after reading. This type of language or questions also fosters cognitive and metacognitive dispositions crucial for comprehension and the development of critical readers. Interestingly, there is the mixed use of language in sharing ideas. This can be noticed in turns 05, 09, and 25 where students switch to the L1. This reveals that the role of the L1 cannot be ignored in an EFL context when students have difficulty sharing ideas in the target language. What is also striking in this extract is that students are able to question the teacher to seek further clarification. This can be seen in turn 16 where S9 is seeking justification. This differed from the comparison class where classroom language primarily focused students' attention on recall knowledge (e.g., vocabulary) and superficial learning. Extract 6.4 reveals an example of this. 
Extract 6.4

01 T: Ok. Let's start. Number one? [T refers to the text: In line 1, what does the phrase 'I lost all sense of the time' mean?]

02 S1: [S1 refers to the phrase 'I have absolutely no idea what the time is' in the text].

03 Ss: Yeah.

04 T: Yes. Number two? [T refers to the text: In line 5, another way of saying 'I want to give all my attention to my lecture' is ...]

05 S2: [S2 refers to the phrase 'I try to concentrate on my lectures' in the text].

$06 \mathrm{~T}$ : เธัดใข้เสล้อ ถ้าปะไอ้วับมาจะล๊ม [We need to get this done because you might forget them after you come back from Lao New Year].

07 T: Ah. Number three. [T refers to the text: In line 13, which noun means someone who is not loyal to their country, friends, or family?]

08 S3: Myself [S3 refers to the word 'myself' in the text].

09 Ss: supernatural power [Ss refer to the word 'supernatural power' in the text]

10 S4: Which line?

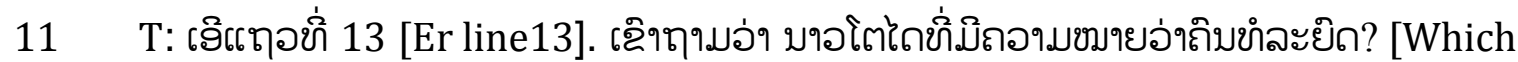
noun means someone who is not loyal to their country?]

12 Ss: a traitor [Ss refer to the word 'a traitor' in the text].

(Observation 5: April 11 th 2018 )

In Extract 6.4 there is a lack of language of thinking for the promotion of deep and meaningful learning. The teacher's language and questions direct pre-service teachers' attention to recall knowledge. In turn 01, the teacher asks a question that directs their full attention to identifying a word in the reading text that has a similar meaning to the phrase 'I lost all sense of time'. This can also be observed in turns 04 and 07 where language and questions focus student attention on mere completion of work, as opposed to meaningful engagement. This also reflects several features of the traditional teaching method, which still plays a principal role in the Lao EFL context and beyond (Emaliana, 2017). This approach limits opportunities for interactive and cooperative learning to occur. One similarity between Extracts 6.3 and 6.4, however, is that the teachers play a central role in drawing students' attention to thinking and answering questions even though the purposes and language use are different.

\subsubsection{Time allocation}

Time allocation is vital for the creation of successful and meaningful learning opportunities. As stated in the literature chapter, prioritizing time for a meaningful 
exploration of concepts in the reading text rather than sitting back waiting to be told what to do or be spoon-fed is important (Gettinger \& Walter, 2012). Although time allocation or management is significant, many teachers might ignore this when it comes to implementing their lessons, which minimizes students' deep and interactive learning opportunities. Time allocation in this respect refers to the extent to which time is prioritized for deep and meaningful learning so that active engagement can be optimized (Ritchhart et al., 2011). This also reflects the behavioral engagement characteristics as discussed in section 6.3.1. In this respect, time allocation differed from class to class. In the implementation class, in-class teaching and learning time was allocated to promote interactive engagement and a meaningful exploration of concepts represented in the text. For instance, $28 \%$ of the total teaching time (2,340 minutes/39 hours) during the 13-week implementation was given to prior knowledge activation, $11 \%$ was spent on inclass silent reading, $28 \%$ was allocated to meaning construction, $11 \%$ was managed for answering meaningful comprehension questions, and 22\% was given to extending students' ideas and reflection. This means that time allocation in this class was intended to accommodate and facilitate active learning (Britton \& Tesser, 1991; Kayode, 2015). In the comparison class, time was not effectively prioritized and managed. The results showed that in-class teaching and learning time was spent on discrete language skills: telling and translating stories (18\%), reading aloud and translating texts (21\%), answering literal or factual comprehension questions (26\%), grammar (12\%), greeting and talking about something outside of the lesson scope (12\%), and vocabulary and pronunciation (11\%). Among many of the differences between the two classes, the total absence of in-class reading time is striking for the comparison class students. In brief, the way in which in-class teaching and learning time was managed and allocated in both learning environments was significantly different. Table 6.11 below summarizes time allocation from each group. 
Table 6.11 Summary of Time Allocation

\begin{tabular}{lclc}
\hline \multicolumn{1}{c}{ Implementation } & $\%$ & \multicolumn{1}{c}{ Comparison } & $\%$ \\
\hline Activating prior knowledge & $28 \%$ & Telling and translating stories & $18 \%$ \\
In-class silent reading & $11 \%$ & Reading aloud and translating texts & $21 \%$ \\
Meaning construction & $28 \%$ & Answering literal or factual questions & $26 \%$ \\
Answering meaningful & $11 \%$ & Grammar focus & $12 \%$ \\
$\begin{array}{l}\text { comprehension question } \\
\text { Extending ideas and }\end{array}$ & & & \\
reflection & $22 \%$ & Talking about something outside the & $12 \%$ \\
\multicolumn{1}{c}{ Total } & & lesson scope & \\
\hline \multicolumn{1}{c}{} & & Vocabulary and pronunciation focus & $11 \%$ \\
\hline
\end{tabular}

\subsubsection{Modeling}

While reviewing related literature, I learned that what teachers/lecturers model or do in the classrooms has a profound influence on shaping students' perceptions and experiences of learning and teaching (Borg, 2003). Modeling in this regard refers to the teacher's pattern or mode of implementing and delivering lessons crucial for students to emulate and learn from. In this respect, the results revealed that how the instructional model or process was demonstrated to the pre-service teachers differed from class to class. In the implementation class, the most common models were the teacher acting as the learner as demonstrated in Extract 6.5 below or as the facilitator of the learning community as seen in Extract 6.3 earlier (Ritchhart et al., 2011), as opposed to the transmitter or fount of knowledge (Archana \& Rani, 2016; Richards, 2017). This helps create a safe, cooperative, and permissive learning environment opportunities for students to interact and explore ideas of the texts.

Extract 6.5

01 T: So...ah...before I ask you those questions, these questions [T is pointing at questions on the power point slide], I would like to remind you of the sport where there are many activities. First you are cycling and then you are swimming and then you are running. Have you ever seen? What is it called?

02 S1: Running?

03 T: Yes. So, there are four or three activities. 
04 S2: Marathon?

05 T: No. First, you're cycling and then you're swimming across the bay and then you're running.

06 S3: ไ๓ภ์ลา [A triathlon].

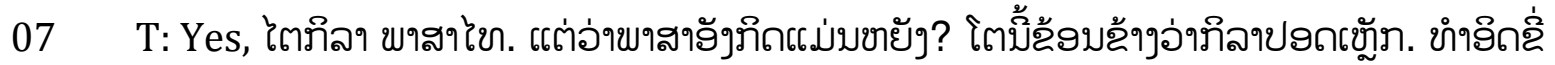

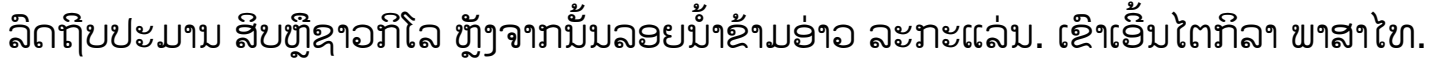
ขาสาจั่ภึถแม่บบ่อู้้. [Yes, that is Thai but what about in English? It is a type of sport that requires strength and patience. You first cycle about ten to twenty kilometers, then you swim across the bay and then continue to run. It is called לn ภ็ลๆ in Thai. I don't know in English].

08 S4: ใด้เธฮราบขูายขึ่สุด [It requires a lot of energy and effort].

$09 \mathrm{~T}$ : Yeah. Very, very, really, absolutely extreme. แล่บปะมาบ สิบภ์โล ละลงยมั้งิ๊ ปะมามสิ่ข้าธังยแอัด [You run around ten kilometers and then swim around four hundred meters].

10 Ss: Oh.

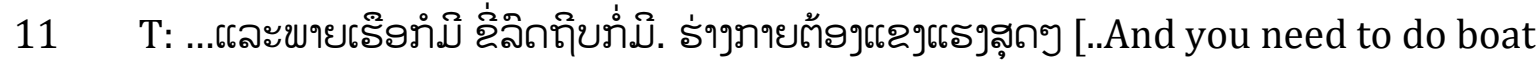
paddling or cycling. Your physical health must be very strong].

(Observation 18: May 4th 2018 ) It can be seen from Extract 6.5 above that the teacher acts as a member of the learning community; he is willing to learn from the students. In turn 01 , the teacher explains to students about a type of extreme sport and asks them whether they know it in English. The teacher is willing to get involved in learning and exchanging ideas with the students regarding the type of sport he is not sure about. In turn 07, the teacher's acknowledgement of a lack of knowledge in identifying the name of this sport reflects that he is not the fount of all knowledge of the topic but requires the students to share with him (Archana \& Rani, 2016). This also demonstrates that both the teacher and students are playing a cooperative role in learning which reduces a sense of stressful authoritarian learning atmosphere. In many EFL contexts, a teacher's acknowledgment of insufficient content knowledge in the presence of their students may not be acceptable as this could make the teacher lose face. Because of this, many teachers avoid talking about the issues that they lack confidence in. This contrasted with the comparison class where the teacher's role was transmitter of knowledge and the learner sole receiver of it. In addition, $90 \%$ of in-class learning models or patterns were teacher-centered, which 
reflects the existent use of the grammar-translation method (Larsen-Freeman \& Anderson, 2011). This interaction mode reflects the IRE where the teacher asks questions and, students respond, followed by an evaluation or feedback as seen in Extract 6.4 (Medina, 2001; Sinclair \& Coulthard, 1975). As employed here, this instructional model encourages passivity and plays a role in shaping pre-service teachers' experiences of learning English reading (Borg, 2006).

\subsubsection{Learning opportunities, thinking routines, and interactions}

As stated in the literature chapter, learning opportunities, thinking routines, and interactions are important features for learning achievement and enhanced comprehension of reading. They are also regarded as the classroom shapers (Ritchhart et al., 2011). Because of their interrelationships, the results of the analyses in terms of this are presented in an integrated manner. As a reminder, learning opportunities refer to inclass opportunities that engross students' attention to novel application, meaningful inquiry, effective communication, and perceived worth (Ritchhart et al., 2011). Thinking routines (activities) refer to procedures or patterns of activities employed regularly to promote active and meaningful learning. To measure this, I focused on the frequently used thinking routines that were selected for integration in the lessons (see Table 6.10). Finally, interactions are viewed as learning occasions when students are encouraged to participate, interact, communicate, and construct meaning of the text through a variety of thinking routines (learning activities) with an aim to achieve learning outcomes (Ritchhart et al., 2011). 
Table 6. 12 Summary of Integrated Thinking Routines

\begin{tabular}{|c|c|c|}
\hline Stages & Frequency & Purpose \\
\hline \multicolumn{3}{|l|}{ Pre-reading } \\
\hline 1. Chalk Talk & $35 \%$ & $\begin{array}{l}\text { To activate prior knowledge and invite all } \\
\text { students to engage in sharing ideas. }\end{array}$ \\
\hline $\begin{array}{l}\text { 2. See-Think- } \\
\text { Wonder }\end{array}$ & $23 \%$ & $\begin{array}{l}\text { To promote an inquiry-based discussion, } \\
\text { observation, interpretation, and curiosity. }\end{array}$ \\
\hline 3. $3-2-1$ & $19 \%$ & $\begin{array}{l}\text { To uncover prior knowledge, make } \\
\text { connections, evaluation, and reasoning skills. }\end{array}$ \\
\hline $\begin{array}{l}\text { 4. Think-Puzzle- } \\
\text { Explore }\end{array}$ & $19 \%$ & $\begin{array}{l}\text { To develop thinking skills, promote curiosity, } \\
\text { and exploration skills. }\end{array}$ \\
\hline $\begin{array}{l}\text { 5. Generate-Sort- } \\
\text { Connection- } \\
\text { Elaborate: } \\
\text { Concept Maps }\end{array}$ & $4 \%$ & $\begin{array}{l}\text { To foster creation, synthesis, connections, and } \\
\text { elaboration skills. }\end{array}$ \\
\hline Total & $100 \%$ & \\
\hline \multicolumn{3}{|l|}{ While-reading } \\
\hline $\begin{array}{l}\text { 1. Claim-Support- } \\
\text { Question }\end{array}$ & $96 \%$ & $\begin{array}{l}\text { To develop interpretation, evidence seeking, } \\
\text { and questioning skills. }\end{array}$ \\
\hline 2. Compass Point & $4 \%$ & $\begin{array}{l}\text { To encourage evaluation and perspective } \\
\text { taking skills. }\end{array}$ \\
\hline Total & $100 \%$ & \\
\hline \multicolumn{3}{|l|}{ Post-reading } \\
\hline $\begin{array}{l}\text { 1. Connect-Extend- } \\
\text { Challenge }\end{array}$ & $46 \%$ & $\begin{array}{l}\text { To connect, extend, and challenge ideas } \\
\text { represented in the text. }\end{array}$ \\
\hline $\begin{array}{l}\text { 2. Sentence-Phrase- } \\
\text { Word }\end{array}$ & $35 \%$ & $\begin{array}{l}\text { To develop skills in capturing the essence of } \\
\text { the text and justification. }\end{array}$ \\
\hline $\begin{array}{l}\text { 3. I used to } \\
\text { think...now I } \\
\text { think..... }\end{array}$ & $15 \%$ & $\begin{array}{l}\text { To foster reflection skills and thinking } \\
\text { development as a result of learning. }\end{array}$ \\
\hline 4. Headline & $4 \%$ & $\begin{array}{l}\text { To reflect and synthesize the essence or core } \\
\text { ideas in the text. }\end{array}$ \\
\hline Total & $100 \%$ & \\
\hline
\end{tabular}

To present the results of the three forces in a coherent and cohesive manner, I followed the three stages of reading instruction: pre-reading, while-reading, and post-reading as discussed in the literature review. In other words, indicators of what was intended in the 
lesson plan, and what students experienced were looked at during the three stages of reading instruction in relation to these three forces. The results revealed that learning opportunities, thinking routines, and interactions for student engagement were considerably different from class to class during the pre-reading stage. In the implementation class, the students successfully engaged in the activities that were designed to activate prior knowledge of the topic. This was conducted through a number of thinking routines that aimed to introduce and explore ideas of the topic: Chalk Talk (35\%), See-Think-Wonder (23\%), Think-Puzzle-Explore (19\%), 3-2-1 (19\%), and Generate-Sort-Connect-Elaborate: Concept Maps (4\%). Extract 6.6 shows what preservice teachers experienced that reflects important elements of the three forces through a Chalk Talk thinking routine to activate students' prior knowledge of the reading topic about 'Effect of Social Media on Teens'. In this interaction, students were encouraged to exchange ideas about the topic in groups and record them on large pieces of papers before displaying them on the classroom walls for further interactions and discussions with the other groups.

\section{Extract 6.6}

01 S1: Ok, Bounma (Pseudonym), you write the topic first.

02 S2: [S2 is writing the topic on the paper: Effects of Social Media on Teens].

02 S3: Advantages and disadvantages.

03 S1: โ๓ words ग่งบ [Let's focus on words first].

04 S3: List words ท่งบ เละ จารบั้บเปับไดเถย [first and then ideas]. [LAUGH] First word is ... uh, addictive, communicate ...

05 S2: Teacher, do we have to do on mind maps ... or ...?

06 T: depends .... mind mapping or you just write key words.

07 Ss: [LAUGHS]

08 S3: Common ideas.

09 Ss: Ah ... Internet, effects, websites, applications, connect, connection,

10 S2: ๙ง่มขายัตรภาะ ถิบขึ่อ่า [What's the word for ...?]

11 S3: What do you want to say, Bounma?

12 S2: ถิบขึก้องรฉองขั้บบา? [Globalized?]

13 S3: Global?

14 S4: Globalization?

15 S2: 2รบเบอใด? [How do spell it?]

16 S5: ป็นออบำ [It has an $\mathrm{L}$ after $\mathrm{G}, \mathrm{hmm}$ ]

17 S6: How about news? [ฉ่ๆอสาบ?] 
19 S3: Ah, advertisements.

20 S6: community,

21 S3: Commercial or advertisement [LAUGH]. Can you search the word on your smartphone to correct them?

22 S4: Here 'advertisement'

(Observation 11: March 23rd, 2018)

Extract 6.6 reflects important features of the learning opportunity, thinking routine, and interaction. In this activity, six pre-service teachers are working in groups following the Chalk Talk thinking routine procedures and trying to activate their prior knowledge of the topic. Through this, they brainstorm ideas and words crucial for meaning construction and comprehension. In turn 04, S3 tries to communicate with his peers about what and where to start to achieve the purpose of the learning activity. This attempt stimulates his peers to share ideas and concepts related to the issue being learned. For instance, in turn 09, students share ideas and words such as 'internet, effects, applications, communication, and connect/connection'. In turn 10, S2 tries to brainstorm a concept word related to the issue and asks his peers to think about the word 'globalization'. In turn 21, S3 asks the members of the group to search the word by using their smartphones. As can be seen, for the pre-service teachers, this experience is beneficial for the time, effort, and interaction they have invested in. This effort also reflects behavioral engagement as students are trying to achieve the task that complies with the classroom norm. This also shows the pattern of student-student interactions while the teacher acts as facilitator (Richards, 2017). What is also striking is that students were positively engaged in working in groups, which reflects the element of affective or emotional engagement. This can be demonstrated in turns 04 and 07 where students were laughing as they are exchanging ideas and belonging to members of the learning community. This experience, however, was not evident in the comparison class where most of the learning opportunities, thinking routines, and interactions directed pre-service teachers' attention to discrete language skills as noted earlier. An instance of this can be seen in Extract 6.7. 


\section{Extract 6.7.}

01 T: Ok before we start reading, I just want you to look at pre-reading one. Yeah, pre-reading talks about ... uh ... name a job that uses the following words: a needle, a drill, etc.

02 Ss: Yeah.

03 T: Ok, who uses a 'needle'?

04 Ss: doctors, nurses, tailors, and etc.

05 T: Yeah. And how about number 2? 'A drill'.

06 Ss: dentists, tattooists,

07 T: What else?

08 S1: Carpenters.

09 T: Yeah, carpenters, or maybe construction or workers. Ok. And how about number three? 'Plastic gloves.

10 Ss: Doctors, nurses, workers.

11 T: Workers, hmm?

12 S2: Cleaners.

13 T: Cleaners maybe. How about number four? 'A truck'.

14 Ss: Drivers.

15 T: Drivers? Hmm. And how about number five? 'Camouflage'.

16 S3: Magicians.

17 S4: Ninja.

18 S5: Hunters

19 T: Yeah. Maybe hunters.

20 S6: Soldiers.

21 T: Soldiers? Yeah, maybe solders. How about number six? 'Jewelry'.

22 Ss: Models.

23 T: Models [LAUGH]. Yeah, fashion models.

24 S7: Jewelers.

(Observation 9: May 2nd 2018)

Extract 6.7 demonstrates that what students experienced in the comparison class reflects a lack of an interactive and meaningful learning opportunity as its primary focus is on vocabulary knowledge, as opposed to prior knowledge activation. In turns $03,05,09,13$, 15 , and 21 , the teacher asks students to identify vocabulary about jobs that can go with the nouns about tools and goes over the answers with them. This mode of learning is not sufficient for establishing and activating their prior knowledge prior to meaning construction (Alfaki \& Siddiek, 2013). This also reflects the IRE pattern (Medina, 2001). In brief, pre-service teachers did not experience deep and meaningful learning opportunities to activate their prior knowledge of the topic, which would be beneficial for meaning construction. 
In the while-reading stage, student engagement opportunities, thinking routines, and interactions were also different from class to class as intended by the lesson plan. In the implementation class, students' attention was drawn to silent-reading and meaning construction of the text as stated in the section 6.3.5.3 through Claim-Support-Question (96\%) and Compass Point (4\%) thinking routines, which were intended to encourage active engagement in extracting meaning from the text. Furthermore, pre-service teachers were given a wide range of opportunities to answer meaningful comprehension questions during this stage: true/false/not given (19\%), summary completion (19\%), multiple choice (13\%), short answer questions (15\%), sentence completion (19\%), and paragraph heading matching (15\%). Extract 6.8 illustrates what students experienced in identifying the main idea of the paragraphs after silent-reading through a Claim-SupportQuestion thinking routine while working in groups.

Extract 6.8

01 S1: What's your idea?

02 S2: Paragraph 1. What do you think guys?

03 S3: What do you think about paragraph 1?

04 S4: Ah, many kinds ... of social media.

05 S2: It talks about someone who is very addicted to social media or...

06 S5: Me too.

07 S6: And they want to use social media at all the times.

08 S2: Yeah, even night times. And then where is key word?

09 S4: [S4 refers to text: turned off the Wi-Fi at $11 \mathrm{pm}$ ]

10 S5: What about you, Kham? What do you think about paragraph 2?

11 S4: โ๓ paragraph 2. ภับอ่าเบบ [I think..]

12 S3: ... ฮับตะลายต่่สุฉะขขบ [... effects of social media on health].

13 S4: เอิผิบภะขิบตั้สุฉะขดบ [Yeah, effects in terms of health].

14 S6: Hmm.

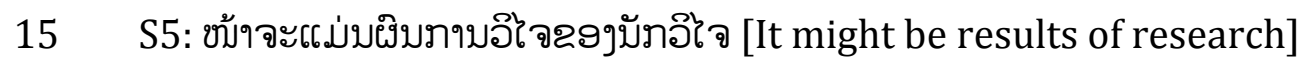

16 S2: What do you think about paragraph 2? What is the claim?

17 S4: ถอๆมส่ร9 [risk] ... depression .... effects ... on healthy. ถ้าบสุฉะขขบ [In terms of health].

18 S2: ละภะเปับโลภละบิ [and there are some symptoms]

19 S4: มิ้บฯ [S4 refers to evidence in text 'teens are so emotionally invested in social media that a fifth of secondary school pupils will make up a night and log on just to make sure they don't miss out]. 
(Observation 11: March 23rd, 2018)

It can be seen from Extract 6.8 that the six pre-service teachers exchange their ideas about the main point of the two reading paragraphs and provide support or evidence in an interactive and meaningful way. This allowed them to think about and reinforce the main point of what they have read instead of translating. In turns 01,02 , and $03, \mathrm{~S} 1, \mathrm{~S} 2$, and S3 respectively try to push the members of the group to think about the main idea of paragraph 1 . This allowed them to express their ideas about the main claim and provide key support from the text. In turn 09, S4 refers to the reading text where she is able to locate key words or information to support her idea. In turn 16, S2 pushes her interlocutors to consider the main point of paragraph 2 . This encouraged her peers to exchange their ideas of the main point and provide supporting evidence crucial for higher-order thinking and comprehension development. This also shows that students are able to extract meaning of the paragraph through working in groups. In turn 19, S2 refers to key-words in the text to support her ideas. This mode of learning experience does not only foster collaborative and active engagement but also develops reading comprehension and critical thinking skills (Ritchhart, 2015).

In addition, student ability to construct meaning of the text was also evident when going over the answers with the teacher. This can be seen from Extract 6.9.

Extract 6.9

01 T: Darling, what is the main claim of the first paragraph?

02 S1: The main idea of paragraph is 'introducing the role of social media'.

03 T: Can you find the evidence?

04 S1: Evidence? [S1 refers to the text 'increased pressure...']

05 T: Ok. How about the main claim of the second paragraph? Ann?

06 S2: Social media impact on teen's health.

07 T: Where is the evidence, Khamsy? Or Nou. Read it out.

08 S3: [S3 refers to text 'teenagers need more sleep than adults ... social media could be detrimental to their health. A lack of sleep can make teenagers tired, irritable, and depressed']. It's about health.

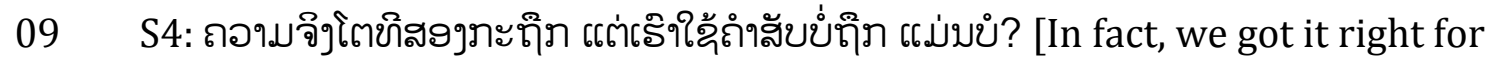
paragraph 2 but we use a wrong phrase to summarize it].

11 Ss: Hmm.

12 T: It's about health. How about you guys? What is the main claim of paragraph 3 ?

13 S5: The third paragraph is about an experience without a phone or smartphone.

14 T: What is the supporting idea? 
15 S6: The supporting idea, evidence is ... uh ... [S6 refers to text: I lost my phone ... disaster... lack access to information and allow me to be constantly looped ...]

(Observation 11: March 23rd, 2018)

Extract 6.9 reveals pre-service teachers' ability to understand and construct meaning of the text. What they experienced here reflects their learning gained as a result of the CoTbased reading instruction. This can be indicated through a number of students' turns in responding to the teacher's questions. In turn $02, \mathrm{~S} 1$ shows that she is able to summarize the main point of paragraph 1 of the text. In order to check a S1's understanding of the text, the teacher pushes her to provide evidence or support from the text which she is able to do. In turn $04, \mathrm{~S} 1$ refers to the text where she is able to locate key words in support of her claim. This can also be seen in turn 07 where the teacher asks S3 to provide further evidence from the text to support the main claim of paragraph 2 . In turn 08 , S3 refers to supporting evidence in the text about the effects of social media on teens' health. This shows that what students experienced in the classroom was meaningful and interactive, which is essential for increased comprehension.

What was also evident during the while-reading stage was answering meaningful comprehension questions. Meaningful questions draw students' attention to infer, predict, and evaluate to name a few (Day \& Park, 2005). An example of this is seen in Extract 6.10 below where a group of students discuss possible answers to a set of multiple-choice questions of the reading text about 'Effect of Social Media on Teens'.

Extract 6.10

01 S1: I chose letter A [S1 reads the answer 'younger generations']

02 S2: I chose A too.

03 S3: Why you chose the same?

04 S1: Because based on the text, it talks about teens.

05 S4: How about number two?

06 S2: I chose $C$ because it [text] talks about effects on health.

07 S3: Er.

08 S2: Bad effects of social media on teens.

09 S3: Yeah.

10 S2: Number three?

11 S3: I chose B. How about you guys?

12 S1: Me too, B. 
13 S3: Boun (Pseudonym)? What?

14 S4: B [S4 repeats the choice B].

15 S1: What's the key word?

(Observation 11: March 23rd, 2018)

The example here shows an important feature of cooperative engagement in attempting to answer these multiple-choice comprehension questions. As Ritchhart et al. (2011) argue, such an interactive dialogue allows students to seek answers to the questions in a meaningful way. In turn 03, S3 asks her peers to provide reasons for their selected answer, which encourages further negotiation of meaning and collaboration (Foster \& Ohta, 2005). In turn 04, S1 further provides reasons for her choice, which reflects important elements of cognitive engagement by using the causal connective because. This can also be seen in turn 06 where S2 refers to the main point of the text that allows her to decide on the answer. What students experienced here reflects significant dimensions of the social and cognitive engagement discussed in section 6.3.1 in terms of reasoning, exchanging ideas, and giving explanations while working in groups.

Extract 6.11 below also shows students' ability to comprehend the text when going over answers to the comprehension questions with the teacher. What is highlighted here is that students are able to provide key words or support of their selected choices by referring back to information stated in the text.

\section{Extract 6.11}

01 T: I need you to give reasons for me. So how many numbers we have?

02 Ss: Six.

03 T: Ok. Number one?

04 Ss: A [Ss repeat the letter A].

05 T: Ok. Letter A [T reads the answer: 'Younger generation']. Could you give me key words?

06 Ss: Teenagers [Ss read the key word 'teenagers']

07 T: [T reads key words ... on teenagers today... right?] and we have 'social media' in the second line.

08 Ss: Yeah.

09 T: And how about number two?

10 Ss: [Some Ss chose B and some chose C].

11 T: The correct one is $B$ [T reads the answer 'a wide range'].

12 S1: Why B? 
13 T: Who chose B?

14 S2: Hong [Pseudonym].

15 T: Hong?

16 S3: Why? [LAUGH].

17 T: So, can you find the key word?

18 S3: [S3 refers to text: In line 2, there are so many social media channels].

19 Ss: Yeah, yeah.

20 T: So many means 'a wide range'.

21 S4: Yeah, yeah.

22 Ss: Oh [LAUGHS].

23 S4: I agree.

24 T: To be critical. How about number three?

25 Ss: B [Ss read the full answer 'being stressful and sleeping disorder']

26 T: Where are the key words? Which paragraph?

27 S5: Paragraph 2, line 2 [S5 refers to text: damaging their sleep...]

28 T: [T refers to text: risk of anxiety and depression ...]

29 Ss: Yeah.

30 T: Number four?

31 Ss: C [Ss repeat the letter C].

32 S6. C for cat.

33 T: Ok, good. Where can you find it?

34 S7: Paragraph 2. [S7 refers to text: ... respond immediately to texts or posts ...].

35 T: Number five?

36 Ss: A [Ss repeat the letter A].

37 T: Ok. Number five's A. Where can you find it?

38 S8: Paragraph 2, last sentence. [S8 refers to text: A lack of sleep can make teenagers tired, irritable, and depressed].

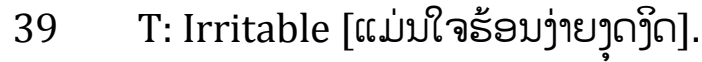

40 Ss: [LAUGHS].

41 T: Ok. The last one?

42 Ss: [Some Ss chose B (a catastrophe) and some C (irritation)].

43 T: Yeah. It's B.

44 Ss: Ya ya ha ...

45 T: Where did you find it?

46 S9: Disaster, paragraph 3.

47 S10: Second line ... paragraph 3.

(Observation 11: March 23rd, 2018)

Extract 6.11 above shows several instances of student understanding and comprehension while participating in the learning activity. In turn 06, students are able to provide key words in support of their choice (A). In turn 18, S3 refers to the reading text and line where she is able to locate key idea or information that allows her to decide 
on the answer. This can also be indicated in turn 27 where S5 provides further evidence in support of her understanding from the reading text. Other examples of this can be seen in turns 34 (S7), 38 (S8), and 46 (S9) where students provide evidence to support their selected choices to demonstrate their comprehension of the text. This reflects their comprehension of the text they have read which is important for strategic and fluent reading development to emerge. What is also worth commenting on is students' choral responses in this interaction. This form of choral responses here shows that most of the students are able to understand and identify support of their claims in relation to the topic while interacting with their peers. Examples of this can be seen in turns 04, 06, and 19 , to name a few where students confirmed their correct answers to the questions. Choral responding is important for fostering active engagement in interacting to the teacher's questions in comparison to traditional responding formats, such as raising hands (Haydon, Marsicano, \& Scott, 2013).

While on one level the interaction pattern of IRE seems similar between the two classes, what was evident in the comparison class was that students were required to answer literal comprehension questions: vocabulary, factual knowledge, times, dates (Day \& Park, 2005). Even though the patterns of interactions are not different between these two extracts, what was intended and what students experienced differed in some ways. Extract 6.12 shows what the comparison class students experienced.

Extract 6.12

01 T: Er. How about comprehension three...uh...four. Complete the sentences with the phrasal verbs. One. [T reads the question: When did your gran .......? On Monday. I'm so sad!] ใส่ยยั่?[What did you choose?]

02 Ss: Pass away.

03 T: Er. Pass away เบ9ะ. No-ed, right? บ่่ป ed เซาะเปับปะจุบับ [Because it is a present form].

04 Ss: No-ed.

05 T: How about number 2? [T reads the question: When did the last Harry Potter book ..........?]

06 S2: Come out.

$07 \mathrm{~T}$ : Come out [ฤ๊าขิมมั้ใด].

08 S3: This morning. 
09 T: This morning [LAUGH]. And number four, oh number three. [T reads the sentence: I hate my new classmates! I don't ........them at all].

10 Ss: Get along with.

$11 \mathrm{~T}$ : Er. 'Get along with' them at all, Hmm. ขู่ใช่่เบาะ [New friends, right?]. [เฉ้้าภับข่ंใด้ ปะมๆบบิ้ละ]. Four? [T reads the sentence: I know smoking is very bad for me, so I'm trying to.....]

12 Ss: Give up.

13 T: Hmm. Give up. Five? [T reads the sentence: I hope the teacher doesn't ............me for not doing my homework].

14 Ss: Get at.

15 T: Get at. Hmm. [T reads the sentence: for not doing my homework]. แบอบิ้ว่ัมิโบๆะ บัภธรม [I can't believe there are these students]. Not good.

16 Ss: [LAUGHS].

17 T: Ok. How about number 6? [T reads the sentence: I don't want to stop; I want to......doing this. It's fun!]

18 Ss: Carry on.

19 T: carry on doing this. It's fun. ข่่ยาภาใุ๊าม่อบเถ [don't want to stop because it's fun]. Ok. That's all about comprehension. Now move on to grammar: Infinitives and gerunds.

(Observation 6: April 19th, 2018)

As Extract 6.12 shows, this type of reading comprehension question fails to focus students' attention on developing deep and meaningful comprehension of the text. In turns $01,05,09,11,13$, and 17, the teacher asks the students to complete the sentences with phrasal verbs from the reading text. What is striking, however, is in turn 08 where S3 is able to provide her own answer to the teacher's question even though it was not intended to be a meaningful question. This indicates that she is doing more than what the teacher is asking even though she is not encouraged to do so in this learning style. What can be interpreted from this is that the teacher had no interest in pursuing meaningful responses but going over the answer with the students throughout the rest of the interaction. In brief, this type of comprehension question focuses attention on factual or recall knowledge, which reflects the common classroom practices as stated in the behavioral engagement. This form of question also reflects the first level of Bloom's taxonomy, Knowledge, due to a lack of an evaluation, analysis, and interpretation (Bloom et al., 1956; Grabe \& Stoller, 2011; Ritchhart et al., 2011). 
In terms of the post-reading stage, a number of learning opportunities, thinking routines, and interactions were also evident in the implementation class to reinforce students' understanding of the topic after reading. In this respect, students were directed to connect, synthesize, and reflect on ideas through 'Connect-Extend-Challenge (46\%), Sentence-Phrase-Word (35\%), I used to think..... Now I think ... (15\%), and Headline $(4 \%)$ thinking routines. This allowed them to think beyond their current knowledge or ideas represented in the text (Ritchhart, 2015). Examples below show what students produced in writing through a 'Sentence-Phrase-Word' thinking routine. In this activity, students are encouraged to select sentences, phrases, and words that are meaningful to them. They also provided reasons for their selections in relation to the text and their own experiences of the topic.

\section{Sentences}

01 S1: 'Many parents like him feel that some of these sports create the perfect opportunity to teach children' because I believe that something hard will make their kids strong people, no pain no gain.

02 S2: 'Many people choose these alternative sports over traditional options' because people are no longer worried about the danger of these alternative or extreme sports. They think it is a way of showing their courage and having fun.

03 S3: 'Extreme sports involve some degree of danger and lots of excitement' because I want to tell someone about what might happen to them when they do these sports.

\section{Phrases}

01 S1: 'self-confidence' because it is very important for you to do something such as giving a speech and taking part in a job interview. You will have more chance to succeed if you are confident yourself.

02 S2: 'a fashion magazine' because it can make me relaxed and keep me updated on fashion.

03 S3: 'a possible way' because I think that every problem has a way out or there is a possible way to solving a problem or challenge.

\section{Words}

01 S1: 'understanding' because it is vital for living together.

02 S2: 'team' because it is important for every work to become successful.

03 S3: 'endurance' because being patient leads to accomplishments. If we try hard, continue for dreams and also accompany with endurance, I am sure it's not very far from achievements.

(Observations 14 and 18: April $3^{\text {rd }}$ and May $4^{\text {th }}, 2018$ ) 
It can be seen from examples that, students are encouraged to reflect on ideas represented in the reading text through a 'Sentence-Phrase-Word' thinking routine. This allowed them to select meaningful sentences, phrases, and words that capture the essence of the texts and expand their point of views. In terms of the sentences, Ss 1-3 select sentences that capture the ideas of how extreme sports are important to young kids, increasingly popular, and involve some degree of danger. In terms of the phrases, Ss 1-3 choose important phrases (e.g., self-confidence, a fashion magazine, and a possible way) that are meaningful. In turn 01, S1 expands her ideas by raising the importance of 'self-confidence' in daily situations (e.g., giving speech and taking a job interview). With regard to the words, Ss1-3 select conceptual words from the texts that allowed them to further justify their meanings and give reasons. In turn 03, S3 selects the word 'endurance' which is, in her opinion, vital for participating in extreme sports and expands this by making its connections to the accomplishments or achievements. This thinking routine allowed them to reinforce ideas, provide reasons, and make connections to their own experiences. In addition, it also allowed them to use the target language, which is important for language development. These qualities of engagement reflect important characteristics of cognitive engagement through the use of causal connective 'because' and giving explanations or reasons (Philp \& Duchesne, 2016).

\subsubsection{Learning environment}

As noted in section 2.6.4, learning environment is important for classroom interactions, student creativity, and engagement (Richardson \& Mishra, 2018; Ritchhart, 2015). In this regard, it refers to both physical and psychological climates that have the potential to encourage active and meaningful engagement (Ritchhart, 2015; Weinstein, 1979) so that specific learning outcomes can be achieved. As discussed in chapter 2, several factors, including classroom physical settings or characteristics play a major role in the teaching of English in Lao EFL pre-service education. One of these is the classroom layout, which was not designed or arranged to facilitate collaborative learning. This can affect students emotionally. To minimize this, I rearranged the seats in the implementation class to accommodate group or pair work learning as stated in the CoT's principles. Figure 6.6 illustrates seating arrangements of the implementation class. 


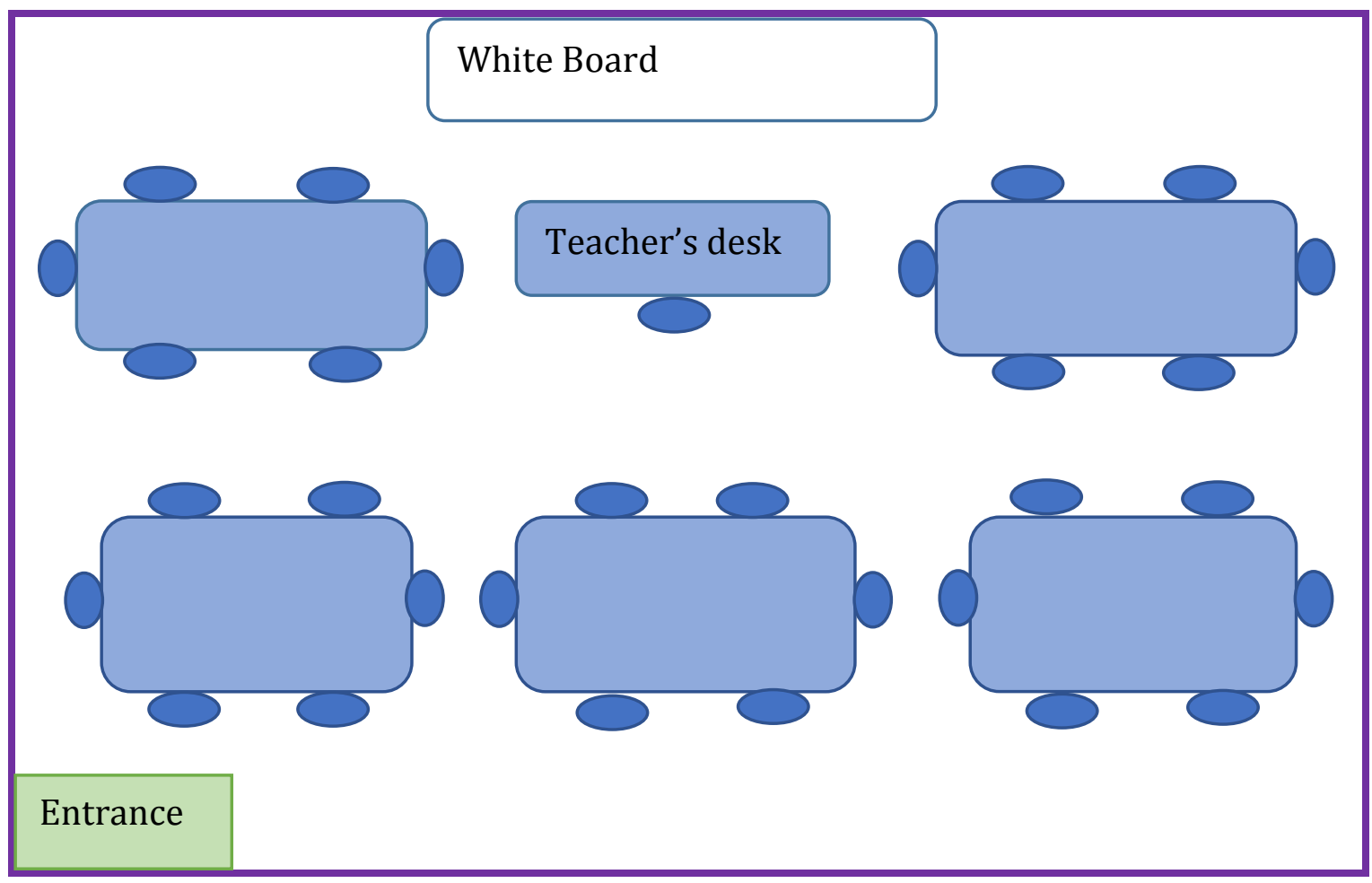

Figure 6. 6 A Visual Diagram of Seating Arrangements

It can be seen that seating was rearranged to facilitate positive academic and emotional outcomes in students (Wannarka \& Ruhl, 2008). This allowed them to work in pairs or groups easily when participating in learning activities which was significant for social interaction or engagement (Storch, 2002). In this arrangement, students were advised to sit in five groups of six to foster collaborative learning. This helped establish the classroom rule or norm which students experienced during the 13-week implementation. Although the classroom setting was not conducive to cooperative learning, attempts were made to address this. This differed from the comparison class where tables and chairs were arranged in the traditional straight-row formation (Weinstein, 1979).

In addition, displays of students' ideas and learning outcomes on the classroom walls (see Figure 6.7) through the Chalk Talk thinking routine showed that the ideas of the members of the learning community were valued and respected. 

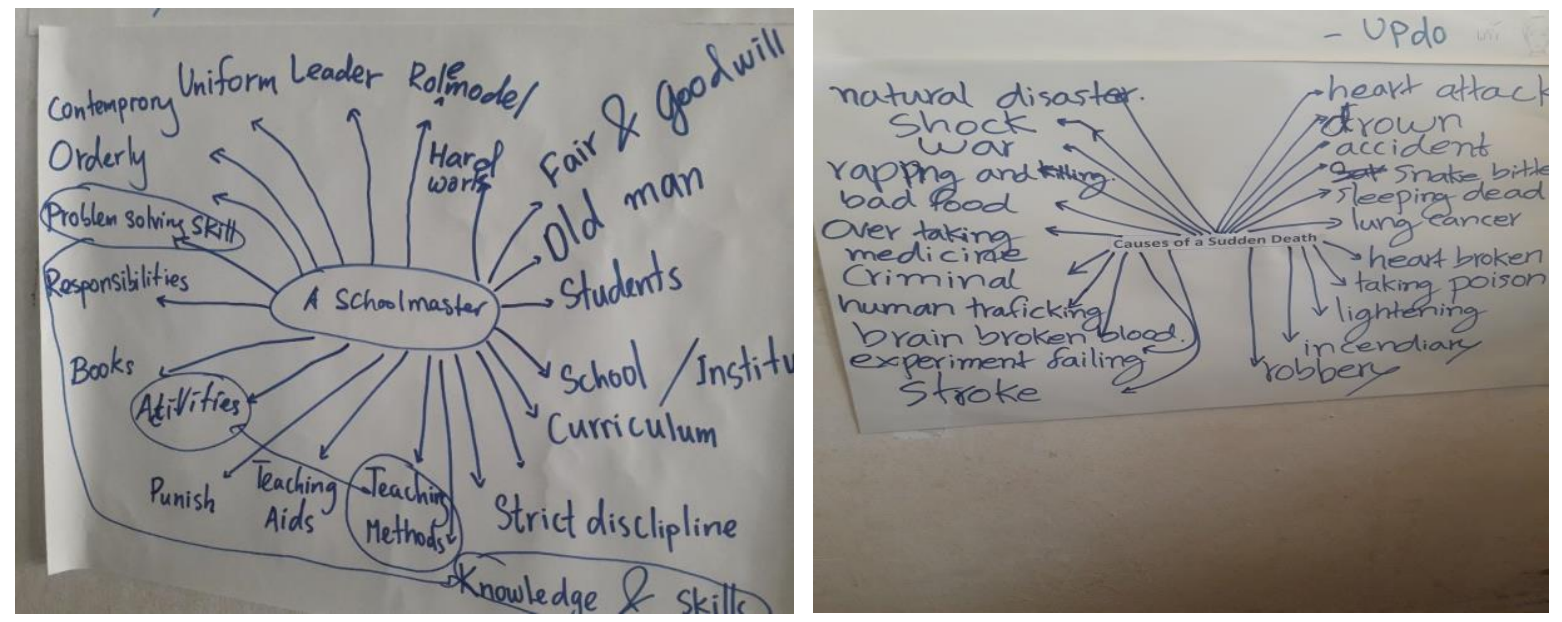

Figure 6. 7 Students' Ideas (May 22nd and June $12^{\text {th }}, 2018$ )

This also allowed the students to revisit, add ideas, and ask questions related to the concepts or ideas learned which fostered on-going investigation, opening up more opportunities for both the teacher and students to come back to the ideas for further discussions when time permits. In terms of the psychological climate, students positively engaged in working in groups, sharing ideas, and rotating around in the classroom (see Figure 6.8).
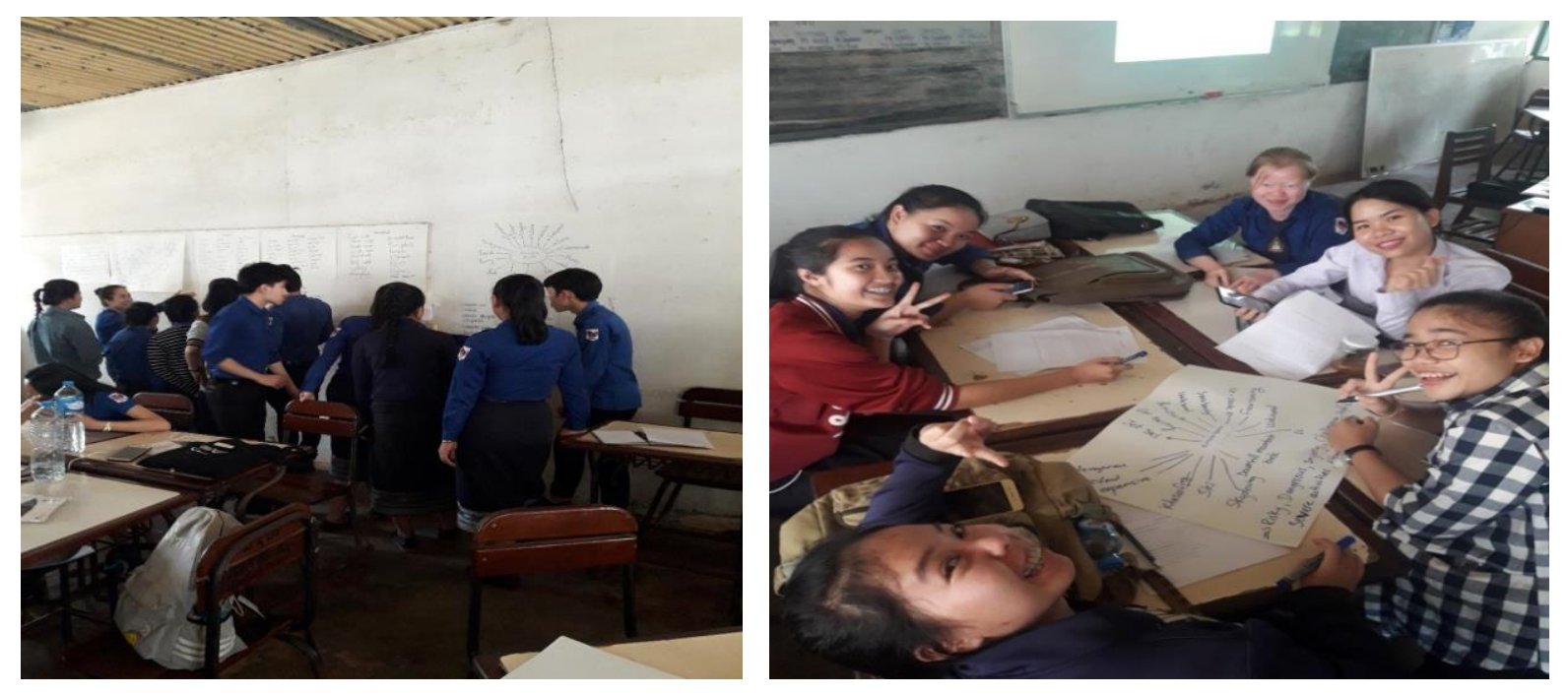

Figure 6. 8 Learning Atmosphere (May $\left.14^{\text {th }}, 2018\right)$ 
As Figure 6.8 demonstrates, students in the implementation class actively engaged in brainstorming and exchanging their ideas through the Chalk Talk thinking routine. They first created a concept map of ideas in groups, then stuck it on the classroom walls and finally moved around to read, comment, and ask questions about the ideas or words written on the papers. This allowed for friendly and meaningful interactions to emerge. This positive learning environment has the potential to increase not only enhanced comprehension but also social interactions reflecting the affective or emotional engagement discussed in 6.3.1. As it shows, students positively engaged in learning while working in groups. This allowed them to cooperate and share ideas crucial for activating prior knowledge and meaning construction. Table 6.11 under section 6.3.5.5summarizes integrated thinking routines during the three stages of reading instruction in the implementation class.

The integration of the thinking routines helped foster active and meaningful engagement for students. Because of this, reading learning was no longer sitting and listening to the teacher lecture or constantly transmit factual information to the students. Through this, students positively participated in learning as they could freely talk about the reading materials without worrying about making mistakes. To further understand this and gain a comprehensive insight into student engagement between the classes, Bloom's taxonomy was employed and the results are presented in section 6.3.6 of this chapter. The following section provides an example of how the teachers treated the same material in the textbook.

\subsubsection{Student engagement comparison between the classes}

In order to demonstrate a difference of how the teachers between the classes treated the same material in the textbook, I compared two learning activities the teachers conducted. I selected chapter 12, which talks about "The Types of Reading Articles" (McAvoy, 2008, p. 105). Specifically, I looked at how the teachers focused students on meaning construction. Extract 6.14 represents the comparison class and Extract 6.15 represents the implementation class. 
Extract 6.14

01 T: Ok. Let's start paragraph 1.

02 S1: Ok. Listen!

03 Ss: Er.

04 S1: [S1 reads paragraph 1 aloud: I'm crazy about gardening; it helps me to relax and forget about the office. I don't have a garden, but I grow plants, and vegetables, too, on our balcony. Every month I get a gardening magazine that I have a subscription to. It's full of practical hints, tropical news, and interesting features. There are articles by famous gardeners who also reply to readers' questions. I spend a lot of time looking up now to grow things on different websites, too, and many seed catalogues are online now.]

05 T: Uh huh.

06 S1: แปขขอางๆจาบ? [Translate, teacher?]

07 S2: Lao version now?

$08 \mathrm{~S} 1$ : [S1 translates text] I'm crazy about gardening 2้อยมัภภ่รอภับภาบเธัดสอบ it

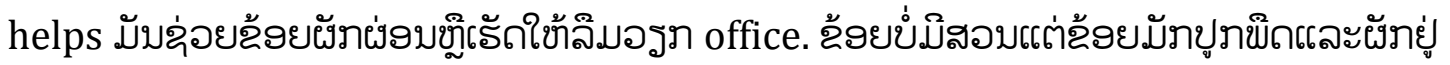
ละบราะงตฉ้งย. Every month I get a gardening magazine แต่ละเถ็งมฉ้งยได้น้้

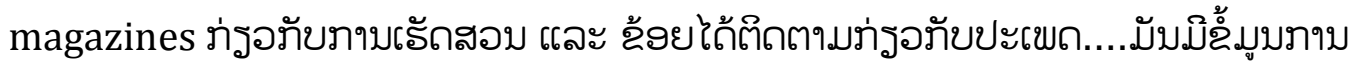
ปะติบัดติอจึร tropical news และ ปิขึออ้ำข้ข้าสิบใจ. There are articles by famous

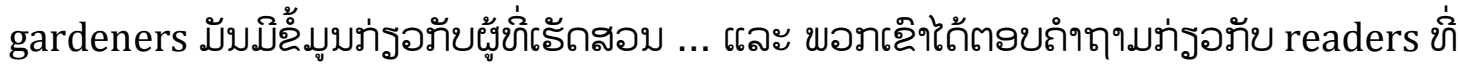
ไป comment. I spend a lot of time 2้งยได้ใฉ้เอลขขูายภ่รอรับภาบธรบภาบสัตรภถภ่รอรับ ภาบปูภขึลผัภใบ websites ต่างๆ และ ขูายธัก seed ขาง catalogues online.

09 T: Hmm. ok. Good!

10 Ss: [CLAP HANDS]. [The same pattern is continued for the subsequent paragraphs].

(Observation 13: June $6^{\text {th }}, 2018$ )

As can be seen, what students experienced in this engagement reflects key features of the grammar-translation approach and teacher-centered method stated earlier (LarsenFreeman \& Anderson, 2011). Although this approach is time saving and convenient for the teacher, it fails to promote realistic conversation and meaningful learning. In addition, translation might be challenging and inaccurate because it is not enough to simply translate word by word or phrase by phrase. As the translation version (turn 08) shows, S1 reads some sentences, words, and phrases before translating them. In other words, he translates every single sentence, word or phrase instead of summarizing the main point of the text (Khoshsima \& Tiyar, 2014). This might not capture the essence or intended meaning of the text. What is also noted is that after S1 has finished reading the text, she immediately asks the teacher whether she should translate it (turn 06). This 
might reflect her experience of the translation practices she has been exposed to previously. In addition, S2 (turn 07) asks her to translate the text. This also reflects the existent practice of this teaching approach in Lao pre-service education. After translating, the classmates give her a huge compliment by clapping their hands for her attempt. This practice reflects important elements of the behavioral engagement where the classroom rule or norm focuses on reading aloud and translating. In addition, this approach may result in passivity in students, creating frustration for them (LarsenFreeman \& Anderson, 2011).

What the comparison class students experienced contrasted with the implementation class where the learning material was used to engage students in meaningful learning. An instance of this can be seen in Extract 6.15 below.

\section{Extract 6.15}

01 T: So read the text on page 105 silently and identify the main idea of each paragraph. Ok. Don't forget ... uh ... to sum up the main ideas or claims. You know claims?

02 Ss: Yes.

[After 10 minutes]

03 T: What is the claim of each paragraph?

$04 \quad \mathrm{~S} 1: \ldots \mathrm{Uh}$...

05 T: How many paragraphs are there?

06 Ss: Six.

07 T: Six paragraphs. What is it about for the texts on page 105?

08 S2: ... activities.

09 T: activities. How many activities are they?

10 Ss: Six activities.

11 T: Six activities. What are they?

12 Ss: ... gardening, playing golf, news ...

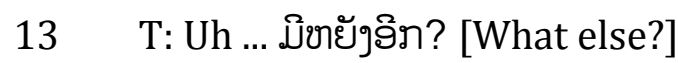

14 S3: ... exams ...

15 S4: Cartoon...

16 S5: ... reading school textbooks...

17 T: So, as you told me there are six. Tell me one by one slowly, ok and loudly?

18 S6: The first one is about...

19 Ss: gardening ...

20 T: Gardening. What is a claim?

21 S7: ... being crazy about gardening...

22 S8: ... the guy who likes gardening ... 
23 S9: ... ideas how to plant vegetables ...

24 T: Ok. Good one. How about you, Sin?

25 S10: His passion on gardening

26 T: his passion ...

27 S10. Yeah. [The same pattern is continued for the subsequent paragraphs].

(Observation 21: May 18 ${ }^{\text {th }}$, 2018)

Extract 6.15 shows that the teacher is attempting to engage students in constructing meaning of the paragraph through the teacher's language of thinking after silent reading. This can be seen in turns $01,03,07,17$, and 20 where the teacher is encouraging students to identify and share the main point of the paragraph. This allowed them to ponder the idea before sharing and interacting with their fellow classmates and the teacher. Through this, they were able to identify the main point of the paragraph as can be seen in turns $21,22,23$, and 25 where they were able to complete the act of paragraph meaning construction. This reveals students' ability to comprehend the main point of the paragraph after reading. This mode of meaning construction among the students was also evident in Extracts 6.1 and 6.8 discussed earlier. What is also evident in this interaction is that it reflects the IRE pattern since the teacher is encouraging students to extract the main point of the paragraph. This pattern, however, was intended to focus students on meaning construction, as opposed to reading aloud and translating. Additionally, it demonstrates that there is a reduction in the use of the L1 compared to the earlier lessons (e.g., Extract 6.3). The increased use of the target language allowed students to develop their communication in English.

As can be seen, between the classes the teachers treated the same material and activity differently. In the comparison class, the teacher focused students on reading aloud and translating which limited interactive and active learning opportunities to emerge. In the implementation class, the teacher directed students' attention to meaning construction and summarizing (Khoshsima \& Tiyar, 2014). This clearly demonstrates that what students experienced in learning reading between the classes differed in terms of the goal and engagement. 


\subsubsection{Learning engagement in terms of Bloom's Taxonomy}

As stated in the literature review, Bloom's Taxonomy would be employed for the analysis of what students experienced in learning reading (Bloom et al., 1956). The adoption of this was to measure how meaningful student engagement was between the classes. As a reminder, each level of the taxonomy is briefly restated here in the context of reading learning engagement. First, knowledge refers to student engagement or involvement in knowledge or information recall. Second, comprehension refers to student engagement in meaning construction and interpretation of the text. This requires meaning negotiation, evaluation, and summarizing skills. Third, application is viewed as student engagement in applying what is learned in novel situations. This allows students to expand their knowledge and increase their understanding. Fourth, analysis refers to student engagement in breaking down ideas or concepts and showing their relationships. This is a process where students make relevant connections and evaluate ideas in an analytical way. Fifth, synthesis is regarded as student engagement in justifying ideas and making decisions on them. Finally, evaluation refers to student engagement in making informed judgments or decisions about the value of ideas represented in the text (Bloom et al., 1956). Indicators of these taxonomies, however, do not occur in a sequence or hierarchy; that is from lower-order to higher-order thinking in actual classroom practices, it is a constant back and forth among these levels (Ritchhart et al., 2011). Because of this, I will look at the overall direction of student engagement in this respect instead of following a sequential order of the taxonomy.

The results of the analysis in terms of student engagement revealed that the extent of student engagement differed considerably between the classes. In the implementation class, student engagement encompassed several important elements of higher-order thinking of Bloom's taxonomy (e.g., application, analysis, synthesis, and evaluation) as demonstrated in the extracts presented earlier. It was beyond mere completion of work. The results also showed that students actively engaged in prior knowledge activation, meaning construction, making connections, and reflection on ideas represented in the texts. This allowed them to summarize, interpret, evaluate, and understand the main 
point of the materials. In contrast, this was not evident in the comparison class where $90 \%$ of student engagement focused on surface learning and discrete language features as pointed out earlier. This orientation reflects lower-order thinking as stated in the taxonomy (knowledge) framework. Based on the above results, I constructed the following model of student engagement (see Figure 6.9) to demonstrate a key distinction between the classes.

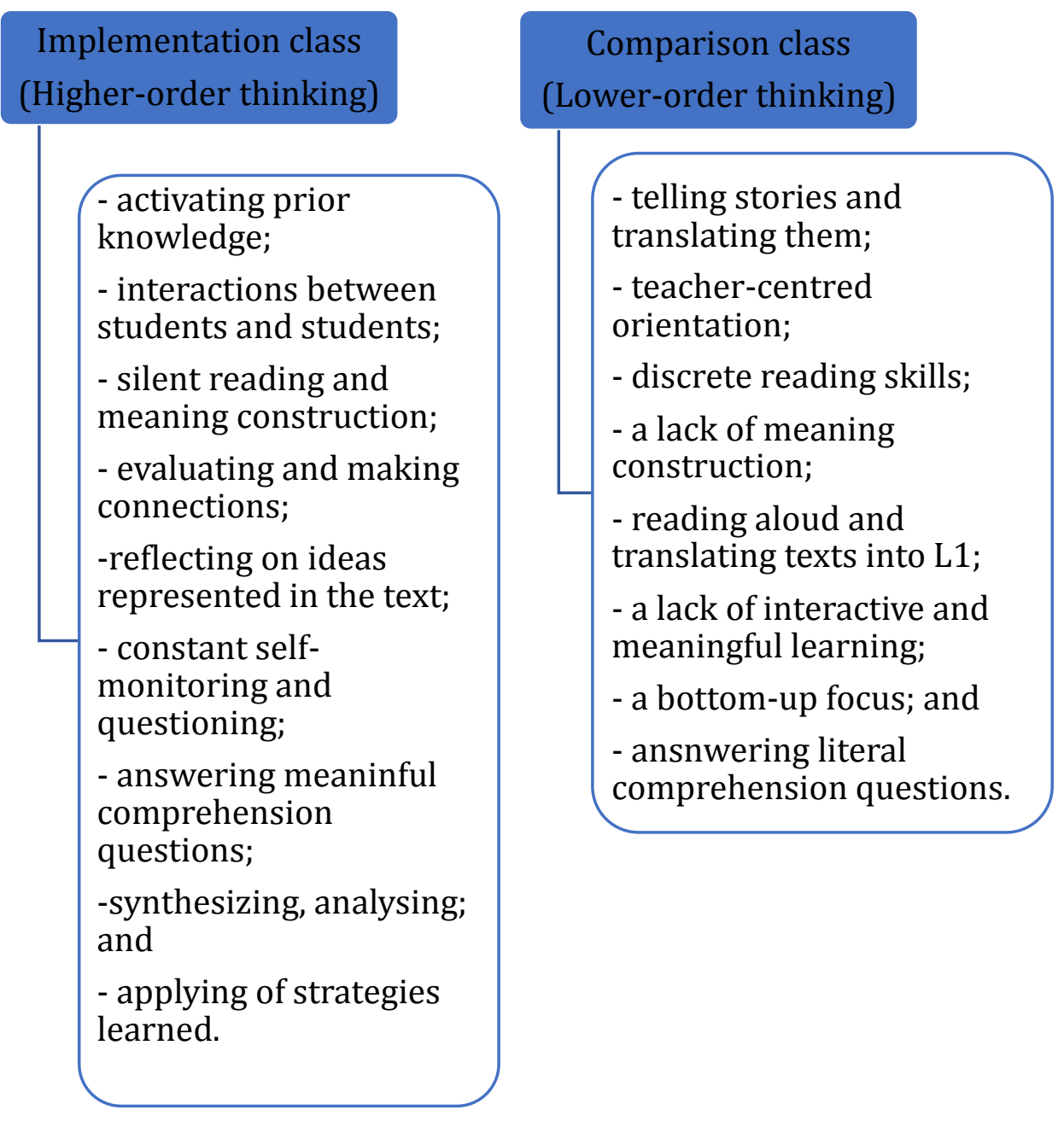

Figure 6. 9 A Comparative Reading Learning Engagement Model

\subsubsection{Section summary}

The results of the qualitative analysis revealed that student engagement in the implementation class was more interactive and meaningful than the comparison. Furthermore, what students experienced differed considerably between the classes in terms of the CoT cultural forces. When compared to the Bloom's taxonomy framework, 
the implementation class tended to apply higher-order learning skills while this was not evident in the comparison class.

\subsection{Chapter summary}

This chapter presented the results of phase 2, consisting of both quantitative and qualitative data. The findings showed that the CoT implementation improved EFL preservice teachers' reading comprehension and fostered interactive and meaningful reading learning engagement. As stated in section 4.3.2, the adoption of the explanatory mixed- methods design was to triangulate the data. To gain deeper insights into what students thought about learning reading, the following chapter will look at students' perceptions of learning reading. 


\section{CHAPTER 7: PERCEPTIONS OF LEARNING READING}

\subsection{Introduction}

As pointed out in the previous chapter, this chapter will look at pre-service teachers' perceptions of learning reading after the 13-week CoT implementation. As a reminder, RQ5 asked:

What are Lao EFL pre-service teachers' perceptions of learning reading in the CoT and comparison classes?

To seek the answer to the question, nine focus group interviews were conducted with both classes (five, comprising twenty-six participants, for the implementation class and

four, comprising twenty-one participants, for the comparison class). Because the interview was voluntary, the number of the participants was unequal. This was, however, sufficient for data generation, corroboration, and saturation (Krueger \& Casey, 2009; Saunders et al., 2018). As stated in section 4.3.6, I also interviewed the implementation class teacher (male) to seek his views of the CoT implementation. In addition, a pre-post perception survey was administered to both classes to triangulate the data. This chapter begins by presenting the results of the focus group interview in section 7.2. Section 7.3 looks at the pre-post perception survey findings. Finally, section 7.4 summarizes the chapter.

\subsection{Focus group interview findings}

As indicated in chapter 6, the CoT implementation benefited Lao EFL pre-service teachers in several important ways compared with the traditional teaching method. Section 7.2.1 looks at students' perceptions of learning reading. Section 7.2.2 addresses students' perceptions in terms of reading learning focus. Section 7.2.3 looks at students' perceptions of learning engagement and social interactions. Section 7.2.4 focuses on students' perceptions of reading comprehension development. Section 7.2.5 discusses students' perceptions of critical reading skills awareness. Section 7.2.6 looks at students' 
perceptions of reading skills and metacognitive reading strategies awareness. Section 7.2.7 concentrates on challenges in learning reading. Section 7.2.8 looks at the participating teacher's perceptions of the CoT implementation and section 7.2.9 summarizes the key points presented in section 7.2 before turning to the results of the pre-post survey in section 7.3. Comparison with the control class will be made to highlight the key differences. As a reminder, participants' comments in this chapter are the translated versions from L1.

\subsubsection{Perceptions of learning reading in general}

As stated in the literature review, what students experience as language learners plays a central role in shaping their beliefs and perceptions of learning and teaching a language. This belief, however, continues to have a long-term impact on their professional endeavors (Borg, 2006). The results of the analysis revealed pre-service teachers' perceptions of learning reading after the 13-week instruction differed considerably between the classes. In the implementation class, the CoT implementation shifted their perceptions of learning reading. Specifically, they perceived English reading learning positively because reading was no longer sitting back and listening to the teacher's lectures. Instead, reading was interactive, collaborative, engaging, meaningful, stimulating, thought-provoking, and fun (Grabe, 2009). When Lao EFL pre-service teachers were engaged in the group reading, there was evidence that they were encouraged to be active and strategic, which is crucial for comprehension development (Philp \& Duchesne, 2016), and shifted their perceptions of learning. This was also evident in the observational findings presented in the previous chapter. Unlike the typical traditional mode, the use of CoT thinking routines promoted students' active involvement and participation. Extract 7.1 shows participants' comments when asked to share perceptions of reading learning in the CoT-based instruction.

\section{Extract 7.1}

01 P1: Uh. In the past it [reading] was not my favorite subject because learning activities were not interesting. Now, I like to learn it because it is more interesting and interactive. We share a lot of ideas.

02 P2: Yeah. I agree with you. I feel that learning reading in this term is more interesting than last term because there are many interesting activities for students to think about the topic. We think a lot ... 
03 P3: ... and the teacher focuses students on meaning of the text and sharing ideas instead of reading aloud and translating ...

04 P4: ... I agree with everyone. I like Chalk Talk because it is a good way of preparing students before reading and I learn many new ideas from the group members ...

05 P1: ... and we have a lot of opportunities to exchange our thinking and ideas. I like the way the teacher implements the lessons ...

06 P5: ... yes, you are right, very interactive and I want every teacher to do like this...

07 P2: ... agree. It is a new approach to teaching, it is cooperative and interactive. The teacher should have done this from year one...

08 Ps: Yeah.

(Group 1: July 25th 2018 )

It can be inferred that the Lao EFL pre-service teachers were in favor of this type of learning interaction and environment as it benefited them and shifted their attitudes toward reading. Through this, they no longer felt reading learning was boring but were willing to make full use of learning opportunities with fellow classmates. What is also compelling is stated in turn 07 where P2 wished this approach had been implemented from year 1 and his peers agreed with him (turn 08). This indicates that they found this teaching approach meaningful and interactive and worth participating in it. Their positive perception of learning is significant for effort and commitment they have put into learning reading, which is important for increased comprehension and the development of better readers.

The above perceptions differed considerably from the comparison class where the students perceived reading learning in different ways. The majority of the interview participants (57\%) expressed positive attitudes toward learning reading because it was a good way for learning discrete language features. This reflects the bottom-up reading model discussed in section 3.3.3. Extract 7.2 below demonstrates this point.

\section{Extract 7.2}

01 P1: I like to learn reading because it is a good way for developing vocabulary knowledge and pronunciation...

02 P2: Yeah, I like to learn reading because it helps me develop my oral fluency and vocabulary knowledge and translation skills.

03 P1: Yeah. We know how to translate the text as well ... After reading we take turns translating paragraphs of the text. We learn from each other because some students translate well. 
04 P3: I agree. I like to learn reading because ... er ... I want to practice my pronunciation and develop my fluency in reading. I want to become a good teacher in the future so if you can read fluently like native speakers, students will believe in you. I also learn grammar from reading. The teacher sometimes focuses on grammatical features of the text.

05 P2: I think it is good to identify and learn grammatical structures. For example, the teacher teaches us about infinitives and gerunds last time. It is quite hard to use them in real situations.

06 P3: This reading subject is helpful in terms of learning language skills. I like it.

(Group 2: July 27th, 2018)

The comments above reveal they are in favor of the traditional and teacher-centered teaching methods. Although this method is useful for learning discrete language features, higher-order or metacognitive reading strategies should also be cultivated to develop competent readers. What is interesting to note here is that none of the participants mentioned the promotion of meaning construction practices and critical reading skills development. This demonstrates a lack of interactive and meaningful learning during the course of reading instruction in this learning condition.

However, $43 \%$ of the pre-service teachers in the comparison class expressed negative attitudes towards reading learning because it was boring, difficult to understand and translate, and not meaningful. Extract 7.3 reveals this point.

\section{Extract 7.3}

01 P1: I don't like to learn reading because it is boring. I never read more than five minutes. When I read, I find it hard to understand and the teacher does not use any interesting or new activities...

01 P2: Hmm ... I have the same feeling as you. It is boring to read aloud and translate text. We want to learn something new and interactive.

03 P3: I don't like it either because it is boring. The teacher uses the same teaching method which is not stimulating for me...

04 P4: I don't like to learn it either. As you said, it is boring because we only use the same approach like reading aloud and translating texts in the textbook, no extra activities or reading texts from other sources.

05 P2: ... And it is hard to understand the text when reading. Although I know word meaning but understanding the gist is challenging.

(Group 1: July 26th 2018 ) 
As the discussion reveals, this learning environment was passive and lacked a meaningful focus. In other words, what students experienced in this learning community was reading aloud, translating, answering comprehension questions, and pronunciation practice, which were echoed with the observational data presented in the previous chapter. This also reflects the results of phase 1 in that pre-service teachers experienced discrete language skills learning, as opposed to meaning construction. What is also interesting to note here is that the teacher used only the same activities and failed to include extra reading sources and materials to promote active learning engagement. This can be noted in turn 04 where $\mathrm{P} 4$ stated that learning reading was mostly a matter of following activities and exercises in the textbook and applying the same teaching method. Although this saves the teacher time and effort, it is not enough for the development of critical and perspective-taking readers. It can be noted that the comparison class students had a mixed view of discrete language skills in learning reading. In brief, $57 \%$ of the comparison group expressed positivity while $43 \%$ of them were negative toward learning reading in the conventional teaching condition. As reported earlier, the case of these two contradictory perceptions were not evident in the implementation group, suggesting that most of them enjoyed the benefits of the CoT implementation.

\subsubsection{Perceptions of reading learning focus}

The results of the pre-perception survey analysis (to be presented in section 7.3) revealed that both classes perceived the main focus of reading learning as discrete language skills learning (e.g., pronunciation and vocabulary). However, after the 13-week instruction, their perceptions in this aspect differed considerably between the classes. In the implementation class, the students perceived reading learning as meaning construction, summarizing the main point, evaluating the main idea, developing reading skills, answering meaningful comprehension questions, oral fluency development, and developing vocabulary knowledge. In other words, students' perceptions shifted from the "bottom-up" to "top town" model and this tendency is associated with higher-order reading skills development (Grabe, 2009; Hudson, 2007), which are important for enhanced comprehension. Extract 7.4 below reveals this aspect. 


\section{Extract 7.4}

$01 \quad$ P1: I think it should be evaluating and answering comprehension questions because it is a way of checking our understanding of what we read ... If we can do this it means we understand the text and should be vocabulary as well.

02 P2: I agree. It should also be the main point of the text as well because reading about ... understands. Without understanding, it is useless. In the past we focused on reading aloud and translating which was hard to understand when reading...

03 P1: Yeah, and pronunciation of words or sentences in the past ....

04 P3: ... yeah, you are right. It should be the main idea of the text or paragraph. After reading we should understand the main point of the text through summarizing.

$05 \mathrm{P} 4:$.... same as everyone. It should be the main point of the text because reading is about understanding. I used to think that reading is about pronouncing word correctly or learning a lot of new words but the teacher states that reading is about meaning and but it should also be vocabulary and pronunciation because they are important for reading.

06 P5: Yeah. In the past ... I used to think that too but the reading teacher in this term restates that reading is a process of summarizing the main point of the text.

07 P4: But I think it should also be focusing on learning new words as well because they are important for comprehension. We learn a lot of new words from the Chalk Talk activity.

08 P3: Yeah, but it should be a secondary focus. The first focus should be meaning of the text I think.

(Group 1: July 25th 2018 )

What is also worth observing is in turns 05 and 06 where P4 and P5 contrasted their perceptions of the reading focus in the past with their current view. This indicates that their perceptions of reading learning focus tended toward meaning construction, as opposed to a discrete language skills orientation. The shift in their thinking appeared not to have been caused by any single factor or what they experienced in the classroom. The students have also taken on board what the teacher has been telling them during the intervention.

In contrast, this tendency differed considerably in the comparison class where their perceptions of the reading focus remained unchanged (discrete language features). In other words, the comparison class viewed reading from a lower-order or bottom-up focus. This is noted in Extract 7.5 below. 


\section{Extract 7.5}

01 P1: Hmm, I think it should be about pronunciation and vocabulary... because if we can read or pronounce words fluently we feel confident, right? Reading aloud is a better way of practicing and improving our pronunciation.

02 P2: I think it should also be new words, pronunciation, translation, and meaning of the text because these are important for reading ...

03 P3: I agree with you guys, pronunciation should be the main focus of reading because I used to have an experience of pronouncing words incorrectly and my friends laughed at me. So, it should be pronunciation first.

04 P4: It should be focusing on fluency, intonation, and pronunciation because these are important for learning reading. If we can read and pronounce words correctly our confidence is getting better.

05 P5: Yeah, I agree with everyone. It should be correct pronunciation and grammar. If we are good at grammar, we can translate the text easier.

(Group 2: July 27th 2018 )

The above comments revealed the participants perceived the focus of reading learning as learning discrete language skills. This reflects their experiences as language learners (Borg, 2003) and the apprenticeship of observation (Lortie, 1975), which still play an influential role in shaping their beliefs and cognition of learning reading. What stands out, however, is turn 02 where P2 perceived meaning of the text as one of the main focuses of reading learning in addition to discrete language skills. Although this was perceived by the pre-service teachers, however, it was not fostered in the actual classroom practices as the observational data revealed.

\subsubsection{CoT promoted meaningful engagement and social interactions}

As stated in section 6.3.2, student engagement plays a significant role in learning achievement and developing social interaction skills (Guthrie et al., 2012). After the 13week instruction, pre-service teachers' perceptions of learning engagement and social interaction differed extensively between the classes. In the implementation class, students perceived learning engagement and social interaction during reading instruction positively because they experienced a sense of increased meaningful and interactive practices. In other words, this reading course focused students' attention on exploring ideas, summarizing the main point, questioning, giving reasons, and collaborative learning through the integration of thinking routines (e.g., Chalk Talk, See- 
Think-Wonder, Claim-Support-Question to name a few) as intended by the lesson plan (Ritchhart et al., 2011). This is noted in Extract 7.6 below.

\section{Extract 7.6}

01 P1: I think ... there is a lot of engagement in learning reading because the teacher uses many activities to encourage students in learning. Some activities are about skimming and summarizing the main idea of the text ...

02 P2: For me uh this reading subject engages students more in learning compared to other subjects. We are encouraged to work in groups and share ideas. Each individual group member has a chance to talk.

03 P3: I think there is a lot of engagement because the teacher encourages us to think and elicit ideas before, during and after reading which is good. But some students find it hard to do.

04 P4: Yeah, a lot of engagement in thinking and answering the peers' and teacher's questions .... We explore or search more information which broadens our knowledge a lot.

05 P5: It also allows students to express their ideas, develop their self-confidence, and new knowledge because the teacher does not focus on being right or wrong when sharing ideas ... it is just perspective-taking ...

06 P6: I think there is a lot of engagement too because the teacher focuses on student-centered learning which allows us to cooperate and work with classmates. I think answering comprehension questions is also good for checking our understanding. More importantly, the teacher encourages us to express and share ideas openly. As you said, this encourages the students to develop their selfefficiency and confidence. The teacher also uses supplementary materials or reading texts. I think it is fun to learn reading, not serious. It is worth investing time and effort in it.

(Group 3: July 26th, 2018)

What the extract demonstrates is that they perceived learning engagement and social interactions in learning reading positively. Based on social constructivism, reading development is beyond psychological and linguistic knowledge. In other words, it engaged and fostered students in active participation, contributing to developing reading comprehension and shaping language learning experiences and social behaviors (Vygotsky, 1978). The comments here also reflect important features of cognitive, social, and behavioral engagement discussed in section 6.3.1. The most interesting point to note is in turn 02 where P2 points out the greater extent to which this course engaged students in learning reading compared with the other subjects learned. What is also apparent is that P3 (turn 03) noted some challenges in working through the process of 
learning reading in the CoT-based instruction. One of the possible reasons for this might be that the students had not had any previous experience of this learning style. Although the students encountered some constraints during the implementation, the benefits of this far outweighed any drawbacks. The results also echoed the participating teacher's view of student engagement. When asked about student engagement, he stated:

I think there is a lot engagement because it is a student-centered method of instruction. They have a lot of opportunities to share ideas and work in groups....they are also encouraged to think beyond what they are learning and use their smartphones to explore or search information. Another thing is that because of the lesson design and implementation, students are stimulated to activate their prior knowledge and construct meaning or content of the text. Because of this, they feel more confident in sharing ideas and interacting with peers although it is new to them.

What is indicated here is students meaningfully participated in learning reading. Specifically, the teacher pointed out several features of social and cognitive engagement (Philp \& Duchesne, 2016) students were encouraged to foster during the CoT-based reading instruction. These include working in groups and sharing ideas, thinking about the topic, searching information, activating prior knowledge, and extracting meaning of the text.

In contrast, student engagement and social interaction in the comparison class differed considerably. The results revealed that the common learning-engagement activities students experienced included: telling stories, answering literal comprehension questions, reading aloud and translating, literal vocabulary learning, practicing pronunciation, and learning grammar. Although these aspects are beneficial for the students, they expressed a lack of interactive and meaningful learning, which is crucial for comprehension development. Extract 7.7 illustrates this point. 


\section{Extract 7.7}

01 P1: I think this reading course helps a little bit in terms of ... learning vocabulary and pronunciation through telling stories, reading aloud, and translating the text. I think it is about $30 \%$. We want to do something uh ... more practical and interactive ...

02 P2: Yeah. I don't think we participate meaningfully in doing activities although we learn many new words and pronunciation because I still find it hard to understand what I read. As you said, we have done the same thing for years. I want the teacher to .... er ... focus students' attention on exploring, discussing, and digging deeper into ideas or interactively.

03 P3: I think it is quite useful in terms of reading aloud, learning pronunciation because we have done this for ages. But we want something interactive and meaningful. We want to focus on how to construct meaning of the text rather the reading loud. I still find it hard to understand when I read. I don't read effectively because I don't know how to do it.

(Group 4: July 28th 2018 )

The comments above demonstrate that although this learning engagement was worthwhile in terms of learning language items, it is insufficient for the development of better readers. The results here also echoed the findings of the observational data presented in the student engagement section of the previous chapter.

\subsubsection{CoT increased reading comprehension}

As stated earlier, one of the main purposes of this quasi-experimental research was to determine the effectiveness of the CoT implementation on pre-service teachers' reading comprehension development. The findings of the focus group interviews revealed that they perceived this teaching method as an effective means for improving their reading comprehension because this shifted away from rote memorization, reading aloud and translating texts. The findings revealed that this course focused their attention on fluency development, identifying main points, developing interpretation skills, and applying metacognitive strategies (Grabe, 2009; Ritchhart, 2015). Extract 7.8 below supports this claim when students were asked to comment on reading comprehension development.

\section{Extract 7.8}

01 P1: I think my reading comprehension improves a lot compared to last semester because when answering comprehension questions, I feel more confident than before. I spend less time .... Uh answering the questions and most of my answers 
are correct. When I first took the pre-test, I did not understand the text at all but when taking the post-test, I was more confident in it ...

02 P2: I agree with you. I think my reading comprehension improves a lot too. When reading in the past, I could not understand the main point of the text. Now I try to focus on meaning instead of translating unknown words first. I think my reading comprehension is improving a lot after learning new techniques.

03 P1: Yeah, we don't have to translate word by word but pay attention to the main point of the text.

04 P3: I agree ... and I think my reading comprehension has improved too. In the past, I translated unknown words first when reading and then read the text again. Now, I read through the text first to get the gist. It helps me a lot when doing this because I can read faster and understand the main point better and faster.

05 P4: I think my reading fluency or speed reading is getting better because I am able to read faster. This is what I have gained from this course.

06 P5: Uh ... My reading comprehension is a bit better as you may know my English background is very weak compared to the others of the class and I am a slower learner too [LAUGH].

07 P2: Yeah, this course is very helpful in terms of meaning construction and summarizing skills development. I feel that my comprehension is improving. I use summarizing skills when reading. This helps a lot in terms of time management and reading fluency development.

(Group 1: July 25th, 2018)

The pre-service teachers made very positive comments about the CoT's effectiveness on their reading comprehension development. They commented on specific skills (e.g., summarizing, fluency development, and meaning construction) they had gained from this course. These qualities of engagement and learning gains play a crucial role in the development of reading comprehension. As pointed out in the literature, one of the facets of the CoT was that it engages students to mutually share ideas and see how their peers address reading difficulty through working in groups (Ritchhart, 2015; Ritchhart et al., 2011). This cooperative learning, in turn, helps foster reading comprehension and social interaction skills. It also assists them with monitoring and evaluating their reading comprehension (Hudson, 2007). The results here also demonstrate the fact that Lao EFL pre-service teachers are in favor of the CoT-based reading instruction. The findings here were also consistent with the participating teacher's comments:

Of course, it helps a lot in terms of their comprehension development because they are encouraged to think and learn independently through sharing, brainstorming, 
cooperating, and meaning construction. The teacher acts as a facilitator for them. This is a new method of reading instruction. I am very satisfied with their learning outcomes and comprehension (98\%) because when they first started this course they could not summarize the main point of the text and their comprehension was very low. However, after being exposed to this they have become more confident in summarizing, analyzing and evaluating the main point of the text, which is crucial for enhanced understanding.

As the teacher noted, the CoT implementation improved Lao EFL pre-service teachers' reading comprehension. The teacher also pointed out that at the beginning of this course, most students lacked confidence in constructing meaning of the text. After the implementation, however, the teacher was very satisfied with the students' learning outcomes; they had become more confident in reading than in the past. This suggests that the implementation of a CoT had positive impacts on students' reading comprehension development in addition to the social interaction promotion (Philp \& Duchesne, 2016). This also reflects the results of the quantitative data analysis stated in section 6.2.

In contrast, the above comments differed considerably from the comparison class. On the one hand, $33 \%$ of the pre-service teachers stated that their reading comprehension slightly improved. This has been stated in Extract 7.9.

\section{Extract 7.9}

01 P1: I think my reading comprehension is slightly better than before after this course. But I still struggle to understand what I read. I want to learn more about reading skills...

02 P2: Yeah. I think my reading comprehension is a little bit better than before because I can understand what I read but I can't pronounce words correctly when reading and it is hard to translate as well.

03 P3: My reading comprehension is improving a little bit, about ... 10\%. I feel so lazy to learn reading because there are a lot of unknown words and I am lazy to check them up in a dictionary [LAUGH] and I don't know how to read effectively.

04 P4: For me, my reading comprehension is about 8 to $9 \%$ better than before but my reading skills are so poor. My pronunciation is just ok and my vocabulary knowledge is getting better...

(Group 4: July 28th, 2018) 
The above comments demonstrate that although the pre-service teachers believed that their reading comprehension slightly improved, they still struggled to read and construct meaning of the text effectively. What is noticeable is that they still needed to develop their reading skills or strategies, hoping to make reading easier and more effective. This can be seen in turns 01 and 04 where P1 and P4 express their desire to improve their reading skills. This suggests that there was a lack of meaningful exposure to these skills in the actual classroom practices. What is also interesting to note here is stated in turn 03 where P3 negatively perceived reading as boring and inactive. This reflects the experiences of learning reading in the traditional or teacher-centered method, which is still practiced in this context. These comments also reflect the results of the statistical analysis presented in chapter 6: that there was a slight improvement in reading comprehension measured by the immediate and delayed post-tests.

On the other hand, $67 \%$ of the comparison class pre-service teachers pointed out that their reading comprehension remained the same after the 13-week reading instruction. This also reflects the results of the $t$ tests presented in chapter 6. Extract 7.10 depicts this aspect.

\section{Extract 7.10}

01 P1: Uh ... I think my comprehension is basically the same. I don't know why but I feel that it is exactly the same. My vocabulary knowledge is better. I think my classmates are the same in terms of their reading comprehension. After reading, I still don't understand what the text is talking about ...

02 P2: I agree with you. My reading comprehension is still the same. I still find it hard to understand what I read although my vocabulary knowledge is better and so is my pronunciation.

03 P1: Hmm. We usually do reading aloud and translating ... yeah.

04 P3: Yeah. I think my reading comprehension is the same because I still do not know how to construct meaning of the text when I read but my vocabulary knowledge is getting better. I have learned new expressions or words from this reading course.

05 P4: I agree with you all. My reading comprehension is ... uh ... the same because the teacher only focuses on reading aloud, translating, and pronunciation of the words. It is boring to do the same pattern of learning activities.

06 Ps: [LAUGHS]. 
07 P5: Hmm. same as everyone [LAUGH]. When I read I find it hard to understand the meaning of the text. I sometimes don't want to read but I have to because I don't want to fail the course.

08 P6: I think I have the same problem. My reading comprehension remains the same. I don't know but that is how I feel about learning reading. I have learned a lot about text translation, intonation, and pronunciation of words through reading aloud.

09 Ps: Yeah.

(Group 3: July 28 ${ }^{\text {th }}, 2018$ )

The above discussion reflects many important features of cognitive, social and emotional engagement discussed in the previous chapter. First, it reveals that the traditional teaching method failed to engage students in thinking and developing reasoning skills in students. Second, there was a lack of social interaction promotion as students were directed to focus on reading aloud and translating the text. Finally, this reflects the students lacked incentive or enthusiasm to learn reading because it was boring. What is also important to point out here is that this reflects the results of phase 1 presented in chapter 5 and the observational data stated in chapter 6 in that this reading learning was focusing on discrete language skills. Another important point to comment on here is that there was laughing when sharing ideas about their reading comprehension development (turns 06 and 07). My interpretation of the students laughing at certain points in the discussion is that they were acknowledging this reading course failed to foster their proficiency development.

\subsubsection{CoT raised critical reading awareness}

As pointed out in section 3.4.3, promoting critical reading in students is important for the development of strategic and analytical readers (Flynn, 1989). Critical reading refers to the ability to analyze, synthesize, and evaluate ideas represented in the text before drawing a conclusion from them (Bloom et al., 1956; Flynn, 1989; Wallace, 2003). In this respect, the results showed that students' perceptions of critical reading awareness between the classes differed considerably after the 13-week instruction. In the implementation class, pre-service teachers stated that the CoT-based reading instruction raised their critical reading awareness and strategies, including: evaluating the text ideas, thinking beyond what was learned, envisioning the topic, synthesizing ideas, and 
judging the main point (Halim, 2011). When asked whether the CoT implementation helped raised their critical reading awareness, the participants commented:

\section{Extract 7.11}

01 Ps: a lot.

02 P3: I think this course makes us wonder and ... er ... think about ideas presented in the text and the teacher always asks the 'why' question. When we read, we are encouraged to think about ideas or claims through a Claim-Support-Question thinking routine.

03 P2: Yeah, I agree. I think this reading class makes me think about the main claim or idea of the text. My thinking skills are getting better when reading because I always think about the 'what' and 'why'.

04 P1: I think my reasoning and wondering skills have developed ... what I am reading is true or not because this course fosters me to think about what I am reading. I sometimes feel like I have a headache because I think too much [LAUGH].

05 P4: Yeah, what I learn most in terms of thinking is from See-Think-Wonder thinking routine. This activity encourages us to think about the topic in terms of the 'what, how, and why' as you said. In brief, this allows me or us to observe, evaluate, and apply. I like it.

06 P5: And evaluating the main claim of the text or paragraph ... which is important. We can use this in the future, I think.

07 P3: I also think it is quite hard and takes time to evaluate the text. We should continue learning this subject on year four because it is important for us.

08 Ps: Yeah.

09 P6: ... I agree with everyone that this course helps a lot in terms of developing thinking. In the past we learn reading by reading aloud and translating without being encouraged to think. However, this reading course stimulates us to think about what we are reading ... I think this is useful because we can develop our thinking skills ...

(Group 4: July 26, 2018)

The above comments reflect higher-order thinking and cognitive dimensions of student engagement discussed in the previous chapter in that this teaching method helped raise their awareness of evaluating ideas represented in the text. First, most interview participants stated that this reading course encouraged them to think about the answer to the 'why' question when approaching the text. This is also important for developing reasoning and wondering skills in students. Second, the discussion reflects the application of the evaluation, analysis, and observation skills (Bloom et al., 1956). These cognitive domains are important for the development of metacognitive reading 
strategies although they were not explicitly taught. The above comments were also congruent with the participating teacher's observation:

I think they have developed a lot in terms of critical reading. Yes, a lot. The activities help students a lot in terms of stimulating them to think because they participate in expressing ideas and the teacher does not focus on seeking specific answers or right or wrong answers from the students. In the past they learned through the grammar translation or traditional method ... they translate word by word. However, after using this method, the students learn meaningfully because they are able to better identify main ideas of the texts or paragraphs through collaborating with their peers. They know how to read faster which saves their time and helps develop their reading speed.

The teacher acknowledges that the CoT implementation was beneficial for raising students' critical-reading awareness, which plays a central role in the development of better readers (Anuar \& Sidhu, 2017). What is also interesting to comment on here is that the teacher acknowledges this course also fostered reading fluency which is beyond the scope of this study.

This differed widely from the comparison class where the pre-service teachers expressed negative perceptions toward reading after the 13-week reading instruction. They stated that they had no experience or exposure to critical reading and the teacher never focused their attention on this when learning reading. Reading in this sense, as stated earlier, was mostly a matter of learning language items. Extract 7.12 depicts this aspect.

\section{Extract 7.12}

01 P1: I don't think so because I am not sure what critical reading skills are [LAUGH]. The teacher never talks about them or teaches us. When I read, I just do the same ... translating the text and new words.

02 P2: I am not sure what they mean to read critically. Have we learned this?

03 Ps: No [LAUGHS].

04 P1: As I said, I don't know what they are. I want to know too.

05 P3: Yeah. I am not sure what they mean because I never use them. The teacher does not teach us this. We just read, translate and answer questions. 
06 P4: I think my critical reading skills are not improving because the teacher does not engage us in thinking when learning.

07 P5: I agree. I don't know ... what they are and how to use them.

08 P6: Yeah. Like many others said, there is a lack of thinking when learning reading. I never analyze or evaluate what I am reading and the teacher does not focus on this.

(Group 1: July 26 $6^{\text {th }}, 2018$ )

What is interesting is that they had no idea of what critical reading skills were as they were not stimulated to do so. Examples can be seen in turns 02 (P2) and 04 (P1) above.

\subsubsection{CoT fostered reading skills and metacognitive reading strategies}

As shown in Table 3.2 of section 3.3.5, proficient readers apply reading skills or strategies flexibly and interchangeably to construct meaning while interacting with the text (Grabe, 2009). They know how, where, and when to use each strategy or skill to address the problem when comprehension suffers. Poor or ineffective readers, in contrast, use these strategies ineffectively and seldom monitor or evaluate their comprehension. The literature review also pointed out two important parts of metacognitive reading strategies. One is cognitive-reading strategies, which refer to general reading strategies. These include: predicting, questioning, clarifying, and summarizing. The other means is monitoring or regulation, the process of monitoring comprehension and taking actions to fix the problem when comprehension breakdown is emerging (Hudson, 2007). The findings demonstrated that EFL pre-service teachers were more confident in applying reading strategies than in the past. They were able to guess, generate questions, summarize the main point, skim, scan, make connections, and evaluate ideas represented in the text. As they gained a sense of confidence and accomplishment in reading, their reading interest and participation increased. This can be seen from Extract 7.13 below when asked about whether their reading skills or strategies improved as a result of the CoT-based reading instruction.

\section{Extract 7.13}

01 P1: I think my reading skills are getting better than before because ... er ... I am able to skim and scan and summarize the main point of the text faster. We have practiced this a lot in this class.

02 P2: Yeah, I agree with you. The teacher engages us in summarizing meaning of the text rather than reading aloud and translating texts. We also engage in thinking and evaluating the text, which is very useful although it is hard to do. 
03 P3: And it is not necessary to translate every word like before, only focusing on the main point of the text and using guessing skills ...

04 Ps: Yeah.

05 P4: I use summarizing skills when identifying the main claim of the text. When reading and encountering unknown words, I try to predict meaning from the context first instead of directly using a dictionary. This helps a lot in terms of time and effort used.

06 P5: Yeah. My skimming and scanning skills have developed a lot. In the past, I found it hard to get the main point of the text because I did not know how to skim and scan for the main point. This reading term helps me a lot.

07 P6: Hmm .... my summarizing skills also are getting better too. I try focus on the main point of the text and when having difficulty understanding I skim the text again.

08 P4: And one more thing that I like about this class is that ... uh ... the teacher is very open for students to share ideas. There is no right or wrong answer so that we don't feel shy or embarrassed if our ideas are not good...

09 P3: Yeah. I like this too and the class atmosphere is not serious. Sometimes I feel that time flies quickly when taking this class. I want every teacher to do like this.

10 Ps: [NODDING HEADS].

(Group 4: July 26th 2018 )

The comments above reveal that after the CoT implementation, Lao EFL pre-service teachers gained control of their English reading management. They pointed out that this course raised their metacognitive reading strategies awareness crucial for reading comprehension. They also said that reading was no longer challenging and boring. In addition, they were able to read flexibly using skills and strategies appropriately. What is important is that developing these skills in students is not easy, it takes time and effort, as stated in turn 02 (P2). Although fostering these skills was challenging, they found them worth the effort. Another aspect that is worth commenting on is that this reading class created a friendly and safe learning environment for students, which reflects the literature discussed in section 3.4.4.2.9. This can be seen in turn 09 where P3 stated that learning reading was fun and worth the time and dedication. In addition, when asked about how they addressed reading difficulty, the results revealed that the participants tended to use higher-order reading skills or strategies first as depicted in Extract 7.14.

Extract 7.14

01 P1: I normally read it again ... I skim the text and try to summarize the main point of the text. If it is necessary, I use a dictionary. 
02 P2: I concentrate and read it again. Even though there are unknown words, I try to focus on the main idea of the text. I sometimes guess by using guessing skills.

03 P3: I agree. I skim first to get the main point without worrying about unknown words. If I want to learn new words from reading, I use a dictionary later on.

04 P4: I try to guess the main point of the text first, I try to ... eliminate irrelevant information and focus on the main point.

05 P1: Yeah...I sometimes evaluate questions first when doing comprehension question exercises to help ... uh ... locate information or ideas stated in the text.

06 P2: I try to read through the text first before guessing the main point.

07 P3: Yeah. I try to scan and skim for specific and general information to understand the text ...

(Group 5: July 27th, 2018)

The comments above suggest that the CoT implementation raised their metacognitive reading skills awareness - useful for their reading management.

In contrast, this differed widely from the comparison class where EFL pre-service teachers indicated a lack of reading strategies or skills practice throughout the 13 week of reading instruction. When asked about how they coped with reading difficulties, most of the participants tended to apply lower-order reading skills (e.g., using a dictionary and Google translate and identifying parts of speech) implying that there was a lack of strategies development. This can be seen in the participants' comments in Extract 7.15 below when asked whether their reading skills or strategies improved as a result of reading learning.

\section{Extract 7.15}

01 P1: No, because the teacher never teaches us this ... I mean the skills. I don't know how to use them as we never practice this ...

02 P2: Yeah. I don't know how to use them too. That's why I cannot read effectively. I do the same when reading a text ...

03 P3: I don't have any reading skills; I think ... I read the same way as I have done. I have heard about skimming and scanning but I am not sure how to use them when reading because the teacher never gets us to practice this ...

04 P4: The teacher only talks about them [reading skills] but never gets students to do in real practices ... that is why we don't know how to apply them ...

05 P5: Yeah ... I wonder what they are and I think we should be taught how to use them in reading.

06 P6: Yeah. I want to learn how to use them too ... I have no reading skills or strategies. I read and translate as usual.

(Group 1: July 26th 2018 ) 
This echoes the findings of the student engagement analysis presented in the previous chapter where the main focus of reading learning was on reading aloud, translating, pronunciation, and vocabulary, as opposed to meaning construction and critical reading skills development. What is important to note here is that students expressed a lack of exposure to reading skills or strategies practice in their reading classes. It is apparent that the discrete language skills-oriented focus still receives considerable attention in teaching and learning reading in Lao pre-service education. This focus, however, is insufficient for the development of proficient and critical readers.

\subsubsection{Challenges in learning reading}

When asked about challenges in learning reading, the participants expressed similar perceptions. Based on the results, I compared and contrasted shared elements perceived by the two groups to have contributed to reading difficulty in the following table.

\section{Table 7. 1 Reading Difficulties}

\begin{tabular}{|c|c|}
\hline \multicolumn{2}{|c|}{ Shared elements } \\
\hline $\begin{array}{l}\text { - } \text { too many Lao Language } \\
\text { subjects; } \\
\text { - new words or vocabulary; } \\
\text { - a lack of reading } \\
\text { skills/strategies; } \\
\text { - a lack of background } \\
\text { knowledge of the topic; and } \\
\text { - pronunciation of words when } \\
\text { reading. }\end{array}$ & \\
\hline \multicolumn{2}{|c|}{ Different elements } \\
\hline Implementation & Comparison \\
\hline $\begin{array}{l}\text { - } \\
\text { - } \text { irrelevant reading texts; } \\
\text { English; } \\
\text { - } \quad \text { complex grammatical } \\
\text { structures; and } \\
\text { - } \quad \text { text structures. }\end{array}$ & $\begin{array}{l}\text { translation of texts; } \\
\text { - a lack of the meaning } \\
\text { construction focus; } \\
\text { - a lack of in-class silent reading; } \\
\text { and } \\
\text { - a lack of reading } \\
\text { resources/materials. }\end{array}$ \\
\hline
\end{tabular}


As can be seen from Table 7.1, several factors make reading challenging for the EFL preservice teachers. First and foremost, a lack of linguistic knowledge and metacognitive reading skills makes reading even more difficult (Grabe, 2009). As stated earlier, reading is a cognitive and interactive process that requires the reader to apply both linguistic knowledge and metacognitive skills to successfully extract meaning from the text (Hudson, 2007). Second, both classes stated that a lack of background knowledge of the topic makes it challenging for the reader to construct meaning. What also made reading learning challenging was that the curriculum included too many Lao language subjects; this limited their class time for English practice, as pointed out in chapter 2.

Although the implementation class had been exposed to interactive and meaningful reading learning, they still perceived the factors presented in Table 7.1 as the main determinants for reading difficulties. These challenges, however, were mitigated after having been exposed to the CoT implementation. What is interesting to note here is that the implementation class focus group participants commented that expressing or sharing ideas in English was challenging in learning reading although it was worth doing. This echoed one of the related studies discussed in section 3.4.7 in that students' lower proficiency made this learning more challenging as they were required to express their ideas in the target language.

\subsubsection{Participating lecturer's perceptions of the CoT implementation}

As stated earlier, I interviewed the implementation class lecturer to obtain his insights into the issue under investigation. The results indicated that the participating lecturer expressed positive reactions toward the CoT implementation although this required a lot of effort and commitment. For instance, when asked to comment on the CoT-based reading instruction, he noted:

I think this teaching method is very good although you need to put a lot of effort and time in planning and designing the lessons. As you may know, our teachers are very busy with their academic and administrative responsibilities. I like this teaching method ... because the teachers know how to control what they are going to teach and the lessons do not allow the teachers to go beyond the scope of the lesson. This means the teacher just focuses on the essence of the lesson and this allows the students to stay focused and worked meaningfully in groups or pairs. It 
allows them to use the target language in learning and sharing ideas. This method also focuses students' attention on meaning of the text rather than on vocabulary and grammar. The teacher also plays a facilitating role in teaching, which is good.

As the lecturer pointed out, the implementation of a CoT benefited pre-service teachers as well as the participating teacher in a number of ways. First, a CoT shifted the teacher's role as transmitter of knowledge to facilitator (Archana \& Rani, 2016). Second, this opened up opportunities for students to cooperate and work in groups meaningfully, which allowed for target language use and interactions to occur. Finally, the CoT engaged students in applying higher-order reading skills when interacting with the text. When asked about the broader pedagogical implications of the CoT, the teacher commented that:

I want other subject teachers to apply this method of teaching by co-teaching if it is possible. The reason is this allows the teachers to exchange ideas through coteaching. I think it is helpful in terms of preparing and developing ourselves. When developing lesson plans based on this teaching method, it is important to share ideas like we have been doing. I have learned a lot from this implementation. In addition, it is a good start for conducting action research, which is very useful for addressing the traditional method of teaching. We can reflect and share ideas if we want to improve or develop our teaching. Through this we can co-teach and learn from one another. This is good because when a teacher is busy the other can substitute or stand by.

The comments suggested that this teaching method could also be integrated into teaching other language skills (e.g. listening and writing). The teacher also stated that this approach could be co-taught since lecturers are overloaded with their teaching hours and administrative work. Co-teaching in this sense refers to two teachers designing the lesson together and independently teaching one class in turn (two teachers co-teach one class/subject). Through co-instruction, teachers have more opportunities to exchange ideas and learn from one another and the issues of workload can be minimized (Hohenbrink, Johnston, \& Westhoven, 1997). In addition, he pointed out that this teaching method is beneficial for classroom action research crucial for his professional and instructional development (Tran, 2018). What the lecturer states here reflects his experience of working with me (the researcher) during the implementation process. He would not have done this without my support. This suggests that the implementation of 
an innovative teaching approach requires the collective effort and ongoing support from peers and colleagues, making the innovation effective. The lecturer's perception here also reflects the sixth principle of the CoT indicated in the literature chapter in the sense that the CoT implementation requires cooperation and support from fellow lecturers and institutions. The failure and ineffectiveness of implementing an innovative teaching approach in many EFL contexts may be due to a lack of institutional support and cooperation from the learning community.

When asked about the main challenges associated with the CoT-based reading instruction, the participating lecturer pointed out that time constraints, classroom environment, and students' proficiency levels were among the top factors. This is noted in the following comments:

I think the main challenge ... is time constraints...or time limitation for the teacher. Teachers have very limited time to prepare their lessons and sometimes there are unexpected meetings or administrative work to attend or do which affect the teaching time. Another challenge is related to the... er... classroom environment and layout of the physical setting which was not conducive to group work learning and there was not an air conditioner, which is very bad in summer as the weather is extremely hot. In addition, students' English proficiency level is low... which is sometimes hard for them to express and exchange ideas in English clearly. Some students have good ideas of the topic but could not express them clearly because of low proficiency. That is why they are sometimes allowed ... uh ... to use their native language but not always.

It is apparent that English lecturers in the Lao pre-service education context are not only busy teaching, but also with their office and administrative work (Thongphanheuangsy, 2014; Vongxay, 2013). This is affecting their teaching preparation and delivery of the lessons. Another constraint is the classroom environment and layout, which also influences the implementation. As stated earlier, the physical setting of the classroom was not contributing to collaborative learning (Weinstein, 1979). This was, however, rearranged to reduce its impact to the lowest level as stated in chapter 6 . What is interesting to note here is the students' low proficiency level to express and exchange their ideas succinctly in English. This reflects the students' perceptions of reading learning difficulty stated in section 7.2.7. 
When asked about whether he would apply this method in his professional journey, the participating lecturer commented that he would definitely integrate it into his own teaching as this teaching method far outweighed its disadvantages. As the teacher noted: I will definitely apply this method because it helps engage students in learning and thinking. More importantly, this teaching method has changed students' attitudes and behaviors towards learning reading, especially from the teacher centered approach to the student-centered approach or cooperative learning. In regard to other subjects, we can integrate the thinking routines into teaching them because, I think, they can be applied to all subject areas. Personally, these thinking routines are appropriate to all subjects in English such as speaking, listening, writing, vocabulary and grammar if planned carefully.

The above comments suggest that the CoT implementation not only benefited students but also the lecturer in some ways. The teacher considered this useful and worth applying in his own teaching as it engages students in learning meaningfully and allows the lecturer to act as a learner or facilitator of the learning community. In addition, he pointed out that this teaching method could be integrated into all English skills teaching, as stated earlier if designed and planned appropriately.

\subsubsection{Section summary}

It can be seen that the Lao EFL pre-service teachers' perceptions of reading learning differed considerably between the classes after the 13-week CoT implementation. In the implementation class, they expressed their positive attitudes toward learning reading. They became more confident and gained greater control over reading management when interacting with the text and were willing to engage more in reading. The participating lecturer also expressed his positive attitude toward the CoT implementation and considered using it in his classroom practices. The following section will look at preservice teachers' perceptions of learning reading in terms of the pre-post survey results. 


\subsection{Pre-post perception survey findings}

As previously stated, a pre-post perception survey was administered to both classes to explore whether there was a change in students' perceptions of learning English reading before and after the 13-week CoT implementation. The data were analyzed using independent sample $t$ tests and paired sample $t$ tests (also known as the repeated measures $t$ tests) to compare the mean scores between and within the classes (Woodrow, 2014). Specifically, the independent sample $t$ tests were performed to compare between the classes' pre and post mean scores while the paired sample $t$ tests were conducted to compare the pre and post mean scores within each class using SPSS version25. Again, as stated in section 6.2.1, the effect size analysis was performed for all $t$ tests used in this study to determine the extent to which the CoT implementation changed perceptions of learning reading. The effect size is used to supplement and confirm the $t$ test results (Kotrlik, Williams, \& Jabor, 2011).

This section consists of five subsections. Section 7.3.1 looks at pre-perception survey results between the classes. Section 7.3.2 compares the pre-post perceptions survey within each class. Section 7.3.3 compares post-perception results between the classes. Section 7.3.4 presents the qualitative results of the survey. Table 7.2 summarizes statistical packages and procedures used in this section.

Table 7. 2 A Summary of Analysis Procedures

\begin{tabular}{lllll}
\hline Step & Statistics & Class & Score & Section \\
\hline 1 & Independent samples $t$ tests & Between the classes & Pre-pre & 7.3 .1 \\
2 & Paired samples $t$ tests & Within the class & Pre-post & 7.3 .2 \\
3 & Independent samples $t$ tests & Between the classes & Post-post & 7.3 .3 \\
\hline
\end{tabular}

There are four categories in each analysis. The four categories aim to compare students' perceptions in terms of: 1) discrete language skills reading learning (4 items), 2) metacognitive reading learning (6 items), 3) reading learning experiences (10 items), and 4) reading learning outcomes (11 items). Each of these will be looked in the following subsections. 


\subsubsection{Pre-perceptions of reading between the classes}

\subsubsection{Perceptions of discrete language skills reading learning}

An independent sample $t$ test was performed and means and standard deviation between the classes are presented in Table 7.3 below.

Table 7. 3 Discrete Language Skills Learning

\begin{tabular}{llrrrrrr}
\hline & \multicolumn{3}{c}{ Implementation } & \multicolumn{4}{c}{ Comparison } \\
\cline { 2 - 7 } & $\mathrm{N}$ & $\mathrm{M}$ & $\mathrm{SD}$ & $\mathrm{N}$ & $\mathrm{M}$ & $\mathrm{SD}$ \\
\hline 1. Translating from L2 to L1 is important for & 30 & 3.93 & .94 & 31 & 4.26 & .93 \\
$\begin{array}{l}\text { learning English reading. } \\
\begin{array}{l}\text { 2. Learning a lot of new words is important for } \\
\text { learning English reading. }\end{array}\end{array}$ & 30 & 4.57 & .50 & 31 & 4.71 & .78 \\
$\begin{array}{l}\text { 3. Learning pronunciation is important for } \\
\text { learning English reading. }\end{array}$ & 30 & 4.47 & .62 & 31 & 4.68 & .97 \\
$\begin{array}{l}\text { 4. Answering comprehension questions is } \\
\text { important for learning English reading. }\end{array}$ & 30 & 4.07 & .64 & 31 & 3.97 & .70 \\
$\quad$ & $\mathbf{3 0}$ & $\mathbf{4 . 2 6}$ &. $\mathbf{3 0}$ & $\mathbf{3 1}$ & $\mathbf{4 . 4 0}$ &. $\mathbf{3 5}$ \\
\hline
\end{tabular}

It can be seen from Table 7.3 that the mean scores of the pre-perceptions between the classes were not significantly different and the standard deviations were similarly dispersed $(M=4.26, S D=.30)$ and $(M=4.40, S D=.35)$. In addition, the results of the independent sample $t$ test found this comparison not to be significant, $t(6)=.61, p=.56>$ .05 with a 95\%-confidence interval of the difference, suggesting that students' perceptions of discrete language skills learning between the classes were not significantly different. The result of an effect size analysis also indicated no significance $(d=0.01)$.When considering a specific item, it can be noted that the most highly rated one by both classes is item $2(M=4.57, S D=.50 ; M=4.71, S D=.78)$, which is about the role of learning new words from reading. It can be implied that learning a lot of new vocabulary was the most important feature for learning English reading. The finding here also reflects the results of phase 1 in terms of vocabulary focus in learning reading. 


\subsubsection{Perceptions of metacognitive reading learning}

Table 7. 4 Metacognitive Reading Learning

\begin{tabular}{|c|c|c|c|c|c|c|}
\hline \multirow[t]{2}{*}{ Items } & \multicolumn{3}{|c|}{ Implementation } & \multicolumn{3}{|c|}{ Control } \\
\hline & $\mathrm{N}$ & M & SD & $\mathrm{N}$ & M & SD \\
\hline $\begin{array}{l}\text { 1. Constructing meaning from a text is } \\
\text { important for learning English reading. }\end{array}$ & 30 & 3.30 & .59 & 31 & 3.81 & .74 \\
\hline $\begin{array}{l}\text { 2. Developing critical reading strategies is } \\
\text { important for learning English reading. }\end{array}$ & 30 & 3.77 & .81 & 31 & 3.77 & .71 \\
\hline $\begin{array}{l}\text { 3. Making connections between what to } \\
\text { be reading with prior knowledge is } \\
\text { important for learning English reading. }\end{array}$ & 30 & 3.80 & .66 & 31 & 3.48 & .81 \\
\hline $\begin{array}{l}\text { 4. Promoting students' reading } \\
\text { independence is important for learning } \\
\text { English reading. }\end{array}$ & 30 & 3.87 & .81 & 31 & 3.68 & .87 \\
\hline $\begin{array}{l}\text { 5. Identifying text organizations is } \\
\text { important for learning English reading. }\end{array}$ & 30 & 3.53 & .90 & 31 & 3.52 & .72 \\
\hline $\begin{array}{l}\text { 6. Activating prior knowledge of the text } \\
\text { is important for learning English } \\
\text { reading. }\end{array}$ & 30 & 3.77 & .77 & 31 & 3.81 & .83 \\
\hline Total & 30 & 3.67 & .21 & 31 & 3.67 & .14 \\
\hline
\end{tabular}

It can be noted from Table 7.4 that the total mean scores of the six items under this category were not significantly different between the implementation class $(M=3.67, S D$ $=.21)$ and the comparison class $(M=3.67, S D=.14)$. In addition, the results of the independent sample $t$ test showed no significance, $t(10)=.047, p=.96>.05$, suggesting that the pre-perception scores between the classes were not significantly different. This was also confirmed by the effect size analysis $(d=0.00)$. The mean scores of all items between the classes are also similar, ranging from 3.30 to 3.87 and standard deviations dispersed from .59 to .90 , meaning that the pre-perceptions of this category were comparable between the classes prior to the implementation. 


\subsubsection{Pre-perceptions of reading learning experiences}

Table 7. 5 Reading Learning Experiences

\begin{tabular}{|c|c|c|c|c|c|c|}
\hline \multirow[t]{2}{*}{ Items } & \multicolumn{3}{|c|}{ Implementation } & \multicolumn{3}{|c|}{ Control } \\
\hline & $\mathrm{N}$ & $M$ & SD & $\mathrm{N}$ & $\mathrm{M}$ & SD \\
\hline $\begin{array}{l}\text { 1. I usually read in English to understand } \\
\text { the meaning of the text }\end{array}$ & 30 & 3.47 & .86 & 31 & 3.58 & .88 \\
\hline $\begin{array}{l}\text { 2. I usually activated prior knowledge } \\
\text { about the reading topic before } \\
\text { interacting with the text. }\end{array}$ & 30 & 2.87 & .73 & 31 & 3.06 & 1.09 \\
\hline $\begin{array}{l}\text { 3. I usually exchanged ideas about what I } \\
\text { read with classmates after reading. }\end{array}$ & 30 & 3.30 & .91 & 31 & 3.03 & .83 \\
\hline $\begin{array}{l}\text { 4. I usually summarized the main idea of } \\
\text { the topic. }\end{array}$ & 30 & 3.43 & .97 & 31 & 3.13 & .95 \\
\hline $\begin{array}{l}\text { 5. I usually identified text organizations } \\
\text { or structures. }\end{array}$ & 30 & 2.63 & .85 & 31 & 2.84 & .86 \\
\hline $\begin{array}{l}\text { 6. I usually analyzed or evaluated the } \\
\text { main claim of the topic. }\end{array}$ & 30 & 3.07 & .78 & 31 & 2.84 & .93 \\
\hline $\begin{array}{l}\text { 7. I was usually encouraged to apply } \\
\text { critical reading strategies or skills. }\end{array}$ & 30 & 2.97 & .99 & 31 & 2.94 & .92 \\
\hline $\begin{array}{l}\text { 8. I usually answered reading } \\
\text { comprehension questions. }\end{array}$ & 30 & 3.30 & .79 & 31 & 3.68 & .97 \\
\hline $\begin{array}{l}\text { 9. I usually involved in developing my } \\
\text { own questions of investigation to } \\
\text { develop my critical reading skills. }\end{array}$ & 30 & 2.77 & .62 & 31 & 3.03 & .91 \\
\hline $\begin{array}{l}\text { 10. I usually monitor my reading } \\
\text { comprehension by evaluating my } \\
\text { achievement of the reading goal set. }\end{array}$ & 30 & 3.03 & .92 & 31 & 3.42 & .80 \\
\hline Total & 30 & 3.08 & .28 & 31 & 3.15 & .30 \\
\hline
\end{tabular}


As the table above demonstrates, both classes' perceived reading learning experiences were similar prior to the CoT implementation. The means and standard deviations of the implementation class $(M=3.08, S D=.28)$ were not different from the control class $(M=$ $3.15, S D=.30$ ) in this aspect. Also, the results of the independent sample $t$ test revealed that the pre-perception scores of this category were not statistically significant, $t(18)=$ $.63, p=.53>.05$ between the classes and effect size analysis $(d=0.24)$ confirmed that there was small significance. 


\subsubsection{Pre-perceptions of learning outcomes}

Table 7. 6 Reading Learning Outcomes

\begin{tabular}{|c|c|c|c|c|c|c|}
\hline \multirow[t]{2}{*}{ Items } & \multicolumn{3}{|c|}{ Implementation } & \multicolumn{3}{|c|}{ Control } \\
\hline & $\mathrm{N}$ & M & SD & $\mathrm{N}$ & M & SD \\
\hline $\begin{array}{l}\text { 1. My English vocabulary knowledge } \\
\text { expands. }\end{array}$ & 30 & 3.37 & .81 & 31 & 3.35 & .83 \\
\hline $\begin{array}{l}\text { 2. I am able to identify claims presented } \\
\text { in the text. }\end{array}$ & 30 & 2.90 & .76 & 31 & 3.06 & .85 \\
\hline 3. My reading comprehension improves. & 30 & 3.43 & .73 & 31 & 3.32 & .87 \\
\hline $\begin{array}{l}\text { 4. I am able to construct meaning of the } \\
\text { text. }\end{array}$ & 30 & 2.90 & .66 & 31 & 3.03 & .94 \\
\hline $\begin{array}{l}\text { 5. I am able to communicate ideas } \\
\text { represented in the text. }\end{array}$ & 30 & 2.97 & .61 & 31 & 3.03 & .83 \\
\hline $\begin{array}{l}\text { 6. I am able to activate my prior } \\
\text { knowledge before interacting with the } \\
\text { text. }\end{array}$ & 30 & 2.73 & .90 & 31 & 2.90 & .84 \\
\hline $\begin{array}{l}\text { 7. I am able to apply my reading } \\
\text { strategies or skills. }\end{array}$ & 30 & 2.85 & .74 & 31 & 2.90 & .90 \\
\hline $\begin{array}{l}\text { 8. I am able to automatically recognize } \\
\text { word meaning in the text. }\end{array}$ & 30 & 2.57 & .89 & 31 & 2.97 & .79 \\
\hline $\begin{array}{l}\text { 9. I am able to monitor my } \\
\text { comprehension while reading. }\end{array}$ & 30 & 2.93 & .90 & 31 & 3.13 & .90 \\
\hline $\begin{array}{l}\text { 10. I become an agent of my own reading } \\
\text { learning. }\end{array}$ & 30 & 3.27 & .78 & 31 & 3.35 & .88 \\
\hline $\begin{array}{l}\text { 11. I am able to identify text structures or } \\
\text { organizations. }\end{array}$ & 30 & 2.80 & .89 & 31 & 3.06 & .89 \\
\hline Total & 30 & 2.97 & .26 & 31 & 3.10 & .16 \\
\hline
\end{tabular}

As Table 7.6 reveals, the mean scores of the pre-service teachers' pre-perceptions of reading learning outcomes were similar between the classes. In the implementation 
class, the means and standard deviations were $(M=2.97, S D=.26)$ while the control class were $(M=3.10, S D=.16)$. The independent sample $t$ test results showed no statistical significance, $t(20)=1.33, p=.19>.05$, suggesting that the pre-perceptions between the classes were comparable in terms of this category. The effect size also showed no significant difference between the groups $(d=0.02)$. The section that follows will look at the results of paired sample $t$ tests of each category within each class to determine whether there was a change in students' perceptions after the 13-week reading instruction.

\subsubsection{Pre-post perceptions comparison findings of each class}

As stated in the methodology chapter and above, the employment of the paired sample $t$ tests was to compare the pre-post mean scores within each class to see if there was any statistically significant change after the implementation. In this regard, I will look at the pre-post mean scores of the implementation class first, followed by the control class before performing independent sample $t$ tests again on the post-perception mean scores between the classes in section 7.3.3. 


\subsubsection{Implementation class}

Each category of the students' perceptions was analyzed and the results are presented in the following subsections.

\subsection{Discrete language skills learning}

Table 7. 7 Discrete language skills Reading Learning

\begin{tabular}{|c|c|c|c|c|c|}
\hline \multirow[t]{2}{*}{ Items } & \multicolumn{3}{|c|}{ Pre-scores } & \multicolumn{2}{|c|}{$\overline{\text { Post-scores }}$} \\
\hline & $\mathrm{N}$ & $\mathrm{M}$ & SD & $\mathrm{M}$ & SD \\
\hline $\begin{array}{l}\text { 1. Translating from L2 to L1 is important for } \\
\text { learning English reading. }\end{array}$ & 30 & 3.93 & .94 & 2.73 & .74 \\
\hline $\begin{array}{l}\text { 2. Learning a lot of new words is important for } \\
\text { learning English reading. }\end{array}$ & 30 & 4.57 & .50 & 3.50 & .75 \\
\hline $\begin{array}{l}\text { 3. Learning pronunciation is important for } \\
\text { learning English reading. }\end{array}$ & 30 & 4.47 & .62 & 2.50 & .82 \\
\hline $\begin{array}{l}\text { 4. Answering comprehension questions is } \\
\text { important for learning English reading. }\end{array}$ & 30 & 4.07 & .64 & 3.50 & .66 \\
\hline Total & 30 & 4.26 & .30 & 3.05 & .51 \\
\hline
\end{tabular}

Table 7.7 displays the descriptive statistics of the pre-post mean scores of the preservice teachers' perceptions toward discrete language skills learning. It can be noted that the total mean scores between the pre $(M=4.26, S D=.30)$ and the post $(M=3.05$, $S D=.51$ ) differed significantly. In addition, the results of the paired sample $t$ test showed that there was a statistical significance between the pre-post perceptions, $t(3)=4.15, p=$ $.02<.05$. The effect size analysis $(d=2.89)$ confirmed that there was a significant difference between the pre and post perceptions of the implementation group regarding this aspect. For all items in Table 7.7, the students regarded them as less important following the CoT implementation than they had at the beginning of the intervention. The largest shifted change was about the role of learning pronunciation, which moved from being the second- highest to the lowest rated. This implies that students may have perceived the other aspects (e.g., meaning construction or critical reading development) 
as the most important ones for learning English reading. Other aspects will be presented below.

\subsection{Perceptions of metacognitive reading learning}

Table 7. 8 Metacognitive Reading Learning

\begin{tabular}{|c|c|c|c|c|c|}
\hline \multirow[t]{2}{*}{ Items } & \multicolumn{3}{|c|}{ Pre-scores } & \multicolumn{2}{|c|}{ Post-scores } \\
\hline & $\mathrm{N}$ & M & SD & M & SD \\
\hline $\begin{array}{l}\text { 1. Constructing meaning from a text is } \\
\text { important for learning English reading. }\end{array}$ & 30 & 3.90 & .59 & 4.38 & .37 \\
\hline $\begin{array}{l}\text { 2. Developing critical reading strategies is } \\
\text { important for learning English reading. }\end{array}$ & 30 & 3.77 & .81 & 4.33 & .60 \\
\hline $\begin{array}{l}\text { 3. Making connections between what to be } \\
\text { reading with prior knowledge is important } \\
\text { for learning English reading. }\end{array}$ & 30 & 3.80 & .66 & 4.10 & .56 \\
\hline $\begin{array}{l}\text { 4. Promoting students' reading independence } \\
\text { is important for learning English reading. }\end{array}$ & 30 & 3.87 & .81 & 4.17 & .53 \\
\hline $\begin{array}{l}\text { 5. Identifying text organizations is important } \\
\text { for learning English reading. }\end{array}$ & 30 & 3.53 & .90 & 3.97 & .55 \\
\hline $\begin{array}{l}\text { 6. Activating prior knowledge of the text is } \\
\text { important for learning English reading. }\end{array}$ & 30 & 3.77 & .77 & 4.20 & .61 \\
\hline Total & 30 & 3.67 & .21 & 4.19 & .15 \\
\hline
\end{tabular}

As Table 7.8 demonstrates, the means and standard deviations of the pre $(M=3.67, S D=$ .21 ) and post $(M=4.19, S D=.15)$ perceptions of metacognitive reading learning differed significantly. Further evidence can be sought from the inferential statistics where the results found this pattern to be statistically significant, $t(5)=4.347, p=.00<.05$. The effect size was also strong $(d=2.84)$, indicating that there was significance. When considering each item, it can be seen that most students viewed meaning construction (item 1) as the most important feature for learning English reading after the CoT implementation, with the means ranging from 3.90 to 4.38 . 


\subsection{Perceptions of reading learning experiences}

Table 7. 9 Reading Learning Experiences

\begin{tabular}{|c|c|c|c|c|c|}
\hline \multirow[t]{2}{*}{ Items } & \multicolumn{3}{|c|}{ Pre-score } & \multicolumn{2}{|c|}{ Post-scores } \\
\hline & $\mathrm{N}$ & M & SD & M & SD \\
\hline $\begin{array}{l}\text { 1. I usually read in English to understand the meaning } \\
\text { of the text }\end{array}$ & 30 & 3.47 & .86 & 4.10 & .49 \\
\hline $\begin{array}{l}\text { 2. I usually activated prior knowledge about the } \\
\text { reading topic before interacting with the text. }\end{array}$ & 30 & 2.28 & .73 & 3.70 & .46 \\
\hline $\begin{array}{l}\text { 3. I usually exchanged ideas about what I read with } \\
\text { classmates after reading. }\end{array}$ & 30 & 3.30 & .91 & 4.30 & .53 \\
\hline 4. I usually summarized the main idea of the topic. & 30 & 3.43 & .97 & 4.10 & .54 \\
\hline 5. I usually identified text organizations or structures. & 30 & 2.63 & .85 & 3.80 & .55 \\
\hline $\begin{array}{l}\text { 6. I usually analyzed or evaluated the main claim of the } \\
\text { topic. }\end{array}$ & 30 & 3.07 & .78 & 3.97 & .49 \\
\hline $\begin{array}{l}\text { 7. I was usually encouraged to apply critical reading } \\
\text { strategies or skills. }\end{array}$ & 30 & 2.97 & .99 & 3.87 & .50 \\
\hline $\begin{array}{l}\text { 8. I usually answered reading comprehension } \\
\text { questions. }\end{array}$ & 30 & 3.30 & .79 & 4.30 & .53 \\
\hline $\begin{array}{l}\text { 9. I usually involved in developing my own questions } \\
\text { of investigation to develop my critical reading skills. }\end{array}$ & 30 & 2.77 & .62 & 4.07 & .45 \\
\hline $\begin{array}{l}\text { 10. I usually monitor my reading comprehension by } \\
\text { evaluating my achievement of the reading goal set. }\end{array}$ & 30 & 3.03 & .92 & 3.87 & .50 \\
\hline Total & 30 & 3.08 & .28 & 4.00 & .20 \\
\hline
\end{tabular}

It can be noticed from Table 7.9 that the pre-post mean scores in terms of reading learning experiences were significantly different between the pre $(M=3.08, S D=.28)$ and post $(M=4.00, S D=.20)$. The results of a paired sample $t$ test also indicated a significant difference, $t(9)=14.19, p=.00<.05$, suggesting that students applied what was represented in each item above more frequently than before the 13-week CoT 
implementation. This was also indicated in the result of the effect size analysis $(d=3.87)$, revealing that there was a strong effect of the CoT on their perceptions.

\subsection{Perceptions of reading learning outcomes}

Table 7. 10 Perceptions of Reading Learning Outcomes

\begin{tabular}{|c|c|c|c|c|c|}
\hline \multirow[t]{2}{*}{ Items } & \multicolumn{3}{|c|}{ Pre-scores } & \multicolumn{2}{|c|}{ Post-scores } \\
\hline & $\mathrm{N}$ & M & SD & $\mathrm{M}$ & SD \\
\hline 1. My English vocabulary knowledge expands. & 30 & 3.37 & .81 & 4.57 & .50 \\
\hline 2. I am able to identify claims presented in the text. & 30 & 2.90 & .76 & 3.87 & .50 \\
\hline 3. My reading comprehension improves. & 30 & 3.43 & .73 & 4.20 & .40 \\
\hline 4. I am able to construct meaning of the text. & 30 & 2.90 & .66 & 3.83 & .37 \\
\hline \multicolumn{6}{|l|}{ 5. I am able to communicate ideas represented in } \\
\hline the text. & 30 & 2.97 & .61 & 3.97 & .32 \\
\hline \multicolumn{6}{|l|}{ 6. I am able to activate my prior knowledge before } \\
\hline interacting with the text. & 30 & 2.73 & .90 & 3.70 & .46 \\
\hline 7. I am able to apply my reading strategies or skills. & 30 & 2.85 & .74 & 3.80 & .61 \\
\hline \multicolumn{6}{|l|}{ 8. I am able to automatically recognize word } \\
\hline meaning in the text. & 30 & 2.57 & .89 & 3.73 & .54 \\
\hline \multicolumn{6}{|l|}{ 9. I am able to monitor my comprehension while } \\
\hline reading. & 30 & 2.93 & .90 & 3.67 & .47 \\
\hline 10. I become an agent of my own reading learning. & 30 & 3.27 & .78 & 4.07 & .36 \\
\hline \multicolumn{6}{|l|}{ 11. I am able to identify text structures or } \\
\hline organizations. & 30 & 2.80 & .89 & 3.70 & .53 \\
\hline Total & 30 & 2.97 & .27 & 3.91 & .36 \\
\hline
\end{tabular}

As the table shows, there was a significant change in the mean scores between the pre $(M$ $=2.97, S D=.27)$ and post $(M=3.91, S D=.36)$ perceptions of reading learning outcomes. The results of a paired sample t-test also revealed a statistical significance, $t(10)=21.54$, $p=.00<.05$, and the effect size was strong $(d=2.95)$, indicating that students' perceptions in terms of reading comprehension development changed after the CoT implementation. This indicates that students believed that their reading comprehension 
improved after the intervention, which reinforces the post-test results stated in chapter 5.

\subsubsection{Control class pre-post mean scores comparison}

Similar to the implementation class, each category of the survey was analyzed using paired sample $t$ tests to examine a change in students' perceptions before and after the intervention. Results are presented in the following subsections.

\subsection{Discrete language skills learning}

Table 7.11 below shows the results of the pre-post perceptions of discrete language skills learning. It can be noted that the results were not significantly different between the pre $(M=4.40, S D=.35)$ and post $(M=4.42, S D=.20)$ perceptions. In addition, the results of a paired sample t-test showed no significance, $t(3)=.22, p=.83>.05$, and the effect size was very small $(d=0.07)$, meaning that students' perceptions of this aspect remained unchanged after the 13 weeks of reading instruction. When looking at each item, it can be noticed that the mean scores were close to one another between the pre-and post-, ranging from 3.97 to 4.71 , meaning that they perceived discrete language features as the most important elements for learning English reading.

Table 7. 11 Discrete Language Skills Learning

\begin{tabular}{|c|c|c|c|c|c|}
\hline \multirow[t]{2}{*}{ Items } & \multicolumn{3}{|c|}{ Pre-scores } & \multicolumn{2}{|c|}{ Post-scores } \\
\hline & $\mathrm{N}$ & M & SD & $\mathrm{M}$ & SD \\
\hline $\begin{array}{l}\text { 1. Translating from L2 to L1 is important for } \\
\text { learning English reading. }\end{array}$ & 31 & 4.26 & .93 & 4.35 & .70 \\
\hline $\begin{array}{l}\text { 2. Learning a lot of new words is important for } \\
\text { learning English reading. }\end{array}$ & 31 & 4.71 & .78 & 4.68 & .54 \\
\hline $\begin{array}{l}\text { 3. Learning pronunciation is important for learning } \\
\text { English reading. }\end{array}$ & 31 & 4.68 & .97 & 4.48 & .57 \\
\hline $\begin{array}{l}\text { 4. Answering comprehension questions is } \\
\text { important for learning English reading. }\end{array}$ & 31 & 3.97 & .70 & 4.19 & .54 \\
\hline Total & 31 & 4.40 & .35 & 4.42 & .20 \\
\hline
\end{tabular}




\subsection{Perceptions of metacognitive reading learning}

Table 7.12 below shows the results between the pre-and post-perceptions of metacognitive reading learning perceived by control class students. The total mean scores revealed a similarity between the pre $(M=3.67, S D=.14)$ and post $(M=3.66, S D=$ .25). The results of a paired sample $t$ test also indicated no significant difference, $t(5)=$ $.21, p=.84>.05$. Effect size $(d=0.04)$ confirmed that there was no difference in this category.

Table 7.12 Metacognitive Reading Learning

\begin{tabular}{|c|c|c|c|c|c|}
\hline \multirow[t]{2}{*}{ Items } & \multicolumn{3}{|c|}{ Pre-scores } & \multicolumn{2}{|c|}{ Post-scores } \\
\hline & $\mathrm{N}$ & M & SD & $\mathrm{M}$ & SD \\
\hline $\begin{array}{l}\text { 1. Constructing meaning from a text is important } \\
\text { for learning English reading. }\end{array}$ & 31 & 3.81 & .74 & 4.06 & .57 \\
\hline $\begin{array}{l}\text { 2. Developing critical reading strategies is } \\
\text { important for learning English reading. }\end{array}$ & 31 & 3.77 & .71 & 3.55 & .81 \\
\hline $\begin{array}{l}\text { 3. Making connections between what to be reading } \\
\text { with prior knowledge is important for learning } \\
\text { English reading. }\end{array}$ & 31 & 3.48 & .81 & 3.58 & .76 \\
\hline $\begin{array}{l}\text { 4. Promoting students' reading independence is } \\
\text { important for learning English reading. }\end{array}$ & 31 & 3.68 & .87 & 3.84 & .63 \\
\hline $\begin{array}{l}\text { 5. Identifying text organizations is important for } \\
\text { learning English reading. }\end{array}$ & 31 & 3.52 & .72 & 3.35 & .60 \\
\hline $\begin{array}{l}\text { 6. Activating prior knowledge of the text is } \\
\text { important for learning English reading. }\end{array}$ & 31 & 3.81 & .83 & 3.58 & .80 \\
\hline Total & 31 & 3.67 & .14 & 3.66 & .25 \\
\hline
\end{tabular}




\subsection{Perceptions of learning experiences}

Table 7.13 Reading Learning Experiences

\begin{tabular}{|c|c|c|c|c|c|}
\hline \multirow[t]{2}{*}{ Items } & \multicolumn{3}{|c|}{ Pre-score } & \multicolumn{2}{|c|}{ Post-scores } \\
\hline & $\mathrm{N}$ & M & SD & M & SD \\
\hline $\begin{array}{l}\text { 1. I usually read in English to understand the } \\
\text { meaning of the text }\end{array}$ & 31 & 3.58 & .88 & 3.61 & .60 \\
\hline $\begin{array}{l}\text { 2. I usually activated prior knowledge about the } \\
\text { reading topic before interacting with the text. }\end{array}$ & 31 & 3.06 & 1.09 & 3.10 & .79 \\
\hline $\begin{array}{l}\text { 3. I usually exchanged ideas about what I read } \\
\text { with classmates after reading. }\end{array}$ & 31 & 3.03 & .83 & 3.05 & .83 \\
\hline 4. I usually summarized the main idea of the topic. & 31 & 3.13 & .95 & 3.18 & .72 \\
\hline $\begin{array}{l}\text { 5. I usually identified text organizations or } \\
\text { structures. }\end{array}$ & 31 & 2.84 & .86 & 3.00 & .57 \\
\hline $\begin{array}{l}\text { 6. I usually analyzed or evaluated the main claim } \\
\text { of the topic. }\end{array}$ & 31 & 2.84 & .93 & 2.80 & .57 \\
\hline $\begin{array}{l}\text { 7. I was usually encouraged to apply critical } \\
\text { reading strategies or skills. }\end{array}$ & 31 & 2.94 & .92 & 2.95 & .65 \\
\hline $\begin{array}{l}\text { 8. I usually answered reading comprehension } \\
\text { questions. }\end{array}$ & 31 & 3.68 & .97 & 3.66 & .77 \\
\hline $\begin{array}{l}\text { 9. I usually involved in developing my own } \\
\text { questions of investigation to develop my critical } \\
\text { reading skills. }\end{array}$ & 31 & 3.03 & .91 & 3.05 & .51 \\
\hline $\begin{array}{l}\text { 10. I usually monitor my reading comprehension by } \\
\text { evaluating my achievement of the reading goal }\end{array}$ & 31 & 3.42 & .80 & 3.40 & .67 \\
\hline Total & 31 & 3.15 & .30 & 3.18 & .28 \\
\hline
\end{tabular}

The results above showed that the mean scores between the pre $(M=3.15, S D=.30)$ and post $(M=3.18, S D=.28)$ perceptions reading learning experiences of this category were not different. In addition, the results of a paired samples $t$ test also revealed no statistical 
significance was found, $t(9)=1.42, p=.18>.05$, suggesting that there was no significant difference. The effect size was very small $(d=0.10)$, indicating that there was no significant difference.

\subsection{Perceptions of reading learning outcomes}

Table 7. 14 Reading Learning Outcomes

\begin{tabular}{|c|c|c|c|c|c|}
\hline \multirow[t]{2}{*}{ Items } & \multicolumn{3}{|c|}{ Pre-scores } & \multicolumn{2}{|c|}{ Post-scores } \\
\hline & $\mathrm{N}$ & M & SD & M & SD \\
\hline 1. My English vocabulary knowledge expands. & 31 & 3.35 & .83 & 3.58 & .67 \\
\hline 2. I am able to identify claims presented in the text. & 31 & 3.06 & .85 & 3.00 & .68 \\
\hline 3. My reading comprehension improves. & 31 & 3.32 & .87 & 3.39 & .66 \\
\hline 4. I am able to construct meaning of the text. & 31 & 3.03 & .94 & 3.03 & .60 \\
\hline $\begin{array}{l}\text { 5. I am able to communicate ideas represented in } \\
\text { the text. }\end{array}$ & 31 & 3.03 & .83 & 3.16 & .45 \\
\hline $\begin{array}{l}\text { 6. I am able to activate my prior knowledge before } \\
\text { interacting with the text. }\end{array}$ & 31 & 2.90 & .84 & 3.29 & .73 \\
\hline 7. I am able to apply my reading strategies or skills. & 31 & 2.90 & .90 & 3.06 & .57 \\
\hline $\begin{array}{l}\text { 8. I am able to automatically recognize word } \\
\text { meaning in the text. }\end{array}$ & 31 & 2.97 & .79 & 3.00 & .68 \\
\hline $\begin{array}{l}\text { 9. I am able to monitor my comprehension while } \\
\text { reading. }\end{array}$ & 31 & 3.16 & .90 & 3.23 & .56 \\
\hline 10. I become an agent of my own reading learning. & 31 & 3.35 & .88 & 3.48 & .57 \\
\hline $\begin{array}{l}\text { 11. I am able to identify text structures or } \\
\text { organizations. }\end{array}$ & 31 & 3.06 & .89 & 3.10 & .59 \\
\hline Total & 31 & 3.10 & .16 & 3.21 & .20 \\
\hline
\end{tabular}

The results of the students' perceptions toward reading learning outcomes before $(M=$ $3.10, S D=.16)$ and after the 13 -week reading instruction $(M=3.21, S D=.20)$ were different. To determine whether this was statistically significant, a paired sample $t$ test was run and the results found this category statistically significant, $t(10)=2.91, p=.01<$ .05 , and the effect size was medium $(d=0.60)$, suggesting that students believed that 
their reading comprehension improved after the 13-week reading instruction. This also reflects the results of the post-test and focus group interviews in that there was a small improvement in reading comprehension development as indicated in chapter 5 . When compared with the implementation class, however, this improvement was statistically different. Before drawing a conclusion on the results of this survey, they are compared with the implementation class through an independent sample $t$ test again. The results are presented in the following section.

\subsubsection{Comparison of post survey mean scores between the classes}

\subsubsection{Perceptions of discrete language skills learning}

Table 7. 15 Discrete Language Skills Learning

\begin{tabular}{llllllll}
\hline & \multicolumn{1}{c}{ Items } & \multicolumn{3}{c}{ Implementation } & \multicolumn{3}{c}{ Comparison } \\
\cline { 2 - 7 } & $\mathrm{N}$ & $\mathrm{M}$ & $\mathrm{SD}$ & $\mathrm{N}$ & $\mathrm{M}$ & $\mathrm{SD}$ \\
\hline $\begin{array}{l}\text { 1. Translating from L2 to L1 is important for } \\
\text { learning English reading. }\end{array}$ & 30 & 2.73 & .74 & 31 & 4.35 & .70 \\
$\begin{array}{l}\text { 2. Learning a lot of new words is important for } \\
\text { learning English reading. }\end{array}$ & 30 & 3.50 & .75 & 31 & 4.68 & .54 \\
$\begin{array}{l}\text { 3. Learning pronunciation is important for } \\
\text { learning English reading. }\end{array}$ & 30 & 2.50 & .82 & 31 & 4.48 & .57 \\
$\begin{array}{l}\text { 4. Answering comprehension questions is } \\
\text { important for learning English reading. }\end{array}$ & 30 & 3.50 & .66 & 31 & 4.19 & .54 \\
$\quad$ Total & $\mathbf{3 0}$ & $\mathbf{3 . 0 5}$ & $\mathbf{. 5 1}$ & $\mathbf{3 1}$ & $\mathbf{4 . 4 2}$ & $\mathbf{. 2 0}$ \\
\hline
\end{tabular}

As the table shows, the total mean scores of the implementation class $(M=3.05, S D=.51)$ and the comparison class $(M=4.42, S D=.20)$ were significantly different. In addition, the results of an independent samples $t$ test demonstrated a significant difference between the post-mean scores of the two classes, $t(6)=4.89, p=.00<.05$, and the effect size indicated a very significant difference $(d=3.53)$. This means that the implementation class's perceptions changed over the 13-week of the CoT implementation. In other words, the implementation class's perceptions regarding this point decreased. This suggests translating, learning a lot of new words, learning pronunciation, and answering 
comprehension questions were perceived as less important for learning English reading than before. These features, however, were perceived as the most important features for learning English reading by the control class.

\subsubsection{Perceptions of metacognitive reading learning}

In terms of the post metacognitive reading learning perception mean scores, the results in Table 7.16 below show a difference between the implementation class $(M=4.19, S D=$ $.30)$ and the control class $(M=3.66, S D=.25)$. The results of an independent sample $t$ test also revealed a statistical significance, $t(10)=3.80, p=.00<.05$, and the effect size was strong $(d=1.91)$, meaning that the implementation class viewed each of the ideas represented in the items as more important features for learning English reading than the control class.

Table 7.16 Metacognitive Reading Learning

\begin{tabular}{|c|c|c|c|c|c|c|}
\hline \multirow[t]{2}{*}{ Items } & \multicolumn{3}{|c|}{ Implementation } & \multicolumn{3}{|c|}{ Control } \\
\hline & $\mathrm{N}$ & M & SD & $\mathrm{N}$ & M & SD \\
\hline $\begin{array}{l}\text { 1. Constructing meaning from a text is } \\
\text { important for learning English reading. }\end{array}$ & 30 & 4.38 & .37 & 31 & 4.06 & .57 \\
\hline $\begin{array}{l}\text { 2. Developing critical reading strategies is } \\
\text { important for learning English reading. }\end{array}$ & 30 & 4.33 & .60 & 31 & 3.55 & .81 \\
\hline $\begin{array}{l}\text { 3. Making connections between what to be } \\
\text { reading with prior knowledge is important } \\
\text { for learning English reading. }\end{array}$ & 30 & 4.10 & .56 & 31 & 3.58 & .76 \\
\hline $\begin{array}{l}\text { 4. Promoting students' reading independence } \\
\text { is important for learning English reading. }\end{array}$ & 30 & 4.17 & .53 & 31 & 3.84 & .68 \\
\hline $\begin{array}{l}\text { 5. Identifying text organizations is important } \\
\text { for learning English reading. }\end{array}$ & 30 & 3.97 & .55 & 30 & 3.35 & .60 \\
\hline $\begin{array}{l}\text { 6. Activating prior knowledge of the text is } \\
\text { important for learning English reading. }\end{array}$ & 30 & 4.20 & .61 & 30 & 3.58 & .80 \\
\hline Total & 30 & 4.19 & .30 & 31 & 3.66 & .25 \\
\hline
\end{tabular}




\subsubsection{Perceptions of reading learning experiences}

Table 7.17 Reading Learning Experiences

\begin{tabular}{|c|c|c|c|c|c|c|}
\hline \multirow{2}{*}{ Items } & \multicolumn{3}{|c|}{ Implementation } & \multicolumn{3}{|c|}{ Control } \\
\hline & $\mathrm{N}$ & M & SD & $\mathrm{N}$ & M & SD \\
\hline $\begin{array}{l}\text { 1. I usually read in English to understand the } \\
\text { meaning of the text }\end{array}$ & 30 & 4.10 & .49 & 31 & 3.61 & .60 \\
\hline $\begin{array}{l}\text { 2. I usually activated prior knowledge about } \\
\text { the reading topic before interacting with } \\
\text { the text. }\end{array}$ & 30 & 3.70 & .46 & 31 & 3.10 & .79 \\
\hline $\begin{array}{l}\text { 3. I usually exchanged ideas about what I read } \\
\text { with classmates after reading. }\end{array}$ & 30 & 4.30 & .53 & 31 & 3.05 & .83 \\
\hline $\begin{array}{l}\text { 4. I usually summarized the main idea of the } \\
\text { topic. }\end{array}$ & 30 & 4.10 & 54 & 31 & 3.18 & .72 \\
\hline $\begin{array}{l}\text { 5. I usually identified text organizations or } \\
\text { structures. }\end{array}$ & 30 & 3.80 & .55 & 31 & 3.00 & .57 \\
\hline $\begin{array}{l}\text { 6. I usually analyzed or evaluated the main } \\
\text { claim of the topic. }\end{array}$ & 30 & 3.97 & .49 & 31 & 2.80 & .57 \\
\hline $\begin{array}{l}\text { 7. I was usually encouraged to apply critical } \\
\text { reading strategies or skills. }\end{array}$ & 30 & 3.87 & .50 & 31 & 2.95 & .65 \\
\hline $\begin{array}{l}\text { 8. I usually answered reading comprehension } \\
\text { questions. }\end{array}$ & 30 & 4.30 & 53 & 31 & 3.66 & .77 \\
\hline $\begin{array}{l}\text { 9. I usually involved in developing my own } \\
\text { questions of investigation to develop my } \\
\text { critical reading skills. }\end{array}$ & 30 & 4.07 & .45 & 31 & 3.05 & .51 \\
\hline $\begin{array}{l}\text { 10. I usually monitor my reading } \\
\text { comprehension by evaluating my } \\
\text { achievement of the reading goal set. }\end{array}$ & 30 & 3.87 & .50 & 31 & 3.40 & .67 \\
\hline Total & 30 & 4.00 & .20 & 31 & 3.18 & .28 \\
\hline
\end{tabular}


It can be seen from the above table that the post-perception means between the classes differed significantly. In the implementation class, the mean scores $(M=4.00, S D=.20)$ was higher than the control class $(M=3.18, S D=.28)$. In addition, an independent sample $t$ test indicated a statistical significance between the post mean scores of the two classes, $t(18)=7.48, p=.00<.05$, and there was a very strong effect size $(d=3.37)$, suggesting that the implementation class tended to apply and experience each of the learning activities stated in the items more often than the control class. 


\subsubsection{Post-perceptions of learning outcomes}

Table 7. 18 Reading Learning Outcomes

\begin{tabular}{|c|c|c|c|c|c|c|}
\hline \multirow[t]{2}{*}{ Items } & \multicolumn{3}{|c|}{ Implementation } & \multicolumn{3}{|c|}{ Control } \\
\hline & $\mathrm{N}$ & M & SD & $\mathrm{N}$ & M & SD \\
\hline $\begin{array}{l}\text { 1. My English vocabulary knowledge } \\
\text { expands. }\end{array}$ & 30 & 4.57 & .50 & 31 & 3.58 & .67 \\
\hline $\begin{array}{l}\text { 2. I am able to identify claims presented in } \\
\text { the text. }\end{array}$ & 30 & 3.87 & .50 & 31 & 3.00 & .68 \\
\hline 3. My reading comprehension improves. & 30 & 4.20 & .40 & 31 & 3.39 & .66 \\
\hline $\begin{array}{l}\text { 4. I am able to construct meaning of the } \\
\text { text. }\end{array}$ & 30 & 3.83 & .37 & 31 & 3.03 & .60 \\
\hline $\begin{array}{l}\text { 5. I am able to communicate ideas } \\
\text { represented in the text. }\end{array}$ & 30 & 3.97 & .32 & 31 & 3.16 & .45 \\
\hline $\begin{array}{l}\text { 6. I am able to activate my prior knowledge } \\
\text { before interacting with the text. }\end{array}$ & 30 & 3.70 & .46 & 31 & 3.29 & .73 \\
\hline $\begin{array}{l}\text { 7. I am able to apply my reading strategies } \\
\text { or skills. }\end{array}$ & 30 & 3.80 & .61 & 31 & 3.06 & .57 \\
\hline $\begin{array}{l}\text { 8. I am able to automatically recognize } \\
\text { word meaning in the text. }\end{array}$ & 30 & 3.73 & .54 & 31 & 3.00 & .68 \\
\hline $\begin{array}{l}\text { 9. I am able to monitor my comprehension } \\
\text { while reading. }\end{array}$ & 30 & 3.67 & .47 & 31 & 3.23 & .56 \\
\hline $\begin{array}{l}\text { 10. I become an agent of my own reading } \\
\text { learning. }\end{array}$ & 30 & 4.07 & .36 & 31 & 3.48 & .57 \\
\hline $\begin{array}{l}\text { 11. I am able to identify text structures or } \\
\text { organizations. }\end{array}$ & 30 & 3.70 & .53 & 31 & 3.10 & .59 \\
\hline Total & 30 & 3.91 & .27 & 31 & 3.21 & .20 \\
\hline
\end{tabular}

As can be seen from Table 7.18, there was a difference in the mean scores between the implementation class $(M=3.91, S D=.27)$ and the control class $(M=3.21, S D=.20)$. The results of an independent sample $t$ test also found this pattern to be significant, $t(20)=$ 
$6.91, p=.00<.05$, and the effect size was strong $(d=2.94)$, suggesting that the implementation class students were more confident than the control class in terms of their ability to learn through reading after the 13-week CoT intervention. The section that follows will look at the qualitative data.

\subsubsection{Qualitative findings of the pre-post perceptions}

The qualitative data in this section were analyzed using a thematic method. There are two sets of data in this regard, the reading focus perceptions and additional comments given by the two classes. Each of these is presented in the following sections.

\subsubsection{Pre-service teachers' perceptions of reading learning focus}

Question four of the survey's section one asked students to complete a sentence about the main focus of learning English reading using their own ideas. This allowed them to provide further insights into the issue under investigation. The results showed that the two classes perceived the main focus of learning reading similarly prior to the implementation of a CoT. Specifically, a majority of them stated that the main focus of learning reading was about practicing pronunciation, learning a lot of new words, translating texts, reading texts correctly, reading for pleasure, linking words, constructing meaning, analyzing texts, and developing reading skills. It can be seen that the students viewed discrete language skills learning as the main focus of learning reading while metacognitive reading was perceived as the least important feature for learning English reading. This also reflects the results of phase 1 presented in chapter 5 . Thus, it can be concluded the students' perceptions of the reading learning focus between the classes were similar before the CoT implementation.

In contrast, the post-survey results revealed that this pattern differed considerably between the classes. In the implementation class, students perceived meaning of the text as the main focus of learning reading, followed by developing reading skills, promoting critical reading, using interactive reading activities, applying metacognitive reading strategies, skimming and scanning, learning new vocabulary, practicing pronunciation, translation, and the appreciation or desire to read more widely. This suggests the 
students' perceptions of reading in this class changed from lower-order skills learning toward meaning of the text and a higher-order reading skills-oriented focus. This reflects the results of focus group interviews presented in the previous section.

While there was a change in students' perceptions toward higher-order reading skills in the implementation class, this remained unchanged in the comparison class. In other words, they still maintained that practicing pronunciation, learning a lot of new vocabulary, translating, answering comprehension questions, and learning grammar were the main focus of learning reading. This also reflects the results of independent samples $t$ tests, paired samples $t$ tests, and focus group interviews presented earlier.

\subsubsection{Additional comments from the survey}

Students were also invited to provide additional comments toward reading learning in the open section provided before and after the 13-week instruction. Although the open section of the questionnaire did not require the participants to comment on the particular focus of the research, they provided useful data about their experiences of reading learning rather than something else. Results of the analysis showed, prior to the implementation, both classes indicated learning reading was a matter of reading correctly, learning a lot of new words, and translating texts as indicated above. After the implementation, students perceived reading learning differently. In the implementation class, most of the students (80\%) who provided comments pointed out that this reading course was very motivational, engaging, thought- provoking, and cooperative. They also stated that this course helped them improve their reading comprehension, foster summarizing skills, enhance participation, and develop reading speed and skills. This was also reinforced in the results of the observational data and focus group interviews presented earlier. In contrast, some of the students $(20 \%)$ who provided additional comments in the comparison class pointed out a need for improving reading instruction in this context. Specifically, they stated that the teacher should have focused on developing students' reading skills, meaning construction, promoting of extensive reading and integrating innovative and interactive learning activities. 


\subsection{Chapter summary}

This chapter presented the results of the students' perceptions of learning reading from focus group interviews and the pre-post perception survey. The results indicated that the implementation class students perceived reading learning positively as the CoT implementation fostered reading comprehension, raised metacognitive strategies awareness, encouraged social interactions and reading skills while these were not evident in the comparison class. In addition, the results indicated several important issues related to EFL reading instruction that need to be discussed and taken into consideration to help inform classroom teachers and educational practitioners concerned. Therefore, the chapter that follows will discuss the research before concluding the thesis. 


\section{CHAPTER 8: DISCUSSION}

\subsection{Introduction}

This chapter discusses important issues drawn from the main findings. I begin this chapter by addressing the main findings that were found in phase 1 , followed by phase 2 on the basis of the theoretical framework reviewed and discussed in chapter 3 and the contextual factors indicated in chapter 2. In addition, the findings are also discussed in relation to the empirical and related studies in the areas of EFL reading instruction, LTC, and a CoT.

Drawing from the results presented from chapters 5 to 7, a number of important issues are looked at in the following sections. Section 8.2 focuses on the results of phase 1 , comprising pre-service teachers' prior experiences of reading, the current state of reading instruction, and the extent to which a CoT was practiced in Lao EFL pre-service teacher education. As pointed out in the methodology chapter, the results of phase 1 were used as baseline data and empirical foundation for the implementation of phase 2 (a classroom-based intervention) because it appeared that the CoT practice was not in place in teaching reading in Lao EFL pre-service education. Section 8.3 discusses the results of phase 2, comprising the effects of the CoT implementation on students' reading comprehension development, learning engagement, and perceptions of learning English reading. Section 8.4 discusses Lao EFL pre-service teachers' prior cognition construction of learning reading. Section 8.5 discusses the participating lecturer's cognition and learning. Section 8.6 looks at a pre-service teacher cognition model in action. The final section, 8.7, summarizes the chapter.

\subsection{Phase 1 results discussion}

In this discussion, I shall relate the main and consistent pictures of the findings here to the Grammar Translation Method (GTM) (Larsen-Freeman \& Anderson, 2011), the concept of 'apprenticeship of observation' (Lortie, 1975), and important elements of the LTC models (Borg, 2006; Macalister, 2012; Woods, 1996) stated in the literature review. 
In addition, I shall also discuss the impacts of the contextual factors stated in chapter 2 on these main findings.

\subsubsection{Pre-service teachers' prior experiences of reading and learning to read}

To help direct this discussion, it is first important to identify the GTM principles (see Table 8.1) related to the main findings of pre-service teachers' prior experiences.

Table 8. 1 Principles of GTM (Larsen-Freeman \& Anderson, 2011, p. 18)

\section{Principles}

1. An ultimate goal of learning a language is to be able to read a text fluently. Students' attention to the target culture is not the main focus.

2. Being able to translate the target text into the other language is an important goal of this method.

3. Being able to communicate in the target language is not the main aim of this method.

4. The teacher is the absolute authority in the classroom while the students act as the only receivers of knowledge, as opposed to contributors of learning.

5. Language learning provides good mental exercises relating to discrete language skills.

6. Explicit instruction of grammatical rules, vocabulary, and pronunciation is useful pedagogical techniques.

Several main findings related to prior experiences of reading and learning to read can be discussed with the above principles. To achieve this, I looked at one participant's interview data as an example, Participant 2 (He), who said that the teacher asked students to read paragraph by paragraph aloud and translate them into Lao, the native language of the students. Extract 8.1 depicts this discussion. As a reminder, all interview extracts in this chapter are translated. 


\section{Extract 8.1}

01 I: I want to ask you about your prior experiences of reading and learning to read in English. How did you learn to read?

02 P2: As I remember ... uh the teacher did not focus on reading for the gist but uh the teacher focused on reading correctly and translation of the text.

03 I: Hmm. What else did the teacher do in teaching reading?

04 P2: The teacher uh read first and ... most of the time the teacher asked the students to read and answer the comprehension questions that follow and complete the space with words given.

05 I: Hmm.

06 P2: It was like uh filling the missing sentences. The teacher did not emphasize on where to pause, stop after a comma or full stop and how to stress when reading a question. The teacher did not focus on this.

07 I: Hmm. What did you do when you learn reading?

08 P2: When I learned reading, I .... uh used a dictionary because if I did not know the meaning of words, I did not feel satisfied. After I knew the meaning of the words, I uh then translated the text into Lao to ensure that I could do it.

From this conversation, a number of important issues can be identified. First, it can be inferred that there was a lack of meaning construction in teaching reading because the teacher paid full attention to language-focused learning (e.g., reading correctly, translation, filling the space or missing sentences with words given, answering comprehension questions). This reflects the existent roles of the GTM principles 2, 3 and 6 stated in Table 8.1 above in the sense that communication of ideas or meaning of the text was not the main focus of reading instruction. A lack of this focus could obstruct the development of proficiency and better readers. As stated in the literature chapter, proficiency is best fostered and achieved when reading instruction has a meaning focus.

He also continues to point out a lack of the teacher's attention to pauses and stops after punctuation marks and how to stress when reading a question (turn 06), which is important for beginning learners and oral fluency development. From his perception, it can be inferred that this area needs more attention in the process of language-focused learning in order to help students become fluent in oral reading. He continues to discuss his experience of learning to read and dealing with unknown words by using a dictionary (turn 08) instead of applying higher-order skills (e.g., predicting, guessing, skimming, and using context clues). What he reported here shows that language-focused learning 
received considerable attention in the course of reading instruction in this context, which fails to reflect Nation's (2009b) observation that "language-focused learning should be a small part of a course" (p. 2).

P2's prior experience of reading was also a part of the apprenticeship of observation (Lortie, 1975) that he experienced in the schooling system. In addition, this experience reflects one element of the LTC models stated in chapter 3 . What he reported here is likely to have shaped his cognition and therefore beliefs about what teaching is. In other words, what he saw, experienced, and did in the classroom and schooling system helped construct what Woods (1996, p. 196) calls BAK of teaching and learning a language. BAK will continue to play a major role in his future learning and behaviors, unless immediate action is taken to reshape his experiences of reading learning.

Although the results showed that the students perceived discrete language skills learning as the main feature for learning reading, the survey results in terms of the pre-service teachers' prior experiences of reading, learning materials, and instruction presented in Table 5.2 revealed that the students were sometimes encouraged to apply higher-order reading skills. However, the extent to which they were motivated to use these skills was minimal, meaning that more needed to be done to cultivate these skills in students. Table 8.2 below illustrates this part of the discussion. Considering a specific item, there was insufficient practice in summarizing skills $(M=2.98, S D=1.04)$. The results here also showed that the pre-service teachers lacked exposure to reading various text types, which is crucial for the development of reading skills and the expansion of content knowledge in different areas $(M=2.88, S D=.96)$. The findings also showed that there was a limited use of supplementary reading materials to engage students in interacting with different reading text types and content knowledge. This echoes the literature discussed in chapters 2 and 4 that there was a lack of reading materials (e.g. novels, graded readers) and resources to support students' independent and out-of-class reading. The only available reading material that was used in the TEP was the textbook (Essential Reading). The findings also revealed limited activation of students' prior 
knowledge of the topic $(M=3.11, S D=.87)$, which is important for the meaningconstruction process and comprehension development. Also, more attention needs to be given to the provision of a clear explanation for students regarding the reading skills or strategies (item 5) to be applied when approaching the text $(M=3.16, S D=1.01$ ). Although the survey results here revealed some extent to which these skills were encouraged, there was a lack of practice in the actual classroom instruction as the observational data results in chapter 5 revealed.

Table 8. 2 The Extent to which Higher-order Reading Skills were Fostered

\begin{tabular}{clll}
\hline Item & Description & M & SD \\
\hline 1 & The teacher asked students to summarize what they read. & 2.98 & 1.04 \\
2 & $\begin{array}{l}\text { I read various types of texts to develop my reading skills or } \\
\text { capability. }\end{array}$ & 2.88 & 0.96 \\
3 & $\begin{array}{l}\text { The teacher used supplementary reading materials to } \\
\text { expose students to different text types. }\end{array}$ & 3.03 & 0.88 \\
4 & $\begin{array}{l}\text { The teacher activated students' prior knowledge of the } \\
\text { topic before reading. }\end{array}$ & 3.11 & 0.87 \\
5 & $\begin{array}{l}\text { The teacher provided a clear explanation about the skills or } \\
\text { strategies to be used in reading. }\end{array}$ & 3.16 & 1.01 \\
\hline
\end{tabular}

The discussion above suggests that Lao EFL pre-service teachers extensively experienced language-focused learning in their schooling. This prior experience reflects the current state of reading instruction, which will be addressed in the following section.

\subsubsection{Current practices of teaching reading in Lao EFL pre-service TEPs}

The previous section discussed pre-service teachers' prior experiences of reading and learning to read in English, which is related to this section. To establish a base for the indepth discussion in this section, I will briefly revisit the results of the classroom observation data, lecturers' semi-structured interviews, and document analysis. The main findings showed that the current state of reading instruction in the Lao EFL preservice TEP was not different from what students experienced as discussed earlier (RQ1). Specifically, the reading lecturers focused on several language features. First, 
reading out loud and translating the text was one of the dominant practices as indicated previously. Extract 8.2 depicts this point.

\section{Extract 8.2}

01 T: Any volunteer to read the text? Ok. One paragraph per one person

02 S1: [Stands up and reads the first paragraph out loud].

03 T: Next paragraph? Any volunteer? [LAUGH]

04 S2: [Stands up and reads the second paragraph aloud. The same pattern is continued for the subsequent paragraphs]

05 T: Final paragraph, paragraph 7?

06 S7: [Stands up and reads the final paragraph out aloud]

07 T: Good job! Tell me your names. I will give you scores for your contributions. How many people?

08 Ss: Yeah. [Tell their names]

09 T: Now translate the paragraphs. Ok. Who can start first?

10 S1: [Stands up and translates the first paragraph into Lao. The same pattern is continued for subsequent paragraphs].

11 T: Good translation! How about the final paragraph, 7?

12 S7: [Stands up and translates the final paragraph into Lao].

13 T: Good job! Tell me your name. I will give you scores for your translation.

14 Ss: [Say their names].

The teacher's and students' interaction in the extract above reveals how reading out loud and translating text receives considerable attention in teaching reading in the Lao EFL pre-service TEP. Translation in L2 reading learning is perceived differently by linguists, teachers, and methodologists (Dagilienė, 2012). In terms of its merits, Schaffner (1998, p. 125) argues that translation could:

- improve verbal agility;

- expand vocabulary in L2;

- develop students' understanding of how languages work;

- consolidate L2 structure for active use; and

- is appropriate for translation course training.

These features, however, direct students to discrete language skills rather than meaning construction and critical reading skills development crucial for the promotion of lifelong and critical readers. This also reflects the literature stated in section 3.2.3 that teaching is a knowledge transmission process as opposed to knowledge construction. Reading, as defined in section 3.3.1, is an interactive process of meaning construction, which 
requires not only linguistic knowledge but also cognitive and metacognitive skills (Grabe, 2009). Thus, in order to help students become better readers, changes in instructional pedagogy may be required.

In terms of its drawbacks, scholars (Malmkjaer, 1998; Schaffner, 1998) state that translation:

- neither defines language competence or promotes target language use;

- is time-consuming in the case of reading;

- misleads and prevents students from thinking in the target language; and

- produces interference.

The findings of my study reflect many of these negative features. First, translation fails to encourage communication of meaning in the target language. As the findings showed, after translation, students were not motivated to think about, and summarize the main point of the text. As a consequence, most of them were not sure about the meaning of the text with which they interacted. It has been stated that "translation is not a communicative activity as it does not involve oral interaction. Then the use of the mother tongue is required, which is not desirable. Moreover, it is boring, both to do and to correct" (Duff, 1994, as cited in Digilienè, 2012, p. 125). Second, translation wastes a lot of class time that is supposed to be given to conducting communicative and interactive activities. By translating the whole text, students are at risk of getting bored and lacking confidence in their translation accuracy as some expressions cannot be directly translated into L1 (Kern, 2008). Additionally, translation may prevent students from thinking about the ideas represented in the text in the target language, which is important for developing critical reading skills. As the findings revealed, students' critical reading skills were not promoted as they were required to focus on learning a lot of new words (Extract 8.3 below) or practicing pronunciation (Extract 8.2 above) and translation instead of meaning construction and comprehension development. Finally, translation may produce interference in the sense that it could transfer negative habits of the mother tongue to the target language. From a linguistic perspective, interference is an interaction or a change in linguistic structures and structural elements (Hatzidaki, 
Santesteban, \& Duyck, 2018). In other words, translation may lead to a change in meaning of expressions and grammatical structures.

Another common pattern of reading instruction in the Lao EFL pre-service TEP to be discussed here is a vocabulary focus. As stated in section 5.3.3.3, this practice received greater attention in teaching and learning English reading where the traditional teaching method still plays an important role (Zhang \& Anual, 2008). However, vocabulary knowledge can be fostered through different ways: contextualization (Jenkins, Stein, \& Wysocki, 1984) rather than direct translation as some words can have different meanings in different contexts. As stated in chapter 5, one possible reason for emphasizing learning new words might have been due to the inclusion of testing vocabulary knowledge in the midterm and semester examinations. Extract 8.3 below, taken from a reading test document I analyzed, illustrates this aspect.

\section{Extract 8.3}

1. Gap filling. (10pts)

\# Fill in each blank with the words given.

\begin{tabular}{|lllll|}
\hline $\begin{array}{l}\text { Adapt } \\
\text { Embrace }\end{array}$ & $\begin{array}{l}\text { Sneaked } \\
\text { Size }\end{array}$ & $\begin{array}{l}\text { Obscene } \\
\text { Servant }\end{array}$ & $\begin{array}{l}\text { Connect } \\
\text { Stadium }\end{array}$ & $\begin{array}{l}\text { Blame } \\
\text { That }\end{array}$ \\
\hline
\end{tabular}

1. People who doesn't meet each other for longtime they often one another.

2. He always think about sex, he is a real person.

3. Mr. Donovan used to be. of Queen Elizabeth in her palace.

4. My girl doesn't like lazy person like me so I to be new one.

5. After test my friend. me because I didn't tell him the answers

6. I keep calling you many time but it not

7. The needles range in. from one-half inch long to six inches.

8. When Manuel into his parents' bedroom.

An international organization. promotes world peace.

10. The Bonjovi band need large space for their concert so they set up at

Source: $1^{\text {st }}$ Semester Examination 2011-2012 (Year 2) 
The example shows that vocabulary testing in reading assessment in this context is still commonly practiced. As a consequence, the inclusion of this has a direct impact on reading instruction in the sense that close attention needs to be paid to vocabulary teaching and learning so that students can cope with the test. In other words, one aspect of reading instruction in this context focused on learning new words, which is required by the testing of reading components that have long been practiced. The inclusion of this, however, may not help enhance text comprehension as vocabulary knowledge is tested on a sentence-based level, as opposed to a contextualized form. The inclusion of this reinforces the practice that they had experienced in the earlier apprenticeship of observation and therefore it is likely to be shaping their cognition and practices of teaching and testing reading in the Lao pre-service teacher education system (Lortie, 1975). The findings of the document analysis revealed that each of the 10 reading test documents included the testing of vocabulary knowledge as a part the reading test components. In addition to testing vocabulary knowledge on the sentence-based level, having students translate vocabulary into L1 is another form of practice in testing vocabulary knowledge of pre-service teachers. This practice will continue to play a major role in teaching and assessing reading comprehension in this context, unless immediate change in instructional pedagogy is taken seriously.

What is also worth commenting on in Extract 8.3 is that students are faced with a lot of grammatically inaccurate language when being tested for vocabulary as most of the items are inaccurate. The lack of the grammatical accuracy indicates low English proficiency in some of the teachers in this context. This can be seen as one of the constraints in the development of language teacher education and English proficiency in LPDR.

The example above was not the only feature that has become standard practice in the Lao EFL pre-service teacher education context. Extract 8.4 below illustrates another feature of the current state of reading instruction, answering comprehension questions and going over the answers. As pointed out in section 5.3.3.4, this practice was evident in 
most of the reading classes observed. Although answering comprehension questions and going over the answers are one of the dominant features of reading instruction, this practice may result in passive learning, which is insufficient for the promotion of analytical and meaningful reading. In addition, most of the comprehension questions in the textbook (McAvoy, 2008) focus on discrete language features (e.g., vocabulary and grammar) rather than meaning identification and construction. This can be noted from Question 2 (08) of Extract 8.4 below. To answer this question, students do not need to think critically about the answer. Instead, they look only for the expression that has a synonymous meaning to the phrase 'forces someone to do something' without being encouraged to extend their thinking about the answer. As Day and Park (2005) state, comprehension questions play an important role in teaching reading if designed and used appropriately and meaningfully. To achieve this, Murtiningsih and Hapsari (2018, p. 163) suggest "teachers need to think beyond the textbooks or reading text sources they are provided with and be willing to modify the materials creatively into more engaging activities". Thus, it is important for the teacher to take this reminder into consideration when designing reading lessons in order to foster 'students' levels of cognitive development, language proficiency, and interest" (Murtiningsih \& Hapsari, 2018, p. 163).

\section{Extract 8.4}

01 T: Now, I would like you to answer the questions.

02 Ss: [Answer the questions individually for 11 minutes]

03 T: Have you finished? Let's check the answers to the questions.

04 Ss: Yeah.

05 T: Number 1. [T reads: How do you know that Hilary's family doesn't live on a single level?]

06 S1: Because she is sitting upstairs.

07 S2: Yes. I agree. This means that there is more than one level.

08 T: Yes. I think so. How about number 2? [T reads: Which verb means forces someone to do something]

09 S3: Uh make someone do something.

10 T: Do you agree?

11 Ss: Yeah. [The same pattern is continued for the subsequent numbers].

Another practice, which was evident in the current state of reading instruction, is a pronunciation focus. As indicated in the reading literature, being able to recognize a 
phonological feature is beneficial for fluency development and comprehension (Holsgrove \& Garton, 2006). In this respect, Engen and Hoien (2002, p. 613) explain:

One possible way to explain this observation is that at least two critical factors in comprehension, vocabulary and short-term memory, are both determined in part by phonological ability. It might also be the case that phonological awareness partly reflects metacognitive processes assumed to be involved in reading comprehension

However, from the data available, there appears to be nothing to suggest that attention to pronunciation was linked to understanding of the text or arose from communication breakdown by requiring attention to a problematic pronunciation feature. However, comprehension is fostered when students read metacognitively (e.g., summarizing, monitoring, and evaluating). In addition, there are other components that facilitate reading comprehension: content and background knowledge, metacognitive and monitoring skills, and reading strategies (Grabe, 2009; Hudson, 2007). The practice of pronunciation in this sense might be helpful in terms of fostering students' confidence when reading out loud.

The results also suggested adherence to the bottom-up reading model discussed in section 3.3.3 where the primary focus is mainly on identifying word meaning, letters, and practicing pronunciation (Grabe, 2009). Although the practice of this is beneficial for beginning learners, it is still insufficient for the development of better readers. What is also interesting to comment on here is that pronunciation knowledge is not tested in the reading assessment. In other words, the focus of this has been traditionally practiced from generation to generation without considering its contribution to and effect on comprehension development. Extract 8.5 below depicts this discussion.

\section{Extract 8.5}

01 I: Ok. I would like you to share your experience of teaching reading. How do you teach reading?

02 P2: I mainly focus on pronunciation of words first before asking students to read and translate the text because this is the main focus of teaching reading.

03 I: Hmm. What do you mean by that? 
04 P2: Uh. I mean uh I first ask students to find out difficult words from the text. After that I write the words on the board to allow all students to see. Then uh I ask them to repeat the words after me together to ensure that they can pronounce all the difficult words correctly. Finally, uh I ask them to find out word meaning in dictionaries before moving to translation with them again.

$05 \quad$ I: $\quad$ Why do you uh focus on pronunciation of words?

06 P2: I think learning reading is a matter of uh pronouncing words or sentences in the text correctly. If students cannot do this, they cannot read and understand the text confidently.

07 I: I see.

In terms of the extent to which the CoT was practiced (RQ2b), the findings revealed an absence of the CoT application in teaching reading. As stated in section 2.6.2, a number of issues influencing the application of the innovative teaching approach can be counted and discussed here. First and foremost, contextual factors play an important role in determining the use of the interactive teaching approach in this context. As stated in section 2.4.2, the LES is top-down where curriculum and course syllabuses are designed and mandated by the macro and meso-levels (MoES, 2009). This centralization puts a lot of pressure and tension on classroom teachers (micro level) as the curriculum may not meet the teachers' and students' needs in actual classroom practices. As a consequence, teaching is delivered in response to the requirements of prescribed curriculum, which affects the integration of innovative teaching approaches and limits teachers' lesson preparation times. Second, the absence of this might have been due to classroom teachers having multiple tasks to deal with (e.g., meetings and administrative tasks) that prevented them from applying innovative teaching methods as pointed out in chapter 5 .

Third, the constant change in curriculum implementation and its content may also result in the absence of the CoT practice in teaching reading. As stated in 2.6, four curriculums were implemented from 1996 to 2015 that put a huge burden on lecturers as implementers in the actual classroom instructional practices. Through observation and interviews, some lecturers refused to teach newly integrated courses as they lacked confidence in and experience of teaching these courses. In addition, there was a lack of pedagogical directions for classroom lecturers, following the constant change. Because of 
this, they had to apply the same teaching method even though the course syllabuses required them to integrate interactive teaching approaches into their lessons. Additionally, the current curriculum (0+4 Programme), includes a large volume of Lao language subjects (e.g., Mathematics, Life Long Learning, Psychology), which limits the amount of English teaching and learning hours. The findings also showed that preservice teachers perceived this limitation as one of the major constraints for learning English reading in this context as they had limited exposure to an English -learning environment in classroom practices.

Fourth, a teacher's low proficiency and lack of competence in the target language also play a part in determining the application of CoT and innovative approaches. As pointed out in section 2.6.5, Lao EFL lecturers were not fully confident in their ability to communicate in the target language as many of them lacked exposure to an Englishspeaking environment (e.g., New Zealand or the UK) or opportunities to undertake a master's degree from English-speaking countries. As a result, many of them avoided using communicative and interactive activities in their classroom and switched to the teacher-centered approach instead. The absence of CoT practice in this context suggests that more needs to be done to upgrade the teaching of English in the Lao EFL pre-service TEP, including English language competency.

Fifth, a lack of reading resources, internet access, and students' low proficiency in the target language also impede the application of the CoT and innovative teaching approaches. As indicated in sections 2.6.3 and 4.4.6, the only teaching material that was used was the textbook, which fails to reflect the local context of the students and lecturers. To develop critical reading in students, a wide range of texts and reading sources should be available to them to help broaden their knowledge and develop their reading skills. In addition, a textbook might not contain authentic language and may fail to reflect real-life situations. The lack of this also reflects the results of the survey in terms of students having limited exposure to reading various types of text (e.g., novels, reports, advertisements) to develop their reading skills and capacity $(M=2.88, S D=.96)$. 
Furthermore, internet access to help the teachers in the classrooms was not available. This hindered the integration of online reading sources and texts into classroom practices. Finally, pre-service teachers' low English proficiency also affected the application of the CoT practice since innovative and communicative activities require students to interact, communicate, and exchange ideas in the target language. Extract 8.6 demonstrates this part of the discussion.

\section{Extract 8.6}

01 I: Do you have any difficulties or challenges in teaching reading?

02 P5: A lack of reading sources, limited access to reading texts, a lack of internet use, and difficult vocabulary. These pose a big challenge for teaching reading.

03 I: Hmm. Anything else?

04 P5 Students' different English backgrounds, incorrect pronunciation, and low English proficiency. Teaching multilevel students requires great care and attention. It is very hard to conduct uh interactive learning activities for students.

In conclusion, the discussion above has identified several important issues that affect the current state of reading instruction in the Lao EFL context and beyond where the traditional teaching method still plays a dominant role. This situation will continue to exist in this context unless appropriate immediate action can be applied within classroom practices. The following section discusses the effects of the CoT implementation on reading comprehension development, learning engagement, and perceptions of learning reading.

\subsection{Phase 2 results discussion}

\subsubsection{Reading comprehension development}

As stated earlier, the main purpose of this phase was to determine the extent to which the CoT implementation improved Lao EFL pre-service teachers' reading comprehension. It was found that the implementation class experienced a significant increase in reading comprehension compared to the control class. This improvement is encouraging to reading instructors who are considering implementing the CoT for their students and classroom practices. The data illustrated that the results were reliable due to the following reasons and measures. First, the mean scores were compared between 
the groups as indicated in Table 6.5. In the implementation class, there was a significant increase $($ Mean difference $=7.13)$ in the post-test mean score $(M=20.30, S D=4.15)$ compared to the pre-test mean score $(M=13.17, S D=4.42)$. In the comparison class, on the other hand, there was a slight increase (Mean difference $=1.62$ ) in the post-test mean score $(M=15.65, S D=5.11)$ compared the pre-test mean score $(M=14.03, S D=4.23)$. Table 8.3 below illustrates a key difference in the mean scores and standard deviations between the classes.

Table 8. 3 Means and Standard Deviations between the Classes

\begin{tabular}{llccccc}
\hline Group & $\mathrm{N}$ & \multicolumn{2}{c}{ Pre-Test } & \multicolumn{2}{c}{ Post-Test } & \multirow{2}{*}{ Difference } \\
\cline { 3 - 6 } & & $\mathrm{M}$ & $\mathrm{SD}$ & $\mathrm{M}$ & $\mathrm{SD}$ & \\
\hline Implementation & 30 & 13.17 & 4.42 & 20.30 & 4.15 & 7.13 \\
Comparison & 31 & 14.03 & 4.23 & 15.65 & 5.11 & 1.62 \\
\hline
\end{tabular}

In addition, the result of the independent sample $t$ test on the post-test between the classes indicated a significant difference, $t(59)=3.894, p=.00<.05$ and had a strong effect size $(d=1.01)$. Second, most of the pre-service teachers in the implementation class scored higher in the immediate post-test, suggesting that the improvement was caused by the 13-week CoT implementation rather some erratic behavior or on/off factor (see Table 8.4). Also, it can be noted from the table that, the lower and medium proficiency students appeared to benefit the most from the implementation. This is consistent with Wang (2009) who found that lower or medium proficiency learners were likely to benefit the most from an intervention (e.g., metacognitive reading strategies training). 
Table 8. 4 Reading Test Scores by the Implementation Class

\begin{tabular}{|c|c|c|c|}
\hline Student ID & Pre-Test & Post-Test & Delayed-Test \\
\hline 1 & 13 & 22 & 24 \\
\hline 2 & 9 & 12 & 9 \\
\hline 3 & 17 & 16 & 20 \\
\hline 4 & 14 & 16 & 14 \\
\hline 5 & 10 & 16 & 15 \\
\hline 6 & 7 & 22 & 24 \\
\hline 7 & 8 & 18 & 22 \\
\hline 8 & 23 & 27 & 26 \\
\hline 9 & 19 & 23 & 24 \\
\hline 10 & 10 & 22 & 23 \\
\hline 11 & 13 & 27 & 26 \\
\hline 12 & 16 & 25 & 24 \\
\hline 13 & 11 & 19 & 21 \\
\hline 14 & 12 & 25 & 20 \\
\hline 15 & 9 & 16 & 19 \\
\hline 16 & 11 & 15 & 13 \\
\hline 17 & 18 & 21 & 21 \\
\hline 18 & 15 & 21 & 22 \\
\hline 19 & 14 & 20 & 19 \\
\hline 20 & 12 & 22 & 22 \\
\hline 21 & 15 & 23 & 24 \\
\hline 22 & 20 & 24 & 23 \\
\hline 23 & 10 & 23 & 23 \\
\hline 24 & 15 & 21 & 19 \\
\hline 25 & 19 & 23 & 24 \\
\hline 26 & 21 & 26 & 25 \\
\hline 27 & 9 & 15 & 17 \\
\hline 28 & 10 & 16 & 17 \\
\hline 29 & 9 & 13 & 15 \\
\hline 30 & 6 & 20 & 22 \\
\hline Total & 395 & 609 & 617 \\
\hline Mean & 13.17 & 20.30 & 20.57 \\
\hline SD & 4.42 & 4.15 & 4.17 \\
\hline
\end{tabular}

The increase in pre-service teachers' reading comprehension performance was also confirmed by the results of the delayed-test $(M=20.57, S D=4.17)$. The results of an 
independent sample $t$ test found this to be statistically significant, $t(59)=4.687, p=.00<$ .05 and the effect size was strong $(d=1.19)$, suggesting that the implementation of the CoT improved pre-service teachers' reading comprehension. In addition, this claim was supported by the results of the focus group interviews presented in section 7.2.4.

The extracts of the implementation class presented in chapters 6 and 7 illustrated several important aspects of reading comprehension development from which students benefited following CoT implementation. First, the participants acknowledged that their reading comprehension improved. This improvement was mainly the direct effect of integrating the CoT thinking routines in teaching reading. Second, they expressed increased confidence when interacting with the text as they knew how to address unknown words and construct meaning from the context. Third, they pointed out that this course helped foster their thinking about the topic, summarizing skills, and reading fluency. Many of them stated that their reading rate improved after this course although this aspect was not measured in this investigation. Fourth, they said that their interest in learning reading increased as reading was no longer passive and boring as it had been in the past. The effects of the CoT implementation here also reflect the third principle of the CoT pointed out in section 3.4.4 - that it fostered deep and meaningful learning resulting in the acquisition of the target language and text comprehension. In addition, the results were consistent with previous studies discussed in sections 3.4.6 and 3.4.7 that a CoTbased instruction fostered language development, meaningful learning, and metacognitive and cognitive learning skills (Hooper, 2016; Linck, 2012; Ritchhart et al., 2009; Salmon, 2008b).

The results of the statistical analysis were compared with the control class to ensure a reliable outcome. It was shown that the implementation group outperformed the comparison group in terms of reading comprehension, as the independent sample $t$ test and effect size revealed in section 6.2. This indicates that the CoT-based instruction had a positive impact on the learning outcomes. Table 8.5 below displays the scores of the 
comparison class. It can be seen that the pre-service teachers performed slightly better in the immediate post-test compared to the pre-test results.

Table 8. 5 Reading Test Scores by the Control Class

\begin{tabular}{|c|c|c|c|}
\hline Student ID & Pre-test & Post-test & Delayed-test \\
\hline 1 & 11 & 12 & 10 \\
\hline 2 & 13 & 13 & 11 \\
\hline 3 & 17 & 21 & 23 \\
\hline 4 & 12 & 14 & 12 \\
\hline 5 & 12 & 12 & 11 \\
\hline 6 & 9 & 6 & 5 \\
\hline 7 & 10 & 14 & 17 \\
\hline 8 & 14 & 9 & 7 \\
\hline 9 & 13 & 14 & 12 \\
\hline 10 & 9 & 11 & 9 \\
\hline 11 & 8 & 10 & 10 \\
\hline 12 & 11 & 18 & 14 \\
\hline 13 & 11 & 17 & 15 \\
\hline 14 & 10 & 12 & 7 \\
\hline 15 & 12 & 15 & 10 \\
\hline 16 & 15 & 18 & 18 \\
\hline 17 & 11 & 15 & 14 \\
\hline 18 & 10 & 11 & 16 \\
\hline 19 & 17 & 10 & 11 \\
\hline 20 & 11 & 8 & 9 \\
\hline 21 & 26 & 27 & 28 \\
\hline 22 & 22 & 25 & 24 \\
\hline 23 & 15 & 18 & 17 \\
\hline 24 & 20 & 22 & 20 \\
\hline 25 & 18 & 21 & 19 \\
\hline 26 & 13 & 16 & 15 \\
\hline 27 & 18 & 20 & 18 \\
\hline 28 & 17 & 21 & 19 \\
\hline 29 & 15 & 18 & 17 \\
\hline 30 & 20 & 22 & 20 \\
\hline 31 & 15 & 15 & 19 \\
\hline Total & 435 & 485 & 457 \\
\hline Mean & 14.03 & 15.65 & 14.74 \\
\hline SD & 4.23 & 5.11 & 5.42 \\
\hline
\end{tabular}


The results in the table were consistent with the results of the focus group interviews of the comparison class pre-service teachers presented in chapter 7. Specifically, when asked whether the reading course improved their reading comprehension, the students pointed out that their pronunciation ability and translation confidence improved instead of their increased understanding of the text. It can be noted that they tended to talk about the discrete linguistic skills focused on in the classroom rather than comprehension and critical reading development improvement. When they expressed their confidence in reading, they meant that they were able to read correctly according to the phonological rule and stress. Being able to read correctly, however, does not guarantee that they comprehend the text since reading is a process of cognitively constructing meaning using both linguistic knowledge and metacognitive reading strategies (Grabe, 2009). The following section discusses learning engagement in order to contribute to our understanding of the issue under examination.

\subsubsection{Learning engagement}

In this discussion, I shall relate the consistent findings to the three main theories: student engagement (Philp \& Duchesne, 2016), cultural forces (Ritchhart, 2015), and Bloom's taxonomy (Bloom et al., 1956) that I used to analyze reading learning participation. Each of these will be discussed in the following subjections.

\subsubsection{Student engagement}

In chapter 6, I introduced four important dimensions of student engagement: cognitive, behavioral, affective or emotional, and social (Fredricks, 2004; Fredricks \& McColskey, 2012; Storch, 2002). The results of the observational analysis presented in chapter 6 indicated that student participation reflected these dimensions, which I will look at further here.

With regard to cognitive engagement, the findings revealed that when pre-service teachers worked in groups to engage in class activities (e.g., Claim-Support-Question, See-Think-Wonder), they were encouraged to think, share ideas, and put in effort to 
achieve the learning outcomes. The quality of engagement can also be seen in several extracts presented in chapter 6 . When they were required to think about the ideas represented in the text, they cognitively engaged in learning beneficial for motivation and comprehension (Corno \& Mandinach, 1983). In addition, indicators of cognitive engagement can be seen from ranges of "collaborative activities, including questioning, completing peer utterances, exchanging ideas, making evaluative comments, giving directions, explanations, or information, justifying an argument, and making gestures and facial expressions" (Philp \& Duchesne, 2016, p. 4). Also, other indicators of cognitive engagement include private speech and exploratory talk (Barnes, 2008) when sharing ideas in pairs or groups. This reflects what Early and Marshall (2008) state: learning engagement requires both behavior and cognition, which are important for digging deeper and understanding. Cognitive engagement was also found through language of thinking pointed out in chapter 6 (e.g., I think, I wonder), giving reasons (e.g., because) when participating in class activities.

In terms of behavioral engagement, the results indicated that students were allocated sufficient "time on task or participation" (Philp \& Duchesne, 2016, p. 7). When students were given time to activate their prior knowledge through Chalk Talk, construct meaning through Claim-Support-Question, and extend ideas through Connect-Extend-Challenge, they invested effort and time in what Gettinger and Walter (2012, p. 653) call "academic engaged time", i.e., the amount of time students are actively involved and predict academic achievement that directly relates to learning outcomes (Fredricks, 2004). The results also revealed that students' participation in learning reading reflects what Anderson (1974, p. 53) refers to as "time-on-task". The degree of behavioral engagement depends on the quality of participation, effort, persistence, and active involvement in learning activities. The results of my research revealed that students meaningfully engaged in learning activities crucial for increased comprehension of the text.

Another aspect of student engagement to be discussed is affective or emotional engagement. As pointed out in section 6.3.1, emotional engagement is viewed as 
"enthusiasm, interest, and enjoyment" (Philp \& Duchesne, 2016, p. 8) in participating in class activities. At the other end of the scale, emotional engagement includes "anxiety, frustration, and boredom as indicators of negative emotional engagement" (p. 8). The findings here revealed that students positively engaged in learning activities as they were eager to share ideas while doing group work, enjoying the social interaction and benefits of discussing common issues and interests. In addition, because of the nature of the CoT-based instruction, the learning environment was friendly, safe, and conducive to collaborative learning, fostering positive emotional engagement.

Finally, social engagement was also evident in the context of the CoT-based reading learning (Svalberg, 2009). As a reminder, social engagement includes "collaborative practices in a community and the social goals of helping other students or cooperating with a teacher" (Guthrie et al., 2012, p. 603). The results of my study stated in chapter 6 showed that pre-service teachers in the implementation group were provided with considerable opportunities to work in groups on learning activities. This allowed them to socially engage in exploring, experiencing, sharing ideas, and presenting their thoughts in a mutual and collaborative manner. Such mutuality and reciprocity are evident and reflect students' collaboration and engagement with their peers. This in turn, as stated by Guthrie et al. (2012, p. 603), fosters "students' reading achievement, knowledge gained from reading, and the kinds of practices in which they engage". Learning is a social endeavor; i.e., students learn things from people around them as the primary source of knowledge development and it enables them to see different points of view and acquire socially constructed knowledge (Johnson \& Johnson, 2009). The findings also revealed that students gained a sense of confidence and socially communicative skills when working in groups to achieve a specific learning goal (e.g., activating prior knowledge of the topic, meaning construction). Following the discussion, I created a conceptual framework for the reading learning engagement process in action as a result of the CoTbased instruction as follows: 


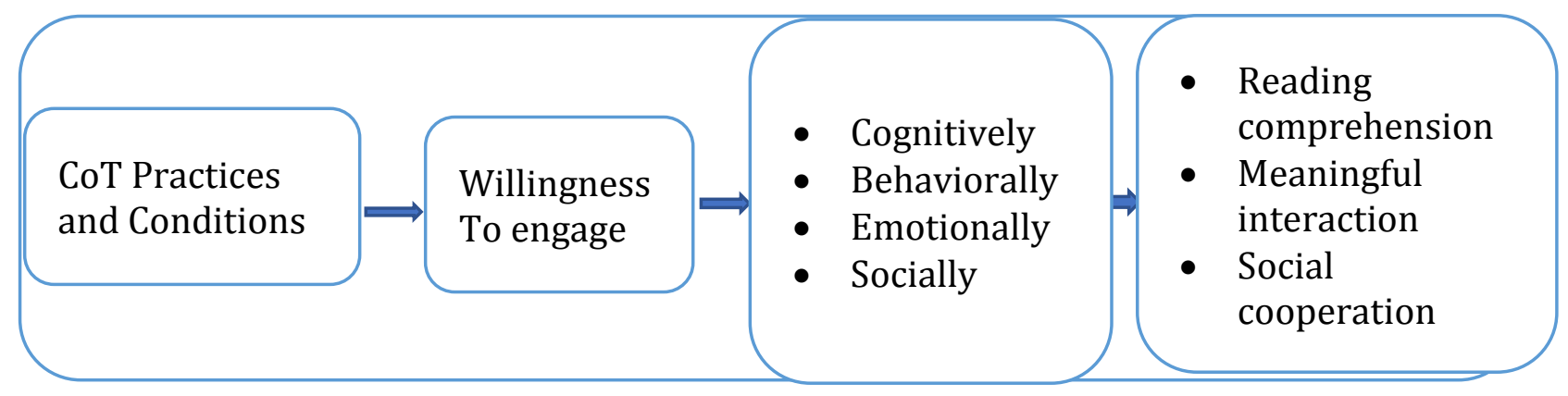

Figure 8. 1 A Model of Reading Learning Engagement Process in Action

As the model illustrates, the CoT implementation plays a foundational role in engaging students cognitively, behaviourally, emotionally, and socially in learning (Philp \& Duchesne, 2016). These forms of student engagement, in turn, foster reading comprehension, meaningful interaction $t$, and social cooperation. Learning is a process that involves both social and individual endeavours and this model adds value to not only solo learning but also social aspects of learning a language (Salomon \& Perkins, 1998).

\subsubsection{Student engagement from cultural forces perspectives}

In section 6.3.5, I analyzed and presented student engagement in terms of the cultural forces to investigate the extent to which these forces were fostered, and observe what students experienced and how they reacted to learning reading as intended by the lesson plans. The results revealed that what students experienced reflect important qualities of the forces, which are worth discussing further to help inform classroom instructional practices. As a reminder, cultural forces are defined by Ritchhart $(2015$, p. 6) as "the shapers of classroom cultures"; taken primarily to help transform a passive learning culture to a more interactive and meaningful learning environment. The forces include: expectations, language, time allocation, modeling, opportunities, thinking routines, interactions, and learning environment. To avoid repetition, the discussion here will focus on key findings that reflect the important features of these theoretical frameworks and empirical studies relating to this.

Drawing from the results presented in chapter 6, a number of important qualities of student engagement (classroom culture and transformation, exploration and relevancy, 
and cooperative and meaningful interaction) can be discussed. These features also reflect what Taylor and Parsons (2011) have synthesized from their extensive review of existing literature in the area of student engagement (Taylor \& Parsons, 2011). These features will be looked at in turn.

First and foremost, a classroom culture or pattern and transformation play an influential role in fostering meaningful learning and shaping students' cognition/perceptions of learning. A classroom culture refers to a pattern or common practice of learning and teaching with the aim of accomplishing learning outcomes (Ritchhart, 2015). As stated in the results of phase 1, the common pattern of reading instruction in the Lao EFL preservice teacher context was traditional and teacher-centered, focusing on learning discrete language skills. This practice, as a consequence, increases what Crick (2012, pp. 675-676) calls "disengagement which manifests as either passive compliance or active rejection of the status quo". Such passive engagement fails to prepare learners to cope with complex situations. Deep engagement, in contrast, requires personal dedication and commitment and the teacher needs to deliver the lesson in a meaningful and purposeful fashion for students (Ritchhart, 2011b). The findings revealed that the classroom culture was transformed from being passive and teacher-dependent to a more active and cooperative one, crucial for reading comprehension development to occur. The outcome here was the result of integrating thinking routines, encompassing important features of the eight cultural forces stated above (Ritchhart, 2015) into classroom practices. Important elements of these (e.g., setting goals, managing appropriate time for exploration, asking critical questions, and using interactive learning activities to name a few) are helpful in promoting meaningful learning and shaping pre-service teachers' perceptions of reading. As stated in LTC theory, what learners see, experience, and do in classrooms plays a significant role in shaping their conceptions of learning (Borg, 2006) as well as "pre-service teachers' professional development" (Altun, 2013, p. 37). Therefore, to cultivate lifelong and critical readers or learners, it is important for reading teachers to transform a passive classroom culture to become more interactive and engaging one. 
Another interesting issue to be discussed here is that the results also revealed that the implementation of a CoT allowed in-depth exploration engagement to occur relevant to authentic situations (relevancy). The results indicated that pre-service teachers were actively encouraged to explore, problem-solve, evaluate, summarize, and synthesize when working in groups or individually on learning activities (e.g., See-Think-Wonder) that reflect the real-world situation; the notion of relevancy (Altun, 2013; Ritchhart, 2015; Ritchhart et al., 2011). In addition, this reflects the definition of the CoT in that "it is promoted as part of the regular, day-to-day experience of all group members" (Ritchhart et al., 2011, p. 219). What they experienced in learning reading reflects their daily experiences as they socially interact with all sources of information, including reading and this experience helps foster their social and interpersonal skills. As Crick (2012, p. 687) posits, "the most powerful engagement for learning occurs where learning is authentic, active and enquiry led." The first condition for exploration is when the students are actively involved in activating prior knowledge and vocabulary knowledge related to the topic to be read. The second is when students participated in meaning construction through a Claim-Support-Question thinking routine, striving for in-depth understanding and expressing ideas through elaborated communication (Crick, 2012).

A final important point to look at is that the results also demonstrated the development of cooperative and meaningful interaction. Cooperative learning is defined as working together to accomplish the shared goals and learning outcomes (Johnson \& Johnson, 1989). Existing literature suggests five important elements of cooperative learning: positive interdependence, individual accountability, face-to-face promotive interaction, social skills, and group processing (Johnson \& Johnson, 1989). The findings in chapters 6 and 7 reflect the important qualities of these elements which will be discussed in turn.

First, the findings revealed that cooperative learning fostered positive interdependence and individual accountability in students. Positive interdependence refers to the perceptions of being associated with other students in order to achieve the goals and 
results beneficial to all group members (Johnson \& Johnson, 1989). The results of my research showed that pre-service teachers benefited from participating in group learning through thinking routines-based instruction. Specifically, when working in groups, they divided what Johnson and Johnson (1989) call responsibility and complementary roles (e.g., note-taker, checker, researcher, and encourager). It can be seen that students were held individually accountable to contribute and share their work. This can be noted when students took turns to represent the entire group to present and explain ideas on the Chalk Talk papers. At the same time, they seemed to understand the social identity of peers and respect them as members or collaborators of the learning community. This collaboration also underlies the common classroom pattern or culture that delineates the values and nature of the learning community in which students situate.

Second, the findings also revealed that student engagement promoted face-to-face interaction (Johnson \& Johnson, 1989). As noted in chapter 6, pre-service teachers were actively engaged in helping, assisting, supporting, and pushing each other's effort to learn. This allowed interpersonal dynamics to occur among them. In addition, this also increased face-to-face interaction among community members. The verbal and nonverbal responses of other group members provided important information concerning students' performance in learning. This can be seen when they presented their ideas in groups concerning issues being learned (e.g., effects of social media on teens). As Johnson and Johnson (1989) state, promoting each other's success results in both higher achievement and in getting to know each other on the personal as well as professional level. Meaningful face-to-face interaction was fostered through group and pair work. This also creates a sense of "belongingness" (Turner et al., 2014, p. 1199) as students were encouraged to establish close relationships with their fellow classmates through working in groups and pairs.

Finally, the findings also displayed the development of social and group processing skills. The former refers to a code of conduct for all group members to follow. In order for group learning to become successful, members require interpersonal and group work 
skills. As the findings showed, students were motivated to take roles, make decisions about the main ideas of texts, build trust and relationships with peers, communicate ideas, and ask questions. These skills started to emerge as they participated in this course (Johnson \& Johnson, 2009; Roseth et al., 2008). The latter, group processing, refers to how well group members are achieving their goals and maintaining effective working relationships (Johnson \& Johnson, 1989). The findings revealed that pre-service teachers learned better when working in groups, brainstorming and sharing ideas as they had more opportunities to seek help and receive feedback from their fellow classmates when comprehension suffered or reading problems started to emerge. In addition, the implementation class teacher acted as a member of the learning community, allowing the students to informally interact with him, facilitating a friendly and safe learning environment (Ritchhart et al., 2011). In sum, the CoT-based reading instruction fostered positive independence, promotive interaction, individualized accountability, social and group processing skills in students. These features are beneficial for the development of both academic knowledge and social interaction skills.

\subsubsection{Student engagement from Bloom's taxonomy perspectives}

Finally, I shall relate the findings of student engagement to Bloom's taxonomy (Bloom et al., 1956) before drawing a conclusion. As stated, there are six levels of Bloom's taxonomy; ranging from Knowledge to Evaluation. The results of student engagement reflect several qualities of higher-order thinking of this framework (e.g., comprehension, application, synthesis, and evaluation). In other words, student engagement in the CoTbased instruction was beyond mere completion of work or surface learning. As can be seen in the findings, several extracts of student engagement depict and support this part of the discussion when students participated in thinking routines (e.g., activating prior knowledge, meaning construction, and evaluating ideas). Specifically, pre-service teachers meaningfully engaged in determining the meaning and purpose of the text and analyzing parts of the passage (e.g., paragraphs), leading to critical thinking development (Mulcare \& Shwedel, 2017). This also reflects the notion of critical thinking and creative thinking pointed out in section 3.4.3 in a sense that they tended to apply higher-order of thinking when participating in groups and sharing ideas. To sum up, students' 
engagement in the CoT-based reading instruction was more interactive, cooperative, and meaningful than for those in the comparison class. This reflects the comparative reading learning engagement model (Figure 6.9) indicated in chapter 6. The following section addresses how CoT-based reading instruction shaped and constructed pre-service teacher cognition.

\subsection{Lao EFL pre-service teachers' prior cognition construction of learning reading}

This section looks at pre-service teachers' language learning cognition construction after the 13-week CoT implementation. In this respect, I will use the pre-perception survey results and the findings of phase 1 as baseline data to trace pre-service teachers' cognition construction, change, and development. To achieve this, I will relate the findings to the LTC theoretical framework (e.g., BAK and models) reviewed in section 3.2 and to the major research findings in the field of EFL pre-service teacher cognition.

\subsubsection{Influence of BAK on prior experiences of reading learning}

As the pre-survey and phase 1 results indicated, Lao EFL pre-service teachers held preconceived notions about reading and learning to read in English in terms of learning discrete language skills. This conception reflects what Woods (1996, p. 196) calls "beliefs, assumptions, and knowledge" (BAK) about language learning (Section 3.2). These components of their cognition, rooted primarily in their EFL reading across a range of settings throughout their learning experiences, were constructed during schooling. Specifically, the results of the pre-perception survey presented in section 7.3.1 illustrated that students believed that discrete language skills learning was key to successful reading learning. This conception also reflects what McKenzie (2008) states the majority of non-native attitudes toward English learning tend to recognize English language learning, including reading, as "a single entity" (p. 66). In other words, they see English reading learning as focusing on linguistic features (e.g., vocabulary and pronunciation), as opposed to meaning construction and metacognitive skills development (Hudson, 2007). 
The following subsections look at a central picture of pre-service teachers' cognition shifts in learning English reading after the 13-week CoT implementation. The discussion here focuses on major changes that were identified in the focus group interview analysis, namely: perceptions of reading and learning focus, comprehension development, critical reading awareness development, and reading skills enhancement that the implementation enabled them to benefit from.

\subsubsection{Cognition of reading and learning focus}

After the 13-week CoT implementation, pre-service teachers' perceptions of reading and learning focus shifted considerably. The results showed that their perceptions changed from having seen reading as learning discrete language skills to meaning construction. This change reflects their experiences of having been exposed to meaning constructionrelated tasks during the 13-week CoT implementation. The main purpose of this teaching approach is to encourage students to focus on understanding the important message conveyed by the writer. The results suggest that frequent exposure to interactive and innovative teaching approaches could change students' perceptions of reading learning focus as this study has demonstrated. It has been stated in literature that change in students' cognition takes a long time (Borg, 2006). However, my research findings show that the CoT-based instruction over 13-weeks could also shape students' cognition of reading and learning focus in this context.

\subsubsection{Pre-service teacher cognition in terms of reading comprehension, critical reading awareness, reading skills, and metacognitive reading awareness}

In this discussion, I shall relate the findings to the theory of metacognitive reading strategies and skills stated in the literature chapter. The adoption of this framework was due to its relevance in terms of understanding how reading comprehension is fostered and how metacognitive reading skills awareness raising contributes to meaning construction and effective reading (Grabe, 2009). In addition, the findings will also be discussed with reading comprehension strategies and skills theories (Afflerbach \& Cho, 2009; Grabe, 2009; Hudson, 2007) discussed in section 3.3.5, and empirical studies in the area. 
First, the findings revealed that summarizing practices or strategies to which students were exposed through a Claim-Support-Question activity helped them construct meaning of the text more effectively. As Cordero-Ponce (2000, p. 330) posits, "Summarization is perhaps one of the most significant and encompassing of all reading strategies available to the learner for effective studying and comprehension." In this vein, when students were encouraged to summarize content of the text, they needed to generate mental connections between ideas represented within the text and their prior knowledge. This generation and connection, in turn, fostered their reading comprehension and memorization of the main point. This claim is consistent with previous studies (CorderoPonce, 2000; Khoshsima \& Tiyar, 2014) in that summarization practices helped students to better construct meaning of the text.

The findings also revealed that reading comprehension was fostered when students were encouraged to apply "generative strategies (e.g., to summarize and to relate paragraphs to their experience) and metacognitive techniques to enhance their reading comprehension". It has been noted that "attention, motivation, and prior knowledge" (Wittrock, 1991, p. 170) help facilitate comprehension. In the present study, students were motivated to pay attention, summarize, and activate their background knowledge of the topic with the aim of fostering meaning construction ability. These aspects helped raise metacognitive reading awareness beneficial for comprehension development to occur. As stated in the reading literature and related studies, motivation plays a major role in facilitating learning achievement (Lin, Wong, \& McBride-Chang, 2012; Pintrich \& Groot, 1990; Wigfield, Gladstone, \& Turci, 2016) while lacking motivation might result in passive learning.

The findings also showed that reading strategies awareness was raised in the implementation group although this was not explicitly taught. In this sense, students were encouraged to skim, scan, construct meaning, raise questions, make connections, monitor comprehension, and evaluate information through various integrated thinking 
routines. These reading comprehension strategies are important for students to mentally interpret meaning of the text. As Hardebeck (2006, p. 12) states, reading comprehension strategies are "mental operations, tools or plans used by readers for facilitating and extending their comprehension". By applying both linguistic knowledge and cognitive operations, reading comprehension can be fostered more successfully. In addition, the implementation of the CoT also raised students' critical reading skills. In other words, they were more critical when interacting with the text than before in the sense that they were able to support their claims or reasons with evidence when encouraged to identify the main point of the text (Flynn, 1989).

\subsection{Participating lecturer's cognition and learning from a CoT-based instruction}

In the previous discussion, I looked at pre-service teachers' perceptions of learning reading in terms of reading comprehension, critical reading and reading skills awareness, and metacognitive reading awareness by relating to the literature review. This section discusses the participating lecturer's perceptions of the CoT-based reading instruction as an add-on to the issue under examination and to help inform L2 and EFL reading instructors with regard to their instructional practices. In fact, limited research exists that investigates how EFL pre-service teacher education lecturers learn about implementing a CoT in their classroom practices. The results of the present study, as stated in section 7.2.7, revealed that the implementation of the CoT benefited the participating teacher. Specifically, the participating lecturer, despite the fact that there was only one participant in this study, expressed his positivity toward the benefits of the CoT implementation. Drawing from the results, five main advantages of the CoT-based reading instructions can be summarized based on the participating teacher's perspective:

- fostered reading comprehension;

- shifted the teacher's role;

- raised student awareness of higher-order reading skills;

- enhanced cooperative learning; and

- promoted teacher professional development (e.g., action research skills and further application of the CoT) 
To contribute to our understanding of how lecturers learn and how that learning affects their cognition of teaching, I shall discuss these aspects with LTC models proposed by Borg (2006) and Macalister (2010) introduced in the literature chapter. As discussed in the models, the psychological construct of teaching is primarily established and shaped by its relationships with schooling, professional coursework, contextual factors, and classroom practices. The extent to which these aspects contribute to teacher learning (Kelly, 2006) and cognition construction will be discussed.

The development of teachers' cognition, learning, and growth is strongly generated by their experiences as learners, at teacher education (professional coursework), their classroom practices and teaching practicum, and the environment (contextual factors) in which they live (Borg, 2006). The present research focused on the importance of classroom practices about teaching reading on the participating teacher's mental life and cognition of teaching.

First, the lecturer pointed out that this intervention helped improve pre-service teachers' reading comprehension. As he stated in section 7.2.7, they became more confident in constructing meaning of the text through this teaching approach. This positive view of reading instruction reflects the idea that this teaching method is beneficial for reading comprehension development. Seeing the benefits from the pre-service teachers' perspectives made the teacher rethink aspects of his own role in teaching reading.

Second, the lecturer's cognition of his role in classroom practices changed as the interview results demonstrated. Through the implementation, the teacher began to realize that the teacher's role in the classroom was to facilitate and be part of the learning community. In this regard, the teacher's perceptions shifted from seeing himself as a main subject-matter knowledge transmitter to facilitator or member of the learning community. This shift is crucial for interactive and active learning to occur as it allows for a safe learning environment to emerge. Although the implementation only lasted 13 weeks, the construction of the lecturer's cognition in terms of this will, hopefully, 
continue to be an important reminder throughout his professional career, despite the existing challenges stated earlier.

Last, the lecturer mentioned that this teaching approach also helped facilitate his professional development and research skills. He pointed out that this teaching method helped develop his action research skills. In order to control for the implementer effect of the implementation, as stated in the methodology chapter, I, as a researcher, avoided being the instructor of the implementation group by inviting this lecturer to participate as my co-investigator. As stated in section 4.3.11, I worked closely with him in order to ensure smooth implementation of the CoT. During the implementation, I shared and explained to the lecturer the implementation procedures and working with him to design all materials, set the schedule, explain the strategies thoroughly, and deliver the pilot lessons for him to observe. Because of this, he learned the benefits of cooperative instruction, which shaped and fostered his teaching and classroom-based research skills beneficial for his own application and professional journey. Again, as pointed out in section 7.2.8, what he stated here reflects his experience of working with me. Without my guidance and assistance, he would not have done this, suggesting that introducing and implementing an innovative teaching approach requires collaborative effort and institutional cooperation.

In sum, when looking at the language teacher cognition construction, there are several contributing factors that need to be taken into consideration: experiences as learners, contextual factors, professional coursework, classroom practices, and BAK (Borg, 2006; Macalister, 2012; Woods, 1996). In this study, the main factor that helped shape the participating lecturer's cognition or perceptions was the classroom instructional practices through conscious reflection of his own action. In other words, the lecturer's cognition was shaped primarily by his classroom instructional experiences and working with me, as a researcher, throughout the implementation process. 


\subsection{Pre-service teacher cognition model in action}

The final research question for this research asks: What are Lao EFL pre-service teachers' perceptions of reading in the CoT-based and comparison classes? In this sense, I argued that in order to change pre-service teachers' prior experiences or perceptions of learning in the Lao EFL context, practical actions must be taken. Following the results introduced from chapters 6 and 7 and discussions in sections 8.4 .3 and 8.5 above, it is important to reflect on how the CoT-based instruction can be seen in a model of LTC. In this respect, various multifaceted features of cognition development can be used to construct a model of pre-service teacher cognition in action to contribute to our understanding of how the CoT-based instruction shaped their experiences of learning. Before combining these key features together, it is worth elaborating on each key aspect in detail based on the LTC model (Borg, 2006).

First, contextual factors have a direct impact on the application of a new and interactive approach to teaching. As stated in chapter 2, the Lao education system is top-down and teacher-centered which creates a barrier for the adoption of innovative teaching approaches. The present research took this into consideration when investigating preservice teachers' prior experiences of learning and tracing their cognition in action by reviewing and discussing its impact on classroom practices as pointed in chapter 2 . It

cannot be separated from the educational setting as different contexts have specific constraints on the education development in which students and teachers are situated.

Second, the CoT-based practices (Ritchhart, 2015) is a process of integrating thinking routines (activities) into lesson plans with the aim of fostering deep and meaningful learning; hoping to shape pre-service teachers' cognition of learning and teaching. This was the main shaper in this research.

Third, BAK and Affect (Macalister, 2012; Woods, 1996) are constructed by extensive exposure to language experiences in a specific context. This experience includes both positive and negative attitudes related to language-learning activities in both L1 and L2. 
Finally, cognition, an unobservable construct (Borg, 2006) largely made up of learning experiences, BAK and Affect, is shaped across settings over a period of time. This construct has direct impacts on language learning and teaching, including classroom actions and behaviors. Figure 8.2 is a model of pre-service teacher cognition in action.

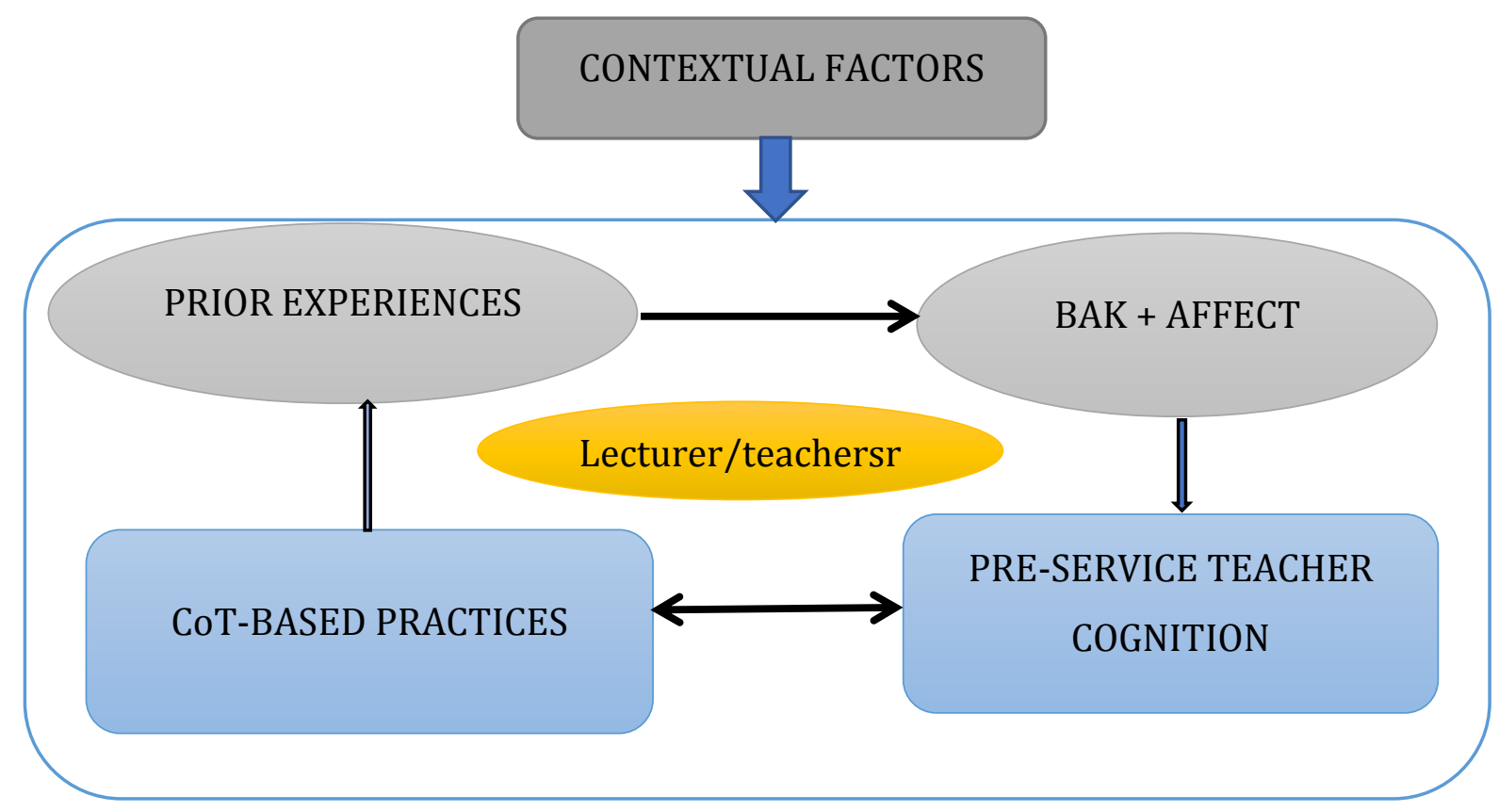

Figure 8. 2 Pre-Service Teacher Cognition in Action

As the model shows, 'contextual factors' are framed as the macro level of LTC construction. As stated in the LTC cognition models in section 3.2.2, contextual factors impact "practice either by modifying cognitions or else directly, in which case incongruence between cognition and practice may result" (Borg, 2006, p. 41). Empirical data showed that Lao education is "a culture-infused school code where teachers are imbued with a strong societal influence against anything new, alien, or different" (Doeden, 2014, p. 298). Although this has been recognized as one of the context-specific constraints for education reform and development in LPDR, actions to address this in practice have not been taken so far. Thus, we see a unidirectional arrow from 'CoT-based practices' to 'prior experiences'. This connection can be reflected in what students experienced in class and these practices became their prior learning experiences. Next, the unidirectional arrow illustrates a move from what EFL pre-service teachers' prior 
experiences toward the students' beliefs, assumptions, knowledge, and other psychological constructs shaping how L2 reading is learned and perceived (BAK and Affect). The interconnected BAK and Affect components shape pre-service teacher cognition. The double-ended arrow demonstrates the dynamic interplay between the pre-service teachers' mental constructs and external intervention. This is meant to reveal how cognition impacts the CoT-based practices, so too CoT-based practices impact cognition. Again, this interaction and impacts operate under the contextual factors, the macro level that has an important influence on the implementation of the CoT.

Finally, this ever-emergent and ongoing process is played by the participating teacher (lecturer), the main facilitator of the learning process in this implementation. Although, as indicated in the literature review, the teacher is operating at the micro level (implementation), he plays an essential role in shaping pre-service teachers' cognition and perceptions of learning reading (Borg, 2003). As stated in section 3.2.1, the emergence and development of LTC is attributed to the recognition that teachers are regarded as "active, thinking, decision makers who play a central role in shaping classroom events and learners' experiences of learning" (Borg, 2006, p. 11). The model here reflects this quote in the sense that the teacher (implementer) is the catalyst for transforming a classroom culture and changing students' perceptions of learning reading. In brief, the construction of pre-service teachers' cognition is operated at an unobservable level (Borg, 2006) and impacted and shaped by a number of contributing factors. These factors also pose challenges for the introduction of new and innovative teaching approaches to teaching English in many EFL contexts. As a consequence, TEPs do not play a major role in shaping pre-service teachers' preconceived beliefs and perceptions of learning a language.

\subsection{Chapter summary}

This chapter first discussed the results of phase 1, pre-service teachers' prior experiences of reading and learning to read in English, the current state of reading instruction, and the extent to which a CoT was practiced in EFL Lao pre-service teacher education. Through this discussion, it was concluded that students experienced an 
extensive practice of discrete language skills learning, as opposed to comprehension development. It then discussed the benefits of the CoT implementation on reading comprehension, student engagement, and perceptions of reading learning. The chapter then looked at the participating teacher's perceptions of teaching reading and the preservice teacher cognition construction model in action. Drawing from the discussion above, important implications for instructional practices and future research directions will be looked at in the following chapter. 


\section{CHAPTER 9: CONCLUSION AND CONTRIBUTIONS}

\subsection{Introduction}

This investigation aimed to seek answers to the central research questions indicated in chapters 1 and 4 . In addition, it also provided answers to the two questions posed in section 1.3. 1) How can teachers develop critical, communicative and strategic students? 2) What method will help the teachers foster the required skills in students? In addition, I also pointed out in section 1.2 that most of the Lao EFL teachers are resistant to change or only accept new teaching approaches in their classroom practices if they are important in the globalized and changing world. In order to help them address the issues, possible solutions drawn from this project are proposed and suggested in section 9.3 of this chapter.

The previous chapter discussed the main findings of the present study. The outcome of the discussion revealed important pedagogical implications for instructional practices and potential areas for future research directions. As stated in the methodology chapter, there were two phases in this research. Phase 1 was an exploratory study consisting of elements of ethnographic research, which investigated pre-service teachers' prior experiences of reading and learning to read in English. I sought to understand the current state of reading instruction in Lao EFL pre-service teacher education and to find out the extent to which a CoT was practiced in reading instruction. Phase 2, a quasiexperimental design, aimed to determine the effects of the CoT implementation on preservice teachers' reading comprehension development, learning engagement, and perceptions of learning English reading. Section 9.2 summarizes the main findings. Section 9.3 addresses theoretical and pedagogical contributions of the study. Limitations of the research are pointed out in section 9.4. Section 9.5 suggests future directions. Section 9.6 concludes this thesis. 


\subsection{Main findings encapsulated}

\subsubsection{Phase 1}

As mentioned earlier, this phase sought to answer the following research questions:

RQ1. What are Lao EFL pre-service teachers' prior experiences of reading and learning to read in English?

RQ2a. What is the current state of reading instruction in Lao EFL pre-service teacher education?

RQ2b. To what extent is a CoT practiced in Lao EFL pre-service teacher education?

As stated earlier, an exploratory ethnographic design was adopted to seek answers to the research questions. Regarding RQ1, the results showed that the Lao EFL pre-service teachers' prior experiences of reading and learning to read were focused primarily on learning discrete language features by reading out loud, translating, pronouncing words, and learning vocabulary. Their prior experiences of reading learning were largely influenced by the dominant use of GTM during their apprenticeship of observation. This becomes a self-perpetuating cycle that is difficult to change. Such practice not only influenced the Lao EFL pre-service teachers' attitudes and behaviors towards reading learning but also hindered the teachers' efforts and determination to apply new and innovative teaching approaches.

Regarding RQ2a, the results revealed that reading instruction in Lao EFL pre-service teachers' education primarily involves paying close attention to teaching discrete language items (e.g., grammar, learning new words, answering comprehension questions, and pronunciation focus) rather than developing comprehension and meaning construction. The findings also indicate a lack of teachers' confidence, efficacy, and persistence to facilitate interactive and meaningful learning in their classroom practices. In other words, very little or no growth was realized in their teaching and the prospect of implementing an innovative teaching approach was not evident although many of the 
teachers had been trained in new ideas at workshops and other forms of professional development, as stated in section 1.2. This situation is expected to continue in teaching English in the Lao EFL pre-service education system. The findings here also reflect the results of RQ1 in that pre-service teachers' prior experiences of reading were extensively concerned with learning language features. The results of RQ2a and RQ2b show that the CoT-based instructional practice was not in place in this context even though it was recognized and acknowledged in the curriculum and education policy. As previously stated, the findings of phase 1 were used as baseline data and to lay a foundation for Phase 2, the CoT implementation.

\subsubsection{Phase 2}

Phase 2, a classroom-based intervention aimed to determine the effects of the 13-week CoT implementation on Lao EFL pre-service teachers' reading comprehension development, learning engagement, and perceptions of learning reading, sought answers to the following research questions:

RQ3. To what extent does the implementation of a CoT improve Lao EFL preservice teachers' reading comprehension?

RQ4. How do Lao EFL pre-service teachers engage in learning reading in the CoTbased and comparison classes?

RQ5. What are Lao EFL pre-service teachers' perceptions of reading in the CoTbased and comparison classes?

After the implementation, an immediate post-test (same as pre-test) and a post-survey (same as pre-survey) were re-administered to both classes to determine whether the implementation improved reading comprehension and changed their perceptions of reading learning. In addition, a delayed-test (same as the pre-and immediate post-test) was conducted two weeks after the immediate post-test to measure comprehension retention. Also, direct classroom observations were conducted during the implementation to investigate what students experienced and engaged in the CoT-based and normal reading instruction. Finally, focus group interviews were conducted to 
explore students' perceptions of learning reading between the two different learning conditions. In brief, two sets of data, quantitative and qualitative, were gathered in this phase. Therefore, the following subsections will first summarize the quantitative results followed by the qualitative findings summary.

\subsubsection{Quantitative findings summary}

The implementation lasted for 13 weeks with two 90-minute learning sessions per week. The implementation class was taught using CoT thinking routines. To ensure the effective implementation, I cooperated with the implementation teacher and designed the lesson plans and learning activities for the classroom instructional practices. For the control group, however, students were taught as normal by a participating teacher.

The statistical results of the post-test indicated a significant difference between the classes. Therefore, it was acknowledged that the CoT implementation significantly improved pre-service teachers' reading comprehension. The results of the delayed-test also revealed a statistical significance in terms of the comprehension retention between the classes. The findings here were also consistent with the results of the focus group interviews and post-survey as presented in chapter 7.

In terms of the post-perception survey, the results found this pattern to be statistically significant on each category (e.g., Discrete Language Skills learning; Metacognitive Reading Awareness; Reading Learning Experiences; and Learning Outcomes) of the postperception survey between the classes. In addition, the paired sample $t$ tests results indicated a statistical significance between the pre- and post- survey of the implementation class under each category as stated in chapter 7 while this pattern was not found to be significant in the comparison class. Therefore, it was acknowledged that the CoT implementation changed students' perceptions of reading and learning to read in English. Further evidence regarding this is depicted in the results of the focus group interviews and observations summarized below. 


\subsubsection{Qualitative findings summary}

As stated in the methodology chapter, qualitative data collection methods (e.g., observations and focus group interviews) were used to obtain data related to learning engagement and perceptions of learning reading between the two classes. With reference to RQ4, the results revealed that student engagement in learning reading between the classes was considerably different. In the implementation class, the results showed that students were more interactive and engaging than the comparison class. As pointed out in chapter 6 , the implementation class students actively and meaningfully participated in thinking, sharing ideas, and reflecting on what they read, which was beneficial for increased comprehension and the development of effective readers. In addition, the results also reflected higher-order thinking as described in terms of Bloom's taxonomy and important aspects of student engagement theories (e.g., cognitive, social etc.). In sum, the reward for the student engagement in the CoT-based instruction was their improved reading comprehension and increased participation when working in groups or pairs.

On the question of learning reading perceptions (RQ5), the findings demonstrated that the implementation class pre-service teachers expressed positivity towards the CoTbased reading learning. What strongly emerged from the interviews was that they stated that the CoT implementation fostered reading comprehension, social interactions, and raised metacognitive reading skills or strategies awareness. In addition, the findings also illustrated that the CoT-based instruction helped transform a passive classroom culture into a more active and engaging learning environment crucial for collaborative learning to occur (Ritchhart, 2015). Furthermore, the CoT implementation also benefited the implementation class lecturer (teacher) in a number of ways as pointed out in section 8.5. Drawing from the results and discussion above, the theoretical and pedagogical contributions of the research are discussed in the following section. 


\subsection{Contributions}

\subsubsection{Theoretical contributions}

Even though this research did not focus on theory building, the study's main theoretical contribution rests in the conceptual models of pre-service teacher cognition and reading learning process in action presented in chapter 8. Earlier research on language learning and teaching investigated pre-service teachers' cognition in general (Borg, 2006; Macalister, 2010; Woods, 1996). Since that time, there has been a large volume of research that has focused on different skills (e.g., grammar, vocabulary, and reading) and this model also adds value to that knowledge.

The present study also adds support to metacognitive reading strategy training as a means of raising students' reading skills and strategies awareness in terms of activating prior knowledge, identifying the main points, evaluating comprehension, and extending ideas. These qualities reflect metacognitive reading strategies or skills discussed in the literature chapter (Wang, 2009). As the findings revealed, students became more aware of their critical reading skills and reading management when reading the text. The findings may also contribute to the field of reading-fluency development given that the CoT implementation was perceived by students to improve their reading rate, contributing to a faster meaning construction process. As students pointed out in the interviews, through the CoT-integrated approach, it was not necessary to read out loud, translate and understand every word to construct meaning of the text. Rather, they applied reading skills (e.g., skimming, scanning, and using prior knowledge) when interacting with the text.

This study also contributes to the area of vocabulary research. As perceived by the students, their vocabulary knowledge broadened from participating in activating vocabulary knowledge related to the topic to be read during the pre-reading stage. As indicated previously, when they took part in the prior knowledge activation activities (i.e., Chalk Talk), students were encouraged to brainstorm concept vocabulary crucial for reading comprehension. 


\subsubsection{Pedagogical contributions}

Drawing from the findings and discussion, pedagogical implications for EFL teachers and students can be highlighted to help shape their classroom practices. As stated by Carrell (1983), skilled readers learn how to do complex reading by doing it repeatedly, over a long period of time, with a lot of different texts and a lot of different opportunities to practice applying strategies, monitoring their process, and evaluating the effectiveness of different strategies for themselves in different reading situations. These aspects of reading strategies should be the main focus of reading instruction in an EFL pre-service education context in order to allow students to independently use these strategies or skills in their personal and professional reading practices. As future teachers, pre-service teachers might impart what they experience and learn in the classroom to the next generation. As stated earlier, CoT-based instruction helped foster reading comprehension, meaningful engagement, and shaped students' perceptions and experiences of learning reading.

\subsubsection{Value for educational practitioners}

As stated in chapter 2, several contextual factors are impacting Lao EFL instruction. One of these factors is that teachers were required to not only teach but also do administrative tasks, limiting their lesson preparation time. These obstacles, however, can be minimized by including thinking routines in classroom practices. First, as indicated in section 3.4.8, thinking routines can be integrated into teaching any English language skills (Ritchhart, 2015) to foster meaningful and active learning. In my research, thinking routines (e.g., Chalk Talk, Claim-Support-Question, and ConnectExtend-Challenge) were integrated into the three stages of reading instruction to address the issue of passive reading learning, which is insufficient for the development of effective readers. The integration of the thinking routines into teaching reading helped students establish background knowledge, construct meaning, raise metacognitive reading strategies awareness, extend their ideas and reinforce their understanding of what they read. The study's main take-home message is that the teachers should encourage these practices in their classroom instruction during the three stages of teaching reading in order to help students become the agents of their own learning. In 
this regard, pedagogical instructions for applying and integrating thinking routines are provided for classroom teachers to follow as stated in the methodology chapter.

Second, thinking routines and cultural forces are the instructional scaffolds that empower both teachers and students to move away from just knowing the correct answers to thinking about, looking closely at, understanding, and questioning what gets learned (Mohammadi, Heidari, \& Niri, 2012; Perkins et al., 2000; Ritchhart \& Perkins, 2008). In addition, through using these routines, the teacher's role changed from a transmitter of knowledge to a facilitator and learner of the learning community as noted in the results of the participating teacher's interview in chapter 7. The findings also have the potential to inform curriculum developers, course designers, and policy makers in shaping their decision-making regarding the Lao EFL pre-service teacher education reform and beyond. Specifically, this research offered a rich and nuanced understanding of how interactive teaching approaches can be applied in a top-down education system context (e.g., LPDR). In addition, no previous studies have focused on the application of the CoT (Ritchhart, 2015) in the areas of EFL pre-service teachers' cognition in action (Borg, 2006) and reading-focused instruction using qualitative methods. Thus, this study makes a positive contribution to ongoing education development in Lao EFL pre-service education and beyond.

Finally, innovative teaching approaches (i.e., CoT) and critical thinking practices should be embedded in language teaching methodology courses so that both pre-service teachers and lecturers can be directly influenced. By incorporating these, the issues of passive and uncritical thinking learning in the top-down national educational system can be addressed.

\subsubsection{Value for EFL pre-service teachers and EFL students}

The results indicate that the CoT implementation benefited EFL pre-service teachers in a number of ways. First, the students' role shifted from being passive to active and cooperative. In other words, they tended to take responsibility for their own learning compared to the comparison class. This shifted role is important for the development of 
autonomous and independent learning, reflecting the notion of learner autonomy (Benson, 2013; Smith, 2007). In addition, the results showed that students were more positive about learning reading than their past-related reading learning experiences. It has been noted that BAK of learning (Woods, 1996) play an influential role in shaping learners' experiences of learning and helping them gain control over their reading behaviors and management. As stated earlier, the integration of thinking routines into teaching reading provided meaningful opportunities for students to brainstorm, share ideas, observe, and wonder about what was read and to be read. Through constant practice in, and exposure to, such learning activities, students' interest and responsibility in their own reading management and cooperative engagement were gradually fostered. From the sociocultural perspective, cooperative learning and peer sharing while participating in classroom activities resulted in meaningful learning and self-efficacy (Vygotsky, 1978).

Finally, although Lao education is top-down and impacted by the centrality of society, tradition, and classroom code where teachers are expected to be highly respected and be the only source of knowledge (Doeden, 2014), the results of my research showed that Lao EFL pre-service teachers preferred the CoT-based learning orientation. Specifically, they gained considerable benefits from critical thinking, summarization skills, and cooperative learning resulting from the integration of thinking routines. When summarizing, students cognitively interacted with the text to construct meaning and monitor their comprehension by applying what Block (1992) calls, "meaning-level cues" rather than "word-level cues" (p. 321) to focus on the decoding part of reading. As preservice teachers benefited from this teaching approach, it is hoped that what they experienced from the implementation will become an important element of their future practices and professional development.

\subsubsection{Policy Implications}

Drawing from the study's main findings, policy implications are suggested as follows. Firstly, I suggest that Lao education policy focuses on promoting critical thinking skills and introducing innovative teaching approaches in the top-down national educational 
system to address the predominant issues. Secondly, education policy should specifically make the integration of thinking routines mandatory for classroom practice so that both teachers and students can be directly influenced. From this study, there is potential for Lao education to achieve higher quality. Finally, education policy should focus on training in-service English teachers in terms of integrating innovative teaching approaches and critical thinking practices into the lessons. Through this, the teachers can independently design the lessons that promote critical thinking skills in their students.

\subsection{Limitations of the study}

Although this research brought about useful pedagogical and theoretical contributions to the areas of LTC, EFL reading instruction, EFL pre-service teacher education development, and a CoT, the limitations need to be pointed out so that potential future research directions can be suggested. First, through observation and attachment at the research site during my data collection, I noticed that the comparison class appeared to have less class time than the implementation class because the teacher had multiple tasks to do as pointed out section 2.5.3. This imbalance might have had an impact on the comparison students' reading performance. And yet, surprisingly, the comparison class teacher was able to finish all of the lessons in the textbook by the end of the semester. This reflects the current state of reading instruction where the goal is to follow the textbook or prescribed curriculum without supplementing with additional sources and integrating interactive approaches. Second, pre-service teachers' L1 literacy skills were not addressed in this research. However, existing literature in the area of $\mathrm{L} 2$ reading has pointed out that there is a transfer and interactional effect of students' L1 literacy skills on L2 reading performance (Clarke, 1980; Koda, 1987; Wang, 2009). This leaves a question mark about the effects of L1 on L2 reading comprehension performance. Therefore, future research should take this into consideration. Third, this research adopted a quasi-experimental design where it was difficult to control what happened in the classroom as I worked with natural settings. These two classes, however, reflect the true nature of the existing learning environment in the EFL context. This research did its best to minimize the impact of this through data triangulation methods (e.g., interviews, 
observations, survey). Finally, the absence of negatively-oriented items in the questionnaire was another limitation since the inclusion of this might have obtained a broader range of insights into the issues under research.

\subsection{Future directions and challenges}

\subsubsection{Future research directions}

Through this long journey, I learned that conducting research, especially classroombased research, is a complex yet meaningful process as it is relevant to several stakeholders (e.g., teachers, students) and is context specific (e.g., classroom code and learning conditions). This directly affects how the study was carried out. For this reason, future research directions are suggested to deepen our understanding and expand our knowledge of reading comprehension development and pre-service teacher cognition construction through the integration of an interactive teaching approach like a CoT. This has also driven my curiosity to learn even more. Drawing from the discussion and limitations pointed out earlier, I suggest the following areas for future investigations:

- conducting a follow-up study on the impact of the CoT implementation on the participating teacher and pre-service teachers as they develop professionally;

- integrating the CoT into teaching other language skills (e.g., vocabulary, writing, listening) to determine its impacts on language skills development and learning engagement;

- conducting similar studies in other EFL and ESL contexts;

- including several experimental groups and participating teachers;

- integrating the CoT into other areas beyond language learning (e.g., history, literature); and

- utilizing a more tightly controlled experimental design to see the CoT effects on reading comprehension, learning engagement, and perceptions of reading.

\subsubsection{Future challenges}

As stated earlier, the findings revealed that the CoT implementation had a positive impact on changing students' perceptions of reading, reading comprehension development, and learning engagement. However, the question to be asked next is: 
How can this sort of change be practically embedded in the Lao EFL pre-service education system to ensure better learning outcomes for Lao students in the future?

From listening to the students' and lecturers' voices through this research, I propose the following solution for addressing the future challenges by:

conducting follow-up training courses on the CoT-based reading instruction for EFL in-service teachers in the LES.

\subsection{Thesis concluding remarks}

In conclusion, this study has provided insights into the promotion of interactive and meaningful reading instruction in the Lao EFL pre-service education context, which I hope, will benefit future practice and education reform in LPDR. I remain optimistic that Lao EFL pre-service education can continue to improve the quality of education and achieve much more than in the past. I am also eager to see future teachers apply and integrate innovative and interactive teaching approaches in their classroom instructional practices. Finally, I am thankful for this opportunity to have worked in this area as a starting point for pre-service teacher education development in this context. I trust that all who have participated in my investigation will continue to contemplate how to further spark initiatives that benefit all in the Lao EFL pre-service education system. 


\section{REFERENCES}

Acocella, I. (2012). The focus groups in social research: Advantages and disadvantages. International Journal of Methodology, 46(4), 1125-1136. doi: 10.1007/s11135011-9600-4

Adams, D., Kee, G. H., \& Lin, L. (2001). Linking research, policy, and strategic planning to education development in Lao People's Democratic Republic. Comparative Education Review, 45(2), 220-241. doi: 10.1086/447662

Afflerbach, P., \& Cho, B. Y. (2009). Identifying and describing constructively responsive comprehension strategies in new and traditional forms of reading. In S. E. Israel \& G. G. Duffy (Eds.), Handbook of research on reading comprehension (pp. 69-90). New York: Routledge.

Akarsu, O., \& Harputlu, L. (2014). Perceptions of EFL students toward academic reading. The Reading Matrix, 14(1), 61-75.

Alfaki, I. M., \& Siddiek, A. G. (2013). The role of background knowledge in enhancing reading comprehension. World Journal of English Language, 3(4), 42-66.

Alshenqeeti, H. (2014). Interviewing as a data collection method: A critical review. English Linguistics Research, 3(1), 39-45.

Altun, T. (2013). Exploring the effects of classroom culture on primary pre-service teachers' professional development. Australian Journal of Teacher Education, 38(9), 37-54. doi: dx.doi.org/10.14221/ajte.2013v38n9.

Ames, D., Maissen, L. B., \& Brockner, J. (2012). The role of listening in interpersonal influence. Journal of Research in Personality, 46(3), 345-349.

Anderson, L. W. (1974). Student involvement in learning and school achievement. California Journal of Educational Research, 26(2), 53-62.

Anuar, N., \& Sidhu, G. K. (2017). Critical reading skills: A survey of postgraduate students' perspectives of critical reading. Social Sciences \& Humanities, 25(3), 163-172.

Archana, S., \& Rani, K. U. (2016). Role of a teacher in English language teaching (ELT). International Journal of Educational Science and Research, 7(1), 1-4.

Asiyai, R. (2014). Students' perception of the condition of their classroom physical learning environment and its impact on their learning and motivation. College Student Journal, 48(4), 716-726. 
Atkinson, P., \& Coffey, A. (1997). Analyzing documentary realities. In D. Silverman (Ed.), Qualitative research: Theory, method and practice (2 ed., pp. 56-75). Thousand Oaks, CA: Sage.

Bachman, L. F., \& Palmer, A. S. (1996). Language testing in practice: Designing and developing useful language tests. Oxford, UK: Oxford University Press.

Baker, L., \& Brown, A. L. (2002). Metacognitive skills and reading. In P. D. Pearson \& R. Barr (Eds.), Handbook of reading research (pp. 353-394). Mahwah, New Jersey: Lawrence Erlbaum.

Baker, T. L. (1988). Doing social research. New York: McGraw-Hill Inc.

Balwant, P. T., Birdi, K., Stephan, U., \& Topakas, A. (2018). Transformational instructorleadership and academic performance: A moderated mediation model of student engagement and structural distance. Journal of Further and Higher Education, 117. doi: 10.1080/0309877X.2017.1420149

Barber, T. X. (1973). Pitfalls in research: Nine investigator and experimenter effects: Second handbook of research on teaching. Chicago: Rand McNally.

Barnard, R., \& Burns, A. (2012). Researching language teacher cognition and practice: International case studies. Bristol, Buffalo: Multilingual Matters.

Barnes, D. R. (2008). Exploratory talk for learning. In N. Mercer \& S. Hodgkinson (Eds.), Exploring talk in school (pp. 1-16). London, UK: Sage.

Benson, P. (2013). Learner Autonomy. TESOL Quarterly, 47(4), 839-843. doi: $10.1002 /$ tesq.134

Benveniste, L., Marshall, J., \& Santibanez, L. (2015). Teaching in Lao PDR. Vientiane, LPDR: Ministry of Education and Sports.

Benveniste, L., Marshall, J. H., \& Santibañez, L. (2007). Teaching in Lao PDR. Lao People's Democratic Republic: World Bank and Ministry of Education.

Berger, R. (2015). Now I see it, now I don't: researcher's position and reflexivity in qualitative research. Qualitative Research, 15(2), 219-234. doi: $10.1177 / 1468794112468475$

Bit Na, K., \& Yusun, K. (2017). The effects of content schema on Korean middle school EFL learners' reading comprehension. Korean Journal of Applied Linguistics, 33(2), 31-50. doi: 10.17154/kjal.2017.6.33.2.31 
Block, E. L. (1992). See how they read: Comprehension monitoring of L1 and L2 readers. TESOL Quarterly, 26(2), 319-343. doi: 10.2307/3587008

Bloom, B. S., Engelhart, M. D., Furst, E. J., Hill, W. H., \& Krathwohl, D. R. (1956). Taxonomy of educational objectives-handbook 1: The cognitive domain. New York: David Mackey.

Bloor, M., Frankland, J., Thomas, M., Robson, K., \& Stewart, K. (2001). Focus groups in social research. Thousand Oaks, CA: SAGE.

Borg, M. (2004). The apprenticeship of observation. ELT Journal, 58(3), 274-276.

Borg, S. (2003). Teacher cognition in language teaching: A review of research on what language teachers think, know, believe, and do. Language Teaching, 36(2), 81-109.

Borg, S. (2006). Teacher cognition and language education: Research and practice. London: Continuum.

Borich, G. D. (2011). Observation skills for effective teaching (6 ed.). Boston: Pearson.

Bounyasone, K., \& Keosada, N. (2011). Cultivating educational research in Lao PDR: For a better future? (Unpublished Doctoral Dissertation), Umea University, Sweden.

Bourke, B. (2014). Positionality: Reflecting on the research process. The Qualitative Report, 19(33), 1-9.

Boutorwick, T. J. (2017). Vocabulary development through reading: A comparison of approaches. (Unpublished Doctoral Thesis), Victoria University of Wellington.

Bowen, G. A. (2009). Document analysis as a qualitative research method. Qualitative Research Journal, 9(2), 27-40. doi: 10.3316/QRJ0902027

Breen, M. P., Hird, B., Milton, M., Oliver, R., \& Thwaite, A. (2001). Making sense of language teaching: Teachers' principles and classroom practices. Applied Linguistics, 22(4), 470-501.

Breznitz, Z. (2006). Fluency in reading: Synchronization of processes. Mahwah: Erlbaum Associates.

Britton, B. K., \& Tesser, A. (1991). Effects of time management practices on college grades. Journal of Educational Psychology, 83(3), 405-410.

Brown, J. D. (2001). Using surveys in language programs. Cambridge: Cambridge University Press. 
Brown, J. D. (2015). Mixed methods research. In J. D. Brown \& C. Coombe (Eds.), The Cambridge Guide to Research in Language Teaching and Learning (pp. 78-87). Cambridge: Cambirdge University Press.

Cain, K. (2007). Syntactic awareness and reading ability: Is there any evidence for a special relationship? Applied Psycholinguistics, 28(4), 679-694.

Cambridge University Press. (2006). Cambridge IELTS 5. Cambridge, UK: Cambridge University Press.

Can, L. T. (1991). Higher education reform in Vietnam, Laos, and Cambodia. Comparative Education Review, 35(1), 170-176.

Carrell, P. L. (1983). Three components of background knowledge in reading comprehension. Language Learning, 33(2), 183-207.

Carrell, P. L., Gajdusek, L., \& Wise, T. (1998). Metacognition and EFL/ESL reading. Instructional Science, 26(1-2), 97-112.

Carrell, P. L., Pharis, B. G., \& Liberto, J. C. (1989). Metacognitive strategy training for ESL reading. TESOL Quarterly, 647-678.

Carrell, P. L., Wise, T., \& Gajdusek, L. (1998). Metacognition and EFL/ESL Reading. Instructional Science, 26, 97-112.

Chai, C. S., Teo, T., \& Lee, C. B. (2009). The change in epistemological beliefs and beliefs about teaching and learning: A study among pre-service teachers. Asia-Pacific Journal of Teacher Education, 37(4), 351-362. doi: 10.1080/13598660903250381

Chatouphonexay, A. (2013). Beliefs about learning English held by students and teachers in the teacher education in Lao PDR. (Unpublished Doctoral Dissertation), Suranaree University of Technology, Thailand.

Chatouphonexay, A., \& Intaraprasert, C. (2014). Beliefs about English language learning held by EFL pre-service and in-service teachers in Lao People's Democratic Republic. English Language Teaching, 7(3), 1-12.

Cherryholmes, C. H. (1992). Notes on pragmatism and scientific realism. Educational researcher, 21(6), 13-17.

Christenson, S. L., Reschly, A. L., \& Wylie, C. (2012). Handbook of research on student engagement. New York, NY: Springer. 
Clarke, M. A. (1980). The short circuit hypothesis of ESL reading - or when language competence interferes with reading performance. Modern Language Journal, 64(2), 203-209.

Clarke, V., \& Braun, V. (2017). Thematic analysis. The Journal of Positive Psychology, 12(3), 297-298. doi: 10.1080/17439760.2016.1262613

Cohen, L., Manion, L., \& Marrison, K. (2011). Research methods in education (7 ed.). London: Routledge.

Cohen, L., Manion, L., \& Morrison, K. (2007). Research methods in education (6 ed.). London: Routledge.

Cohen, J. (1988). Statistical Power Analysis for the Behavioral Sciences. New York, NY: Routledge Academic.

Combe, C., \& Davidson, P. (2015). Constructing questionnaire. In J. D. Brown \& C. Combe (Eds.), The Cambridge Guide to Research in Language Teaching and Learning (pp. 217-223). Cambridge: Cambridge University Press.

Cordero-Ponce, W. L. (2000). Summarization instruction: Effects on foreign language comprehension and summarization of expository texts. Reading Research and Instruction, 39(4), 329-350. doi: 10.1080/19388070009558329

Corno, L., \& Mandinach, E. B. (1983). The role of cognitive engagement in classroom learning and motivation. Educational Psychologist, 18(2), 88-108. doi: $10.1080 / 00461528309529266$

Cota Grijalva Sofía, D., \& Ruiz-Esparza Barajas, E. (2013). Pre-Service teachers' beliefs about language teaching and learning: A longitudinal study. Profile Issues in Teachers' Professional Development, 15(1), 81-95.

Cowie, N. (2009). Observation. In J. Heigham \& R. A. Croker (Eds.), Qualitative research in applied linguistics: A practical introduction (pp. 165-181). New York, NY: Palgrave Macmillan.

Crandall, J. (2000). Language teacher education. Annual Review of Applied Linguistics, 20, 34-38.

Creswell, J. W. (1994). Research design: Qualitative and quantitative approaches. Thousand Oaks, CA: SAGE.

Creswell, J. W. (2007). Qualitative inquiry research design: Choosing among five approaches (2nd ed.). Thousand Oaks, CA: SAGE. 
Creswell, J. W. (2013). Research design: Qualitative, quantitative, and mixed methods approaches. Thousand Oaks, CA: SAGE.

Creswell, J. W., \& Clark, V. L. P. (2007). Designing and conducting mixed methods research (2 ed.). Thousand Oaks, CA: SAGE.

Creswell, J. W., \& Miller, D. L. (2000). Determining validity in qualitative inquiry. Theory into practice, 39(3), 124-130.

Crick, R. D. (2012). Deep engagement as a complex system: Identity, learning power, and authentic enquiry. In S. L. Christenson, A. L. Reschly \& C. Wylie (Eds.), Handbook of Research on Student Engagement (pp. 675-694). Boston MA: Springer.

Croker, R. A. (2009). An introduction to qualitative research. In J. Heigham \& R. A. Croker (Eds.), Qualitative Research in Applied Linguistics: A practical Introduction. New York: Palgrave Macmillan.

Dagilienè, I. (2012). Translation as a learning method in English language teaching. Studies about Languages, 21(2), 124-129.

Darr, C. W. (2012). Measuring student engagement: The development of a scale for formative use. In S. L. Christenson, A. L. Reschly \& C. Wylie (Eds.), Handbook of Research on Student Engagement (pp. 707-723). Bosten, MA: Springer.

David P, D., \& Lori E, S. (2011). Measuring skewness: A forgotten statistic? Journal of Statistics Education, 19(2), 1-18. doi: 10.1080/10691898.2011.11889611

Day, R., \& Park, J. S. (2005). Developing reading comprehension questions. Reading in a Foreign Language, 17(1), 60-73.

Doeden, L. (2014). Teacher change: Exploring the adoption of an innovative ELT strategy by English language teachers in Lao PDR. (Unpublished PhD Thesis), Bilola University, USA.

Dörnyei, Z. n. (2007). Research methods in applied linguistics: Quantitative, qualitative, and mixed methodologies. Oxford: Oxford University Press.

Dörnyei, Z. n., \& Taguchi, T. (2010). Questionnaires in second language research : construction, administration, and processing (2 ed.). New York: Routledge.

Drisko, J. W., \& Maschi, T. (2016). Content analysis: Pocket guides to social work research methods. Oxford: Oxford University Press.

Duke, N. K., \& Pearson, P. D. (2008). Effective practices for developing reading comprehension. The Journal of Education, 189(1/2), 107-122. 
Early, M., \& Marshall, S. (2008). Adolescent ESL students' interpretation and appreciation of literary texts: A Case study of multimodality. Canadian Modern Language Review, 64(3), 377-397. doi: 10.3138/cmlr.64.3.377

El-Okda, M. (2005). EFL student teachers' cognition about reading instruction. The Reading Matrix, 5(2), 43-60.

Elliott, C. (2014). Locally Situated Literacies and the Challenges of English Language Education in Laos. (Unpublished Doctoral Thesis), University of WisconsinMadison, USA.

Ellis, R. (2008). Learner beliefs and language learning. Asian EFL Journal, 10(4), 7-25.

Ellis, R., \& Barkhuizen, G. P. (2005). Analysing learner language. Oxford, NY: Oxford University Press.

Emaliana, I. (2017). Teacher-centred or student-centred learning approach to promoting learning? Journal of Social Humanities, 10(2), 59-70.

Emapsworld of LPDR. (2017). Laos Province Maps. Retrieved September 2, 2017 from http://www.emapsworld.com/laos-provinces-map.html

Emerson, R. M., Fretz, R. I., \& Shaw, L. L. (2011). Writing ethnographic fieldnotes (2 ed.). Chicago: The University of Chicago Press.

Engen, L., \& Hoien, T. (2002). Phonological skills and reading comprehension. Reading and Writing: An Interdisciplinary Journal, 15(7-8), 613-631. doi:

10.1023/A:1020958105218

England, N. (2017). Developing an interpretation of collective beliefs in language teacher cognition research. TESOL Quarterly, 51(1), 229-238. doi: 10.1002/tesq.334

Ennis, R. H. (1993). Critical thinking assessment. Theory into Practice, 32(3), 179-186. doi: $10.1080 / 00405849309543594$

Entwistle, N., Skinner, D., Entwistle, D., \& Orr, S. (2000). Conceptions and beliefs about "Good teaching": An integration of contrasting research areas. Higher Education Research \& Development, 19(1), 5-26. doi: 10.1080/07294360050020444

Farrell, T. S. C. (2002). Lesson planning. Methodology in language teaching: An anthology of current practice (pp. 30-39). New York: Cambridge University Press.

FED. (2017). Educational statistics and information. Vientiane, LPDR: National University of Laos. 
Feng, Z. (2014). Using teacher questions to enhance EFL students' critical thinking ability. Journal of Curriculum and Teaching, 2(2), p147.

Fernandez-Toledo, P., \& Salager-Meyer, F. (2009). Approaches to English as a foreign language reading comprehension: Research and pedagogy. International Journal of English Studies, 9(2), 1-6.

Field, A. (2005). Discovering statitistics using SPSS (2 ed.). London: Sage Publication.

Fisher, D., \& Frey, N. (2010). Building and activating background knowledge. Principal Leadership, 11(4), 62-64.

Fisher, D., \& Frey, N. (2012). Background knowledge: The overlooked factor in reading comprehension. New York: Mc Graw Hill Education.

Flavell, J. H. (1978). Metacognitive development. In J. M. Scandura \& C. J. Brainerd (Eds.), Structural/process theories of complex human behavior (pp. 213-245). Amsterdam, The Netherlands: Sijthoff and Noordhoff.

Flavell, J. H. (1979). Metacognition and cognitive monitoring: A new area of cognitivedevelopmental inquiry. American Psychologist, 34(10), 906-911.

Flynn, L. L. (1989). Developing critical reading skills through cooperative problem solving. The Reading Teacher, 42(9), 664-668.

Foster, P., \& Ohta, A. S. (2005). Negotiation for meaning and peer assistance in second language classrooms. Applied Linguistics, 26(3), 402-430.

Fredricks, J. A., Blumenfeld,P. C., \& Paris, A. H. (2004). School engagement: Potential of the concept, state of the evidence. Review of Educational Research, 74(1), 59-109.

Fredricks, J. A., \& McColskey, W. (2012). The measurement of student engagement: A comparative analysis of various methods and student self-report instruments. In S. L. Christenson, A. L. Reschly \& C. Wylie (Eds.), Handbook of research on student engagement (pp. 763-782). Boston, MA: Springer US.

Gettinger, M., \& Walter, M. J. (2012). Classroom strategies to enhance academic engaged time. In S. L. Christenson, A. L. Reschly \& C. Wylie (Eds.), Handbook of research on student engagement (pp. 653-673). New York, NY: Springer US.

Ghufron, M. A. (2016). Process-genre approach, product approach, and students' selfesteem in teaching writing. Indonesian EFL Journal: Journal of ELT, Linguistics, and Literature, 2(1), 37-54. 
Golafshani, N. (2003). Understanding reliability and validity in qualitative research. The Qualitative Report, 8(4), 597-606.

Grabe, W. (1991). Current developments in second language reading research. TESOL Quarterly, 25(3), 375-406.

Grabe, W. (2000). Textual coherence and discourse analysis. Australian Review of Applied Linguistics(16), 65-82.

Grabe, W. (2003). Using discourse patterns to improve reading comprehension. Paper presented at the Proceeding of the 2002 JALT Conference, Tokyo, Japan.

Grabe, W. (2009). Reading in a second language: Moving from theory to practice. Cambridge: Cambridge University Press.

Grabe, W. (2010). Reading in a second language (2nd ed.). Oxford, UK: Oxford University Press.

Grabe, W., \& Stoller, F. L. (2011). Teaching and researching reading (2 ed.). Longman: Pearson.

Green, S. B., \& Salkind, N. J. (2011). Using SPSS for windows and macintosh: Analyzing and understanding data (6th ed.). Boston: Prentice Hall.

Guthrie, J. T. (2004). Teaching for literacy engagement. Journal of Literacy Research, $61(1), 1-29$.

Guthrie, J. T., \& Cox, K. E. (2001). Classroom conditions for motivation and engagement in reading. Educational Psychology Review, 13(3), 283-302.

Guthrie, J. T., Wigfield, A., \& You, W. (2012). Instructional contexts for engagement and achievement in reading. In S. L. Christenson, A. L. Reschly \& C. Wylie (Eds.), Handbook of research on student engagement (pp. 601-634). Boston, MA: Springer US.

Halim, S. M. A. (2011). Improving EFL majors' critical reading skills and political awareness: A proposed translation program. International Journal of Educational Research, 50(5-6), 336-348.

Hamm, S., \& Robertson, I. (2010). Preferences for deep-surface learning: A vocational education case study using a multimedia assessment activity. Australasian Journal of Educational Technology, 26(7), 951-965. 
Hamza, M. K., \& Griffith, K. G. (2006). Fostering problem solving \& creative thinking in the classroom: Cultivating a creative mind. National Forum of Applied Educational Research Journal -Electronic, 19(3), 1-30.

Hardebeck, M. (2006). Effectiveness and usage of reading comprehension strategies for second grade Title 1 students. (Unpublished Master Thesis), Minesota State University, Minesota.

Harris, M. J., \& Rosenthal, R. (1985). Mediation of interpersonal expectancy effects: 31 Meta-Analyses. Psychological Bulletin, 97(3), 363-386. doi: 10.1037/00332909.97.3.363

Hartman, H. J. (1998). Metacognition in teaching and learning: An introduction. Instructional Science, 26(1), 1-3. doi: 10.1023/A:1003023628307

Hashemi, S. Z., \& Borhani, A. (2014). The significance of syntactic knowledge in reading comprehension test performance. Modern Journal of Language Teaching Methods, $4(4), 49-56$.

Hatzidaki, A., Santesteban, M., \& Duyck, W. (2018). Is language interference a graded or an all-or-none effect? Evidence from bilingual reported speech production. Bilingualism: Language and Cognition, 21(3), 489-504. doi: 10.1017/S1366728917000736

Hausman, C. S., \& Goldring, E. B. (2001). Sustaining teacher commitment: The role of professional communities. Peabody Journal of Education, 76(2), 30-51.

Haydon, T., Marsicano, R., \& Scott, T. M. (2013). A comparison of choral and individual responding: A review of the literature. Preventing School Failure, 57(4), 181-188. doi: 10.1080/1045988X.2012.682184

Hayes, G. (2015). Population situation analysis: LPDR. Retrieved June 2, 2017 from http://lao.unfpa.org/sites/asiapacific/files/pub-pdf/PSA\%20LAYOUT.pdf

Heigham, J., \& Sakui, K. (2009). Ethnography. In J. Heigham \& R. A. Croker (Eds.), Qualitative research in applied linguistics: A practical introduction (pp. 91-111). New York, USA: Palgrave Macmillan.

Hellekjær, G. O. (2009). Academic English reading proficiency at the university level: A Norwegian case study. Reading in a Foreign Language, 21(2), 198-222.

Herrenkohl, L. R., \& Guerra, M. R. (1998). Participant structures, scientific discourse, and student engagement in fourth grade. Cognition and Instruction, 16(4), 431-473. doi: $10.1207 /$ s1532690xci1604_3 
Hiebert, E. H., \& Daniel, M. (2018). Comprehension and rate during silent reading: Why do some students do poorly? Reading and Writing, 32(7), 1795-1818.

Hohenbrink, J., Johnston, M., \& Westhoven, L. (1997). Collaborative teaching of a social studides methods course: Intimidation and change. Journal of Teacher Education, 48(4), 293-300. doi: 10.1177/0022487197048004007

Holsgrove, J. V., \& Garton, A. F. (2006). Phonological and syntactic processing and the role of working memory in reading comprehension among secondary school students. Australian Journal of Psychology, 58(2), 111-118. doi: 10.1080/00049530600730476

Hooper, T. (2016). Improving academic writing through thinking routines. Kwansei Gakuin University Humanities Review, 20, 47-63.

Horwitz, E. (1995). Beliefs about Language Learning. International Journal of Educational Research, 23(7), 283-294.

Horwitz, E. K. (1988). The beliefs about language learning of beginning university foreign language students. The Modern Language Journal, 72(3), 283-294.

Hu, M., \& Nation, P. (2000). Unknown vocabulary density and reading comprehension. Reading in a Foreign Language, 13, 403-430.

Hudson, T. (2007). Teaching second language reading. Oxford: Oxford University Press.

Hughes, A. (1989). Testing for language teachers (15ted.). Cambridge: Cambridge University Press.

Hunter, D. A. (2014). A practical guide to critical thinking: Decidng what to do and believe (2nd ed.). Hoboken, New Jersey: John Wiley \& Sons.

Hunter, J. D., \& Yates, J. (2002). In the Vanguard of Globalization: The World of American Globalizers. In P. L. Berger \& S. P. Huntington (Eds.), Many globalizations: Cultural diversity in the contemporary world (pp. 323-357). Oxford, UK: Oxford University Press.

IELTS. (2017). Free IELTS practice activities and resources. Manchester, Britain: British Council.

Irfan, H., \& Shelina, B. (2016). Bloom's Taxonomy (cognitive Domain) in higher education settings: Reflection brief. Journal of Education and Educational Development, 3(2), 288-300. doi: 10.22555/joeed.v3i2.1039 
Irvin, J. L. (1990). Reading and middle school student: Strategies to enhance literacy. Boston, MA: Allyn \& Bacon.

Iser, W. (1972). The reading process: A phenomenological approach. New literary history, $3(2), 279-299$.

Ivankova, N. V., \& Creswell, J. W. (2009). Mixed Methods. In J. Heigham \& R. A. Croker (Eds.), Qualitative research in applied linguistics: A practical Introduction (pp. 135161). New York, NY: Palgrave Macmillan.

Iwai, Y. (2011). The effects of metacognitive reading strategies: Pedagogical implications for EFL/ESL teachers. The Reading Matrix, 11(2), 150-159.

Iwai, Y., Filce, H., \& Ramp, E. (2011). Academic English reading for international college students: The role of metacognitive reading strategies. Research in the Schools, 18(2), 75-88.

Jacobs, G. M., \& Farrell, T. S. (2003). Understanding and Implementtng the CLT (Communicative Language Teaching) Paradigm. The Regional English Language Centre Journal, 34(1), 5-30.

Jenkins, J. R., Stein, M. L., \& Wysocki, K. (1984). Learning vocabulary through reading. American Educational Research Journal, 21(4), 767-787.

Jiang, X. (2012). Effects of discourse structure graphic organizers of EFL reading comprehension. Reading in a Foreign Language, 24(1), 84-105.

Jiang, Y. (2015). Chinese college students' English reading comprehension in silent and loud reading mode. English Language Teaching, 8(4), 24-30.

Johnson, D. W., \& Johnson, R. T. (1989). Cooperation and competition: Theory and research. Edina, MN: Interaction.

Johnson, D. W., \& Johnson, R. T. (2009). An educational psychology success story: Social interdependence theory and cooperative learning. Educational Researcher, 38(5), 365-379. doi: 10.3102/0013189X09339057

Johnson, R. B., Teddlie, C., \& Tashakkori, A. (2012). Common "core" characteristics of mixed methods research. American Behavioral Scientist, 56(6), 774-788. doi: $10.1177 / 0002764211433795$

Johnston, P. (1984). Prior knowledge and reading comprehension test bias. Reading Research Quarterly, 19(2), 219. doi: 10.2307/747364 
Jurasaite-Harbison, E., \& Rex, L. A. (2010). School cultures as contexts for informal teacher learning. Teaching and Teacher Education, 26(2), 267-277. doi: 10.1016/j.tate.2009.03.012

Kasper, G. (2015). Conducting interivews. In J. D. Brown \& C. Coombe (Eds.), The Cambridge guide to research in language teaching and learning (pp. 209-216). Cambridge: Cambridge University Press.

Kayode, G. M. (2015). Impacts of teachers' time management on secondary school students' academic performance in Ekiti State, Nigeria. International Journal of Secondary Education, 3(1), 1-7. doi: 10.11648/j.ijsedu.20150301.11

Kelley, T. D., \& Sharif, N. M. (2005). Understanding the mindset of higher education CIOs. Educause Quarterly, 28(4), 33-43.

Kelly, P. (2006). What is teacher learning? A social-cultural perspective. Oxford Review of Education, 32(4), 505-519.

Kennedy, C. (1988). Evaluation of the management of change in ELT projects. Applied Linguistics, 9(4), 329-342.

Kennedy, C., \& Kennedy, J. (1996). Teacher attitudes and change implementation. System, 24(3), 351-360. doi: 10.1016/0346-251X(96)00027-9

Kern, R. G. (2008). The role of mental translation in second language reading. Studies in second language acquisition, 16(4), 441-461. doi: 10.1017/S0272263100013450

Kheirzadeh, S., \& Tavakoli, E. (2012). The causes of reading difficulty: The perception of Iranian EFL post-graduate and under-graduate students. Journal of Language Teaching and Research, 3(1), 147-152.

Khoshsima, H., \& Tiyar, F. R. (2014). The effect of summarizing strategy on reading comprehension of Iranian intermediate EFL learners. International Journal of Language and Linguistics, 2(3), 134-139. doi: 10.11648/j.ijll.20140203.11

King, E., \& Walle, D. (2010). Indigenous peoples, poverty and development. World Bank: USA.

Kitzinger, J. (1995). Introducing focus groups. British Medical Journal, 311(7000), 299302.

Kobayashi, M. (2002). Method effects on reading comprehension test performance: text organization and response format. Language Testing, 19(2), 193-220. doi: 10.1191/0265532202lt227oa 
Koda, K. (1987). Cognitive strategy transfer in second language reading. In J. Devine, P. Carrell \& D. E. Eskey (Eds.), Research in Reading in English as a Second Language (pp. 125-144). Washington, D. C: Teachers of English to Speakers of Other Languages (TESOL).

Koda, K. (2007). Reading and language learning: Crosslinguistic constraints on second language reading development. Language Learning, 57(1), 1-44. doi: 10.1111/j.1467-9922.2007.00411.x

Kostons, D., \& Werf, G. V. D. (2015). The effects of activating prior topic and metacognitive knolwedge on text comprehension scores. British Journal of Educational Psychology, 85(3), 264-275.

Kotrlik, J. W., Williams, H. A., \& Jabor, M. K. (2011). Reporting and interpreting effect size in quantitative agricultural education research. Journal of Agricultural Education, 52(1), 132. doi:10.5032/jae.2011.01132

Krashen, S. D. (2004). The power of reading: Insights from the research (2 ed.). Westport, Conn: Libraries Unlimited.

Krippendorff, K. (2004). Content analysis: An introduction to its methology. London, UK: Sage.

Krueger, R. A., \& Casey, M. A. (2009). Focus groups: A practical guide for applied research (4 ed.). Thousand Oaks, CA: Sage.

Kubanyiova, M., \& Feryok, A. (2015). Language teacher cognition in applied linguistics research: Revisiting the territory, redrawing the boundaries, reclaiming the relevance [Special issue]. Modern Language Journal, 99(3), 435-636. doi: $10.1111 /$ modl.12239

Kuzborska, I. (2011). Links between teachers' beliefs and practices and research on reading. Reading in a Foreign Language, 23(1), 102-128.

Lachanthaboune, S., Somsanith, P., \& Lee, Y. (2008). The Development of Education. Paper presented at the International Conference on Education, Geneva, Switzerland.

Lam, Y. (2000). Technophilia vs. technophobia: A preliminary look at why secondlanguage teachers do or do not use technology in their classrooms. Canadian Modern Language Review, 56(3), 389-420.

Lao People's Democratic Republic. (2016). World bank: Washington, USA.

Lao People's Revolutionary Party. (2016). 10th congress. Vientiane, Laos: Prime Minister's Office. 
Larsen-Freeman, D., \& Anderson, M. (2011). Techniques \& principles in language teaching. Oxford, NY: Oxford University Press.

Laufer, B. (1989). What percentage of text lexis is essential for comprehension? In L. n. Christer \& N. Marianne (Eds.), Special language: From humans thinking to thinking machines (pp. 316-323). Clevedon, UK: Multilingual Matters.

Laufer, B., \& Ravenhorst-Kalovski, G. C. (2010). Lexical threshold revisited: Lexical text coverage, learners' vocabulary size and reading comprehension. Reading in a Foreign Language, 22(1), 15.

Law on Education. (2007). National assembly. Vientiane: Laos.

Lee, I. (2017). Classroom writing assessment and feedback in L2 school contexts. Singapore: Springer.

Lin, D., Wong, K., \& McBride-Chang, C. (2012). Reading motivation and reading comprehension in Chinese and English among bilingual students. An Interdisciplinary Journal, 25(3), 717-737. doi: 10.1007/s11145-011-9297-8

Linck, L. J., Wolberg, R. L., \& Salmon, A. K. . (2012). Creating a culture of thinking that cultivates the perspective-taking disposition. Paper presented at the Proceedings of the 11th Annual College of Education \& GSN Research Conference (pp.99-104), Miami: Florida International University.

Lincoln, Y. S., \& Guba, E. G. (1985). Naturalistic inquiry. Beverly Hills, Calif: Sage Publications.

Lortie, D. C. (1975). Schoolteacher: A sociological study. Chicago: University of Chicago Press.

Macalister, J. (2010). Investigating teacher attitudes to extensive reading practices in higher education: Why isn't everyone doing it? RELC Journal, 41(1), 59-75. doi: $10.1177 / 0033688210362609$

Macalister, J. (2011). Today's teaching, tomorrow's text: Exploring the teaching of reading. ELT Journal, 65(2), 161-169. doi: 10.1093/elt/ccq023

Macalister, J. (2012). Pre-service teacher cognition and vocabulary teaching. RELC Journal, 43(1), 99-111. doi: 10.1177/0033688212439312

Macalister, J. (2014). Teaching reading: Research into practice. 47(3), 387-397. doi: $10.1017 /$ S026144481400007X 
Macalister, J. (2016a). Adapting and adopting materials. Issues in Material Development, 57-64.

Macalister, J. (2016b). Tracing it back: Identifying the impact of a trans-national language teacher education programme on classroom practice. RELC Journal, 47(1), 59-70. doi: doi: 10.1177/0033688216631204

Mackey, A. (2016). Second language research: Methodology and design (2nd ed.). London: Routledge.

Mackey, A., \& Gass, S. M. (2005). Second language research: Methodology and design. New Jersey: Lawrence Erlbaum Associates.

MacKinnon, A., \& Thepphasoulithone, P. (2014). Educational reform in Laos: A case study. International Journal of Educational Studies, 1(1), 19-34.

Maguire, M., \& Delahunt, B. (2017). Doing a thematic analysis: A practical, step-by-step guide for learning and teaching scholars. All Ireland Journal of Teaching and Learning in Higher Education, 8(3), 3351-33514.

Majida Mohammed Yousef, D. (2016). Using thinking routines as a pedagogy for teaching English as a second language in Palestine. Journal of Educational Research and Practice, 6(1), 1-18.

Malmkjaer, K. (1998). Translation and language teaching. Manchester: Jerome.

Mano, Q. R., \& Guerin, J. M. (2018). Direct and indirect effects of print exposure on silent reading fluency. Reading and Writing, 31(2), 483-502.

Manolom, T., Promphakping, B., \& Mee-Udon, F. (2015). The local connection of wellbeing in Lao social cultural construction. Asian Social Science, 11(3), 78-90.

Marin, L. M., \& Halpern, D. F. (2011). Pedagogy for developing critical thinking in adolescents: Explicit instruction produces greatest gains. Thinking Skills and Creativity, 6(1), 1-3.

Marshall, C. (1991). Teachers' learning styles: How they affect student learning. The Clearing House, 64(4), 225-227. doi: 10.1080/00098655.1991.9955852

Martin, J. R. (2008). Genre relations: mapping culture. London: Equinox Pub.

Mattheoudakis, M. (2007). Tracking changes in pre-service EFL teacher beliefs in Greece: A longitudinal study. Teaching and Teacher Education: An International Journal of Research and Studies, 23(8), 1272-1288. doi: 10.1016/j.tate.2006.06.001 
McAvoy, J. (2008). Essential Reading 2. Oxford: Macmillan.

Mckay, S. L. (2006). Researching second language classrooms: ESL \& applied linguistics professional series. Mahwah, NJ: Lawrence Erlbaum.

McKenzie, R. M. (2008). Social factors and non-native attitudes towards varieties of spoken English: a Japanese case study. International Journal of Applied Linguistics, 18(1), 68-88.

Meadows, K. A. (2003). Questionnaire design. British Journal of Community Nursing, $8(12), 562-570$.

Medina, L. (2012). Effects of strategy instruction in an EFL reading comprehension course: A case study. Profile Issues in Teachers Professional Development, 14(1), 79-89.

Medina, P. (Producer). (2001). The intricacies of initiate-response-evaluate in adult literacy education. Adult Education Research Conference. Retrieved from https://newprairiepress.org/aerc/2001/papers/49/

Menkabu, A., \& Harwood, N. (2014). Teachers' conceptualization and use of the textbooks on medical English course. In N. Harwood (Ed.), English language teaching textbooks: Content, consumption, production (pp. 145-177). Basingstoke: Palgrave Macmillan.

Merton, R. K. (1972). Insiders and Outsiders: A chapter in the sociology of knowledge. American Journal of Sociology, 78(1), 9-47. doi: 10.1086/225294

Ministry of Education and Sports. (2008). National education reform strategy 2006-2015. Ministry of Education and Sports: Vientiane, LPDR.

MoES. (2009). Education sector development framework 2009-2015. Ministry of Education and Sports: Vientiane, LPDR.

MoES. (2015b). Education and sports sector development plan (2016-2020). Vientiane, LPDR: Ministry of Education and Sports.

MoES. (2015c). Education vision to 2030, strategy to 2025 and education sector development plan (2016-2020). Vientiane, LPDR: Ministry of Education and Sports.

Mohammadi, E. N., Heidari, F., \& Niri, N. D. (2012). The relationship between critical thinking ability and reading strategies used by Iranian EFL Learners. English Language Teaching, 5(10), 192-201. doi: 10.5539/elt.v5n10p192 
Mokhtari, K., \& Reichard, C. A. (2002). Assessing students' metacognitive awareness of reading strategies. Journal of Educational Psychology, 94(2), 249-259. doi: 10.1037/0022-0663.94.2.249

Mokhtari, K., \& Sheorey, R. (2002). Measuring ESL students' awareness of reading strategies. Journal of Developmental Education, 25(3), 2-10.

Morvay, G. (2012). The Relationship between syntactic knowledge and reading comprehension in EFL learners. Studies in Second Language Learning and Teaching, 2(3), 415-438. doi: 10.14746/ssllt.2012.2.3.8

Mount, R. (2006). Making thinking visible. Idiom, 42(3), 5-10.

Mulcare, D. M., \& Shwedel, A. (2017). Transforming Bloom's Taxonomy into classroom practice: A practical yet comprehensive approach to promote critical reading and sudent participation. Journal of Political Science Education, 13(2), 121-137.

Mumford, M. D., Medeiros, K. E., \& Parlow, P. J. (2012). Creative thinking: Processes, strategies, and knowledge. The Journal of Creative Behavior, 46(1), 30-37.

Murphy, J. P. (1990). Pragmatism: From peirce to davidson. Boulder, CO: Westview Press.

Murtiningsih, S. R., \& Hapsari, W. (2018). Teaching reading to encourage critical thinking and collaborative work. In A. Burn \& J. Siegel (Eds.), International Perspectives on Teaching the Four Skills in ELT (pp. 153-165). Palgrave Macmillan: Cham.

Natalia, I. V., \& Greer, J. L. (2015). Mixed methods research and analysis. In B. Paltridge \& A. Phakiti (Eds.), Research Methods in Applied Linguistics (pp. 63-81). New York, USA: Bloomsbury.

Nation, I. S. P. (2006). How large a vocabulary is needed for reading and listening? The Canadian Modern Language Review, 63(1), 59-81.

Nation, I. S. P. (2009a). Teaching ESL/EFL reading and writing. New York: Routledge.

Nation, I. S. P. (2009b). Teaching ESL/EFL Reading and Writing. ESL and Applied Linguistics Professional Series: Taylor \& Francis.

Nation, I. S. P., \& Ming-Tzu, K. W. (1999). Graded readers and vocabulary. Reading in a Foreign Language, 12(2), 355-380.

Nation, I. S. P. (2007). The Four Strands. Innovation in Language Learning and Teaching, 1(1), 2-13. doi: 10.2167/illt039.0 
Nation, I. S. P. (2009c). Reading faster. International Journal of English Studies, 9(2), 131144.

Nation, I. S. P., \& Macalister, J. (2010). Language curriculum design. New York \& London: Routledge.

National Assembly. (2003). Constitution of Laos. Vientiane, Laos: National Assembly.

National University of Laos. (2010). Bachelor of education in English pedagogy. Vientiane, LPDR: National University of Laos.

$\mathrm{Ng}$, C., \& Brendan, B. (2017). Improving reading and reading engagement: An international focus. In C. NG \& B. Bartlett (Eds.), Improving reading and reading engagement in the 21st century (pp. 3-16). Brisban, Australia: Springer.

Nordström, C. S. (2001). Qualitative research requires quality concepts of its own. Management Decision, 39(7), 551-556. doi: 10.1108/EUM0000000005801

Nowell, L. S., Norris, J. M., White, D. E., \& Moules, N. J. (2017). Thematic analysis: Striving to meet the trustworthiness criteria. International Journal of Qualitative Methods, 16(1). doi: $10.1177 / 1609406917733847$

NUOL. (2017). Vision and mission of National University of Laos. Vientiane, Laos.

Nuttall, C. (1996). Teaching reading skills in a foreign language. Oxford: Macmillan Heinemann.

Onwuegbuzie, A. J., \& Leech, N. L. (2007). Sampling designs in qualitative research: Making the sampling process more public. The Qualitative Report, 12(2), 238-254.

Ozmen, K. S. (2012). Exploring student teachers' beliefs about language learning and teaching: A longitudinal study. Current Issues in Education, 15(1), 1-16.

Padberg, B. (1997). Theories in use: A comparison of reading models, their application to the classroom and their influence in German reading textbooks at the intermediate level of language instruction. (Doctoral Dessertation), New York University, USA.

Pajares, M. F. (1992). Teachers' beliefs and educational research: Cleaning up a messy construct. Review of Educational Research, 62(3), 307-332. doi: $10.3102 / 00346543062003307$

Palfreyman, D. M. (2015). Ethnography. In J. D. Brown \& C. Coombe (Eds.), The Cambridge guide to research in language teaching and learning (pp. 146-154). Cambridge: Cambridage University Press. 
Palinkas, L. A., Horwitz, S. M., Green, C. A., Wisdom, J. P., Duan, N., \& Hoagwood, K. (2015). Purposeful sampling for qualitative data collection and analysis in mixed method implementation research. Administration and Policy in Mental Health and Mental Health Services Research, 42(5), 533-544.

Pallant, J. (2013). SPSS survival manual: A step by step guide to data analysis using SPSS for Windows (5 ed.). Crows Nest: Allen \& Unwin.

Pang, J. (2008). Research on good and poor reader characteristics: Implications for L2 reading research in China. Reading in a Foreign Language, 20(1), 1-18.

Pardo, L. S. (2004). What every teacher needs to know about comprehension. The Reading Teacher, 58(3), 272-280.

Paris, S. G., Wasik, B. A., \& Turner, J. C. (1991). The development of strategic readers. In R. Barr, M. L. Kamil, P. B. Mosenthal \& P. D. Pearson (Eds.), Handbook of Reading Research (pp. 609-640). New York and London: Longman.

Patton, M. Q. (1990). Qualitative evaluation and research methods (2 ed.). Newbury Park, CA: Sage.

Paul, R., \& Elder, L. (1992). The minature guide to critical thinking: Concepts and tools. CA, USA: The Foundation for Critical Thinking.

Peacock, M. (2001). Pre-service ESL teachers' beliefs about second language learning: A longitudinal study. System, 29(2), 177-195.

Perkins, D. (2009). Making learning whole: How seven principles of teaching can transform education. San Francisco, CA: Jossey-Bass.

Perkins, D., Tishman, S., Ritchhart, R., Donis, K., \& Andrade, A. (2000). Intelligence in the wild: A dispositional view of intellectual traits. Educational Psychology Review, 12(3), 269-293. doi: 10.1023/A:1009031605464

Perlazzo, L., \& Sypnieski, K. H. (2018). Activating prior knolwedge. In L. Perlazzo \& K. H. Sypnieski (Eds.), The teacher's toolbox: Hundreds of pratical ideas to support your students (pp. 57-63). New Jersey: Jossey-Bass.

Phetsiriseng, I. (2009). Education reform context and progress in LPDR: Focusing on basic education. In Y. Hirosato \& Y. Kitamura (Eds.), The political economy of educational reforms and capacity development in Southeast Asia: Cases of Cambodia, Laos and Vietnam (pp. 265-282). UNESCO: Springer.

Philp, J., \& Duchesne, S. (2016). Exploring engagement in tasks in the language classroom. Annual Review of Applied Linguistics, 36, 50-72. 
Pintrich, P. R. (2002). The role of metacognitive knowledge in learning, teaching, and assessing. Theory into Practice, 41(4), 219-225. doi: 10.1207/s15430421tip4104_3

Pintrich, P. R., \& Groot, E. V. D. (1990). Motivational and self-regulated learning components of classroom academic performance. Journal of Educational Psychology, 82(1), 33-40. doi: 10.1037/0022-0663.82.1.33

Pohl, M. (2012). Developing a classroom culture of thinking: A whole school approach. TEACHJournal of Christain Education, 5(1), 7-9.

Population Statistics. (2017). Laos Population. Retrieved May 15, 2017 from http://worldpopulationreview.com/countries/laos-population/

Pressley, M. (2006). Reading instruction that works: The case for balanced teaching (3rd ed.). New York: Guilford Press.

Prior, A., Goldina, A., Shany, M., Geva, E., \& Katzir, T. (2014). Lexical inference in L2: predictive roles of vocabulary knowledge and reading skill beyond reading comprehension. An Interdisciplinary Journal, 27(8), 1467-1484. doi: 10.1007/s11145-014-9501-8

Pritchard, R. (1990). The effects of cultural schemata on reading processing strategies. Reading Research Quarterly, 25(4), 273-295.

Punch, K. F. (2009). Introduction to research methods in education. Thousand Oaks, CA: Sage.

Purpura, J. E., Brown, J. D., \& Schoonen, R. (2015). Improving the validity of quantitative measures in applied linguistics research. Language Learning, 65(1), 37-75. doi: 10.1111/lang.12112

Ramli, N. H., Ahmad, S., Taib, M. Z. M., \& Masri, M. (2014). Principals' perception on classroom physical environment. Social and Behavioral Sciences, 153, 266-273. doi: $10.1016 /$ j.sbspro.2014.10.060

Renandya, W. A., Lee, L. W., Wah, C. L. K., \& Jacobs, G. M. (1999). A Survey of English language teaching trends and practices in Southeast Asia. Asian Englishes, 2(1), 37-65. doi: 10.1080/13488678.1999.10801018

Richards, J. C. (2001). The role of textbooks in a language program. Retrieved August 30, 2017 from http://www.finchpark.com/courses/tkt/Unit 23/role-oftextbooks.pdf 
Richards, J. C. (2017). Teaching English through English: Proficiency, pedagogy and performance. RELC Journal, 48(1), 7-30. doi: 10.1177/0033688217690059

Richards, K. (2009). Interviews. In J. Heigham \& R. A. Croker (Eds.), Qualitative research in applied linguistics: A practical introduction (pp. 182-199). New York: Palgrave Macmillan.

Richardson, C., \& Mishra, P. (2018). Learning evironments that support student creativity: Developing the SCALE. Thinking Skills and Creativity, 27, 45-54.

Richardson, V., \& et al. (1991). The Relationship between Teachers' Beliefs and Practices in Reading Comprehension Instruction. American Educational Research Journal, 28(3), 559-586.

Ritchhart, R. (2000). Developing intellectual character: A dispositional perspective on teaching and learning. ProQuest Dissertations Publishing.

Ritchhart, R. (2001). From IQ to IC: A dispositional view of intelligence. Roeper Review, 23(3), 143-150.

Ritchhart, R. (2002). Intellectual character: What it is, why it matters, and how to get it. San Francisco: Jossey-Bass.

Ritchhart, R. (2011a). Teacher institutes: Creating powerful learning opportunities. Retrieved August 5, 2017 from https://www.youtube.com/watch?v=da0VF/zllfw

Ritchhart, R. (2012). Creating a culture where thinking and understanding can thrive. Retrieved June 5, 2017 from https://www.youtube.com/watch?v=faXX-hETf68

Ritchhart, R. (2015). Creating cultures of thinking: The 8 forces we must master to truly transform our schools. San Francisco, CA: Jossey-Bass.

Ritchhart, R., Church, M., \& Morrison, K. (2011). Making thinking visible: How to promote engagement, understanding, and independence for all learners. San Francisco, CA: Jossey-Bass.

Ritchhart, R., Church, M., \& Morrison, K. (2011b). Making thinking visible: how to promote engagement, understanding, and independence for all learners. British Journal of Learning Support, 27(2).

Ritchhart, R., \& Perkins, D. (2008). Making thinking visible. Educational Leadership, 65(5), 57-61.

Ritchhart, R., Perkins, D., \& Turner, T. (2007). Cultures of thinking. Project Zero at Harvard Graduate School of Education: Update on Current Work. 
Ritchhart, R., \& Perkins, D. N. (2005). Learning to think: The challenges of teaching thinking. University of Cambridge: Cambride University Press.

Ritchhart, R., Turner, T., \& Hadar, L. (2009). Uncovering students' thinking about thinking using concept maps. Metacognition and Learning, 4(2), 145-159. doi: $10.1007 / \mathrm{s} 11409-009-9040-\mathrm{x}$

Robinson, K. (2010). Changing education paradigms. Retrieved June 19, 2017 from http://www.thersa.org

Robinson, K. (2013). Ken Robinson: How to change education [video file]. Retrieved from https://www.youtube.com/watch?v=BEsZOnyQzxQ

Rose-Duckworth, R., \& Ramer, K. (2009). Fostering learner independence: An essential guide for K-6 educators. Thousand Oaks, CA: Corwin Press.

Roseth, C. J., Johnson, D. W., \& Johnson, R. T. (2008). Promoting early adolescents' achievement and peer relationships: The effects of cooperative, competitive, and individualistic goal structures. Psychological Bulletin, 134(2), 223-246.

Ruggiero, V. R. (2011). Beyond Feelings: A guide to critical thinking (9th ed.). New York, USA: McGraw Hill.

Saengouthay, O. (2016). The influence of non-governmental organisations (NGOs) on primary education policy in Laos. (Unpublished Master's Thesis), Victoria University of Wellington, New Zealand.

Salmon, A. K. (2008a). Promoting a culture of thinking in the young child. Early Childhood Education Journal, 35(5), 457-461. doi: 10.1007/s10643-007-0227-y

Salmon, A. K. (2008b). Young English language learners making thinking and language visible. Colombian Applied Linguistics Journal(10), 126-141.

Salomon, G., \& Perkins, D. N. (1998). Individual and social aspects of learning. Review of Research in Education, 23, 1-24.

Saunders, B., Sim, J., Kingstone, T., Baker, S., Waterfield, J., Bartlam, B., . . B Burroughs, H. (2018). Saturation in qualitative research: exploring its conceptualization and operationalization. International Journal of Methodology, 52(4), 1893-1907. doi: 10.1007/s11135-017-0574-8

Schadler, M., \& Thissen, D. M. (1981). The development of automatic word recognition and reading skills. Meory and Cognition, 9(2), 132-141. 
Schaffner, C. (1998). Qualification for professional translators: Translation in language teaching versus teaching translation. Manchester: Jerome.

Schmitt, N., Jiang, X., \& Grabe, W. (2011). The percentage of words known in a text and reading comprehension. Modern Language Journal, 95(1), 26-43. doi: 10.1111/j.1540-4781.2011.01146.x

Schneider, M., Rittle-Johnson, B., \& Star, J. R. (2011). Relations among conceptual knowledge, procedural knowledge, and procedural flexibility in two samples differing in prior knowledge. Developmental Psychology, 47(6), 1525-1538. doi: $10.1037 / \mathrm{a} 0024997$

Schraw, G., \& Moshman, D. (1995). Metacognitive theories. Educational Psychology Review, 7(4), 351-371. doi: 10.1007/BF02212307

Scott, J. (1990). A matter of record : documentary sources in social research. Cambridge, U.K: Polity Press.

Scrivener, J. (2012). Classroom management techniques. Cambridge, UK: Cambridge University Press.

Seliger, H. W., \& Shohamy, E. G. (1989). Second language research methods. Oxford: Oxford University Press.

Shapiro, S. S., \& Wilk, M. B. (1965). An analysis of variance test for normality (complete samples). Oxford Journals, 52(3/4), 591-611.

Sharifirad, G. R., Rezaeian, M., Jazini, A., \& Etemadi, Z. S. (2012). Knowledge, attitude and performance of academic members regarding effective communication skills in education. Journal of Education and Health Promotion, 1(1), 8-13. doi: 10.4103/2277-9531.104812

Shein, P. P., \& Chiou, W. B. (2011). Teachers as role models for students' learning styles. Social Behavior and Personality: An International Journal, 39(8), 1097-1104.

Shernoff, D. J., Kelly, S., Tonks, S. M., Anderson, B., Cavanagh, R. F., Sinha, S., \& Abdi, B. (2016). Student engagement as a function of environmental complexity in high school classrooms. Learning and instruction, 43, 52-60. doi: 10.1016/j.learninstruc.2015.12.003

Sinclair, J. M., \& Coulthard, R. M. (1975). Towards an analysis of discourse: The English used by teachers and pupils. London: Oxford University Press.

Smith, R. (2007). Learner autonomy. ELT Journal, 62(4), 395-397. doi: $10.1093 /$ elt/ccn038 
Souriyavongsa, T., Rany, S., Abidin, M. J. Z., \& Mei, L. L. (2013). Factors causes students low English language learning: A case study in the National University of Laos. International Journal of English Language Education, 1(1), 179-192.

Stahl, S. A., Sinatra, R., \& Gregory, J. F. (1991). Defining the role of prior knowledge and vocabulary in reading comprehension: The retiring number 41. Journal of Reading Behaviour, 23(4), 487-508.

Starfield, S. (2015). Ethnographic Research. In B. Paltridge \& A. Phakiti (Eds.), Research methods in applied linguistics: A practical resource (pp. 137-152). New York, USA: Bloomsbury Academic.

Stebbins, R. A. (2001). Exploratory research in the social sciences. Thoudand Oaks, London: Sage.

Storch, N. (2002). Patterns of interaction in ESL pair work. Language Learning, 52(1), 119-158.

Stuart, H., \& Deluse, S. R. (2009). A critical review of Harvard's Project Zero. Issues in Integrative Studies, 27, 86-112.

Stürmer, K., Könings, K., \& Seidel, T. (2013). Declarative knowledge and professional vision in teacher education: Effect of courses in teaching and learning. British Journal of Educational Psychology, 83(3), 467-483.

Surjosuseno, T. T., \& Watts, V. (1999). Using Bloom's taxonomy to teach critical reading in English as a foreign language classes. Queensland Journal of Educational Research, 15(2), 227-244.

Suwanarak, K. (2012). English language learning beliefs, learning strategies and achievement of Masters students in Thailand. TESOL in Context, 3, 1-15.

Svalberg, A. M.-L. (2009). Engagement with language: Interrogating a construct. Language Awareness, 18(3-4), 242-258.

Tavakol, M., \& Dennick, R. (2011). Making sense of Cronbach's alpha. International Journal of Medical Education, 2, 53-55. doi: 10.5116/ijme.4dfb.8dfd

Taylor, L., \& Parsons, J. (2011). Improving student engagement. Current Issues in Education, 14(1), 1-33.

Taylor, L., \& Weir, C. J. (2012). Introduction. In L. Taylor \& C. J. Weir (Eds.), IELTS Collected Papers: Research in reading and listening assessment (pp. 1-33). Cambridge: Cambridge University Press. 
Teddlie, C., \& Yu, F. (2007). Mixed methods sampling: A typology with examples. Journal of Mixed-Methods Research, 1(1), 77-100.

Tennent, W. (2015). Understanding reading comprehension: Processes and practices: Los Angeles : SAGE.

The $8^{\text {th }}$ National Assembly Session. (2019). National Assemby. Vientiane, LPDR.

Thepphasoulithone, P. (2009). Reforming teacher education in Lao People's Democratic Republic. (Unpublished Doctoral Dessertation), Simon Fraser University, Burnaby, BC, Canada.

Thongphanheuangsy, P. (2014). Challenges facing English teacher training in Lao PDR: A study of the Faculty of Education, National University of Laos. (Unpublished Master's Thesis), Sophia University, Japan.

Tishman, S., Perkins, D. N., \& Jay, E. S. (1995). The thinking classroom: Learning and teaching in a culture of thinking: Allyn and Bacon.

Tomlinson, B. (2012). Materials development for language learning and teaching. Language Teaching, 45(2), 143-179. doi: 10.1017/S0261444811000528

Tran, T. (2018). Action research in the English language classroom. Modern English Teacher, 27(3), 6-9.

Tsai, C. C. (2005). Cognition and metacognition of English reading strategies in successful Taiwanese comprehensive high school student readers: Opportunities and obstacles. (Unpublised Doctoral Dissertation), University of Wyoming, USA.

Turner, J. C., Christensen, A., Kackar-Cam, H. Z., Trucano, M., \& Fulmer, S. M. (2014). Enhancing students' engagement: Report of a 3-year intervention with middle school teachers. American Educational Research Journal, 51(6), 1195-1226.

UNDAF 2012-2015. (2015). Country analysis report: Lao People's Democratic Republic. Retrieved February 19, 2017 from http://www.la.undp.org/content/dam/laopdr/docs/Legal\%20Framework/UND P LA CAR 2012 2015.pdf

UNESCO. (2011). World Data on Education. UNESCO, NY: International Bureau of Education.

Van Driel, J. H., Bulte, A. M. W., \& Verloop, N. (2007). The relationships between teachers' general beliefs about teaching and learning and their domain specific curricular 
beliefs. Learning and Instruction, 17(2), 156-171. doi:

10.1016/j.learninstruc.2007.01.010

Vellutino, F. R. (2003). Individual differences as sources of variability in reading comprehension in elementary school children. In A. P. Sweet \& C. E. Snow (Eds.), Rethinking reading comprehension (pp. 51-81). New York: Guilford Press.

Vibulphol, J. (2004). Beliefs about language learning and teaching approaches of preservice EFL teachers in Thailand. (Unpublised Doctoral dissertation), Oklahoma State University.

Viphavanh, P. (2014). Lao education policy and vision. Ministry of Education and Sports: LPDR.

Vongxay, H. (2013). The implementation of communicative language teaching (CLT) in an English department in a Lao higher educational institution: A case study. (Unpublished Master's Thesis), Unitec Institution of Technology, New Zealand.

Vygotsky, L. S. (1978). Mind in society. Cambridge: Havard University Press.

Wallace, C. (2003). Critical reading in language education. New York: Palgrave Macmillan.

Walsh, S. (2011). Exploring classroom discourse: language in action. New York: Routledge.

Wan, W., Low, G. D., \& Li, M. (2011). From students' and teachers' perspectives: Metaphor analysis of beliefs about EFL teachers' roles. An International Journal of Educational Technology and Applied Linguistics, 39(3), 403-415. doi: 10.1016/j.system.2011.07.012

Wang, H. C., \& Shih, S. C. (2011). The role of language for thinking and task selection in EFL Learners' oral collocational production. Foreign Language Annals, 44(2), 399416. doi: 10.1111/j.1944-9720.2011.01135.x

Wang, M. T. (2009). Effects of metacognitive reading strategy instruction on EFL high school students' reading comprehension, reading strategies awareness, and reading motivation. (Unpublished Doctoral Thesis), University of Florida, USA.

Wannarka, R., \& Ruhl, K. (2008). Seating arrangments that promote positive academic and behavioural outcomes: A review of empirical research. Support for Learning, 23(2), 89-93.

Weigle, S. C., Yang, W., \& Montee, M. (2013). Exploring reading processes in an academic reading test using short answer questions. Language Assessment Quarterly, 10(1), 28-48. doi: 10.1080/15434303.2012.750660 
Weinstein, C. S. (1979). The physical environment of the school: A review of the research. Review of Educational Research, 49(4), 577-610.

Wesely, P. M. (2012). Learner attitudes, perceptions, and beliefs in language learning. Foreign Language Annals, 45(1), 98-117. doi: 10.1111/j.1944-9720.2012.01181.x

Wigfield, A., Gladstone, J. R., \& Turci, L. (2016). Beyond cognition: Reading motivation and reading comprehension. Child Development Perspectives, 10(3), 190-195. doi: 10.1111/cdep.12184

Wilson, N. S., \& Bai, H. (2010). The relationships and impact of teachers' metacognitive knowledge and pedagogical understandings of metacognition. Metacognition and Learning, 5(3), 269-288.

Wittrock, M. C. (1991). Generative teaching of comprehension. The Elementary School Journal, 92(2), 169-184. doi: 10.1086/461686

Wong, M. S. L. (2010). Beliefs about language learning: A study of Malaysian pre-service teachers. RELC Journal, 41(2), 123-136. doi: 10.1177/0033688210373124

Woodrow, L. (2014). Writing about quantitative research in applied linguistics. Basingstoke, NY: Palgrave Macmillan.

Woods, A., Luke, A., \& Weir, K. (2010). Curriculum and syllabus Design. In P. Peterson, E. Baker \& B. McGaw (Eds.), International encyclopedia of education (3 ed ed., pp. 362-367). Oxford, England: Elsevier.

Woods, D. (1996). Teacher cognition in language teaching: Beliefs, decision-making, and classroom practice. Cambridge: Cambridge University Press.

Xiaohui, H., \& Li, S. (2011). Teacher cognition of intercultural communicative competence in the Chinese ELT context. Intercultural Communication Studies, 20(1), 175-192.

Yongqi Gu, P. (2016). Questionnaires in language teaching research. Language Teaching Research, 20(5), 567-570. doi: 10.1177/1362168816664001

Zhang, L. J., \& Anual, S. B. (2008). The role of vocabulary in reading comprehension: The case of secondary school students learning English in Singapore. Regional Language Centre Journal, 39(1), 51-76. doi: 10.1177/0033688208091140 
LIST OF APPENDICES 


\section{Appendix 1: Pre-service Teacher's Semi-Structured Interview Guide (Phase 1)}

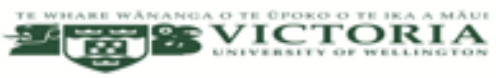

Any questions before we start?

1. Demographic information

- Years of learning English. How long have you learned English?

- Interest in learning English. Why do you want to learn it?

- Motivation of learning English. What motivates you to learn English?

2. Prior experiences of English reading learning styles/strategies

- When? When did you start learning reading?

- Strategies used (what, how, and why?) How did you learn to read in English?

- Impact on learning outcomes. Tell me about the results of learning reading.

3. Prior experiences at school or education programme. What type of reading learning experience have experienced on the TEP? What did the teacher do when teaching reading?

- Vocabulary focus

- Grammar focus

- Pronunciation focus

- Interactions/discussions

- Activities for reading learning (pair/group work, individual, debate, etc.)

4. Experiences of reading materials. What type of reading materials have you and your teacher used for this course? What do you think about them?

- Textbooks

- Fiction/non-fiction sources

- Online sources

- Localised vs internalized themes

5. Challenges in learning to read in English. Tell me about difficulty or challenges in learning reading?

- Vocabulary

- Grammar

- Concept

6. What is the main focus of reading learning? Why?

7. Any other information would you like to add? 


\section{Appendix 2: Lecturer's Semi-Structured Interview Guide (Phase 1)}

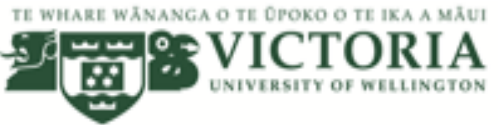

Any questions before we start?

1. Teaching experiences at the English teacher education programmme.

- How long have you been teaching English?

- How many subjects apart from reading?

2. English reading teaching methodology.

- How to engage learners in learning reading?

- What do you do when you teaching reading? How do you teach reading?

- Why use those approaches?

3. What is your main goal of teaching reading?

- Key important features for reading instruction.

4. Can you give an example of your effective reading lesson and why?

5. Difficulties and challenges in teaching reading. What is the main difficulty in teaching reading? Why?

6. How to address the difficulties. How do you address the problem or difficulty of teaching reading? 


\section{Appendix 3: Observation Guide (Phase 1)}

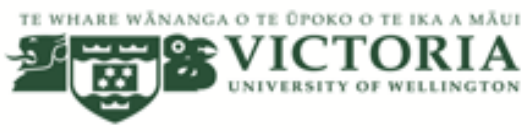

1. Classroom climate (interactions between the teachers and students before the lessons start, the language teachers use to engage learners in the lesson, how teachers establish a positive atmosphere for learning)

2. Pre-reading tasks and activities (how teachers conduct class activities, and how these activities engage learners in learning)

3. Activities and methods teachers apply during and after the reading processes (how these activities foster deep and meaningful learning)

4. Activities to promote and foster a culture of thinking (what and how tasks are used and conducted to cultivate learners' critical and creative thinking skills in exploring concepts and constructing meaning)

5. Materials used (what types of teaching materials are used to foster deep and interactive reading instruction?).

6. Degree of participation, interaction, and engagement (time management, language of thinking, opportunities to explore concepts). 


\section{Appendix 4: Survey (Phase 1)}

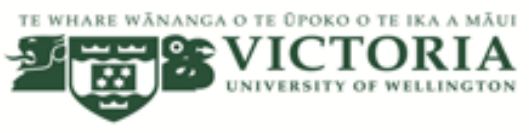

\section{Instructions}

This questionnaire aims to survey pre-service teachers' prior experiences of reading and learning to read in English. It consists of three sections and it should not take more than $\underline{\mathbf{1 5}}$ minutes to complete this survey.

\section{Section 1: Demographic Information}

\section{Section 2: Perceptions of Learning English Reading}

Section 3: Prior Experiences in Reading, Materials, and Instruction

\section{Section 1: Demographic Information}

\section{Directions:}

Please answer the following questions by putting a ' $\checkmark$ ' into the box provided that applies to you.

1. Age:
(1). $15-20$ years old $\square$
(2). 21-25 years old $\square$
(3). More than 25 years old $\square$

2. Gender:
(1). Male $\square$
(2). Female $\square$

3. How long have you been learning English?
(1). 1 -2 years $\square$
(2). 3-4 years $\square$
(3). More than 4 years $\square$

4. How important do you think the reading skill is?
(1). Very important $\square$
(2). Important $\square$
(3). Moderately important $\square$
(4). Slightly important $\square$
(5). Not important $\square$ 


\section{How would you rate your reading ability?}
(1). Excellent $\square$
(2). Very good $\square$
(3). Satisfactory $\square$
(4). Poor $\square$
(5). Very poor $\square$

\section{Which year of the English teacher education programme are you?}

(1). First year $\square$

(2). Second year $\square$

(3). Third year $\square$

(4). Fourth year $\square$

\section{Section 2: Perceptions of English Reading Learning}

Directions: Statements below are about your general perceptions of English reading. Five numbers that follow each statement $(1,2,3,4$, and 5$)$ mean the following:

1 Strongly disagree

2 Disagree

3 Neither agree nor disagree

4 Agree

5 Strongly agree|

After reading each statement, put a $(\sqrt{ })$ under the number $(1,2,3,4$, or 5$)$ that best indicates your perceptions regarding English reading.

\begin{tabular}{|c|c|c|c|c|c|c|}
\hline Item & Statement & 1 & 2 & 3 & 4 & 5 \\
\hline 1 & $\begin{array}{l}\text { Translating from L2 to L1 is important for learning English } \\
\text { reading. }\end{array}$ & & & & & \\
\hline 2 & $\begin{array}{l}\text { Learning a lot of new words is important for learning English } \\
\text { reading. }\end{array}$ & & & & & \\
\hline 3 & $\begin{array}{l}\text { Learning grammatical rules is important for learning English } \\
\text { reading. }\end{array}$ & & & & & \\
\hline 4 & $\begin{array}{l}\text { Summarizing the main idea of a text is important for learning } \\
\text { English reading. }\end{array}$ & & & & & \\
\hline 5 & Reading out loud is important for learning English reading. & & & & & \\
\hline 6 & $\begin{array}{l}\text { Pronouncing words or sentences correctly is important for } \\
\text { learning English reading. }\end{array}$ & & & & & \\
\hline 7 & $\begin{array}{l}\text { Monitoring or evaluating comprehension is important for } \\
\text { learning English reading. }\end{array}$ & & & & & \\
\hline 8 & $\begin{array}{l}\text { Constructing meaning is important for learning English } \\
\text { reading. }\end{array}$ & & & & & \\
\hline 9 & $\begin{array}{l}\text { Developing critical thinking skills about a reading topic is } \\
\text { important for learning English reading. }\end{array}$ & & & & & \\
\hline 10 & $\begin{array}{l}\text { Answering comprehension questions is important for } \\
\text { learning English reading. }\end{array}$ & & & & & \\
\hline
\end{tabular}

If you wish to add other ideas in addition to the above mentioned, feel free to do so in the space below. 


\section{Section 3: Prior Experiences in Reading, Materials, and Instruction}

Directions: Statements below are about your prior experiences in reading, materials, and instruction. Five numbers that follow each statement $(1,2,3,4$, and 5$)$ mean the following:

1 "Never"

2 "Very rarely"

3 "Sometimes" (50\%)

4 "Very often"

5 "Always"

After reading each statement, put a tick $(\sqrt{ })$ under the number $(1,2,3,4$, or 5$)$ that best matches your experience of learning to read in English.

\begin{tabular}{|c|c|c|c|c|c|c|}
\hline Item & Statement & 1 & 2 & 3 & 4 & 5 \\
\hline 1 & $\begin{array}{l}\text { I read various types of texts (e.g., novels, reports, } \\
\text { advertisements, etc.) to develop my reading skills or capacity. }\end{array}$ & & & & & \\
\hline 2 & $\begin{array}{l}\text { I used various reading sources (e.g., online websites, } \\
\text { newspapers, magazine, etc.) in addition to reading the textbooks } \\
\text { used in the class. }\end{array}$ & & & & & \\
\hline 3 & $\begin{array}{l}\text { In addition to textbooks, the teacher also used other } \\
\text { supplementary reading materials to expose learners to different } \\
\text { text types. }\end{array}$ & & & & & \\
\hline 4 & $\begin{array}{l}\text { A balance existed in the reading lesson between teacher- } \\
\text { initiated and student-initiated tasks. }\end{array}$ & & & & & \\
\hline 5 & $\begin{array}{l}\text { The teacher activated learners' prior knowledge of the topic } \\
\text { before reading. }\end{array}$ & & & & & \\
\hline 6 & $\begin{array}{l}\text { The teacher provided a clear explanation about the skills or } \\
\text { strategies to be used in reading. }\end{array}$ & & & & & \\
\hline 7 & $\begin{array}{l}\text { The teacher used reading materials suitable to my English } \\
\text { proficiency. }\end{array}$ & & & & & \\
\hline 8 & $\begin{array}{l}\text { The teacher focused learners on constructing meaning of the } \\
\text { text. }\end{array}$ & & & & & \\
\hline 9 & $\begin{array}{l}\text { The teacher provided meaningful or effective consultation to } \\
\text { learners regarding learning reading. }\end{array}$ & & & & & \\
\hline 10 & $\begin{array}{l}\text { The teacher used assessment practices aligned with planned } \\
\text { goals or actual instruction. }\end{array}$ & & & & & \\
\hline 11 & $\begin{array}{l}\text { The teacher established a safe and respectful environment for } \\
\text { meaningful interaction in learning reading. }\end{array}$ & & & & & \\
\hline 12 & $\begin{array}{l}\text { The teacher encouraged learners to think about the concept } \\
\text { represented in the text when teaching reading. }\end{array}$ & & & & & \\
\hline 13 & The teacher asked learners to summarize what they read. & & & & & \\
\hline 14 & $\begin{array}{l}\text { The teacher designed and included extra activities (e.g., retelling } \\
\text { the text content, sequencing the events, short summary, debates, } \\
\text { presentations, etc.) for learners to do after reading to further } \\
\text { increase understanding of the text. }\end{array}$ & & & & & \\
\hline
\end{tabular}

Thank you for participating in this survey. If you wish to add any other comments, feel free to do so below. 


\title{
Appendix 5: Sample Reading Test Document
}

\section{Faculty of Education \\ Subject: Reading}

\begin{abstract}
Name:........................................
\end{abstract}
Class:.

Time: 50minutes

Marks $25 \%$

\section{Vocabulary}

a. Carry on $=$

b. forgetfultt.

c. Getting along with-

d. Outgoing \#

e. Came out $=$

F. Efficient \#

f. Passed away $=$

H. Level-headed \#

g. Awful = i. Odd \#

\section{Matching}

Mateh the words in column A with their meanings in column B.

1.

Ex:_a__ dairy products aisle

2._Greenland

3._acronym

4.

5.

6.

7.

8.

9.

10. processing plant mine

grind

7. medicine man

8. sails

9. code

10. invented

\section{Read the text}

1 Gift giving traditions vary from country to country. Knowing some basic customs can save you a lot of embarrassment when you travel. Here are some rules for gift giving in the United States.

2 If you are invited to someone's home for dinner, you should bring a small gift to show your appreciation to the host or hostess. A bouquet of flowers or a box of chocolates is an appropriate gif for this occasion. 
3 If you are invited to a wedding, find out the name of the store where the couple is registered. When you go there, give the sales clerk the couple's name, and you will get a list of possible gifts. You can be sure the couple will like whatever you buy. After all, they wrote the list themselves!

4 Finally, only elementary school students give present to their teachers_and it is student's choice, not an obligation. It not expected and not considered appropriate for university students to give gifts to their professors.

\section{A. What do these words refer to? (10pts)}

1. this occasion(par.2, line3)

2. there (par.3, line 2)

3. they (par. 3, line 3)

4. their (par.4, line 1)

5. it (par. 4 , line 2$)$

B. Who do you think the text written for? Cheek ( $\checkmark$ ) the correet answer. (2pts)

1. school children in the United States

2. foreign students coming to study in the United States

3. tourists planning a vacation to the United States

\section{Text completion}

\& Complete the text with the words following in the box (20pts)

\begin{tabular}{|l}
\hline Motivation satisfaction choose environment flexible \\
opportunity depends on poll least staying \\
\hline
\end{tabular}

Why do most people to stay with their current employer? The answer usually their age, life circumstances, and personal A recent on our website asks the same question. The top reason for on the job was nature of the work job Coming in a close second was schedule and work-life balance. Next was work and corporate culture, followed by advancement and personal growth. Salary and benefits were the important. 


\section{Appendix 6: Reading Test and Answer Key (Phase 2)}

Reading Test

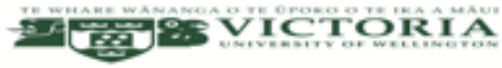

Candidate Name:

Time duration: $60 \mathrm{mns}$

Instructions for test-takers

- Write your first name and surname in the space at the top of this page.

- Read the instructions for each part of the test carefully.

- Answer all the questions.

- Use pencil.

\section{Information for test-takers}

- There are $\underline{34}$ items/questions on this test.

- Each question carries one mark.

\section{Reading Text 1: True, False, Not Given}

Read text below and answer questions 1-7

\section{Mail Order Brochure \\ Want some great clothing ideas for your family?}

Our key for clothing specials in July: $\mathbf{M}$ for men, $\mathbf{W}$ for women, $\mathbf{C}$ for children

\section{For under $\$ 10$}

- Cotton socks $\mathbf{C}$-made of pure cotton for long wearing.

- Woollen socks C - to keep young feet warm in winter.

- Sports socks $\mathbf{M}$ - to go with jeans and other casual clothes.

- Patterned belts $\mathbf{W}$ - to go with jeans and other casual clothes.

\section{For under $\$ 25$}

- Cotton shirts $\mathbf{W}$-for day and evening wear.

- Silk shirts M- five sizes, in designer colours, for that special occasion.

- T-shirts C - hard-wearing, white with a variety of animal motifs.

- Colour T-shirts M W-cotton and polyester blend, plain colours, no ironing.

\section{For under $\$ 50$}

- Blue jeans M W-non-shrink, colourfast, small sizes only.

- Silk shirts $\mathbf{M} \mathbf{W}$ - plain and patterned, all sizes.

- Hooded jacket $\mathbf{C}$ - protects from the wind, 4 sizes, large strong pockets.

- Jacket $\mathbf{W}$-waterproof with zipper front, all sizes.

Or you can buy a gift voucher so that someone else can choose. These come in $\$ 10, \$ 20$, and $\$ 50$. 


\section{Additional monthly specials for July to September}

July- $\$ 10$ coupon with any purchase over $\$ 60$

August- travel alarm clock worth $\$ 19.95$ free with purchases of $\$ 80$ or more!

September - children's backpacks. Free with any credit card purchase over $\$ 75$

Note: Postage and packing charges

These are applied to each order as follows:

\section{Within Australia:}

$\$ 7.95$ per address, regular post

$\$ 17.95$ for Express Delivery Service (overnight)

\section{Overseas:}

Surface Mail (allow at least two months for delivery)

Airmail (allow around two weeks delivery to most places)

\section{Do the following statements agree with the information given in the text above? Write}

- $\mathbf{T}$ if the statement agrees with the information in the text.

- F if the statement does not agree with the information in the text.

- NG if the information is not given or mentioned in the text.

\section{Questions}

1. Women's cotton socks cost less than men's.

2. Men's silk shirts are available in more than five colours.

3. Children's T-shirts come in a variety of colours.

4. The child's jacket has four pockets.

5. If you buy clothes worth $\$ 80$ in August, you will receive a free alarm clock.

6. The charge for special next-day delivery in Australia is $\$ 7.95$.

7. All clothing is guaranteed to arrive within two months. 


\section{Reading Text 2: Short Comprehension Questions}

Read the text below and answer the questions 8-12. Choose NO MORE THAN THREE WORDS

AND/OR A NUMBER from the text and write them in the space provided at the end of each sentence below.

\section{Important Notice: Product Return}

Fancy Foods wishes to inform the public that pieces of metal have been found in some jars of Fancy Foods Chicken Curry (spicy). The numbers of the jars involved are from J6617 to J6624. The batch number is printed on the bottom of each jar.

If you have any jars with these batch numbers, please return them (preferably unopened) to the supermarket where you buy them. You can also return them to the factory (Fancy Foods Retailers, Blacktown). Fancy Foods will pay $\$ 10$ for each jar returned unopened and $\$ 5$ for each already opened.

No payment will be made for empty jars, which do not need to be returned. However, the Retailing Manager will be interested to hear from people who have eaten chicken curry from any of the above batch numbers. In particular, it will be helpful if they can give information about the place of buying of the product.

Jars of Fancy Foods Chickens Curry (Coconut) and Fancy Foods Chicken Curry (Mango) have not been affected and do not need to be returned.

\section{Reward}

Fancy Foods will pay a reward of $\$ 10,000$ to $\$ 50,000$ for information which leads to the punishment of any person found guilty of placing metal pieces in its products. If you have such information, please contact the Customer Relations Manager, Fancy Foods Retailers, Blacktown.

8. What has been found in some Fancy Foods products?

9. Where can you find the batch number on the Jars?

10. How much will you receive for an opened jar of contaminated Chicken Curry?

11. If you have eaten Chicken Curry from a jar with one of the batch numbers listed, whom should you contact?

12. What is the maximum reward Fancy Foods is offering for information about who contaminated their product? 


\section{Reading Text 3: Heading Matching}

Read the list of New Book Releases below and choose the correct number of book titles provided below (1-11) by writing the number in the space given at the end of each description from 13-21. There are more titles than the descriptions.

\section{List of Books Titles}

1. Field Guide to Native Birds of Australia

2. The Bush on Two Wheels: 100 Top Rides

3. Bush Foods of Australian Aborigines

4. A Pictorial History of the Dinosaur in Australia

5. Bushwalking in Australia

6. World Geographica

7. Driving Adventures for 4-wheel-driveVehicles

8. Survival Techniques in the Wild

9. Encyclopaedia of Australian Desert

10. Guide to the Art of the Australian Desert

11. Field Guide to Animals of the World

\section{New Books Releases}

13. This book describes the creativity of native people living in the driest parts of Australia. Stunning reproductions of paintings, beautiful photography and informative text.

14. Pocket-sized maps and pictures with detailed information on the nesting sites and movement patterns of Australia. This is a classic booklet suitable for both beginners and specialists.

15. Packed full of information for the eager walker, this book is a must. Photographs, maps and practical advice will guide your journeys on foot through the forests of the southern continent.

16. More than-an atlas - this book contains maps, photographs and a lot of information on the land and climate of countries from around the globe.

17. Australia's premier mountain biking guidebook - taking you through a host of national parks and state forests.

18. Here's the A-Z of Australian native animals - take an in-depth look at their lives and characteristics, through fantastic photographs and informative text.

19. Graphic artists have worked with researchers and scientists to show how these prehistoric animals lived and died on the Australian mainland.

20. A definitive handbook on outdoor safety - with a specific focus on tool, food, first aid, special clothing and bush skills.

21. Detailed guides to 15 scenic car tours that will take you onto fascinating wilderness tracks and along ways that you could otherwise have missed. 


\section{Reading Text 4: Sentence Completion}

Read the following short text and complete the questions 22-25 that follow. Choose $\underline{N O}$ MORE THAN THREE WORDS AND/OR A NUMBER from the passage for each answer.

\section{Life on Earth}

Life on Earth starts around 3.8 billion years ago and has since gradually developed and varied by the process of natural selection to be adapted to almost every environment possible. There are currently about 1.9 million animals, plants, and other forms of life on Earth.

Life can be found in every corner and place of the world, from the extreme environments of deep sea hydrothermal vents and the coldest conditions of the Polar Regions to comfortable habitats found at the equator.

Looking back through time, by means of the fossil and phylogenetic record, we can see that the Earth has been home to many more living things than are alive today. Taking a historical perspective shows that life is constantly evolving, with the success and control of different groups waxing and waning over time.

The diversity of life is truly amazing, but all living things do share certain similarities. All living things can replicate, and the replicator molecule is DNA. As well, all living things contain some ways of changing the information stored in DNA into products used to build cellular machinery from fats, proteins, and carbohydrates.

22. The world has been developed and changed by for over 3.8 billion years.

23. The past history of the species that used to exist on earth can be found through the record.

24. The coming and going of specific groups and species can illustrate to us that life is forever

25. Without , life forms would not be able to replicate. 


\section{Reading Text 5: Multiple Choice}

Read the text below and choose the correct answer, A, B, or C by circling the letter for questions 26-30 that follow.

\section{Genetically Modified Food (GM Food)}

GM food is produced from plants which have had their genes changed in the lap. Scientists "cut and paste" a gene from another living thing into a plant's DNA to give a new characteristic. This can be to increase yield or to allow the plant to exist in a more difficult environment than normal. Pro-GM scientists say this means cheaper more plentiful food but opponents argue we do not know the result of destroying the nature.

Farmers have modified their crops for thousands of years by crossing similar species. However, modern GM is arguable. Critics say modified crops could "escape" and cross with wild plants, with unknown results. They also argue that more chemicals are used on some GM fields which may have a negative impact on wildlife. And while no study has found GM food to be harmful to humans, people who disagree with this say that it is too soon to be sure.

A group of biotechnology experts say it is time to loosen Europe's strict laws on genetically modified crops. In a report came out today they argue that genetically modified crops have been used safely for years, so no longer need to be automatically treated as unsafe. They also say that genetically modified crops should be reclaimed from many types of companies and treated as a public good.

26. The genetic make-up of GM foods has been....
A. twisted
B. altered
C. cut

27. By genetically engineering plants, they are.....
A. likely to increase in size
B. able to produce more
C. not able to exist in difficult conditions

28. One issue with GM plants is the potential to ........
A. breakout causing undetermined consequence
B. infect wild plants with unknown results
C. cross pollinate

29. It is thought by specialists in biotechnology that policies governing GM crops should be...
A. heightened
B. relaxed
C. reviewed

30. GM foods ought to be...
A. reclaimed for the use of multinational companies
B. used safely
C. no longer privatised. 


\section{Reading Text 6: Summary Completion}

Read the text below and select NO MORE THAN THREE WORDS from the text to complete the summary questions 31-34 that follow.

\section{Don't Be Late}

\section{Basic Advice for an Interview}

I know this advice may not sound important and something that you already know, but it still happens. You can never know what might make you late. It could be just public transport problems, but most of the time arriving late is because you didn't plan well. Running late not only suggests poor time management skills but shows a lack of respect for the company. Arriving late is an excellent way to give your interviewer a bad first feeling about you and we all know how important first impressions are. Plan your journey as well as possible, even by checking the public transport website the night before if you have to. Jump on the Internet and figure out exactly where your interview is and make note of a few things so that you don't get confused if you get lost, manage your time so that you make it to the interview at least ten to fifteen minutes early.

\section{Ask Questions}

A lot of applicants tend to think that an interview is the step of being asked questions. This is far from the truth. Interview ought to be a discussion, so you should be ready with your own questions too. A good interviewer will usually allow for enough time to let you ask as many questions as you want at the end of the discussion. Therefore, prepare questions on the topics you're interested in. Ask questions about the company and their products. You don't want to show a complete lack of knowledge of what the company does; you want to show an interest. Hiring manager skills will think that you have looked into their organisation's website, so increase the scope of your research study efforts. Try to understand what the organisation's goals are in the short, medium and long term how the projects you'll work on will help the organization.

\section{Basic Advice for an Interview}

Being late for an interview shows bad planning, bad (31) a lack

of respect, and it gives a bad first impression. Plan your journey-use the internet and make some notes. Try to be 10-15 minutes, but do not come too early.

An interview should be a (32) so prepare lots of questions on the company and its (33) . Do more than just research the interviewing

company's website. Know what the different (34) of the company are and how you'll be a part of them. 
Answer Key

Text 1: Questions 1-7 (True, False, Not Given)
1. NG
2. NG
3. $\mathrm{F}$
4. NG
5. T
6. $\mathrm{F}$
7. $\mathrm{F}$

Text 2: Questions 8-12 (Comprehension questions)
8. pieces of metal
9. (on) the bottom
10. $\$ 5$
11. (the) Retailing Manager
12. $\$ 50,000$

Text 3: Questions 13-21 (Heading Matching)
13. Book A (9)
14. Book B (1)
15. Book C (4)
16. Book D (5)
17. Book E (2)
18. Book F (8)
19. Book G (3)
20. Book H (7)
21. Book I (6)

Text 4: Questions 22-25 (Sentence Completion)

22. natural selection

23. fossil and phylogenetic

24. evolving

25. DNA

Text 5: Questions 26-30 (Multiple Choice)

26. B

27. B

28. C

29. B

30. C

Text 6: Questions 31-34 (Summary Completion)

31. time (management) skills

32. discussion

33. products

34. goals

${ }^{*}()$ Words in the brackets are optional; they are correct, but not necessary. 


\section{Appendix 7: Observation Tool (Phase 2)}

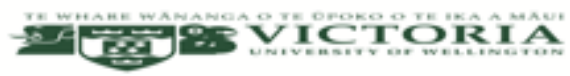

1. Expectations or objectives teachers are trying to accomplish.

- What teachers are attempting to achieve (grammar, vocabulary, pronunciation, translation, strategies, critical and strategic reading skills, analysis of text organisation, etc.)

2. Language of thinking or classroom language

- The frequency and the extent to which critical thinking language are used to engage and motivate learners to think beyond the surface and to encourage learners to exchange ideas in an interactive and meaningful way.

3. Time allocation

- Management of time for in-depth discussions and interactions.

- Flexibility of time to facilitate meaningful learning.

4. Teacher modelling of learning reading

- Teacher commitment to cultivating deep learning.

- Teacher passion in learners' ideas or interests about a reading topic.

5. Opportunities

- Opportunities for interactive, collaborative, and reflective learning. How many times?

- To what extent is every learner encouraged to participate in learning?

6. Thinking routines or activities

- Thinking routines used to conduct deep and meaningful learning. How often are they used?

- Evidence of learners' familiarity to instructional routines used.

7. Interactions or engagement

- Deep and meaningful interactions through pair work or group work. How often?

- Engagement in exploring ideas or concepts through discussions, debates, presentations, etc.

- Effectiveness of pair or group work.

8. Physical environment

- Arrangements of class space or seats for meaningful collaborations and interactions

- Displays ideas, concept language, identification of claims, and thinking products. 


\section{Appendix 8: Focus Group Interview Tool (Phase 2)}

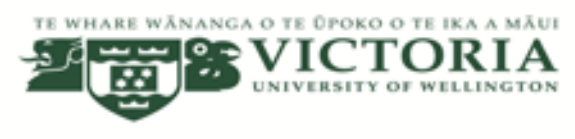

Any question before we start?

1. Perceptions of reading

- As a student, do like to learn reading? Why? Why not?

- In your opinion, what should be the main focus of learning reading? Why?

2. Perceptions of participation or engagement

- Do you think the reading activities conducted in your reading class promoted engagement or participation? If yes, to what extent? If no, why?

- Can you name types of activities/routines you were engaged in and what do you think about them?

3. Perceptions of learning outcomes/development

- Do you think your reading comprehension has improved as a result of the reading class? Why? Why not?

- Do you think your critical reading skills have improved as a result of the reading class? Why? Why not?

- Do you think your reading skills or strategies have developed or improved as a result of the reading class? Why? Why not?

- When you're reading and you come to something you don't know, what do you do?

- How would you help someone having difficulty reading? Why?

- What would a/your teacher do to help that person?

4. Difficulties or challenges in learning English reading

- What do you think the main difficulties are in learning English reading? Why? 


\section{Appendix 9: Pre-Post Perceptions Survey (Phase 2)}

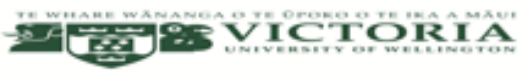

\section{Explanations to respondents}

This questionnaire aims to investigate Lao EFL pre-service teachers' perceptions of learning reading in the CoT and comparison classes. The survey should take around 15-20 minutes. There are two sections in this survey as follows:

\section{Section 1: Demographic Information}

\section{Section 2: Perceptions of Learning English Reading}

\section{Section 1: Demographic Information}

\section{Directions:}

Please read the following questions and statements and put a $\checkmark$ beside the answer that applies to you.

1. Age:

(1). 16-20 years old $\square$

(2). 21-25 years old $\square$

2. Gender:

(3). More than 25 years old $\square$

(1). Male $\square$

(2). Female

3. How long have you been learning English?

(1). 0 - 1 year $\square$

(2). 2 - 3 years $\square$

(3). $4-5$ years $\square$

(4). More than 5 years $\square$

4. Complete the following statement by using your own idea in regard to your perceptions of learning reading.

In my opinion, the main focus of learning reading (is/should be)

\section{Section 2: Questions about Perceptions of Learning Reading}

Directions: After reading each statement in the tables below, circle the number (1, 2, 3, 4, or 5) that is true for you. Five numbers follow each statement mean the following:

1 Strongly disagree

2 Disagree

3 Neither agree or nor disagree

4 Agree

5 Strongly agree

The following statements ask about your perceptions of learning to read in English. To what extent do you agree or disagree with the statements? 


\begin{tabular}{|c|c|c|c|c|c|c|}
\hline Item & Statement & \multicolumn{5}{|c|}{ Scale } \\
\hline \multicolumn{7}{|c|}{ Discrete Language Skills Learning } \\
\hline 1 & $\begin{array}{l}\text { Translating from L2 to L1 is important for } \\
\text { learning English reading. }\end{array}$ & 1 & 2 & 3 & 4 & 5 \\
\hline 2 & $\begin{array}{l}\text { Learning a lot of new words is important for } \\
\text { learning English reading. }\end{array}$ & 1 & 2 & 3 & 4 & 5 \\
\hline 3 & $\begin{array}{l}\text { Learning pronunciation is important for } \\
\text { learning English reading. }\end{array}$ & 1 & 2 & 3 & 4 & 5 \\
\hline 4 & $\begin{array}{l}\text { Answering comprehension questions is } \\
\text { important for learning English reading. }\end{array}$ & 1 & 2 & 3 & 4 & 5 \\
\hline \multicolumn{7}{|c|}{ Metacognitive Reading Learning } \\
\hline 5 & $\begin{array}{l}\text { Constructing meaning from a text is important } \\
\text { for learning English reading. }\end{array}$ & 1 & 2 & 3 & 4 & 5 \\
\hline 6 & $\begin{array}{l}\text { Developing critical reading strategies is } \\
\text { important for learning English reading. }\end{array}$ & 1 & 2 & 3 & 4 & 5 \\
\hline 7 & $\begin{array}{l}\text { Making connections between what to be read } \\
\text { with prior knowledge is important for learning } \\
\text { English reading. }\end{array}$ & 1 & 2 & 3 & 4 & 5 \\
\hline 8 & $\begin{array}{l}\text { Promoting learners' reading independence is } \\
\text { important for learning English reading. }\end{array}$ & 1 & 2 & 3 & 4 & 5 \\
\hline 9 & $\begin{array}{l}\text { Identifying text organizations is important for } \\
\text { learning English reading. }\end{array}$ & 1 & 2 & 3 & 4 & 5 \\
\hline 10 & $\begin{array}{l}\text { Activating prior knowledge of the text is } \\
\text { important for learning English reading. }\end{array}$ & 1 & 2 & 3 & 4 & 5 \\
\hline
\end{tabular}

The following statements ask about your recent experiences in learning to read in English. To what extent do you agree or disagree with the statements?

\begin{tabular}{|c|c|c|c|c|c|c|}
\hline Item & Statement & \multicolumn{5}{|c|}{ Scale } \\
\hline \multicolumn{7}{|c|}{ Reading Learning Experiences } \\
\hline 11 & $\begin{array}{l}\text { I usually read in English to understand the } \\
\text { meaning of the text. }\end{array}$ & 1 & 2 & 3 & 4 & 5 \\
\hline 12 & $\begin{array}{l}\text { I usually activated prior knowledge about the } \\
\text { reading topic before interacting with the text. }\end{array}$ & 1 & 2 & 3 & 4 & 5 \\
\hline 13 & $\begin{array}{l}\text { I usually exchanged ideas about what I read with } \\
\text { classmates after reading. }\end{array}$ & 1 & 2 & 3 & 4 & 5 \\
\hline 14 & I usually summarized the main idea of the topic. & 1 & 2 & 3 & 4 & 5 \\
\hline 15 & $\begin{array}{l}\text { I usually identified text organizations or } \\
\text { structures. }\end{array}$ & 1 & 2 & 3 & 4 & 5 \\
\hline 16 & $\begin{array}{l}\text { I usually analysed or evaluated the main claims } \\
\text { of the topic. }\end{array}$ & 1 & 2 & 3 & 4 & 5 \\
\hline 17 & $\begin{array}{l}\text { I was usually encouraged to apply critical } \\
\text { reading strategies or skills. }\end{array}$ & 1 & 2 & 3 & 4 & 5 \\
\hline 18 & $\begin{array}{l}\text { I usually answered reading comprehension } \\
\text { questions. }\end{array}$ & 1 & 2 & 3 & 4 & 5 \\
\hline 19 & $\begin{array}{l}\text { I usually involved in developing my own } \\
\text { questions of investigation to develop my critical } \\
\text { reading skills. }\end{array}$ & 1 & 2 & 3 & 4 & 5 \\
\hline 20 & $\begin{array}{l}\text { I usually monitored my reading comprehension } \\
\text { by evaluating my achievement of the reading } \\
\text { goal set. }\end{array}$ & 1 & 2 & 3 & 4 & 5 \\
\hline
\end{tabular}


The following statements ask about learning outcomes from the reading lessons. To what extent do you agree or disagree with the statements?

冊

\begin{tabular}{|c|c|c|c|c|c|c|}
\hline Item & Statement & \multicolumn{5}{|c|}{ Scale } \\
\hline \multicolumn{7}{|c|}{ Reading Learning Outcomes } \\
\hline 21 & My English vocabulary knowledge expands. & 1 & 2 & 3 & 4 & 5 \\
\hline 22 & $\begin{array}{l}\text { I am able to identify claims represented in the } \\
\text { text. }\end{array}$ & 1 & 2 & 3 & 4 & 5 \\
\hline 23 & My reading comprehension improves. & 1 & 2 & 3 & 4 & 5 \\
\hline 24 & I am able to construct meaning of the text. & 1 & 2 & 3 & 4 & 5 \\
\hline 25 & $\begin{array}{l}\text { I am able to communicate ideas represented in } \\
\text { the text. }\end{array}$ & 1 & 2 & 3 & 4 & 5 \\
\hline 26 & $\begin{array}{l}\text { I am able to activate my prior knowledge before } \\
\text { interacting with the text. }\end{array}$ & 1 & 2 & 3 & 4 & 5 \\
\hline 27 & I am able to apply my reading strategies or skills. & 1 & 2 & 3 & 4 & 5 \\
\hline 28 & $\begin{array}{l}\text { I am able to automatically recognise word } \\
\text { meaning in the text. }\end{array}$ & 1 & 2 & 3 & 4 & 5 \\
\hline 29 & $\begin{array}{l}\text { I am able to monitor my comprehension while } \\
\text { reading. }\end{array}$ & 1 & 2 & 3 & 4 & 5 \\
\hline 30 & I become an agent of my own reading learning. & 1 & 2 & 3 & 4 & 5 \\
\hline 31 & $\begin{array}{l}\text { I am able to identify text structures or } \\
\text { organizations. }\end{array}$ & 1 & 2 & 3 & 4 & 5 \\
\hline
\end{tabular}

Thank you for your participation. If you wish to add any other comments, feel free to do so below. 


\section{Appendix 10: Sample Pre-Reading Activities from Textbook}

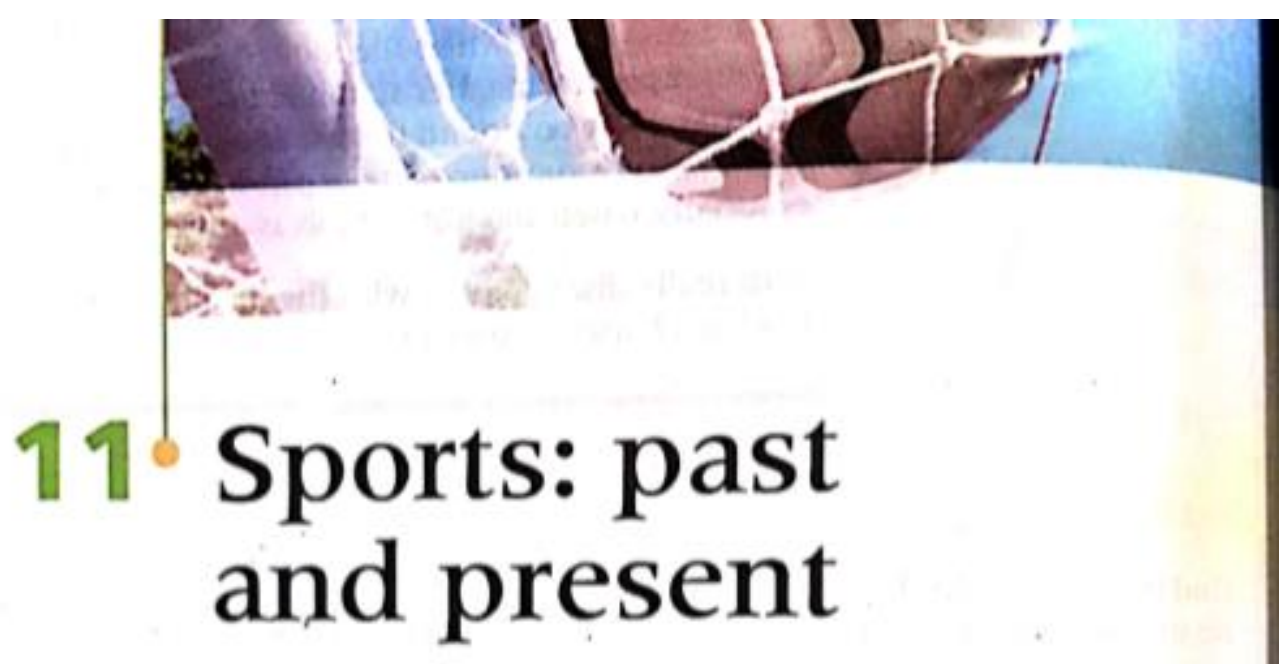

PRE-READING 1 Complete the sentences about football with the verbs in the past tense. Use each verb only once.

beat draw win send off lose be

1 Spain lost to South Korea in the quarter-finals.

2 Italy won won the World Cup in Germany.

3 Japan and Croatia drew 0-0 in the opening match.

4 At half-time South Korea were in the lead.

5 Chelsea beat Manchester United 4-1 yesterday.

6 The referee sent off two players in last night's match.

PRE-READING 2 Underline the word that does not belong in each group.

$\begin{array}{llllll}1 & \text { goalkeeper } & \text { striker } & \text { fan } & \text { substitute } & \text { soccer player } \\ 2 \text { field } & \text { ticket } & \text { ball } & \text { net } & \text { half-way line } \\ 3 \text { half-time } & \text { full-time } & \text { injury time } & \text { extra time } & \text { overtime } \\ 4 \text { score } & \text { shoot } & \text { kick } & \text { result } & \text { head } \\ 5 \text { crowd } & \text { red card } & \text { whistle } & \text { referee } & \text { penalty } \\ 6 \text { qualifying } & \text { knockout } & \text { trophy } & \text { semi-finals } & \text { final } \\ & \text { sound } & \text { stage } & & & \end{array}$




\section{Appendix 11: Sample CoT-Based Reading Lesson Plan}

$\mathbf{T}=$ Teacher

Ss $=$ Students

Topic: Accessories of Life

Textbook: Essential Reading 2

Date of Teaching: May 15, 2018

Duration: 90 minutes

Teaching aids: a projector, markers, large pieces of papers, textbook, and hand-outs.

\section{Objectives: This lesson aims to focus students on:}

1. activating prior knowledge of the topic through a Chalk Talk thinking routine;

2. identifying/summarizing the main idea of the text through a Claim-Support-Question thinking routine;

3. identifying information of opinion through a 'true, false, or not given' activity;

4. connecting, extending, and challenging ideas represented in the text through a| Connect-Extend-Challenge thinking routine; and

5. unpacking new vocabulary and ideas related to the topic.

\begin{tabular}{|c|c|c|}
\hline 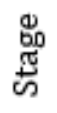 & Thinking routine integration & కี \\
\hline
\end{tabular}

1. Chalk Talk Thinking Routine

a. Introducing: $\mathrm{T}$ shows a slide with a term 'Accessories of life' and asks $\mathrm{Ss}$ to think about its meaning in groups of five. They can share ideas about it or use their smart phones to find out its definition if they wish to.

b. Eliciting: $\mathrm{T}$ elicits answers from each group and writes them on the board and share ideas with the Ss.

c. Presenting Chalk Talk: T asks students to work in groups of five and places large pieces of papers with the prompt 'Accessories of life' on the table of each group and asks Ss to brainstorm ideas or words related to the prompt by writing down on the paper as many as they can.

d. Circulating: T asks each group to circulate around the papers to read, ask questions, give comments, or add more ideas.

e. Facilitating: $\mathrm{T}$ asks Ss to come back to their original seats and reflect on ideas, comments, and connect ideas that are similar.

f. Sharing ideas: $\mathrm{T}$ asks $\mathrm{Ss}$ to share ideas about responses to the prompt by asking:

- What common ideas or issues did you see? Why?

- What surprised you? Why?

- What ideas did you learn from the responses? Why?

g. Demonstrating: $\mathrm{T}$ asks Ss to stick the papers on the classroom walls for them to revisit their work and add more ideas later on if they wish to. 
2. Claim-Support-Question Thinking Routine

a. Setting up: T explains the meaning of the word 'Claim' to students if it is used for the first time by pointing out that 'a claim refers to an idea or opinion that is being presented by the writer. It is the main point of the text'.

b. Identifying/summarizing: $\mathrm{T}$ asks Ss to read the text and identify the main idea/claim of the text silently and individually.

c. Identifying support: $\mathrm{T}$ asks Ss to identify support or evidence of the main idea or claim and evaluate it for critical judgements or decisions to believe.

d. Raising questions: $T$ invites Ss to think beyond the support and ask questions about what might make them hesitant about the truth or accuracy of the claim or idea identified.

e. Sharing: T asks Ss to share their ideas in groups from (b-d) by joining them in sharing ideas.

f. Identifying information: Tasks Ss to skim the text again and answer the 'true, false, not given' question.

3. Connect-Extend-Challenge

a. Connecting: After reading, $\mathrm{T}$ asks $\mathrm{Ss}$ to think about what they have learned and encourages them to connect to ideas or experiences they have already known by asking 'how did the ideas or information you have just learned connect to your past experiences?'

b. Extending: T invites Ss to think about how their ideas have extended, broadened, or deepened as a result of the new learning experiences by asking 'How have your ideas been extended in some way, taking it in new or further deeper directions?'

c. Challenging: T encourages Ss to consider ideas that seem challenging in the topic by asking 'What challenges or puzzles have come up in your mind about the topic? Why?

d. Sharing ideas: $T$ invites Ss to share ideas from (a-c) in groups and the teacher also joins the discussion. 


\section{Appendix 12: Participating Teacher's Interview Tool (Phase 2)}

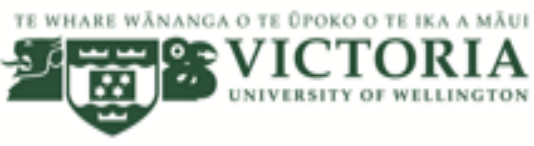

Any questions before we start our discussion?

1. The teacher's perceptions of learners' participation through a CoT instruction?

- Did the implementation of a CoT promote deep and meaningful engagement in learning reading? Why? Why not?

- Did the use of thinking routines/activities (e.g., See-Think-Wonder, Claim-SupportQuestion) help develop student critical thinking in terms of learning reading? Why? Why not?

2. The teacher's perceptions of students' reading comprehension/outcomes

- Do you think the implementation of a CoT has improved student reading comprehension? Why? Why not?

3. The teacher's perceptions of challenges/difficulties in implementing a CoT

- What do you think of the lessons you implemented?

- Did you have any challenges in implementing the reading lessons through a CoT? Why? Why not?

\section{Future implementation of a CoT}

- Will you use some the thinking routines (e.g., Chalk Talk, Connect-Extend-Challenge) in your own teaching in the future? Why? Why not? 


\title{
Appendix 13: Sample Observation Transcriptions
}

\author{
Topic: Effects of Social Media on Teens \\ Date of observing: March 23rd, 2018. \\ Duration: $90 \mathrm{mns}$ (13:00-14:30). \\ T: Teacher \\ Ss: students
}

Pre-reading: Activating prior knowledge through a Chalk Talk thinking routine

In this routine/activity, students were asked to work in groups of five to six to create a concept map about the effects of social media on teens. They first shared ideas or words related to the topic by writing them on the Chalk Talk papers. After that they stuck the papers on the classroom's walls to display their concept maps. Finally, they were asked to rotate around the classroom to read, ask questions, and comment on the other groups' ideas or words.

\section{Brainstorming ideas or words about 'Effects of Social Media on Teens'}

01 S1: 0k, Bounmak (Pseudonym) you write the topic first. [S1 is writing the topic on the paper: Effects of Social Media on Teens].

02 S2: Advantages and disadvantages.

03 S1: in words rigy [Let's focus on words first].

04 S3: List words riอม ตละ เขับ [first and] ideas. [LAUGH] First word is ... ah ... addictive, communicate ...

05 S1: Teacher, do we have to do on mind maps...or..?

06 T: Depends....mind mapping or you just write key words.

07 Ss: [LAUGHS]

08 S3: Common ideas.

09 Ss: Ah...Internet, effects, websites, applications, [LAUGH], connect.. Connection,

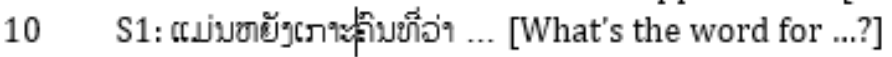

11 S3: What do you want to say, Bounmak [pseudonym]?

$12 \mathrm{~S} 1$ : ถิมขึรัจาระองขึ้มา? [globalized?]

13 S3: global?

14 S4: Globalization?

15 S1: \&รมเรอใด? [How do spell it?]

16 S5: ปิเฮอบำ [It has an L first, hmm]

17 S6: How about news? [ฉ่าจราบ?]

18 Ss: News.

19 S3: Ah, advertisements.

20 S6: Community

21 S3: Commercial or advertisement [LAUGH]. Can you search the word on your smartphone to correct them?

22 S4: Here 'advertisement'

23 S3 +S6: entertainment.

24 S2: Yeah, I like it.

25 S3: A lot [LAUGH].

26 S1: Addicted.

27 S6: ถาอบิ์เจิาไจเกยย? [How about ideas? 


\section{Appendix 14: Participating Teacher's Interview Transcriptions}

\begin{tabular}{|c|c|c|}
\hline Time & Person & Content \\
\hline \multicolumn{3}{|c|}{ Perceptions of student engagement or participation } \\
\hline \multirow[t]{2}{*}{ 0:01 } & I & $\begin{array}{l}\text { Did the implementation of a CoT promote deep and meaningful } \\
\text { engagement in learning reading? Why? Why not? }\end{array}$ \\
\hline & $\mathrm{T}$ & $\begin{array}{l}\text { I think there is a lot engagement because it is a student-centred method } \\
\text { of instruction. They have a lot of opportunities to share ideas and work } \\
\text { in groups .... they are also encouraged to think beyond what they are } \\
\text { learning and use their smartphones to explore or search information. } \\
\text { Another reason is that, because of the lessons designed and } \\
\text { implementation, students are stimulated to activate their prior } \\
\text { knowledge and construct meaning or content of the topics. Because of } \\
\text { this, they feel more confident in sharing ideas and interacting with } \\
\text { peers although it is new to them. }\end{array}$ \\
\hline \multirow[t]{2}{*}{ 5:01 } & I & $\begin{array}{l}\text { Did the use of thinking routines/activities (e.g., See-Think-Wonder, } \\
\text { Claim-Support-Question) help develop students' critical thinking in } \\
\text { terms of learning reading? Why? Why not? }\end{array}$ \\
\hline & $\mathrm{T}$ & $\begin{array}{l}\text { I think they have developed a lot in terms of critical reading. Yes, a lot. } \\
\text { The activities help students a lot in terms of stimulating them to think } \\
\text { because they participate in expressing ideas and the teacher does not } \\
\text { focus on seeking specific answers or right or wrong answers from the } \\
\text { students. In the past they learned through the grammar translation } \\
\text { method or traditional method ... they translate word by word. } \\
\text { However, after using this method, the students learn meaningfully } \\
\text { because they are able to identify main ideas of the texts or paragraphs } \\
\text { through collaborating with their peers. They know how to read faster } \\
\text { which saves their time. }\end{array}$ \\
\hline \multicolumn{3}{|c|}{ Perceptions of students' reading comprehension/outcomes } \\
\hline \multirow[t]{2}{*}{$8: 20$} & I & $\begin{array}{l}\text { Do you think the implementation of a CoT has improved student } \\
\text { reading comprehension? Why? Why not? }\end{array}$ \\
\hline & $\mathrm{T}$ & $\begin{array}{l}\text { Of course it helps a lot in terms of their comprehension development } \\
\text { because they are encouraged to think and learn independently through } \\
\text { sharing, brainstorming, cooperative learning, and community learning. } \\
\text { The teacher acts as a facilitator for them. This is a new method of } \\
\text { reading instruction. I am very satisfied with their learning outcomes } \\
(98 \%) \text { because when they first started this course, they could not } \\
\text { summarize main points of texts and their comprehension was very low. } \\
\text { However, after being exposed to CoT they are able to summarize, } \\
\text { analyse and evaluate main points of the text which is crucial for } \\
\text { enhanced understanding. }\end{array}$ \\
\hline
\end{tabular}




\section{Appendix 15: Sample Focus Group Interview Transcriptions}

$\mathbf{M}=$ Moderator

Ps = participants

\begin{tabular}{|c|c|}
\hline $\mathrm{M} / \mathrm{Ps}$ & Content \\
\hline $\mathrm{M}$ & As a student, do you like to learn reading? Why? Why not? \\
\hline Ps & $\begin{array}{l}\text { P1: Uh .... in the past it was not my favourite subject because learning } \\
\text { activities were not interesting. Now, I like to learn it because it is more } \\
\text { interesting and interactive. We share a lot of ideas ... } \\
\text { P2: ... yeah. I agree with you. I feel that learning reading in this term is more } \\
\text { interesting than last term because there are many interesting activities for } \\
\text { students to think about the topic. We think a lot ... } \\
\text { P3: ... and the teacher focuses students on meaning of the text and sharing } \\
\text { ideas instead of reading aloud and translating ... } \\
\text { P4: ... I agree with everyone. I like the Chalk Talk because it is a good way of } \\
\text { preparing students before reading and I learn many new ideas from group } \\
\text { members,.. } \\
\text { P1: ... and we have a lot of opportunities to exchange our thinking and ideas } \\
\ldots \text { I like the way the teacher implements lessons ... } \\
\text { P5: ... yes, you are right, very interactive and I want every teacher to do like } \\
\text { this ... } \\
\text { P2: ... agree. It is a new approach to teaching, it is cooperative and } \\
\text { interactive. The reading teachers should have done this from year one ... } \\
\text { Ps: Yeah. }\end{array}$ \\
\hline M & In your opinion, what should be the main focus of learning reading? Why? \\
\hline Ps & $\begin{array}{l}\text { P1: I think it should be evaluating and answering comprehension questions } \\
\text { because it is a way of checking our understanding of what we read ... if we } \\
\text { can do this it means we understand the text ... and should be vocabulary as } \\
\text { well ... } \\
\text { P2: ... I agree. It should also be the main point of the text as well because } \\
\text { reading is about understanding. Without understanding, it is useless ... In the } \\
\text { past we focused on reading aloud and translating ... } \\
\text { P1: ... yeah and pronunciation of words or sentences ... } \\
\text { P3: Yes, you are right. It should be main ideas of the text or paragraph. After } \\
\text { reading we should understand the main point of the text through } \\
\text { summarizing ... } \\
\text { P4: ... same as everyone. It should be the main point of the text because } \\
\text { reading is about understanding. I used to think that reading is about } \\
\text { pronouncing words correctly or learning lot of new words but ... the teacher } \\
\text { said reading is about meaning ... and then it should be vocabulary and } \\
\text { pronunciation because they are important for reading ... } \\
\text { P5: ... yeah, in the past I used to think that too but the reading teacher in this } \\
\text { term focuses students on summarising the main point of the text ... } \\
\text { P4: ... but I think it should be focusing on learning new words as well } \\
\text { because they are important for comprehension ... } \\
\text { P3: ... yeah, but it should be a secondary focus. The first focus should be } \\
\text { meaning of the text I think.. }\end{array}$ \\
\hline
\end{tabular}




\title{
Appendix 16: Sample One-on-One Interview Transcriptions (Phase 1)
}

\author{
26.12 minutes \\ I = Interview \\ P2= Participant 2
}

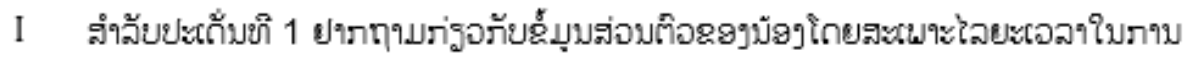

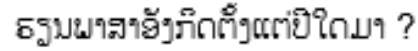

The point of discussion today is about your experiences of learning English. How long have you been learning English?

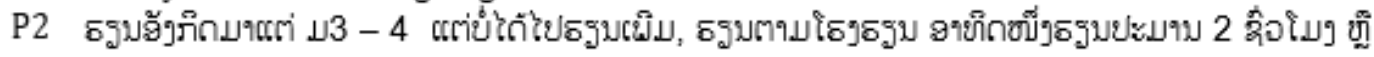

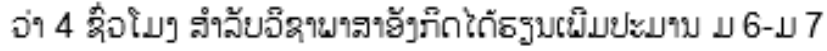

I have been learning English since I was on years three to four, but I did not take extra classes. I just learned from school. It was about two or four hours per week. I started to learn extra English classes when I was on years six or seven of upper secondary school.

I จั่าธรมบิย่?

Did you pay for extra English classes?

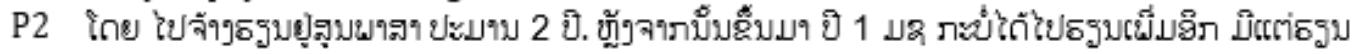
ตาบบะชาจ๊ยะยาไวเล๊ย.

Yes, I studied at an English centre about two years. When I entered the university, I stop taking extra English classes, I only studied from the teacher education programme.

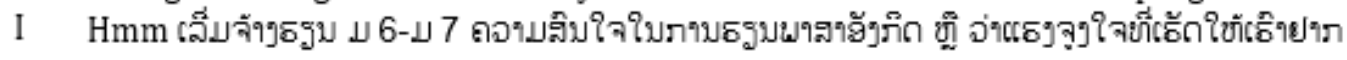
ธรมเุม่มซยัต?

Hmm, you started learning extra classes on years six or seven. What was your motivation in learning English?

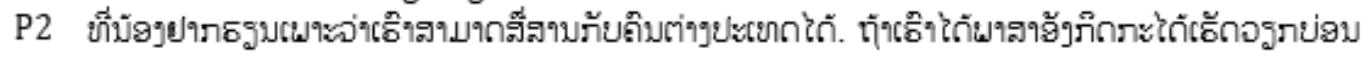

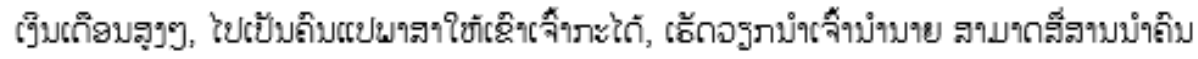
เ่่ารปะขขกไกั.

Because I wanted to communicate with foreigners. If I can use English well, I might get a good job with a higher wage; I can be a translator or work with high ranking government officials because I am able to communicate with foreigners.

I ฮึ

$\mathrm{Hmm}$

P2 เป็มเก็อบร์จะสุงขูายภจ่าถิบขำบะกา.

Salary is higher than those who cann't use English.

I ก๊รอ่ายัธุ้อ่าใัม?

It is better, right?

P2 ใกย.

Yes.

I ชมายลอาบอ่าเปับแธรจจรใจขางกังบดาฉิย.

It means that your motivation of learning English was driven by job opportunities.

P2 โกยแบบแล๊ว.

Yes, that is right.

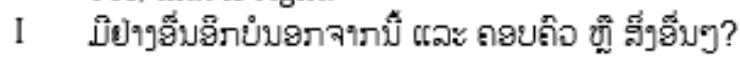

Anything else besides this and what about family and other factors? 


\section{Appendix 17: Sample Information Sheet}

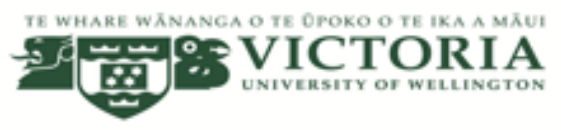

Research title: Implementing of a Culture of Thinking in Lao EFL Pre-Service Teacher Education: A Case of Reading

Thank you for your interest in this project. Please read this information before deciding whether or not to take part. If you decide to participate, thank you. If you decide not to take part, thank you for considering my request.

\section{Who am I?}

My name is Say Phonekeo and I am a PhD student in Applied Linguistics and Language Studies at Victoria University of Wellington. This research project is work towards my dissertation.

\section{What is the aim of the project?}

This project aims 1) to investigate the Lao EFL pre-service teachers' prior experiences in reading and learning to read in English; 2) to explore the current state of English reading instruction; 3) to find out the extent to which a culture of thinking (CoT) is practiced in this context; and 4) to determine the effects of a COT implementation on Lao EFL pre-service teachers' reading comprehension, engagement, and perceptions. This research has been approved by the Victoria University of Wellington Human Ethics Committee, approval number is 24391 .

\section{How can you help?}

If you agree to take part, I will interview you on your campus or in your school library. I will ask you questions about your prior experiences in reading and learning to read in English. The interview will take around 50 minutes. I will record the interview and write it up later. You can stop the interview at any time, without giving a reason. You can withdraw from the study by contacting me at any point before December $15^{\text {th }}$, 2017. If you withdraw, the information you provided will be destroyed or returned to you.

\section{What will happen to the information you give?}

This research is confidential. This means that the researchers named below will be aware of your identity but the research interviewed data will be summarized using pseudonyms so that your identity will not be disclosed in any reports, presentations, or public documentation. However, you should be aware that in small projects your identity might be obvious to others in your community

You will not be named in the final report, but your organisation will be named if you have the authority to agree to this on behalf of the organisation. 
Only my supervisors and I will read the notes or transcript of the interview. The interview transcripts, summaries and any recordings will be kept securely and destroyed 2 years after the research ends.

\section{What will the project produce?}

The information from my research will be used in my $\mathrm{PhD}$ dissertation.

\section{If you accept this invitation, what are your rights as a research participant?}

You do not have to accept this invitation if you don't want to. If you do decide to participate, you have the right to:

- withdraw from the study before December $15^{\text {th }}, 2017$;

- choose not to answer any question;

- ask for the recorder to be turned off at any time during the interview;

- ask any questions about the study at any time;

- ask for a copy of your interview recording (if it is recorded);

- read over and comment on a written summary of your interview;

- agree on another name for me to use rather than your real name;

- read any reports of this research by emailing the researcher to request a copy.

If you have any questions or problems, who can you contact?

If you have any questions, either now or in the future, please feel free to contact either:

\section{Human Ethics Committee information}

If you have any concerns about the ethical conduct of the research you may contact the Victoria University HEC. 


\section{Appendix 18: Sample Consent Form}

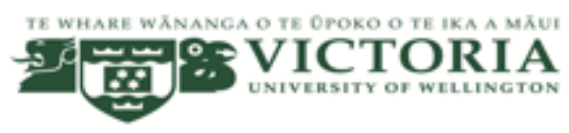

Project Title: Implementing of a Culture of Thinking in Lao EFL Pre-Service Teacher Education: A Case of Reading

This consent form will be held 2 years after completion of this research.

Researcher: Say Phonekeo, School of Linguistics and Applied Language Studies, Victoria University of Wellington.

- I have read the Information Sheet and the project has been explained to me. My questions have been answered to my satisfaction. I understand that I can ask further questions at any time.

- I agree to take part in an audio-recorded semi-structured interview.

\section{I understand that:}

- I may withdraw from this study at any point before December $15^{\text {th }}, 2017$, without giving any reason, and any information that I have provided will be returned to me or destroyed.

- The information I have provided will be destroyed right after the research is finished.

- The interview will take a round 30 minutes and will be conducted on campus or in the school library.

- Any information I provide will be kept confidential to the researcher and the supervisor. I understand that the results will be used for a $\mathrm{PhD}$ report and a summary of the results may be used in academic reports and/or presented at conferences.

- My name will not be used in reports, nor will any information that would identify me.

- I can ask for the recorder to be turned off any time during the interview.

- I would like a copy of the transcript of my interview:

Yes $\square \quad$ No $\square$

- I would like a summary of my interview:

Yes $\square \quad$ No $\square$

- I would like to receive a copy of the final report and have added

Yes $\square \quad$ No my email address below.

Signature of participant:

Name of participant:

Date:

Contact details: 


\section{Appendix 19: Human Ethics Approval}
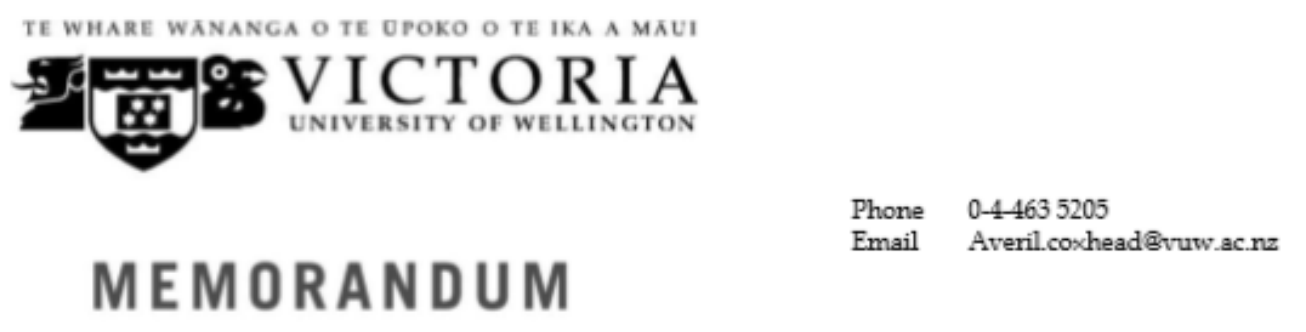

\begin{tabular}{l|l}
\hline TO & Say Phonekeo \\
\hline COPY TO & John Macalister \\
\hline FROM & Dr Averil Coxhead, Acting Convener, Human Ethics Committee \\
\hline
\end{tabular}

\begin{tabular}{l|l}
\hline DATE & 30 May 2017 \\
\hline PAGES & 1 \\
\hline SUBJECT & $\begin{array}{l}\text { Ethics Approval: 24391 } \\
\text { The Implementation of a Culture of Thinking in a Lao EFL Context: } \\
\text { A Case Study of Reading in a Public University }\end{array}$ \\
\hline
\end{tabular}

Thank you for your application for ethical approval, which has now been considered by the Standing Committee of the Human Ethics Committee.

Your application has been approved from the above date and this approval continues until 14 February 2020. If your data collection is not completed by this date you should apply to the Human Ethics Committee for an extension to this approval.

Best wishes with the research.

Averil Coxhead,

Acting Convener, Victoria University Human Ethics Committee 


\section{Appendix 20: Permission Letter for Data Collection}

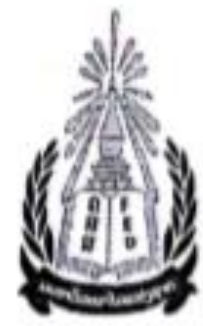

Ministry of Education and Sports

National University of Laos

Faculty of Education

Tel: +85621770473

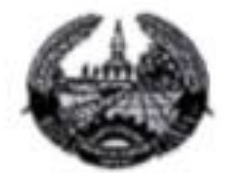

Lao People's Democratic Republic

Peace Independence Democracy Unity Prosperity
No. 969 . $/ F E D / 2017$

Date.21 April 2017

\section{Letter of Acceptance}

Dear Say Phonekeo,

With reference to the letter of request dated on April 21, 2017, I am pleased to grant my permission to you to conduct your PhD study entitled The Implementation of a Culture of Thinking in a Lao EFL. Context: A Case Study of Reading in a Public University at the Faculty of Education, National University of Laos, starting from September 2017 to July 2018. You are allowed to:

1. conduct interviews;

2. administer questionnaires;

3. observe English reading classes;

4. recruit two teachers to participate in reading instruction (Phase II):

5. recruit two intact English classes from the education program for Phase II;

6. administer a pre-post-delayed reading test;

7. collect some reading lesson plans for further analysis; and

8. Have access to other information and resources relevant to your study.

In addition, you will be treated as one of our staff and you will receive appropriate supervision regarding your research and our institution. You might also be asked to conduct a seminar to English teachers to share your experiences of the area you are investigating.

On behalf of Faculty of Education and National University of Laos, 1 understand that all target participants will be given an information sheet and consent form to participate in your project. In addition, I understand that your project will not have a negative impact on both participants and the institution. However, I believe that your project will make a great contribution to the teaching of English in the Lao EFL context and elsewhere.

Ilook forward to welcoming you to our institution soon.

Regards,

Dean of Faculty of Education

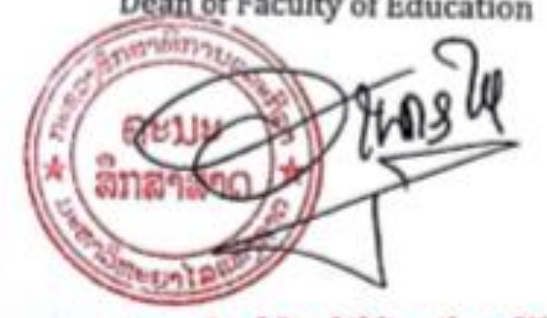

Assoc.Prof.Dr. Athitouthay CHATOUPHONEXAY 